\title{
FINAL REPORT: EPRI-USDOE COOPERATIVE AGREEMENT: COFIRING BIOMASS WITH COAL
}

\author{
Contract No. DE-FC22-96PC96252 \\ Also Supported by US Department of Energy \\ Energy Efficiency and Renewable Energy \\ Biomass Power Program \\ And \\ US Department of Energy \\ National Energy Technology Laboratory
}

Prepared by:

David A. Tillman

FOSTER 园 WHEELER

Perryville Corporate Park

Clinton, New Jersey 08809-4000

September, 2001 


\title{
FINAL REPORT: EPRI-USDOE COOPERATIVE AGREEMENT: COFIRING BIOMASS WITH COAL
}

\author{
Project Management \\ For the Cooperative Agreement:
}

\author{
USDOE-EERE: Dr. Raymond Costello \\ USDOE -NETL: Dr. Sean Plasynski \\ EPRI: Dr. Evan Hughes
}


"This report was prepared as an account of work sponsored by an agency of the United States Government. Neither the United States Government no any agency thereof, nor any of their employees, makes any warranty, express of implied, or assumes any legal liability of responsibility for the accuracy, completeness, or usefulness of any information, apparatus, product, or process disclosed, or represents that its use would not infringe privately owned rights. Reference herein to any specific commercial product, process, or service by trade name, trademark, manufacturer, or otherwise does not necessarily constitute or imply its endorsement, recommendation, or favoring by the United States Government or any agency thereof. The views and opinions of authors expressed herein do not necessarily state or reflect those of the United States Government or any agency thereof." 


\section{EXECUTIVE SUMMARY}

The Electric Power Research Institute (EPRI) established a program in 1992 aimed at commercializing the cofiring of biomass fuels in coal-fired boilers. Through this program, with support from the Tennessee Valley Authority (TVA) and with some funding from the Office of Energy Efficiency and Renewable Energy (EE-RE) of the US Department of Energy (USDOE), initial engineering studies were completed along with fuel characterizations and special studies. Cofiring tests were conducted at the Allen Fossil Plant and the Kingston Fossil Plant of TVA. GPU Genco participated in this effort with cofiring tests at the Shawville Generating Station. In 1996 EPRI and the Federal Energy Technology Center (FETC) - now the National Energy Technology Laboratory (NETL) of USDOE—established a cooperative agreement to further the commercialization of cofiring biomass in coal-fired boilers. Subsequently, EE-RE joined the Cooperative Agreement. This Cooperative Agreement has been in place for 5 years, sponsoring and supporting tests and demonstrations, and also supporting special studies required to promote commercialization of cofiring.

In establishing the Cooperative Agreement, EPRI brought a going program and significant industrial/utility partners: TVA, GPU Genco, Northern Indiana Public Service Company (NIPSCO), Allegheny Energy Supply Co., LLC, Southern Company, Madison Gas \& Electric, and others. The EPRI program already had significant success in engineering and test programs, with completed test programs at TVA and GPU Genco. USDOE-NETL brought project management skills to an evergrowing program; and these skills were essential to drive the program towards a successful commercialization objective. USDOE also brought fresh funding at a time when uncertainty regarding utility deregulation made such outside funding essential to the continued success of the program.

The Cooperative Agreement was used to sponsor cofiring testing at the Seward Generating Station of GPU Genco and the Michigan City Generating Station of NIPSCO. It was used to sponsor longer and more substantial cofiring demonstrations at Colbert Fossil Plant of TVA, Seward Generating Station, Bailly Generating Station of NIPSCO, and the Albright Generating Station of Allegheny Energy Supply Co., LLC. The Cooperative Agreement was used also to provide supplementary, supporting, funding to cofiring demonstrations at Plant Gadsden of Alabama Power, a Southern Company, Blount St. Station of Madison Gas \& Electric, and Greenidge Station of New York State Electric and Gas (NYSEG), now AES. Separate supplementary studies developed under the Cooperative Agreement included the construction of a fuels database and the evaluation of gasification-based cofiring at Allen Fossil Plant.

Taken together, the activities pursued under the cooperative agreement moved cofiring significantly towards the objective of broad-based commercialization. These tests, demonstrations, and studies demonstrated that cofiring could be a cost-effective means for reducing $\mathrm{NO}_{\mathrm{x}}, \mathrm{SO}_{2}$, and fossil-based $\mathrm{CO}_{2}$ along with such trace metals as mercury. While virtually all tests noted modest decreases in boiler efficiency, some noted the ability to recover lost boiler capacity when the unit is encountering wet coal. Further, these tests and demonstrations documented that cofiring could be employed in creative ways to achieve environmental benefits without sacrificing the economics of plant operations. These tests and 
demonstrations, along with the changing regulatory framework applicable to utilities, documented the issues remaining to be resolved by further research and demonstration activities.

The entire EPRI cofiring program has been in existence of some 9 years. This report presents a summary of the major elements of that program, focusing upon the following questions:

- In pursuit of increased use of renewable energy in the US economy, why was electricity generation considered the most promising target, and why was cofiring pursued as the most effective near-term technology to use in broadening the use of biomass within the electricity generating arena?

- What were the unique accomplishments of EPRI before the development of the Cooperative Agreement, which made developing the partnership with EPRI a highly cost-effective approach for USDOE?

- What were the key accomplishments of the Cooperative Agreement in the development and execution of test and demonstration programs-accomplishments which significantly furthered the process of commercializing cofiring?

The results shown in the chapters of this report document the answers to these questions. Further, they document several of the unresolved issues that merit attention with future research. 


\section{CONTENTS}

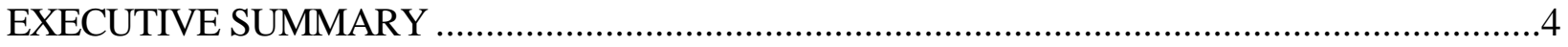

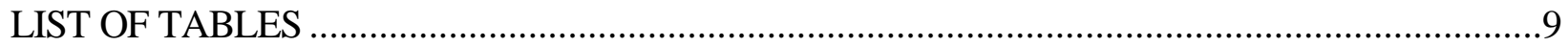

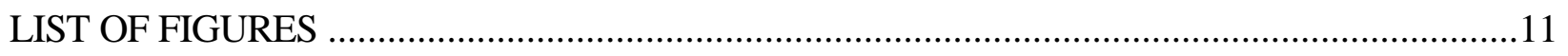

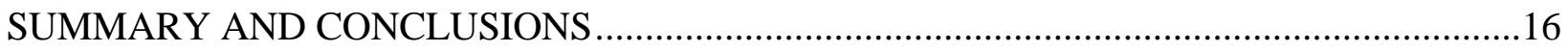

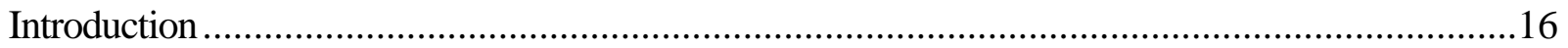

Electricity in US Energy Supply, and the Role of Renewables ..................................................16

The Initial EPRI Cofiring Program......................................................................................19

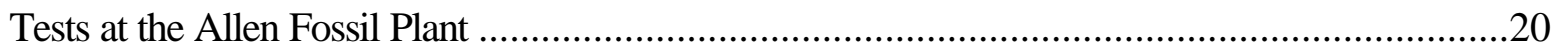

Tests at the Kingston Fossil Plant and the Shawville Generating Station....................................21

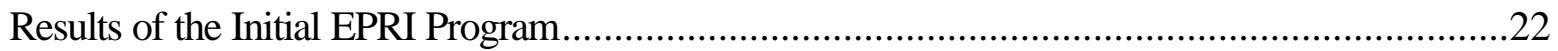

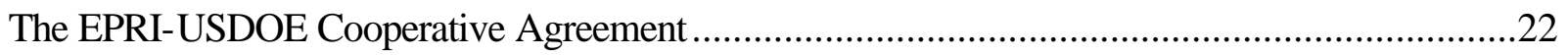

Achievements of the Cooperative Agreement for Cofiring in Wall-Fired PC Boilers .......................23

Commercializing Cofiring at the Colbert Fossil Plant of TVA .................................................23

Testing and Demonstrating Cofiring at the Seward Generating Station.........................................24

Support for the Blount St. Station Testing of Switchgrass Cofiring .........................................2.

Cofiring Tests and Demonstrations in Tangentially Fired Boilers......................................................31

Results of the Greenidge Program, Partially Supported by the Cooperative Agreement ...............31

Results of the Gadsden Program, Partially Supported by the Cooperative Agreement ..................31

Demonstrating Woody Biomass Cofiring at Albright Generating Station......................................33

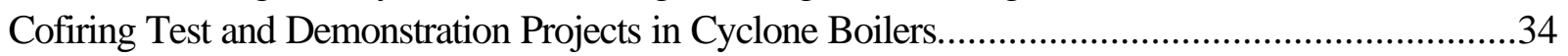

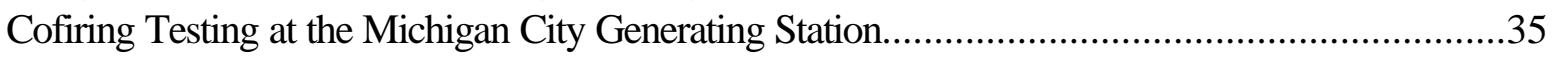

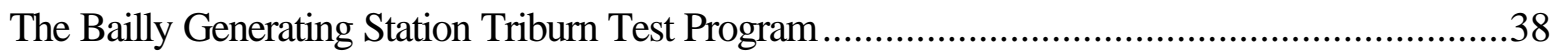

Conclusions From the Test Program of the Cooperative Agreement ..............................................43

Special Studies Associated with the EPRI-USDOE Cooperative Agreement ..................................45

Future Research Requirements to Commercialize Cofiring ............................................................45

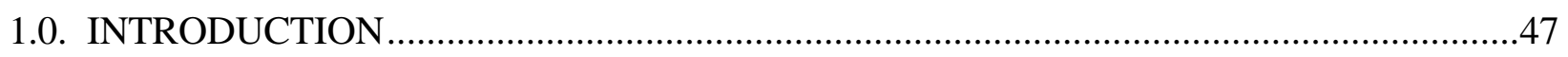

1.1. The Basis for Focusing on Cofiring ................................................................................4

1.2. The EPRI - USDOE Cofiring Program........................................................................

1.3. Specific Projects For the Cooperative Agreement ...........................................................54

1.4. Organization of This Report.......................................................................................56

2.0. EPRI COFIRING RESEARCH PRIOR TO THE COOPERATIVE AGREEMENT WITH

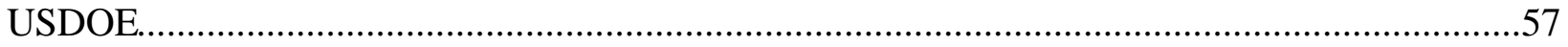

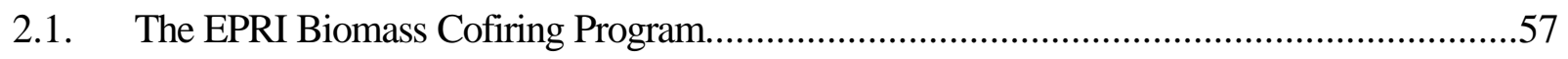

2.1.1. Industry Experience With Cofiring When Program Was Initiated ................................57

2.1.2. Structuring the Initial EPRI Cofiring Program...........................................................5

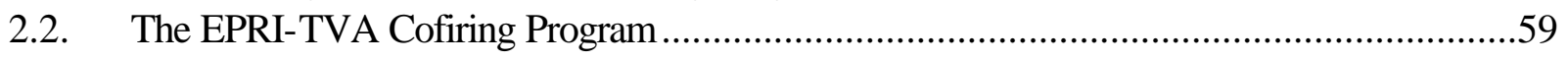

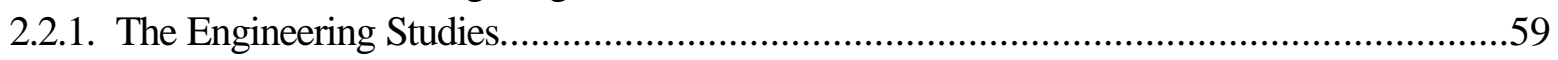

2.2.2. Cofiring Testing at the Allen Fossil Plant.................................................................64 


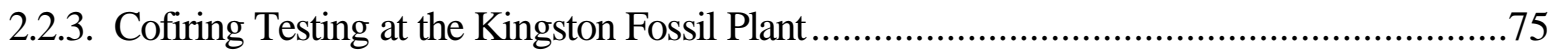

2.2.3. Conclusions Regarding the EPRI-TVA Program.......................................................79

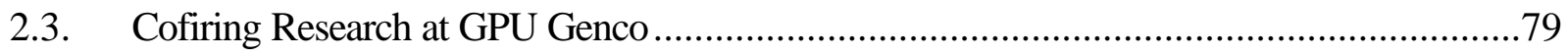

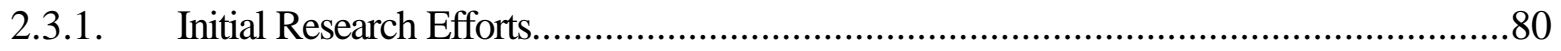

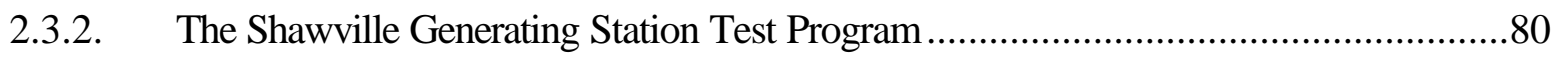

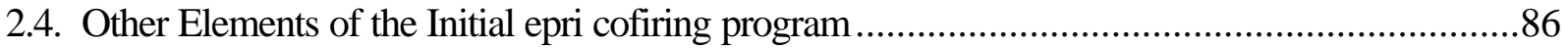

2.5. Conclusions Concerning the Initial EPRI Program ................................................................ 87

3.0. COOPERATIVE AGREEMENT DEVELOPMENT OF COFIRING IN WALL FIRED

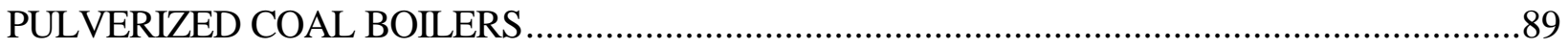

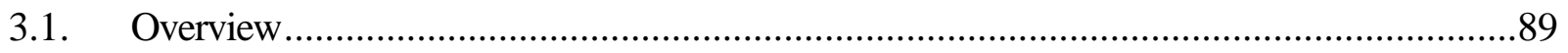

3.2. The Colbert Fossil Plant Cofiring Installation.................................................................... 89

3.2.1. Cofiring Materials Handling Design ............................................................................99

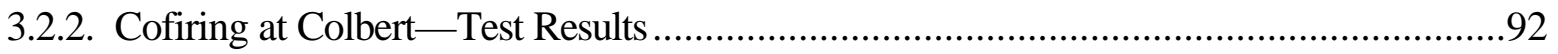

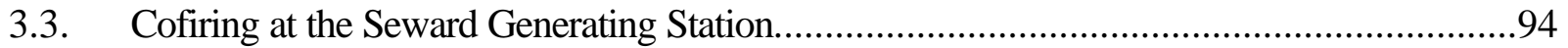

3.3.1. The Parametric Test Program at Seward Generating Station...........................................95

3.3.2. The Seward Generating Station Demonstration .............................................................108

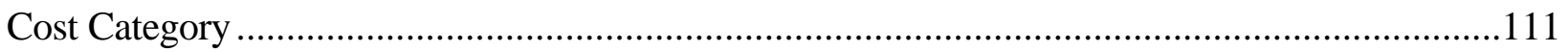

3.3. The Blount St. Station Switchgrass Cofiring Test.............................................................120

3.3.1. The Blount St. Station Facility..........................................................................120

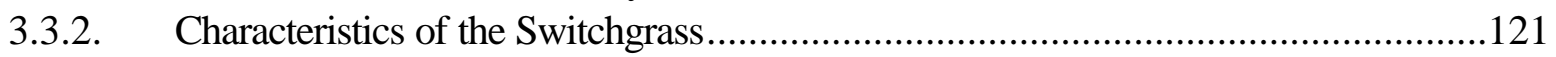

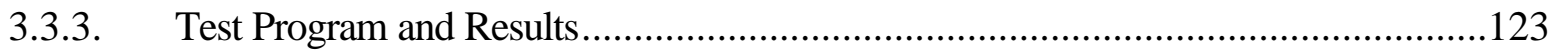

3.4. Conclusions Regarding Cofiring in Wall Fired Pulverized Coal Boilers .............................126

4.0. COOPERATIVE AGREEMENT SUPPORT FOR COFIRING IN TANGENTIALLY-FIRED

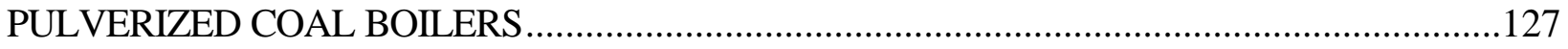

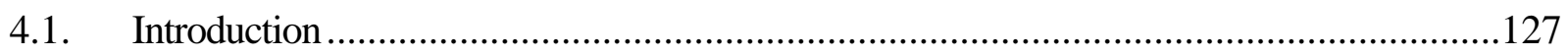

4.2. Demonstrating Biomass Cofiring at Greenidge Station ..................................................127

4.3. Cofiring at the Albright Generating Station of Allegheny Energy Supply Co., LLC............128

4.3.1. Design of the Albright Generating Station Cofiring System............................................129

4.3.2. Demonstration Results....................................................................................133

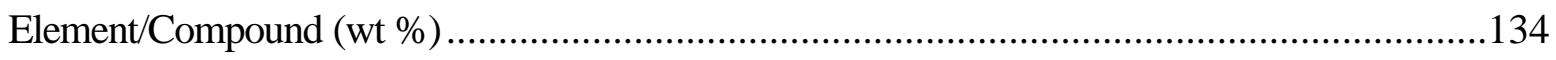

4.4. Switchgrass Cofiring Testing at Plant Gadsden............................................................141

4.5. Conclusions Regarding Cofiring in Tangentially-Fired Pulverized Coal Boilers ...................146

5.0. COOPERATIVE AGREEMENT SUPPORT FOR COFIRING IN CYCLONE BOILERS 147

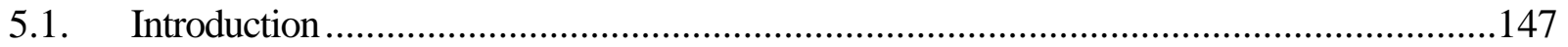

5.2. Cofiring Testing at Michigan City Generating Station ......................................................148

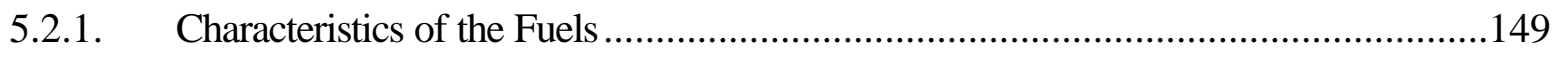

5.2.2. The Cofiring Tests.....................................................................................................154

5.3. The Triburn Demonstration at Bailly Generating Station....................................................160

5.3.1. Overview of the Program ......................................................................................160

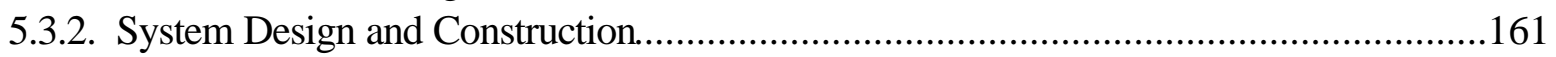

5.3.3. Triburn Testing and Associated Results................................................................164 
5.3.3.3. Environmental Impacts from the Triburn Program.............................................169

5.4. Conclusions Regarding Cyclone Cofiring..............................................................178

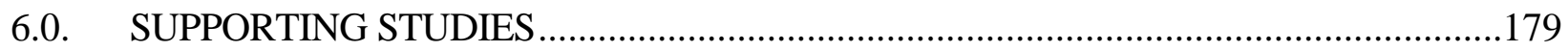

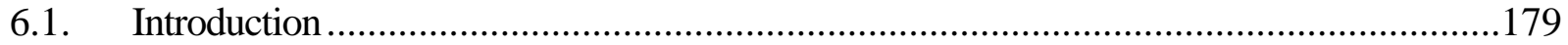

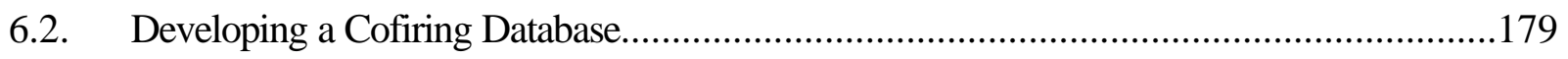

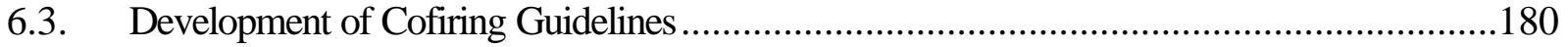

6.4. Assessment of Gasification-based Cofiring at Allen Fossil Plant ...................................181

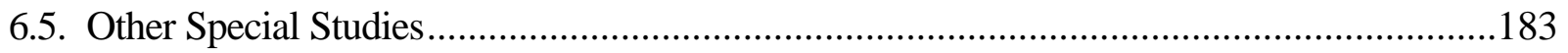

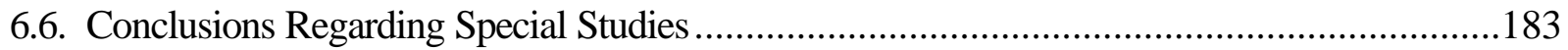

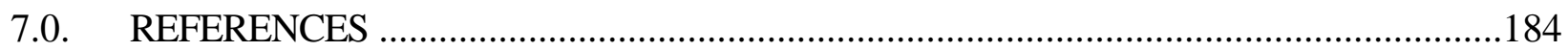

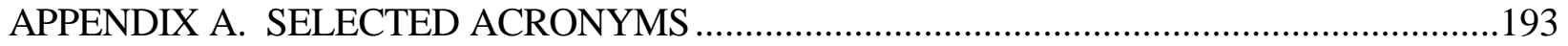




\section{LIST OF TABLES}

$\underline{\text { Page }}$

Table S-1. Test Results at the Seward Generating Station, July 1997........................................25

Table S-2. Boiler Efficiencies Measured at the Blount Station Cofiring Test ..................................30

Table 1-1. Biomass Contribution to US Energy Production and Consumption................................49

Table 1-2. The Distribution of Utility Boilers by Fuel Type in the UDI Database ...........................51

Table 2-1. Fuels Used in Assessment of Spontaneous Combustion Assessment ............................61

Table 2-2. Fuel Blends Used in Spontaneous Combustion Assessment.........................................62

Table 2-3. $\mathrm{NO}_{\mathrm{x}}$ Reductions at the Allen Fossil Plant When Firing Illinois Basin Coal and Sawdust ....64

Table 2-4. Fuels Used for Cofiring Tests at the Allen Fossil Plant ..............................................67

Table 2-5. Kinetic Parameters for Devolatilization of Sawdust and Illinois Basin Coal.....................70

Table 2-6. Characteristics of Individual Fuels Burned During the Shawville Tests ...........................82

Table 2-7. Unit 2 Average Feeder Speeds and Boiler Capacities Achieved at the Shawville Test......84

Table 2-8. Unit 3 Mill Outlet Temperatures at the Shawville Cofiring Test....................................85

Table 3-1. Impact of Cofiring on Sieve Analysis at Colbert Fossil Plant ......................................93

Table 3-2. Impact of Cofiring on Boiler Efficiency at Colbert Fossil Plant ....................................93

Table 3-3. Equipment List for Parametric Testing at Seward Generating Station..............................97

Table 3-4. Motor List for the Original Seward Cofiring Tests ..................................................98

Table 3-5. Composition of Fuels Burned at Seward Generating Station........................................98

Table 3-6. Calculated Flame Temperatures During December 1996 Seward Tests .......................102

Table 3-7. Carbon Monoxide Emissions from Cofiring Tests at Seward Generating Station............103

Table 3-8. Kinetic Parameters for Sawdust and Pittsburgh Seam Bituminous Coal........................107

Table 3-9. Capital Cost Breakdown for the Seward Demonstration System ................................111

Table 3-10. Composition and Characteristics of Fuels Used in Seward Cofiring Demonstration ......112

Table 3-11. Test Conditions at the Seward Generating Station Demonstration.............................113

Table 3-12. Basic Results at the Seward Generating Station Demonstration..................................114

Table 3-13. Typical Proximate and Ultimate Analysis for Switchgrass......................................122

Table 3-14. Ash Elemental Analysis of Switchgrass Inorganic Matter .......................................123

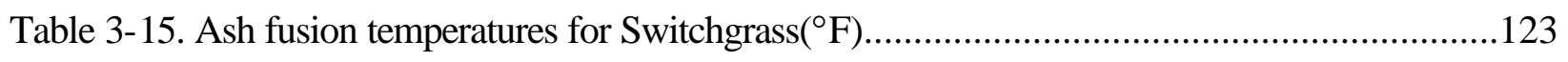

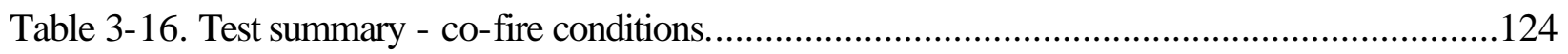


Table 3-17. Average measured flue gas emissions at 3\% excess oxygen. 125

Table 4-1. Typical Analyses of the Coal and Sawdust at Albright Generating Station .......................134

Table 4-2. Probability That The Equation, or any Term, Occurred Randomly .................................138

Table 5-1. Proximate and Ultimate Analysis of Fuels Burned at Michigan City Cofiring Tests ..........150

Table 5-2. Structural and Kinetic Data Representative of Fuels Burned at Michigan City Cofiring Tests151

Table 5-3. Test Conditions at the Michigan City Cofiring Test Program...........................................155

Table 5-4. Efficiency Measurements During Cofiring Tests at Michigan City Generating Station.......156

Table 5-5. Airborne Emissions From Cofiring at Michigan City Generating Station...........................158

Table 5-6. Capital Cost of the Bailly Station Cofiring System .........................................................164

Table 5-7. Fuel Blends Tested at Bailly Generating Station...............................................................164

Table 5-8. Proximate and Ultimate Analyses of Fuels Burned During Bailly Demonstration...............165

Table 5-9. Some Characteristics of Fuels Burned During the Bailly Demonstration............................165

Table 5-10. Selected Trace Metal Concentrations in Fuels Burned During the Bailly Demonstration

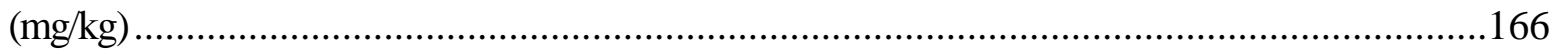

Table 5-11. Structural and Kinetic Data Representative of High Sulfur Coal and Petroleum Coke Burned at the Bailly Generating Station Triburn Demonstration .................................................166

Table 5-12. Summary of Heat and Material Balance Closures.........................................................167

Table 5-13. Average Unburned Carbon Percentages in Flyash at Bailly Generating Station..............169

Table 5-14. Significance of Total Equations and Individual Terms for Equations [20] and [21] Expressed as Probability that the Term Occurred as a Random Event.....................................171

Table 5-15. Trace Metal Concentrations in the Baseline Coal Blend and in the Triburn Fuel (7.5 Percent Wood Waste/22.5 Percent Petroleum Coke/70 Percent Coal) Expressed in lb/10 ${ }^{6}$ Btul 74

Table 5-16. Concentrations of Vanadium and Nickel in the Fuels Burned at Bailly Generating Station (values in $\mathrm{mg} / \mathrm{kg}$ or ppmw) 


\section{LIST OF FIGURES}

$\underline{\text { Page }}$

Figure S-1. Energy Consumption in the USA, 1850 - 2000 .................................................17

(Enzer, Dupree, and Miller, 1975; Energy Information Administration, 2000)...............................17

Figure S-2. Energy Consumption by Sector in the US Economy..............................................18

Figure S-3. Distribution of Energy Consumption in the US Economy .........................................18

Figure S-4. The Growth of Renewable Energy Resources in the US Economy ..............................19

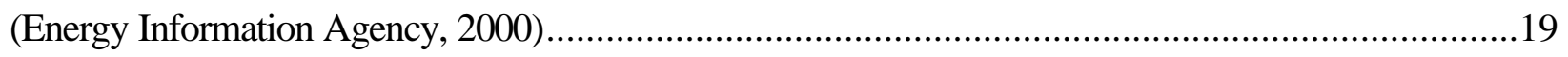

Figure S-5. The Influence of Fuel Volatility on $\mathrm{NO}_{\mathrm{x}}$ Emissions at the Allen Fossil Plant Cofiring Tests (Tillman et. al., 1996) ..............................................................................................21

Figure S-6. Materials Handling at the Colbert Fossil Plant Cofiring Installation..............................24

Figure S-7. $\mathrm{NO}_{\mathrm{x}}$ Reduction During the Parametric Testing at the Seward Generating Station............26

Figure S-8. The Seward Generating Station Cofiring Demonstration Facility ................................28

Figure S-9. Efficiency Results from the Cofiring Demonstration at Seward Generating Station ...........29

Figure S-10. $\mathrm{NO}_{\mathrm{x}}$ Emissions Measured During the Seward Generating Station Demonstration..........29

Figure S-11. The Switchgrass Cofiring Facility at Plant Gadsden with the Tractor Feeding a Bale, and the Pneumatic Transport Pipe Carrying the Switchgrass to the Boiler ......................................32

Figure S-12. Ribbon Cutting at the Albright Cogeneration Facility Dedication................................33

Figure S-13. Impact of Cofiring on Cyclone Feeder Speeds When Cofiring Wood Waste and PRB

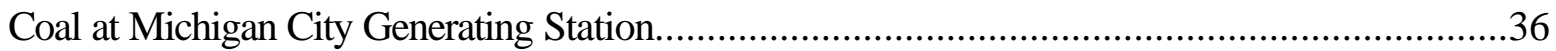

Figure S-14. Boiler Efficiencies Calculated for the Michigan City Generating Station Cofiring Tests ...37

Figure S-15. $\mathrm{NO}_{\mathrm{x}}$ Emissions at the Michigan City Cofiring Tests ...............................................38

Figure S-16. The Pole Barn at Bailly Generating Station With a Pile of Blended Opportunity Fuel.....40

Figure S-17. Operation of the Reclaim and Opportunity Fuel/Coal Blending System at Bailly Generating Station.

Figure S-18. Emissions of Carbon Monoxide, Total Hydrocarbons, and Sulfur Trioxide at the Bailly

Generating Station Triburn Demonstration (values in ppmvd corrected to 3\% $\mathrm{O}_{2}$ ) ...................42

Figure S-19. $\mathrm{NO}_{\mathrm{x}}$ Emissions Measured During the Bailly Triburn Tests ......................................43

Figure S-20. $\mathrm{NO}_{\mathrm{x}}$ Reduction Caused by Cofiring-All Tests Sponsored by the EPRI-USDOE

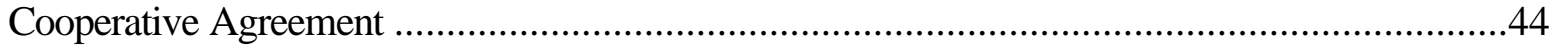

Figure 1-1. Historical Trends in US Energy Consumption by Fuel.............................................48 
Figure 1-2. Historical Trends in Percentage Distribution of US Energy Consumption.......................49

Figure 1-3. Importance of Electricity Generation in US Fuel Consumption...................................50

Figure 1-4. Average Capacity of Steam-Electric Generating Systems Installed, 1940 - 1995...........50

Figure 1-5. The Global Carbon Cycle ..................................................................................53

Figure 2-1. Reburn Effectiveness of Wood Fuel Relative to Coal and Natural Gas at $2600^{\circ} \mathrm{F}(1720 \mathrm{~K}) 63$

Figure 2-2. Reburn Effectiveness of Wood Fuel Relative to Coal and Natural Gas at $2060^{\circ} \mathrm{F}(1400 \mathrm{~K}) 64$

Figure 2-3. The Trommel Screen Installed at the Allen Fossil Plant ............................................66

Figure 2-4. Managing the Biomass Fuel Supply at the Allen Fossil Plant ....................................67

Figure 2-5. The Influence of Fuel Nitrogen Content on NOx Emissions at the Allen Fossil Plant Cofiring Tests.

Figure 2-6. Influence of Volatility on $\mathrm{NO}_{\mathrm{x}}$ Emissions at the Allen Fossil Plant...............................71

Figure 2-7. Release of Nitrogen Volatiles Relative to Carbon Volatiles and Total Volatiles from Sawdust based upon data from Pennsylvania State University............................................71

Figure 2-8. $\mathrm{NO}_{\mathrm{x}}$ Emissions at the Allen Fossil Plant as a Function of Furnace Exit Gas Temperature.72

Figure 2-9. $\mathrm{NO}_{\mathrm{x}}$ Emissions as a Function of Excess Oxygen at Allen Fossil Plant...........................73

Figure 2-10. Summary Impacts of Cofiring on $\mathrm{NO}_{\mathrm{x}}$ Emissions at the Allen Fossil Plant ....................74

Figure 2-11. Hardgrove Grindability Index for Cofiring Tests at Kingston Fossil Plant.....................76

Figure 2-12. Percent Fuel Passing 50 Mesh at Kingston Fossil Plant as a Function of Cofiring Level.77

Figure 2-13. Percent Fuel Passing 100 Mesh at Kingston Fossil Plant as a Function of Cofiring Level.78

Figure 2-14. Percent Fuel Passing 200 Mesh at Kingston Fossil Plant as a Function of Cofiring Level.79

Figure 2-15. Impact of Cofiring on Mill Amps at Shawville Unit \#2 During Cofiring .....

Figure 2-16. Impact of Cofiring on Ball-and-Race Mill Feeder Speeds at Shawville Generating Station Unit \#2 .84

Figure 2-16. Impact of Cofiring on Mill Outlet Temperatures and Capacities at Shawville Unit \#3 .....85

Figure 3-1. The Colbert Fossil Plant of TVA .......................................................................90

Figure 3-2. Colbert Fossil Plant Cofiring Installation..............................................................92

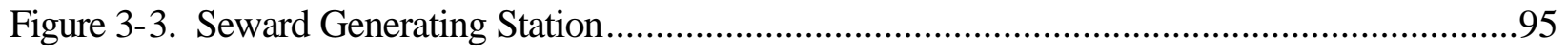

Figure 3-4. Elevation View of the Original Pneumatic Transport System at Seward........................96

Figure 3-5. Design of the Burner Tip Modifications at Seward................................................96

Figure 3-6. Photograph of the Burner Tip Insert for Biomass Cofiring at Seward ...........................97

Figure 3-7. Unburned Carbon in Flyash During the Seward Parametric Tests ..............................100

Figure 3-8. Boiler Efficiency Measured During the Seward Parametric Tests ...............................101 
Figure 3-9. Boiler Efficiency at the Seward Tests as Influenced by Cofiring Level (Btu Basis)..........102

Figure 3-10. $\mathrm{NO}_{\mathrm{x}}$ Emissions Measured at the Seward Parametric Tests as a Function of Cofiring (mass basis).

Figure 3-11. $\mathrm{NO}_{\mathrm{x}}$ Emissions Measured at the Seward Parametric Tests as a Function of Cofiring (heat input or Btu basis)

Figure 3-12. $\mathrm{NO}_{\mathrm{x}}$ Emissions as a Function of Volatile/Fixed Carbon Ratio During the Parametric Tests at Seward Generating Station.....

Figure 3-13. Percentage $\mathrm{NO}_{\mathrm{x}}$ Reductions Measured During Parametric Testing at Seward Generating Station. .107

Figure 3-14. The Seward Demonstration Facility Walking Floor Sawdust Unloader. .109

Figure 3-15. Installation of the Trommel Screen for Sawdust Preparation at Seward Generating Station109

Figure 3-16. Flexible Pipe Connections for the Sawdust at the Seward Burner Front .110

Figure 3-17. Boiler Efficiency Loss as a Function of Cofiring Percentage (Mass Basis) at the Seward Generating Station Cofiring Demonstration. 115

Figure 3-18. Boiler Efficiency Loss as a Function of Cofiring Percentage (Heat Input Basis) at the Seward Generating Station Cofiring Demonstration. .115

Figure 3-19. Influence of Cofiring on Excess Oxygen Used in Combustion .................................116

Figure 3-20. Influence of Cofiring on Unburned Carbon in the Flyash.

Figure 3-21. $\mathrm{NO}_{\mathrm{x}}$ Emissions During the Seward Demonstration as a Function of Cofiring Percentage (Mass Basis). .118

Figure 3-22. $\mathrm{NO}_{\mathrm{x}}$ Emissions During the Seward Demonstration as a Function of Cofiring Percentage (Heat Input Basis) .119

Figure 3-23. $\mathrm{NO}_{\mathrm{x}}$ Emissions at the Seward Generating Station Cofiring Demonstration as a Function of Volatile/Fixed Carbon Ratio ... 119

Figure 3-24. Boiler \#8 at Blount St. Station, Used for Switchgrass Cofiring .121

Figure 3-25. The Opportunity Fuel Handling System at Blount St. Station Used for Switchgrass Cofiring.

Figure 3-26. $\mathrm{NO}_{\mathrm{x}}$ Emissions in $\mathrm{g} / \mathrm{MJ}$ at Blount St. Station as a Function of Volatile/Fixed Carbon Ratio of the Combined Fuel Feed. 126

Figure 4-1. Overview of the Cofiring Installation at Albright Generating Station.............................130

Figure 4-2. Sawdust Being Transported Up the Walking Floor Unloader. .131

Figure 4-3. Sawdust Being Screened on the Disc Screen .131

Figure 4-4. Sawdust Being Metered on the Weigh Belt Feeder . 132

Figure 4-5. The Sawdust Injector in the Albright Boiler \#3 .132 
Figure 4-6. Controls for the Cofiring System at Albright Generating Station

Figure 4-7. Opacity Emissions (Percent) as a Function of Cofiring at Albright Generating Station. ...135

Figure 4-8. Influence of Cofiring on Carbon Monoxide Emissions at Albright Generating Station.....135

Figure 4-9. $\mathrm{SO}_{2}$ Emissions as a Function of Cofiring at Albright Generating Station (mass basis) .....136

Figure 4-10. $\mathrm{SO}_{2}$ Emissions as a Function of Cofiring at Albright Generating Station (heat input basis)136

Figure 4-11. $\mathrm{NO}_{\mathrm{x}}$ Reduction from Cofiring at the Albright Generating Station.

Figure 4-12. Comparison of Observed and Predicted $\mathrm{NO}_{\mathrm{x}}$ Emissions Based Upon Equation [16] ..138

Figure 4-13. Nitrogen Volatile Evolution from Sawdust as a Function of Temperature.

Figure 4-14. Nitrogen Volatile Evolution from Sawdust Normalized to Total Volatiles.

Figure 4-15. Nitrogen Volatile Evolution from Coal Burned at Albright Generating Station 140

Figure 4-16. Switchgrass Burned at Plant Gadsden. 141

Figure 4-17. Transporting Switchgrass to the Tub Grinder at Plant Gadsden.

Figure 4-18. Loading the Tub Grinder with Baled Switchgrass 142

Figure 4-19. The Switchgrass Tub Grinder at Plant Gadsden.

Figure 4-20. The Pneumatic Transport Pipe for Switchgrass at Plant Gadsden..... 143

Figure 4-21. The Splitter for Transporting Switchgrass to Opposite Corners of \#2 Boiler. 144

Figure 4-22. Evolution of Nitrogen from Switchgrass Obtained From the Plant Gadsden Tests 145

Figure 4-23. Evolution of Nitrogen Normalized to Total Volatile Yield from Switchgrass Obtained from the Plant Gadsden Test..... .146

Figure 5-1. Screening Urban Wood Waste at Michigan City Generating Station..... 148

Figure 5-2. The Blend of Urban Wood Waste/Shoshone Coal Stocked Out in the Michigan City Generating Station Coal Yard. 149

Figure 5-3. Nitrogen and Total Fuel Volatile Evolution Patterns for Black Thunder Coal. 152

Figure 5-4. Volatile Evolution Patterns for Caballo Rojo Coal.

Figure 5-5. Volatile Evolution Patterns for Shoshone Coal.

Figure 5-6. Impact of Cofiring on Cyclone Feeder Speeds at Michigan City Cofiring Tests 155

Figure 5-7. Estimated Flame Temperatures During Cofiring at Michigan City Generating Station .....157

Figure 5-8. Furnace Exit Gas Temperatures Measured During Cofiring Tests at Michigan City Generating Station. 158

Figure 5-9. Impact of Cofiring on $\mathrm{NO}_{\mathrm{x}}$ Emissions at Michigan City Generating Station..... 159

Figure 5-10. Impact of Cofiring on FEGT, and the Consequence for $\mathrm{NO}_{\mathrm{x}}$ Emissions 159

Figure 5-11. The Pole Barn at Bailly Generating Station With a Pile of Blended Fuel. 162 
Figure 5-12. The Trommel Screen Installed at the Bailly Generating Station Cofiring Project. 162

Figure 5-13. The Above Ground Reclaim and Conveyor System Used for Cofiring at Bailly Generating Station. 163

Figure 5-14. Statistical Analysis of Closure for all Tests at the Bailly Generating Station Demonstration168 Figure 5-15. $\mathrm{NO}_{\mathrm{x}}$ Emissions in $\mathrm{lb} / 10^{6}$ Btu Calculated from Heat Balances and F-Factor Computations 170

Figure 5-16. Concentrations of $\mathrm{CO}, \mathrm{THC}$, and $\mathrm{SO}_{3}$ as a function of fuel blend, with values expressed in ppmvd at 3 percent $\mathrm{O}_{2}$ .173

Figure 5-17, Concentrations of $\mathrm{CO}, \mathrm{THC}$, and $\mathrm{SO}_{3}$ as a function of fuel blend, with values expressed in $\mathrm{lb} / 10^{6} \mathrm{Btu}$ .173

Figure 5-18. Partitioning of Vanadium and Nickel During Triburn Testing at Bailly Generating Station175 Figure 5-19. X-Ray Diffraction Run \#1 on Bailly Generating Station Flyash for Forms of Vanadium176 Figure 5-20. X-Ray Diffraction Run \#2 on Bailly Generating Station Flyash for Forms of Vanadium177 


\section{SUMMARY AND CONCLUSIONS}

\section{INTRODUCTION}

Increasing the contribution and role of renewable energy sources within the US economy has long been a policy goal of both Republican and Democratic Presidents, dating back to the Carter Administration. The emphasis on this policy, today, comes from a desire to reduce the generation of greenhouse gas emissions, reduce other environmental consequences of energy production and consumption, broaden the base of energy supply, and promote local economic activity. EPRI, USDOE, and numerous other organizations have established significant programs to accomplish this objective. The Clinton Administration put forth the goal of tripling the use of biomass by the year 2020 as an articulation of this objective. The Administration of President George W. Bush has articulated its support for increased use of renewable energy_including biomass cofiring - in the Cheney Report (National Energy Policy Development Group, 2001).

\section{ELECTRICITY IN US ENERGY SUPPLY, AND THE ROLE OF RENEWABLES}

Increasing the role of biomass and the other renewable energy resources requires recognition of the changing structure of energy consumption in the US, both in terms of fuel supply and in terms of end use patterns. Figures S-1 through S-4 highlight these changes. Figure S-1, energy consumption in the US from 1850 through 2000 indicates that biomass was once the dominant fuel in the economy. Silvicultural fuel farms were used prior to 1850 as a means for fueling the iron industry (Walker, 1966). And, although coal has lost relative market share, it has become the dominant fuel of the electricity industry. Biomass, principally wood, lost out to the fossil fuels because it had a lower energy density and had to be harvested and gathered, rather than extracted and distributed. Figures S- 2 and S- 3 show energy consumption by sector since 1950. Clearly electricity generation shows the most growth, and has become the dominant fuel-consuming sector. Symbolically the electric furnace-based mini-mill has displaced the blast furnace as the representative of the steel industry. Thermomechanical pulping (TMP) and its cousins (chemi-thermomechanical pulping or CTMP) are beginning to challenge kraft pulping for pre-eminence in the pulp and paper industry. Figure S-4 shows the growth in renewable energy consumption since 1950. The use of wood and biomass now exceeds 3 Exajoules (EJ) or quads (1 EJ $=1 \times 10^{18}$ Joules; $1 \times 10^{15}$ Btu (quad) $=1.05 \times 10^{18} \mathrm{~J}$ or $\left.1.05 \mathrm{EJ}\right)$. Biomass energy consumption now exceeds hydroelectric energy consumption; together they about equal nuclear power consumption (Energy Information Agency, 2000). Biomass usage has about doubled since 1970, exhibiting a compound annual growth rate of about 2.5 percent.

EPRI, recognizing the growing use of biomass and the growing use of fuels for electricity generation from both an absolute and relative perspectives, developed a significant program to incorporate biomass firing in existing coal-fired electricity generating stations-cofiring. Supplying fuel to the electricity generating industry provides the most rapid means for increasing the use of biomass in energy supply; 
cofiring biomass in efficient, reheat, coal-fired boilers provides the most efficient method for using wood and crop materials for electricity generation. Further, only $7000 \mathrm{MW}_{\mathrm{e}}$ of US electricity generating capacity is fueled with biomass; this arena provides a fertile field for wood and crop fuel growth.

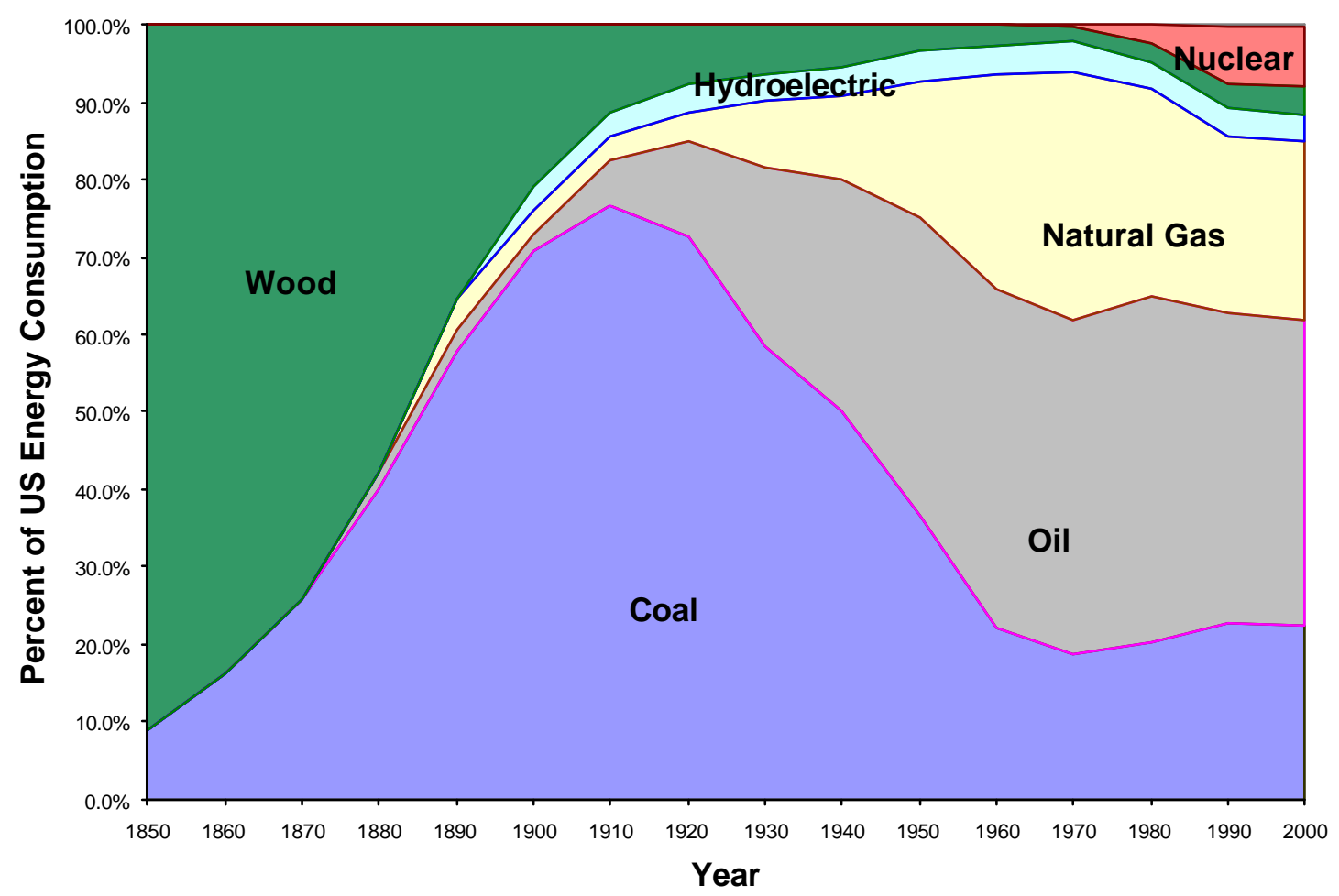

Figure S-1. Energy Consumption in the USA, 1850 - 2000

(Enzer, Dupree, and Miller, 1975; Energy Information Administration, 2000) 


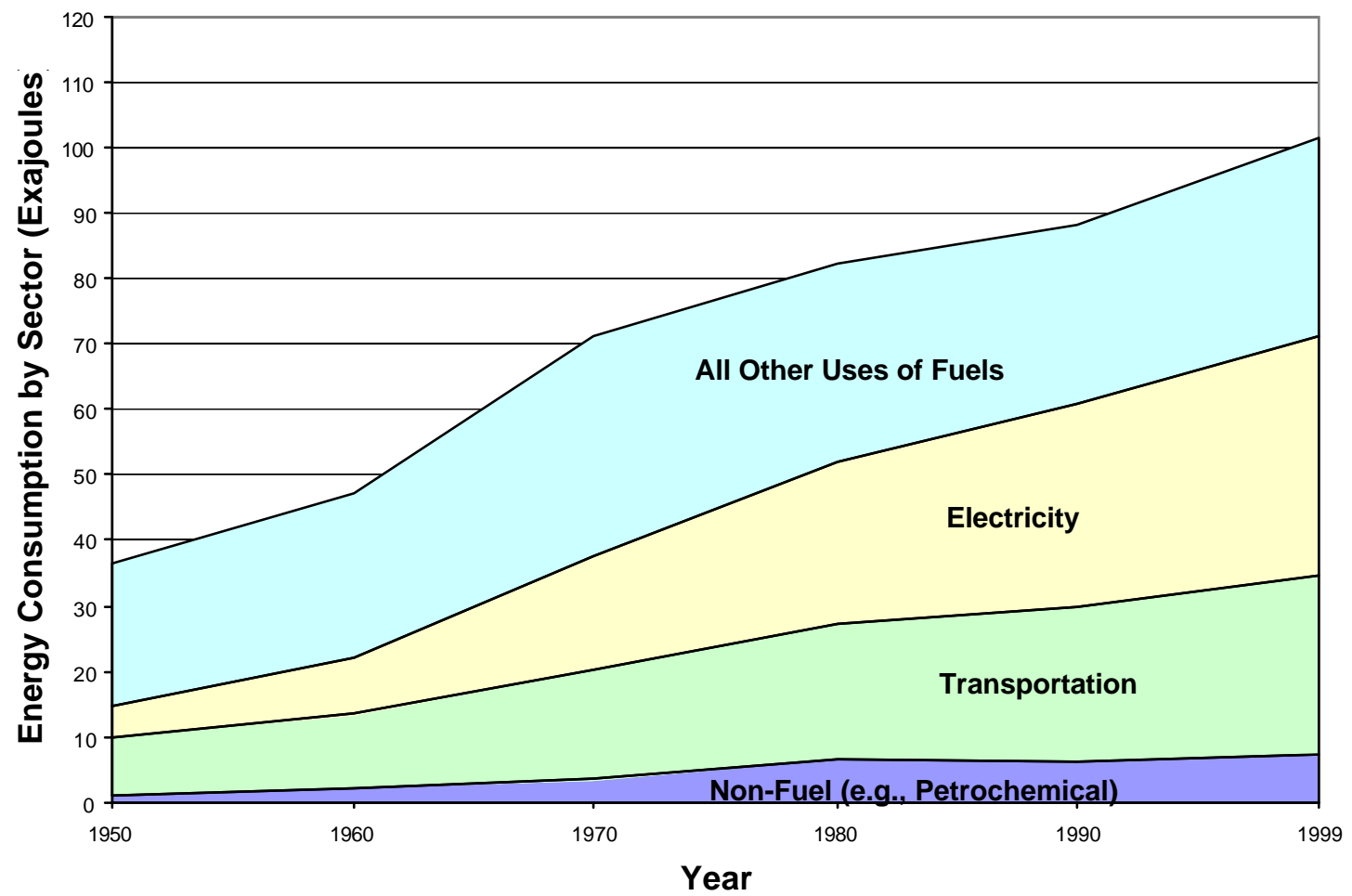

Figure S-2. Energy Consumption by Sector in the US Economy (Energy Information Agency, 2000)

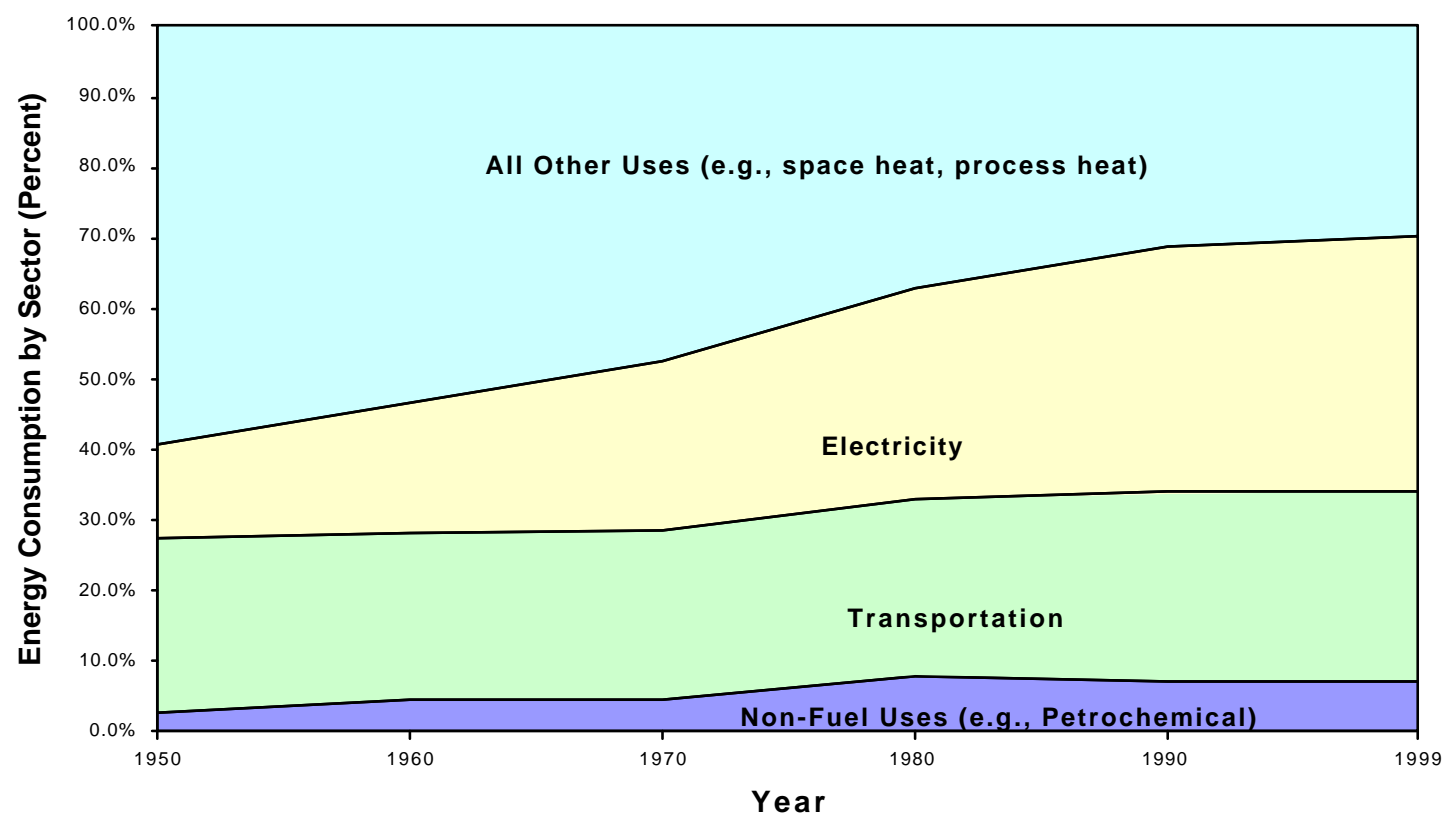

Figure S-3. Distribution of Energy Consumption in the US Economy (Energy Information Agency, 2000) 


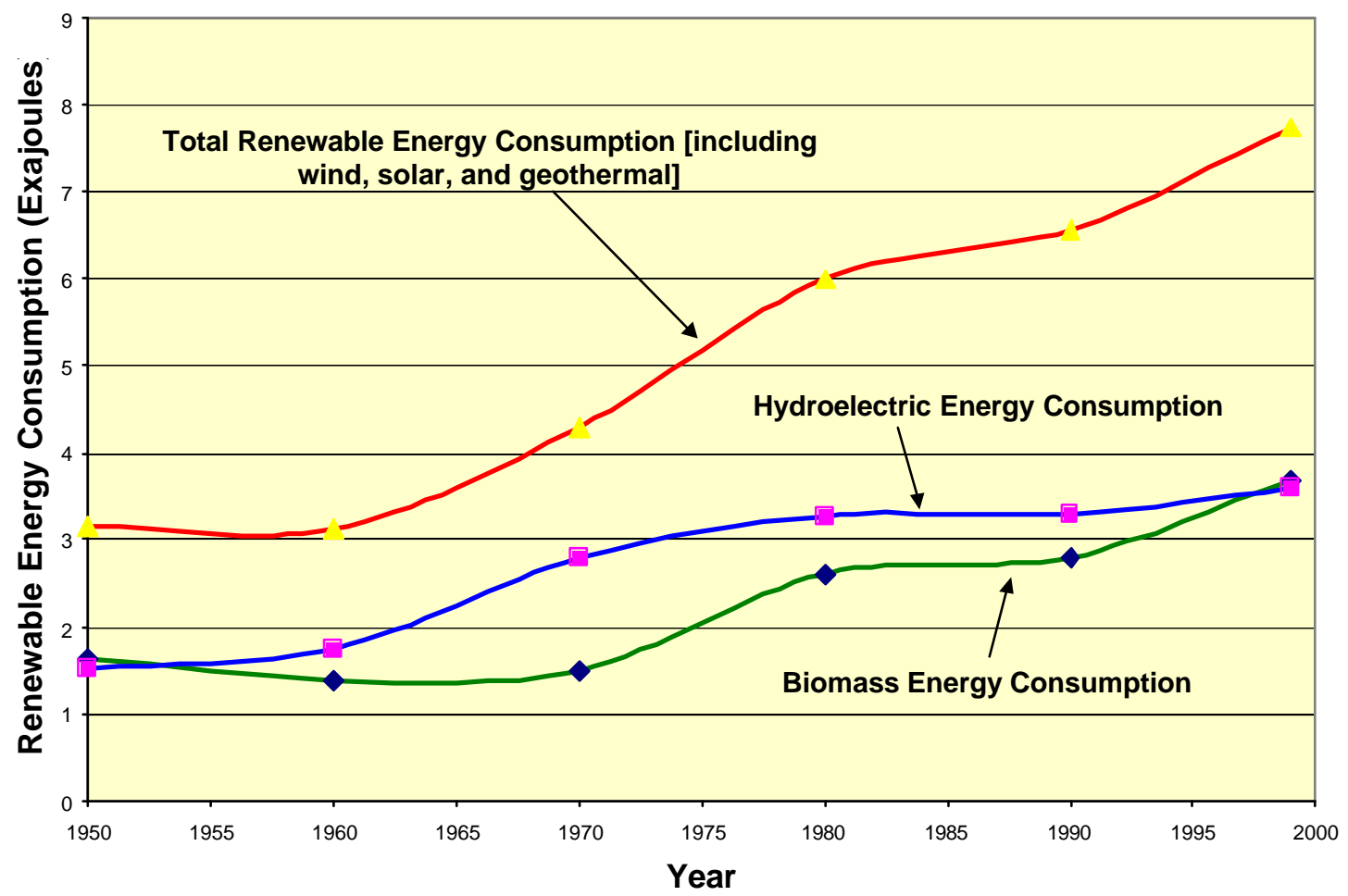

Figure S-4. The Growth of Renewable Energy Resources in the US Economy (Energy Information Agency, 2000)

\section{THE INITIAL EPRI COFIRING PROGRAM}

EPRI constructed its cofiring program through its renewable energy program. The effort was directed by a committee of utilities interested in the use of biomass including Southern Company, Northern States Power, Tacoma Public Utilities, Wisconsin Power \& Light, Tennessee Valley Authority (TVA), Northern Indiana Public Service Company (NIPSCO), GPU Genco, Madison Gas \& Electric (MG\&E), and others. The initial EPRI Cofiring Program, co-sponsored by TVA and supported by USDOE Office of Energy Efficiency and Renewable Energy (EE-RE) began with engineering studies of cofiring at all TVA Fossil Plants. EPRI contracted with Ebasco Environmental—now a part of Foster Wheeler-as its primary contractor to execute he cofiring program beginning with the engineering studies. The initial studies led to detailed engineering evaluations at the Allen Fossil Plant, the Kingston Fossil Plant, and the Shawnee Fossil Plant. These represented a cyclone boiler, a tangentially fired (Tfired) pulverized coal (PC) boiler and a wall fired PC boiler. These initial engineering studies led to the conclusion that cofiring could be a cost-effective approach to the voluntary global climate challenge program. They led to specialized studies by Ebasco Environmental and Reaction Engineering International concerning the flow of wood-coal blends through bunkers, consistency among biomass fuels available to power plants, the ability to store biomass fuels without experiencing spontaneous combustion, and other operational issues necessary to proceed from studies to field testing of the cofiring concept. These special studies also included an analysis by Reaction Engineering concerning the 
ability to use sawdust and other woody biofuels as reburn fuel (see Harding and Adams, 2000). Woody biomass is virtually equivalent to coal or natural gas as a reburn fuel (Adams and Harding, 1996).

\section{Tests at the Allen Fossil Plant}

The test programs were the culmination of the EPRI cofiring program. Cofiring tests were conducted at the Allen Fossil Plant, cyclone boiler installation, during 1994, 1995, and 1996. Cofiring percentages up to 20 percent by mass (10 percent by heat input) were tested. Base coals employed included both Illinois basin coal and Utah bituminous coal. Experiments were conducted varying the particle size of the biomass from $6.25 \mathrm{~mm}(1 / 4$ " x 0 ") to $38 \mathrm{~mm}$ (11/2" x 0"). Experiments were conducted varying the excess $\mathrm{O}_{2}$ percentage from 2.2 percent to 3.5 percent. Some experimentation was conducted varying the primary air/secondary air ratio, and including tire-derived fuel chips with the sawdust.

The Allen Fossil Plant tests set the stage for all subsequent tests in cofiring, and documented the ability of this technology to reduce fossil $\mathrm{CO}_{2}$ emissions along with $\mathrm{SO}_{2}$ emissions. Further, these tests documented the ability of cofiring to achieve such reductions with modest efficiency penalties. The tests were most significant, however, in documenting the ability of sawdust cofiring to reduce $\mathrm{NO}_{\mathrm{x}}$ emissions. When cofiring with $<6.25 \mathrm{~mm}$ particles, tests at the Allen Fossil Plant resulted in the ability to reduce NOx emissions conforming to the following equation:

$$
\mathrm{NO}_{\mathrm{x}}=0.000423(\mathrm{FR})+0.0904\left(\mathrm{EO}_{2}\right)+1.554(\mathrm{FN})-0.629(\mathrm{~V} / \mathrm{FC})-0.752
$$

Where $\mathrm{NO}_{\mathrm{x}}$ is measured in $\mathrm{kg} / \mathrm{GJ}$, FR is firing rate in $\mathrm{GJ} / \mathrm{hr}, \mathrm{EO}_{2}$ is excess $\mathrm{O}_{2}$ expressed as a percentage (total basis), $\mathrm{FN}$ is fuel nitrogen expressed in $\mathrm{kg} / \mathrm{GJ}$, and $\mathrm{V} / \mathrm{FC}$ is the volatile/fixed carbon ratio from the proximate analysis. Alternatively:

$$
\mathrm{NO}_{\mathrm{x}}=0.001(\mathrm{FR})+0.210\left(\mathrm{EO}_{2}\right)+1.554(\mathrm{FN})-1.46(\mathrm{~V} / \mathrm{FC})-1.748
$$

Where $\mathrm{NO}_{\mathrm{x}}$ is expressed in $\mathrm{lb} / 10^{6} \mathrm{Btu}$, FR is firing rate expressed in $10^{6} \mathrm{Btu} / \mathrm{hr}$, and $\mathrm{FN}$ is fuel nitrogen expressed in $\mathrm{lb} / 10^{6} \mathrm{Btu}$.

The biomass tested had a low fuel nitrogen content (typically $0.1-0.3$ percent) and a very high V/FC ratio (typically $>4.0$ ) particularly when compared to coal. Consequently it drives the results downward. The coefficient of determination $\left(r^{2}\right)$ for this equation—in SI or English measure-is 0.86 . The probabilities that these terms are random occurrences are as follows:

- Equation: $5.14 \times 10^{-8}$

- FR: 0.108

- $\mathrm{EO}_{2}: 0.090$

- FN: 0.006

- V/FC: 0.0002 
These data suggest a very robust equation. The volatility influence is particularly important, as shown in Figure S-5.

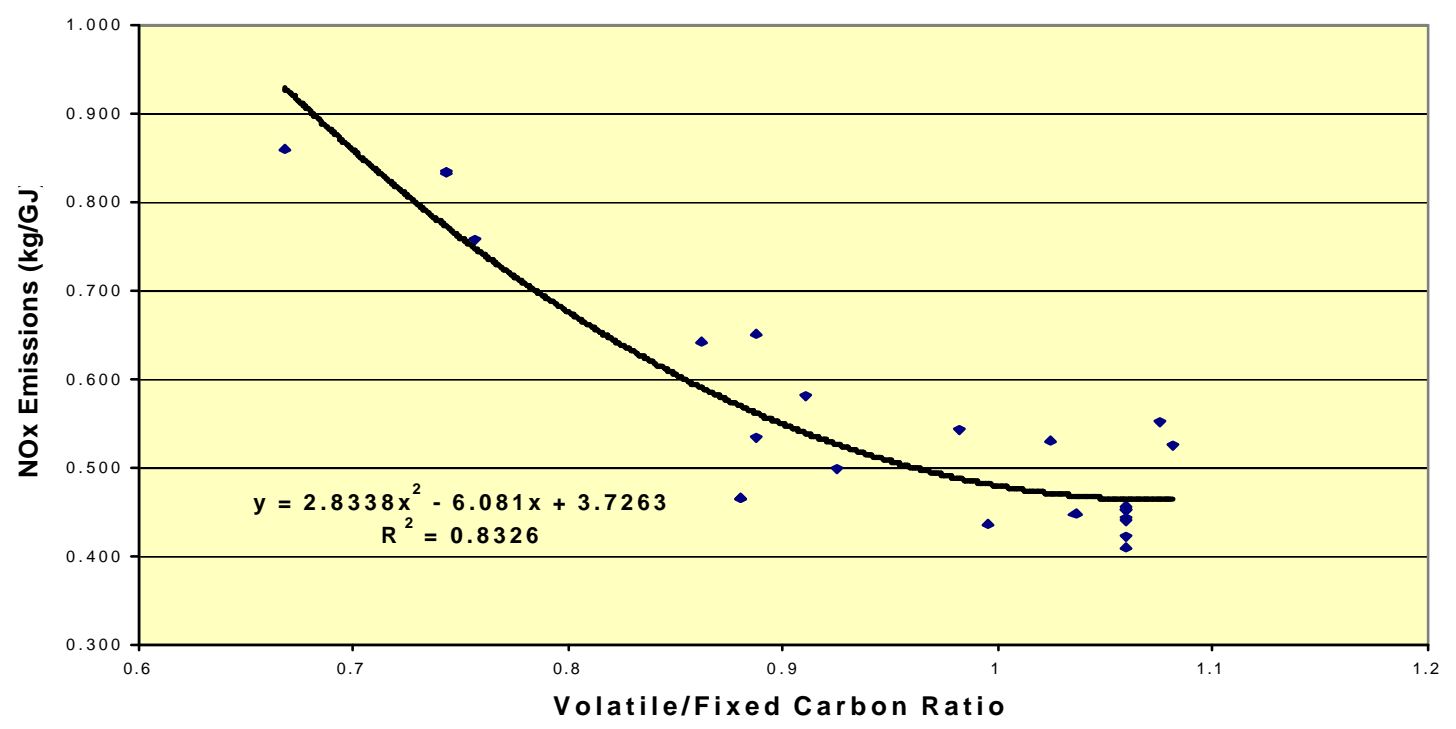

Figure S-5. The Influence of Fuel Volatility on $\mathrm{NO}_{\mathrm{x}}$ Emissions at the Allen Fossil Plant Cofiring Tests (Tillman et. al., 1996)

Tests at the Allen Fossil Plant also confirmed that particle size had a significant influence on the ability to reduce $\mathrm{NO}_{\mathrm{x}}$ emissions. As particles became larger, the $\mathrm{NO}_{\mathrm{x}}$ reduction decreased. When particles reached $25 \mathrm{~mm}$ in size, there was no reduction in oxides of nitrogen. Under such conditions diffusion effects reduced the practical volatility of the biomass in the cyclone barrel.

\section{Tests at the Kingston Fossil Plant and the Shawville Generating Station}

EPRI also supported testing at the Kingston Fossil Plant of TVA, and the Shawville Generating Station of GPU Genco. The Shawville tests were also partially sponsored by the Federal Energy Technology Center (FETC, now NETL) of USDOE. These tests involved blending woody biomass with coal on the coal pile and then transporting the blend to pulverizers before firing it in PC boilers.

The Kingston Fossil Plant tests involved firing blends up to 5 percent by mass in a $200 \mathrm{MW}_{\mathrm{e}} \mathrm{T}$-fired boiler. Sawdust was the biomass fuel. These tests documented that low percentage cofiring has minimal impact on boiler efficiency or temperature distribution. However the practice of cofiring decreased the Hardgrove Grindability Index (HGI) of the fuel blend, and it degraded the product of the pulverizers. The sieve analysis showed significant problems with the product of bowl mills, particularly as the blend approached 5 percent sawdust (mass basis). 
The Shawville tests involved firing blends of sawdust, right-of-way trimmings, and hybrid poplar grown on closed coal mines with coal. Tests occurred in boiler \#2, a $138 \mathrm{MW}_{\mathrm{e}}$ wall-fired unit, and boiler \#3, a $190 \mathrm{MW}_{\mathrm{e}} \mathrm{T}$-fired unit. Unit \#2 was equipped with a low- $\mathrm{NO}_{\mathrm{x}}$ firing system. For these tests, cofiring blends were prepared off-site at ratios of 3 percent woody biomass/97 percent coal. The blends were transported to the power plant for combustion. The Shawville tests documented that, for generating stations that are pulverizer capacity limited, cofiring has a serious consequence. The 3 percent cofiring blends caused reductions in boiler capacity of $\sim 8$ percent. The cause of boiler capacity loss in boiler \# 2 was the impact of biomass on table feeder speeds - and the fact that the feeders could not move more fuel regardless of speed. The cause of boiler capacity loss in boiler \#3 was the degradation in mill outlet temperature. In both cases the cofiring increased the mill amps required for pulverizing, thereby increasing the house load during cofiring.

\section{Results of the Initial EPRI Program}

The initial EPRI program, then, resulted in significant engineering and special studies along with initial parametric testing of cofiring. The program favorably resolved concerns including the ability of bunkers to store and move woody biomass/coal blends successfully. The program successfully allayed fears of spontaneous combustion. It highlighted the potential of cofiring in cyclone boilers, and highlighted potential problems with cofiring in PC boilers when introducing blended fuels through the pulverizers. Such technology can be applied, but under limited conditions. This research pointed to the greater potential for cofiring in PC boilers by separately preparing the biomass for injection into the furnace, rather than blending it with coal upstream of the PC. Additional research led to the development of fuels databases.

\section{THE EPRI-USDOE COOPERATIVE AGREEMENT}

EPRI and NETL (then FETC) constructed a cooperative agreement to further the commercialization of cofiring. EPRI brought a successful research and testing program to NETL. This program included significant utility partners: TVA, GPU Genco, NIPSCO, New York State Electric and Gas (NYSEG), MG\&E, Southern Company, and others. EPRI brought a program with significant momentum-a program that had resolved many of the issues associated with cofiring. NETL brought significant financial resources to this research program. These financial resources would later be significantly strengthened with funds from the Office of Energy Efficiency and Renewable Energy (EE-RE). Equally significantly, NETL brought project management skills to the program that enabled it to proceed from engineering studies and short-term parametric testing to the construction and implementation of cofiring demonstrations necessary for the commercialization of this technology.

The Cooperative Agreement led to testing, demonstrations, and special studies for cofiring biomass with coal in wall-fired PC boilers, T-fired PC boilers, and cyclone boilers. At the same time the Cooperative Agreement provided for analyses of institutional issues impeding the commercialization of cofiring: the impacts of environmental regulations (e.g., New Source Review) as they are interpreted and applied, 
the impacts of deregulation on utility investments and on various state regulations (e.g., Portfolio Standards), and the potentials for various tax incentives. These actions have led cofiring to the brink of broad-based commercial deployment.

\section{ACHIEVEMENTS OF THE COOPERATIVE AGREEMENT FOR COFIRING IN WALL-FIRED PC BOILERS}

Through the Cooperative Agreement, EPRI and USDOE pursued demonstration and commercialization of cofiring at the Colbert Fossil Plant of TVA and the Seward Generating Station of GPU Genco; and supported the test program at Blount St. Station of Madison Gas \& Electric (see Plasynski, Costello, Hughes, and Tillman, 1999; Hughes and Tillman, 1996).

\section{Commercializing Cofiring at the Colbert Fossil Plant of TVA}

During 1997, the Tennessee Valley Authority performed the extensive pre-commercial testing required to implement low percentage cofiring at its Colbert Fossil Plant (Rollins, Reardon, and Tillman, 1998). Colbert is a 1,300 MW generating station with four $190 \mathrm{MW}$ boilers and a $550 \mathrm{MW}$ boiler. Cofiring was largely tested and commercialized using boiler \#3, with a blend of 4 percent biofuel/96 percent coal. In the process of commercializing low percentage cofiring, TVA implemented a low cost, highly effective materials handling system and conducted emissions testing required to commercialize this practice. The consequence is an incubator utility for the cofiring of waste wood with coal in a wall-fired pulverized coal boiler. The Colbert installation involved installing a pole barn and a large trommel screen. The product from the trommel screen, sized at 55 tonne/hr (60 ton/hr), was blended directly with coal on the belts feeding the bunkers. Figure S- 6 depicts the materials handling facility. 


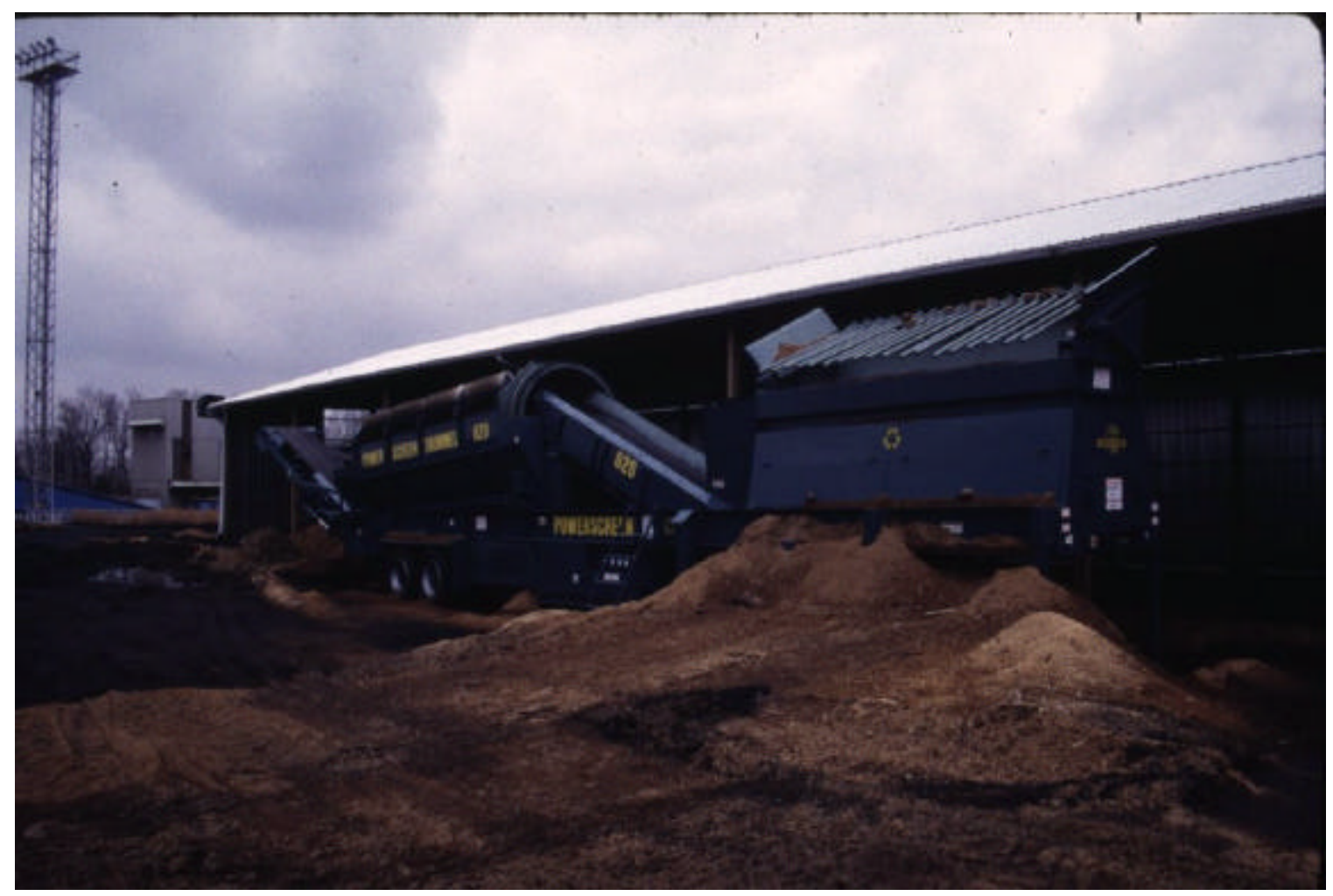

Figure S-6. Materials Handling at the Colbert Fossil Plant Cofiring Installation

The impacts of cofiring at Colbert Fossil Plant were minimal. There was no impact on boiler capacity, as the unit has spare pulverizer capacity. Mill amps did increase, however, by about 8 percent. There was no consistent, measurable impact on boiler efficiency. During baseline (100 percent coal) tests, boiler efficiencies ranged from 81.9 percent to 83.6 percent. When cofiring at 4 percent sawdust, boiler efficiencies ranged from 82.9 percent to 83.5 percent.

There were no cofiring impacts on $\mathrm{NO}_{\mathrm{x}}$ or opacity emissions. It can be calculated that there was a 2 percent reduction in $\mathrm{SO}_{2}$ emissions, although this was not shown by measurement. The cofiring percentage was too small. There was no impact on opacity. The impact on fossil $\mathrm{CO}_{2}$ emissions again could be calculated as a reduction of 2 percent. The tests were sufficiently successful that cofiring was commercialized at the Colbert Fossil Plant (Rollins, Reardon, and Tillman, 1998).

\section{Testing and Demonstrating Cofiring at the Seward Generating Station}

EPRI and USDOE, through the Cooperative Agreement, began a test program at the Seward Generating Station in December 1996. Tests were conducted in 1996 and July 1997, leading to construction of a demonstration facility and further testing (see Battista, Hughes, and Tillman 2000; Battista, Tillman, and Hughes, 2000; Battista, Tillman, and Hughes, 1999; Tillman, 1999a). Seward Station consists of three boilers (\#12, \#14, and \#15) feeding two turbines. Boiler \#12, which was selected for the cofiring testing, is a 1950 vintage Babcock and Wilcox $(\mathrm{B} \& \mathrm{~W})$ front wall-fired boiler, with a capacity of approximately $37.7 \mathrm{~kg} / \mathrm{sec}(300,000 \mathrm{lb} / \mathrm{hr})$ of $45.9 \mathrm{~atm} / 446^{\circ} \mathrm{C}\left(675 \mathrm{psig} / 835^{\circ} \mathrm{F}\right)$ 
steam. Along with Boiler \#14, a twin to \#12 except it has been modified with low NOx burners, it feeds steam to a common header that, in turn, feeds a 64 MW (net) Westinghouse steam turbine (Unit \#4). The net heat rate for these units is approximately $14.98 \mathrm{MJ} / \mathrm{kWh}(14,200 \mathrm{Btu} / \mathrm{kWh})$. The third boiler (\#15) is a 147 MWe (gross) Combustion Engineering (CE) boiler built in 1957 which is a tangentially-fired pulverized coal boiler.

During the parametric tests, Boiler \#12 was equipped with a biomass surge bin, metering augers, lock hoppers, and transport pipes. The transport pipes connected the biomass delivery system to the unused centerpipes of the three top burners. Each burner was equipped with a separate metering auger, a separate lock hopper, and a separate blower. Each such system could deliver 2.72 tonne/hr (6,000 $\mathrm{lb} / \mathrm{hr}$ ) of sawdust to the boiler. As a practical matter, however, the unit was typically operated in the 2tonne/hr range. The demonstration project consisted of co-firing sawdust with pulverized coal in a 32 MWe wall-fired pulverized coal boiler (\#12) by utilizing separate injection of the wood at a rate of approximately 2 tonnes per hour (up to 10 percent on a heat basis) for an extended period of time.

The initial tests were conducted with green sawdust (39 percent moisture), old sawdust (49 percent moisture), and dry sawdust at 14 percent moisture. Cofiring levels ranged from 0 percent to 18 percent on a mass basis or 10 percent on a heat input basis. These tests demonstrated that there would be no deleterious capacity impacts from cofiring, that efficiency losses could be modest and manageable, and that emissions impacts would be beneficial. Table S-1 summarizes the test results from the July 1997 parametric tests used to transition from the parametric testing to the demonstration.

Table S-1. Test Results at the Seward Generating Station, July 1997

\begin{tabular}{|c|c|c|c|c|c|c|c|}
\hline Test No & Wood Type & \multicolumn{2}{|c|}{ Cofiring $\%$} & Boiler $\eta, \%$ & \multicolumn{2}{l|}{ LOI, $\%$} & \multicolumn{2}{|c|}{ NOx Emissions } \\
\hline & & Mass & Heat & & & Kg/GJ & Lb/10 ${ }^{6}$ Btu \\
\hline 1 & None & 0 & 0 & 85.62 & 6.92 & 0.41 & 0.95 \\
\hline 2 & Fresh Sawdust & 3.4 & 1.47 & 85.79 & 4.61 & 0.37 & 0.85 \\
\hline 3 & Fresh Sawdust & 6.4 & 2.83 & 85.71 & 5.86 & 0.37 & 0.85 \\
\hline 4 & Fresh Sawdust & 9.5 & 4.31 & 85.47 & 6.02 & 0.36 & 0.83 \\
\hline 5 & Fresh Sawdust & 13.0 & 6.04 & 85.03 & 7.84 & 0.36 & 0.83 \\
\hline 6 & Fresh Sawdust & 16.1 & 7.60 & 84.21 & 8.68 & 0.34 & 0.80 \\
\hline 7 & Dry Sawdust & 13.8 & 8.11 & 85.74 & 5.09 & 0.35 & 0.82 \\
\hline 8 & Dry Sawdust & 17.2 & 10.3 & 84.09 & 10.16 & 0.34 & 0.78 \\
\hline 9 & Fresh Sawdust & 17.9 & 8.53 & 84.65 & 5.89 & 0.34 & 0.80 \\
\hline 10 & Old Sawdust & 4.4 & 1.61 & 86.13 & 5.50 & 0.37 & 0.87 \\
\hline 11 & Old Sawdust & 8.2 & 3.05 & 85.26 & 6.70 & 0.37 & 0.85 \\
\hline 12 & Old Sawdust & 11.9 & 4.31 & 85.62 & 3.12 & 0.36 & 0.84 \\
\hline 13 & None & 0 & 0 & 86.07 & 6.65 & 0.37 & 0.87 \\
\hline
\end{tabular}

When the parametric tests were combined, they yielded an efficiency regression equation as follows $\left(\mathrm{r}^{2}\right.$ $=0.89$ ) 


$$
\eta=87.6-0.14\left(\mathrm{EO}_{2}\right)-0.16(\mathrm{UBC})-0.11(\mathrm{~W})
$$

Where $\mathrm{EO}_{2}$ is percent excess $\mathrm{O}_{2}$ measured on a wet basis, $\mathrm{UBC}$ is percent unburned carbon in the flyash, and $\mathrm{W}$ is percent wood in the fuel mix on a heat input or Btu basis. The probabilities of the equation, or any component, being random are as follows: total equation, 0.000125; intercept, $4.24 \times 10^{-24} ; \mathrm{EO}_{2}, 0.77$; UBC, 0.0027 ; and $\mathrm{W}, 0.00072$. The impact of cofiring is to reduce boiler efficiency by about 1 percent for every 10 percent on a heat input basis—or 1 percent for every 20 percent on a mass input basis.

The parametric tests also demonstrated that carbon conversion-combustion efficiency-was not degraded by cofiring. Carbon monoxide measurements taken during the December 1996 tests showed a range of $8.5 \mathrm{ppmv}$ to $18 \mathrm{ppmv}$ when cofiring percentages ranged from 0 to 20 (mass basis). Benefits demonstrated during the December 1996 tests included the ability to recover some capacity lost due to the impacts of wet coal on the pulverizer. These benefits were of particular economic significance.

NOx emissions reductions were pronounced at the Seward Generating Station parametric tests, as is shown in Figure S-7. Again the driving variable, determined statistically, was the volatile/fixed carbon ratio from the proximate analysis.

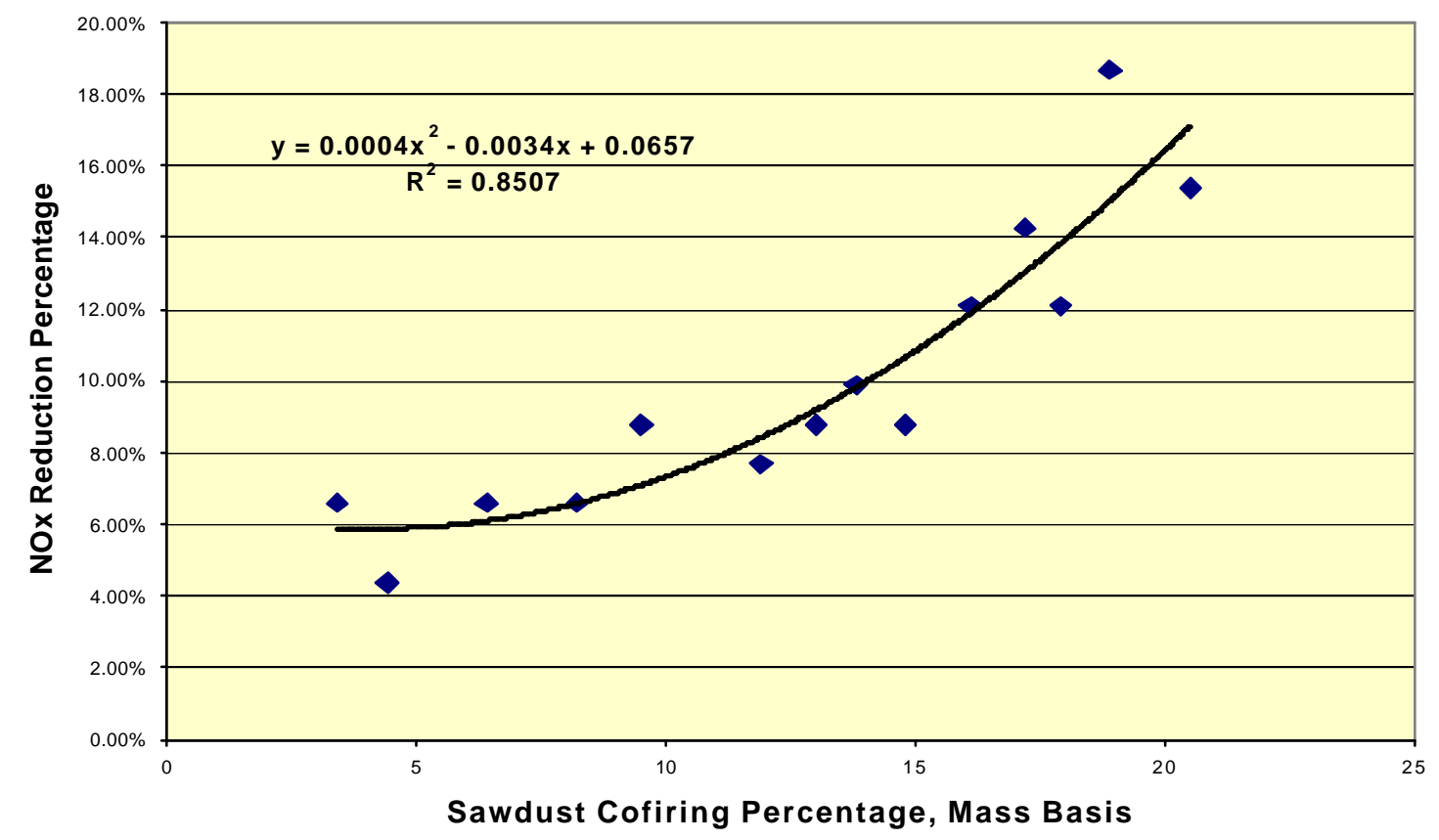

Figure S-7. $\mathrm{NO}_{\mathrm{x}}$ Reduction During the Parametric Testing at the Seward Generating Station

The success of the parametric tests led to the construction of a demonstration facility (see Figure S-8). The demonstration facility consisted of a walking floor unloader, capable of receiving sawdust from a walking floor truck. This unloader fed a trommel screen producing a biomass fuel with a top particle 
size of $6.25 \mathrm{~mm}$. The screened sawdust was then stored in a silo. When reclaimed from the silo it was transported across a weigh belt feeder to the feed screws and rotary airlocks. It was then injected into the centerpipe of the middle burner in each row of burners.

The results of the demonstration were highly favorable. Capacity was not reduced as a function of cofiring. Efficiency reductions were modest until cofiring percentages exceeded 12, as is shown in Figure S-9. Operationally there were no problems with opacity, unburned carbon or LOI in the flyash, or CO emissions.

The most dramatic results again were in the area of $\mathrm{NO}_{\mathrm{x}}$ reduction, as is shown in Figure $\mathrm{S}-10$. The data underlying Figure S-9 resulted in the following regression equation $\left(r^{2}=0.93\right)$ :

$$
\mathrm{NO}_{\mathrm{x}}=18.92-647.4\left(\mathrm{~W}_{\mathrm{m}}\right)+9.66(\mathrm{~L})+59.9\left(\mathrm{EO}_{2}\right)
$$

Where $\mathrm{NO}_{\mathrm{x}}=$ oxides of nitrogen, ppmvd at $3 \% \mathrm{O}_{2}$ (dry basis), $\mathrm{L}=$ load measured as main steam flow in $\mathrm{kg} / \mathrm{sec}, \mathrm{EO}_{2}=$ excess $\mathrm{O}_{2}$ reported in the control room (total basis), and $\mathrm{W}_{\mathrm{m}}=$ wood cofiring percentage, mass basis. The equation is quite robust. The probability that the results as a whole are a random occurrence is $4.3 \times 10^{-6}$, the probability that the $\mathrm{W}_{\mathrm{m}}$ term is a random event is $8.3 \times 10^{-7}$, the probability that the $\mathrm{L}$ term occurs randomly is $2.1 \times 10^{-5}$, and the probability that the $\mathrm{EO}_{2}$ term occurs randomly is $2.3 \times 10^{-5}$. Significance of terms can also be treated as $1-$ the probability that any term (or the equation as a whole) occurred as a random event. The significance of the equation and the $\mathrm{W}_{\mathrm{m}}$ term exceed 99.999 percent. The significance of the $\mathrm{L}$ and $\mathrm{EO}_{2}$ terms exceeds 99.99 percent. This is a very robust equation. The English measure equivalent is as follows:

$$
\mathrm{NO}_{\mathrm{x}}=0.026-0.899\left(\mathrm{~W}_{\mathrm{m}}\right)+0.0017(\mathrm{~L})+0.083\left(\mathrm{EO}_{2}\right)
$$

Where $\mathrm{NO}_{\mathrm{x}}$ is measured in $\mathrm{lb} / 10^{6} \mathrm{Btu}, \mathrm{W}_{\mathrm{m}}$ is cofiring percentage, mass basis, $\mathrm{L}$ is load measured as main steam flow in thousand pounds/hr (kpph), and $\mathrm{EO}_{2}$ is excess oxygen (total basis).

A similar pair of equations can be developed based upon biomass cofiring as a heat input percentage. 


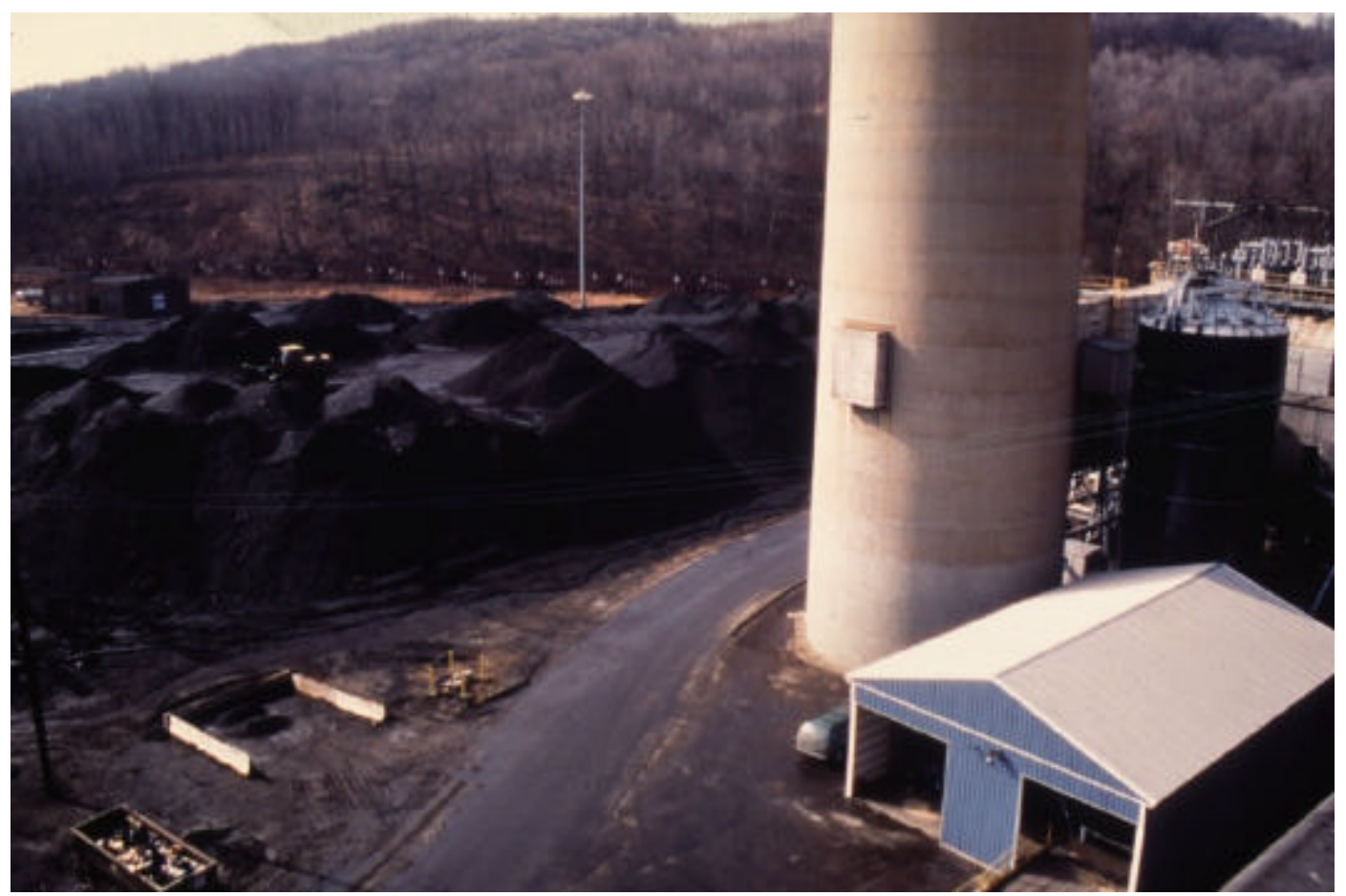

Figure S-8. The Seward Generating Station Cofiring Demonstration Facility

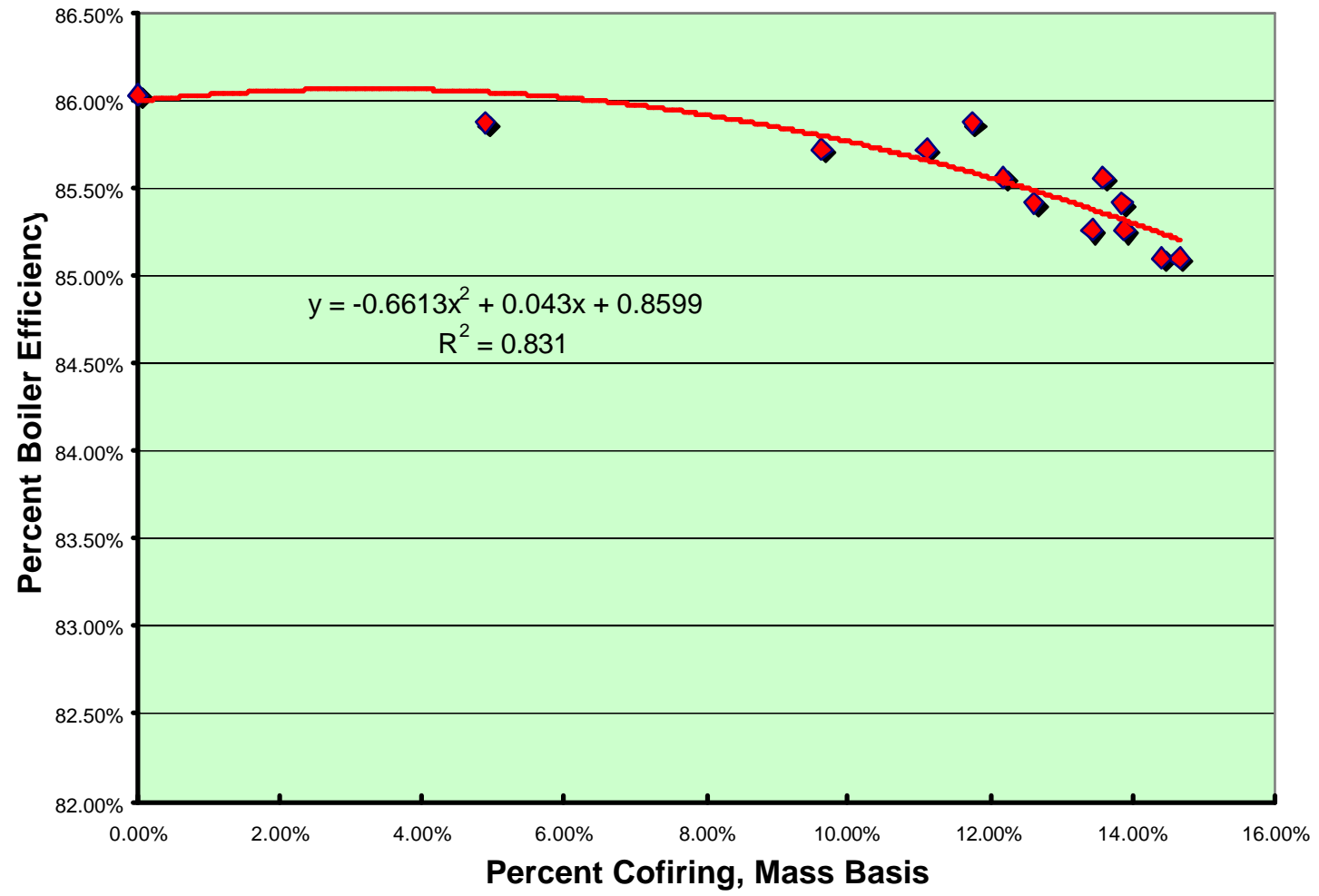


Figure S-9. Efficiency Results from the Cofiring Demonstration at Seward Generating Station

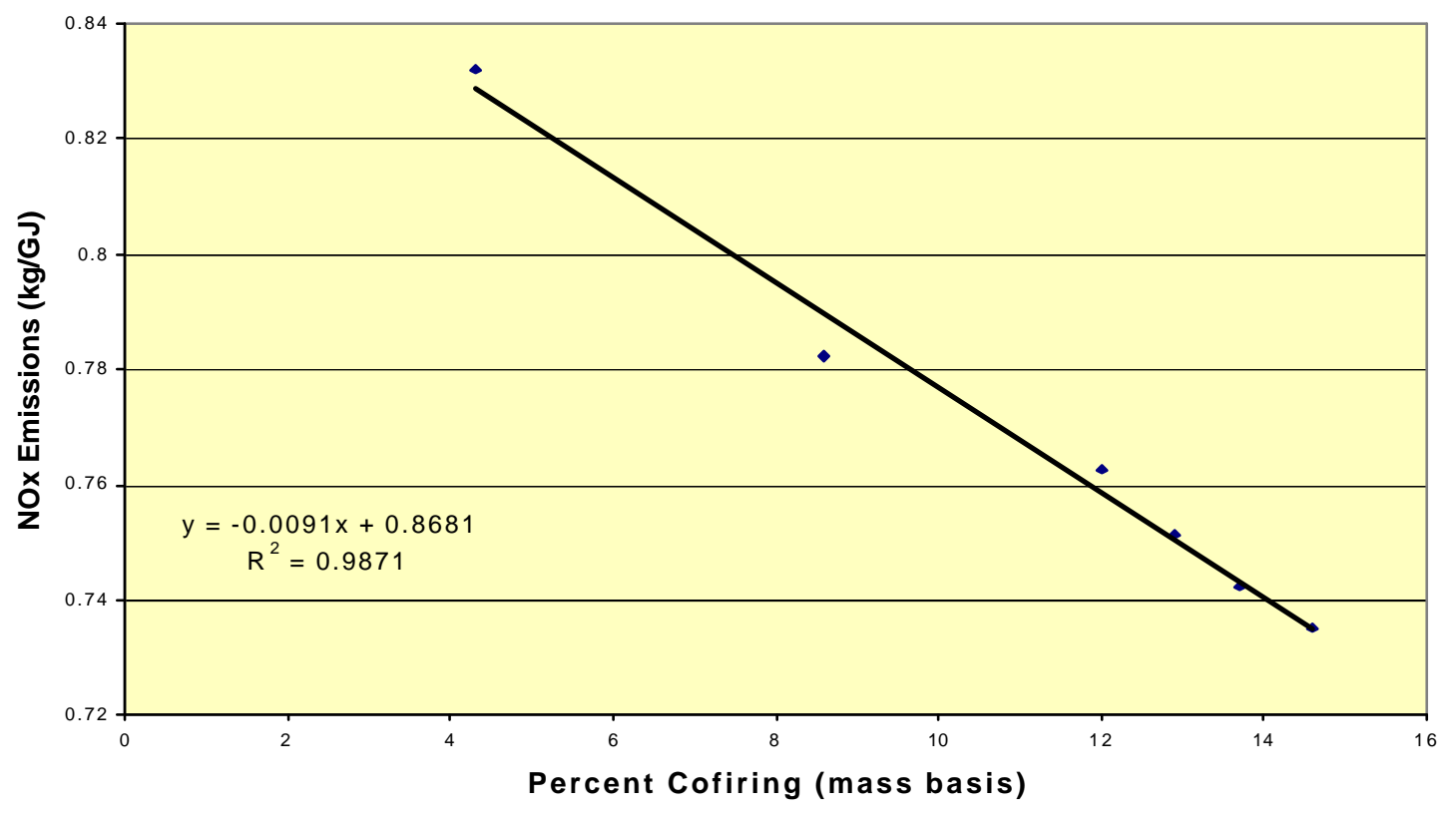

Figure S-10. $\mathrm{NO}_{\mathrm{x}}$ Emissions Measured During the Seward Generating Station Demonstration

The Seward Generating Station Demonstration promised considerable success. However the economics of deregulation intervened. The station was sold by GPU to Sithe Energies, and then by Sithe Energies to Reliant Energy. Further, its high heat rate and high inherent $\mathrm{NO}_{\mathrm{x}}$ emissions level made it uneconomic to continue operations on a regular basis. Consequently the demonstration had to be discontinued at the Seward location. It was relocated to the Albright Generating Station as will be discussed subsequently.

\section{Support for the Blount St. Station Testing of Switchgrass Cofiring}

Under a grant from the Great Lakes Regional Biomass Program, the University of Wisconsin and MG\&E conducted parametric tests of cofiring switchgrass with coal at the Blount St. Station. This was the first test cofiring switchgrass with coal in a utility boiler. EPRI, through the Cooperative Agreement, became a cosponsor of the project along with Wisconsin Power \& Light (now Alliant Energy) and Nebraska Public Power District. USDOE-NETL also participated directly in this test program (Ragland and Aerts, 1996).

The cofiring testing at Blount St. Station was conducted in a 50 MWe non-reheat boiler generating $180,000 \mathrm{~kg} / \mathrm{hr}(400,000 \mathrm{lb} / \mathrm{hr})$ of $8600 \mathrm{kPa} / 510^{\circ} \mathrm{C}\left(1250 \mathrm{psig} / 950^{\circ} \mathrm{F}\right)$ steam. At full load this boiler typically consumes 23.6 tonne/hr (26 ton/hr) of bituminous coal. The combustion system includes balland race pulverizers feeding pulverized coal to three rows of burners; each row has three individual 
burners. The test program employed the existing cofiring system which is normally used to fire paperderived fuel (PDF) into the boiler. In the test program switchgrass was reduced in particle size first by a hammermill at the plant, and then by a tub grinder off site. The switchgrass was then bunkered in surge hoppers at the plant and reclaimed for firing through separate injection ports between the first and second (from the bottom) rows of burners.

The switchgrass at Blount Station was cofired at mass percentages of 7.1 to 15.3 percent (heat input percentages of 4.3 to 10.2). The base coal was an Illinois Basin bituminous coal from Indiana. The results of cofiring at Blount Station included a reduction in efficiency of about 1 percent, as shown in Table S-2.

Table S-2. Boiler Efficiencies Measured at the Blount Station Cofiring Test

\begin{tabular}{|c|c|c|}
\hline $\begin{array}{c}\text { Test } \\
\text { Condition }\end{array}$ & $\begin{array}{c}\text { Load } \\
(\mathrm{MW})\end{array}$ & $\begin{array}{c}\text { Efficiency } \\
(\%)\end{array}$ \\
\hline Coal & 40.2 & 87.48 \\
\hline Coal & 40.7 & 87.63 \\
\hline Coal & 48.8 & 87.18 \\
\hline Coal & 49.2 & 87.48 \\
\hline Co-fire & 39.9 & 86.50 \\
\hline Co-fire & 40.1 & 86.60 \\
\hline Co-fire & 43.8 & 86.29 \\
\hline Co-fire & 46.4 & 86.02 \\
\hline Co-fire & 47.3 & 86.38 \\
\hline Co-fire & 48.3 & 86.60 \\
\hline Co-fire & 49.0 & 86.39 \\
\hline Co-fire & 49.1 & 86.60 \\
\hline Co-fire & 49.2 & 86.49 \\
\hline Co-fire & 49.6 & 86.97 \\
\hline
\end{tabular}

Source: Aerts and Ragland, 1997.

Efficiency penalties included, particularly, increased air heater exit temperature as a function of supplying the switchgrass with ambient outside air, thereby reducing the quantity of air passing through the air heater.

More significantly than the efficiency reduction experienced, Aerts and Ragland (1997) report a 31 percent decrease in $\mathrm{NO}_{\mathrm{x}}$ emissions as a function of switchgrass cofiring. Again they attribute this $\mathrm{NO}_{\mathrm{x}}$ reduction to the increased volatility of the fuel as measured in the volatile/fixed carbon ratio of the combined switchgrass and coal feed. 


\section{COFIRING TESTS AND DEMONSTRATIONS IN TANGENTIALLY FIRED BOILERS}

The Cooperative Agreement was used to test and demonstrate cofiring in T-Fired boilers as well as wall-fired boilers. Through the Cooperative Agreement, EPRI and USDOE provided some support to the cofiring demonstration at Greenidge Station of New York State Electric and Gas (NYSEG) and to the cofiring testing at Plant Gadsden of Alabama Power, a Southern Company. USDOE also relocated the equipment from the Seward Generating Station to the Albright Generating Station of Allegheny Energy Supply Co., LLC. and implemented a demonstration at that facility.

\section{Results of the Greenidge Program, Partially Supported by the Cooperative Agreement}

NYSEG (now AES) began testing cofiring at Greenidge Station, a facility located on Seneca Lake in Dresden, NY. The unit selected for testing and demonstration was a 108 MWe T-fired boiler with a net station heat rate of $10.34 \mathrm{MJ} / \mathrm{kWh}(9818 \mathrm{Btu} / \mathrm{kWh})$ (Benjamin, 1996a). NYSEG opted for separate fuel preparation and separate fuel injection based upon its own evaluation of cofiring alternatives (Benjamin, 1996b). Support for this project was largely internally derived, with some support from New York State Energy Research and Development Authority (NYSERDA) and the EPRI-USDOE Cooperative Agreement.

The NYSEG project employed equipment obtained from the Rochester, NY refuse-derived fuel (RDF) project. After testing screening of biomass, the project opted for pulverizing all fuel to a top size of 6.25 $\mathrm{mm}$, with a desired fuel particle size of $3.18 \mathrm{~mm}$.

The project has been a significant success, and operates now as a commercial unit, firing over 30,000 tons of dry biomass/year. The initial test results indicated that the system had the potential to reduce $\mathrm{NO}_{\mathrm{x}}$ emissions by about $400-500 \mathrm{~kg} /$ day $(0.4-0.5 \mathrm{ton} /$ day $)$. The system had the potential to reduce $\mathrm{SO}_{2}$ emissions as well, while not causing problems with unburned carbon in the flyash (Benjamin, 1996a). Currently the estimates are that $\mathrm{NO}_{\mathrm{x}}$ is reduced, but modestly (Battista and Hughes, 2000) while $\mathrm{SO}_{2}$ emissions are reduced by 15 percent.

\section{Results of the Gadsden Program, Partially Supported by the Cooperative Agreement}

Under separate contract with USDOE, Southern Research Institute and Southern Company have evaluated cofiring switchgrass at Plant Gadsden. This installation houses two $60 \mathrm{MW}_{\mathrm{e}}$ non-reheat Tfired boilers. The unit is fired with eastern bituminous coal. The EPRI-USDOE Cooperative Agreement provided additional funding to this project. This project is described in progress reports; in Bush, Boylan, and Bransby, 1999; and in Boylan, Bush, and Bransby, 2000). 
In the Plant Gadsden test program, the original intent had been to co-pulverize switchgrass and coal prior to feeding the material to the boiler. However, bunker tests demonstrated that this would cause significant operational problems. Consequently Southern Company opted for a separate injection design.

In the Southern Company project, bales of switchgrass were stored outside. Those stored bales of switchgrass were then retrieved and fed into a tub grinder for particle size reduction. The chopped switchgrass was then stored in a surge hopper prior to pneumatic transport to the boiler. It was blown to the boiler and injected in opposite corners of the unit. Testing included evaluating the elevation of the switchgrass injection (between the A and B elevation of coal buckets, or between the B and C elevation of coal buckets). Figure S-11 depicts this test program.

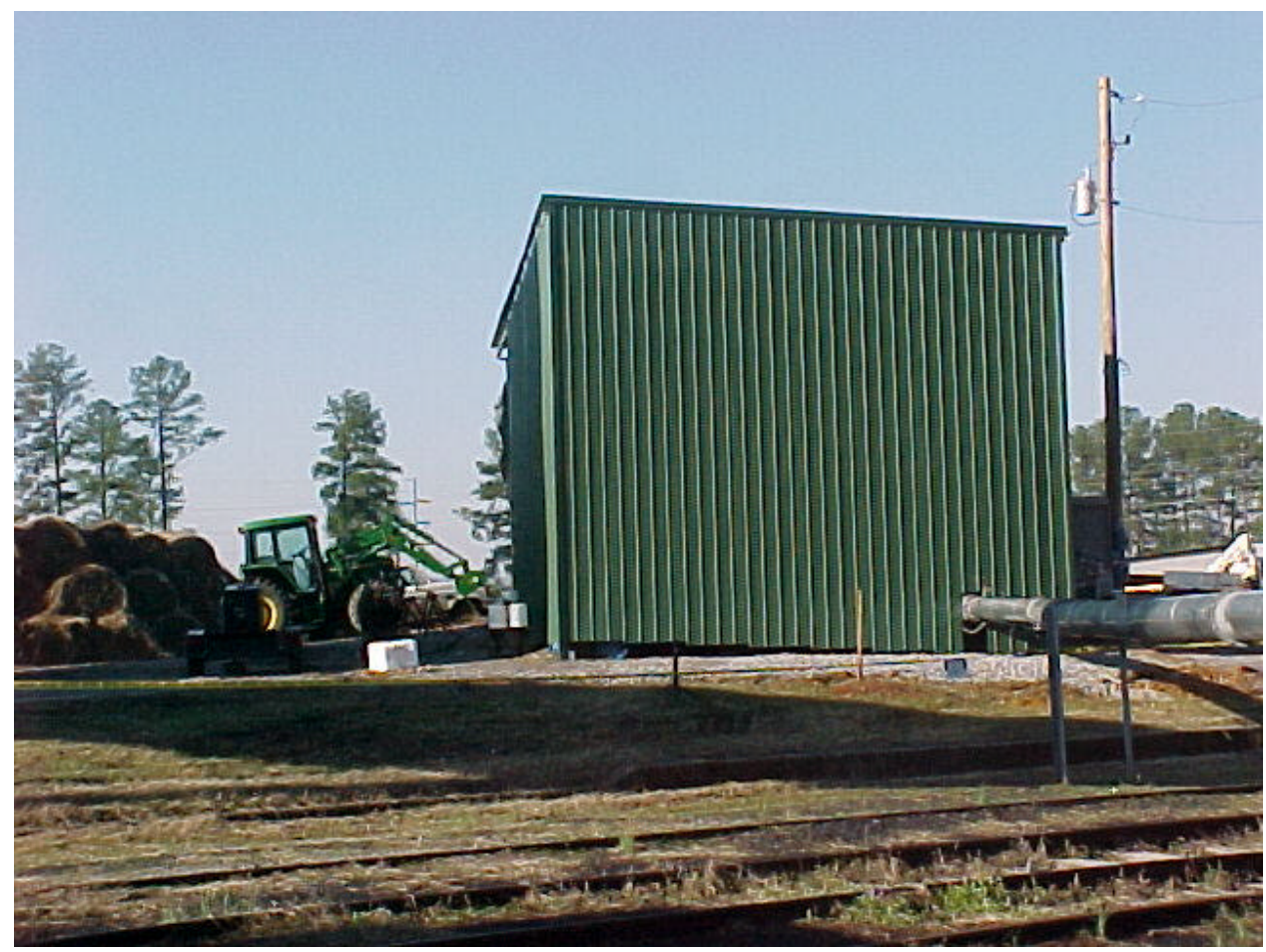

Figure S-11. The Switchgrass Cofiring Facility at Plant Gadsden with the Tractor Feeding a Bale, and the Pneumatic Transport Pipe Carrying the Switchgrass to the Boiler

Results of this test program are only now being analyzed. Data presented by Southern Company at the Biomass Cofiring Project Review Meeting, June 21-22, 2001 (Boylan et. al., 2001) indicated that the project did not achieve a $\mathrm{NO}_{\mathrm{x}}$ reduction; however it did not experience a $\mathrm{NO}_{\mathrm{x}}$ increase. $\mathrm{SO}_{2}$ emissions did decrease as a function of cofiring. The absence of a $\mathrm{NO}_{\mathrm{x}}$ reduction may have resulted from the harvesting and storage practices associated with the switchgrass, rather than inherent properties of the fuel itself. While there were other operational issues with this test program, no fatal flaws were uncovered in the cofiring of switchgrass with coal in T-fired boilers. 


\section{Demonstrating Woody Biomass Cofiring at Albright Generating Station}

With the premature closing of the Seward Generating Station USDOE-NETL and EPRI worked with Allegheny Energy Supply Co., LLC to develop a second cofiring demonstration at the Albright Generating Station. Albright Generating Station is comprised of 3 boilers: 2 are $70 \mathrm{MW}_{\mathrm{e}}$ wall-fired units and boiler \#3 is a $140 \mathrm{MW}_{\mathrm{e}} \mathrm{T}$-fired boiler. Boiler \#3 is equipped with a separated overfire air (SOFA) system, making it an ideal candidate for a cofiring demonstration focusing upon $\mathrm{NO}_{\mathrm{x}}$ emissions. Recognizing that the mechanism typically identified with $\mathrm{NO}_{\mathrm{x}}$ reduction from cofiring involves volatile flooding of the combustion zone, there was some question regarding whether this mechanism would complement—or compete with—the use of a SOFA system for $\mathrm{NO}_{\mathrm{x}}$ reduction.

The demonstration was constructed at Albright including a walking floor unloader supplying sawdust to a disc screen for removal of oversized particles. The screened sawdust would then be transported to a silo for storage. Upon reclaim from the silo, the sawdust would be transported through a weigh belt feeder to metering screws and rotary airlocks. The sawdust would be blown into opposite corners of the boiler. There are four elevations of coal injection in boiler \#3; the sawdust is injected between the B and $\mathrm{C}$ rows - right in the middle of the fireball.

The capacity of the cofiring facility was increased relative to the Seward project. The system is capable of delivering 6 tonnes/hr of sawdust, or over 10 percent (mass basis) of the fuel fired in the unit. The unit was dedicated June 29, 2001. The ribbon cutting is depicted in Figure S-12.

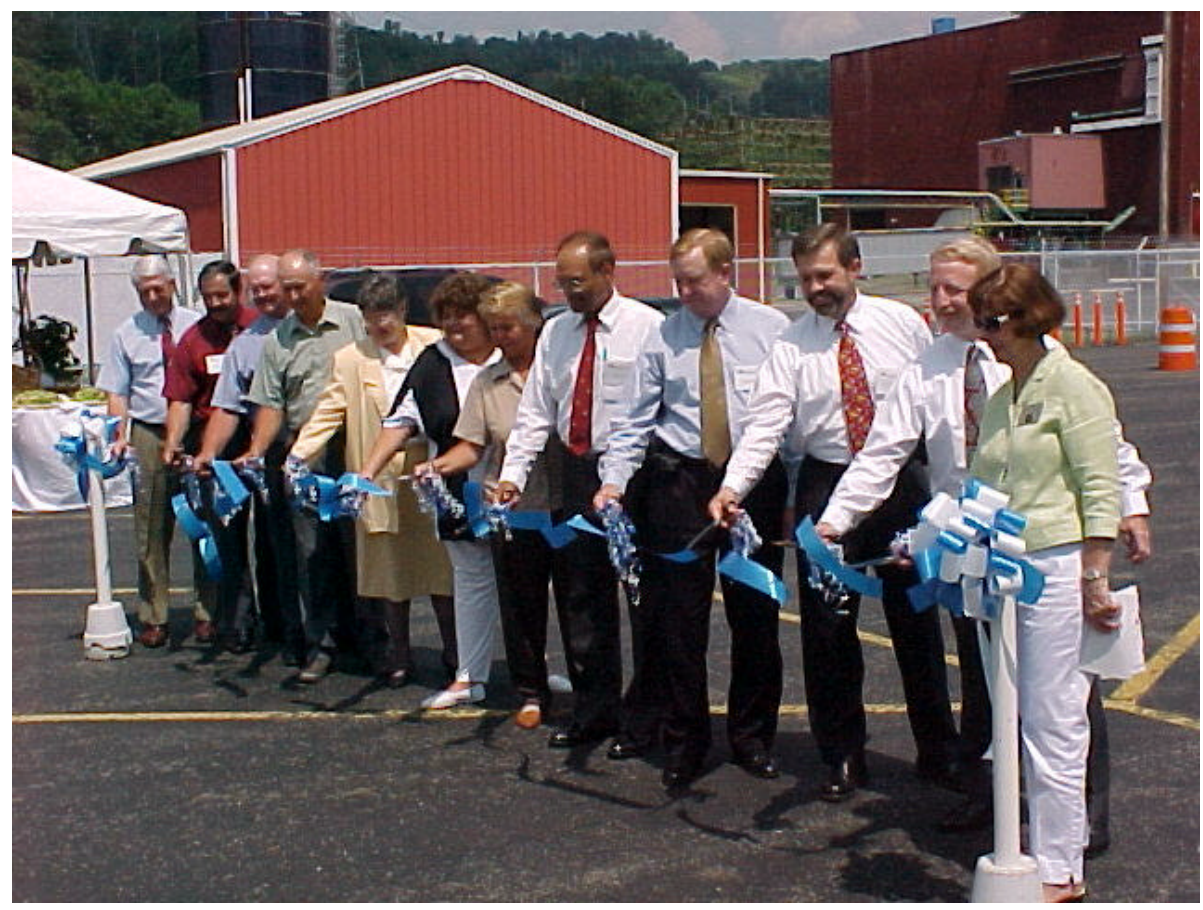

Figure S-12. Ribbon Cutting at the Albright Cogeneration Facility Dedication 
To date there have been over 200 hours of operation on this demonstration, cofiring between 3 and 6 tonnes/hr into the boiler. Boiler operations have ranged from $90 \mathrm{MW}_{\mathrm{e}}$ to $138 \mathrm{MW}_{\mathrm{e}}$ (gross) during baseline testing and between $120 \mathrm{MW}_{\mathrm{e}}$ and $138 \mathrm{MW}_{\mathrm{e}}$ when cofiring sawdust.

Results from this testing have been generally favorable. $\mathrm{SO}_{2}$ emissions have followed percentage cofiring on a heat input basis ( 0 to 5 percent). Opacity has been unaffected by cofiring, and $\mathrm{CO}$ emissions have also been unaffected by cofiring.

$\mathrm{NO}_{\mathrm{x}}$ emissions have been reduced as a function of cofiring, and the biomass injection system can be used to work with the SOFA system. With 68 test hours of data, the following regression equation has been developed $\left(r^{2}=0.87\right)$ :

$$
\mathrm{NO}_{\mathrm{x}}=0.097+3.19 \times 10^{-5}(\mathrm{H})-0.0036\left(\mathrm{~W}_{\mathrm{t}}\right)+0.0126\left(\mathrm{EO}_{2}\right)-0.00023(\mathrm{SOFA})
$$

Where $\mathrm{NO}_{\mathrm{x}}$ is measured in $\mathrm{kg} / \mathrm{GJ}$ of heat input, $\mathrm{H}$ is heat input in $\mathrm{GJ} / \mathrm{hr}, \mathrm{W}_{\mathrm{t}}$ is the sawdust feed rate in tonnes/hr, $\mathrm{EO}_{2}$ is the excess $\mathrm{O}_{2}$ measured in the control room (total basis), and SOFA is the total of the three levels of SOFA damper positions expressed as a percentage. This equation, with 67 degrees of freedom, has a probability of random occurrence, rather than as a consequence of the variables, of $2.49 \times 10^{-27}$. The intercept has a probability of random occurrence of 0.045 . The heat input has a probability that its influence is random of 0.209 ; it may not be a significant variable in this boiler. The probability that the influence of sawdust input is a random occurrence is $6.6 \times 10^{-6}$. The probabilities that the influence of excess $\mathrm{O} 2$ and SOFA damper positions are random occurrences are 0.00098 and $5.26 \times 10^{-20}$ respectively.

The English equivalent of this equation is as follows:

$$
\mathrm{NO}_{\mathrm{x}}=0.225+7.83 \times 10^{-5}(\mathrm{H})-0.0008\left(\mathrm{~W}_{\mathrm{t}}\right)+0.029\left(\mathrm{EO}_{2}\right)-0.005(\mathrm{SOFA})
$$

Where $\mathrm{NO}_{\mathrm{x}}$ is measured in $\mathrm{lb} / 10^{6} \mathrm{Btu}, \mathrm{H}$ is measured in $10^{6} \mathrm{Btu} / \mathrm{hr}$, and $\mathrm{W}_{\mathrm{t}}$ is measured in tons/hr. The statistical measures are identical between equations [S-6] and [S-7].

The Albright cofiring demonstration is on going. It will be operated for 720 test hours over a range of loads and a range of cofiring percentages. Additionally, the SOFA damper positions will be used as a significant variable. Sieve analysis of the sawdust will also be treated as a significant variable. The results to date, however, are sufficiently promising that the $\mathrm{NO}_{\mathrm{x}}$ reductions are expected to continue through future test hours.

\section{COFIRING TEST AND DEMONSTRATION PROJECTS IN CYCLONE BOILERS}

The research at the Allen Fossil Plant documented the significant potential for cofiring in cyclone boilers. There no pulverizers cause inherent limitations, and the biomass can be blended with coal on the coal belts without limiting the cofiring percentage. Foster Wheeler, conducting the cofiring tests at Allen 
Fossil Plant, demonstrated consistent cofiring at 20 percent (mass basis) sawdust with coal — equivalent to 10 percent on a heat input basis.

NIPSCO is a utility with significant cyclone capacity, and with capacity dedicated to the firing of western and Powder River Basin (PRB) coals. NIPSCO has a significant commitment to reduction of fossil $\mathrm{CO}_{2}$ emissions; at the same time it faces the pressures of a deregulated electricity generation market. NIPSCO undertook extensive cofiring testing in cyclone boilers at Michigan City Generating Station and Bailly Generating Station.

\section{Cofiring Testing at the Michigan City Generating Station}

The \#12 boiler at Michigan City is a baseload power plant. It has a gross nameplate capacity of 540 $\mathrm{MW}_{\mathrm{e}}$ and a net capacity of $469 \mathrm{MW}_{\mathrm{e}}$. The boiler was converted from Illinois basin bituminous coal to western and PRB coals. Net capacity is a function of boiler condition, due to the use of PRB coals. Net capacities involve derating the unit based upon the condition of the boiler. At the time of testing, $430 \mathrm{MW}_{\mathrm{e}}$ was considered to be the capacity of the unit. Economizer exit temperature limited boiler capacity, as it measured the extent to which the boiler had tenacious deposits that could only be removed during an outage. Testing at Michigan City, described by Tillman et. al. (1997) and Tillman et. al. (1998a), was designed to address the following concerns:

- Cofiring in a large (e.g., >400 MWe) boiler

- Cofiring in a supercritical boiler generating 24.1MPa (3500 psig) steam

- Cofiring in a boiler with flue gas recirculation

- Cofiring biomass in a boiler fired with PRB coal.

The biomass supply for the Michigan City Generating Station tests was clean urban wood wasteurban woody material that did not include any treated lumber. It was ground to $<3.18 \mathrm{~mm}(<1 / 2$ ") particles and then blended with Shoshone coal in the coal yard. This blend was then mixed with either Black Thunder or Caballo Rojo coal on the belts feeding the power plant bunkers. The blend of coal used for baseline testing was 60 percent PRB/40 percent Shoshone coal. The blend of fuel used for cofiring testing was 50 percent PRB/40 percent Shoshone/10 percent urban wood waste (mass basis).

Testing cofiring with a PRB coal blend presented some challenges. The coal alone had a lower calorific value than bituminous coal. Typically the coal blend contains $22-23 \mathrm{MJ} / \mathrm{kg}$; this compares to bituminous coal at about $27.9 \mathrm{MJ} / \mathrm{kg}(12,000 \mathrm{Btu} / \mathrm{lb})$. The blend of wood waste and coal at Michigan City had a calorific value of $21.3 \mathrm{MJ} / \mathrm{kg}$. Typically the coal blend had a volatile/fixed carbon ratio of 0.95; this is dramatically higher than the V/FC ratio for even high volatile bituminous coal. The blend of wood waste and coals at Michigan City Generating Station had a V/FC ratio of $1.25-1.45$. The coals fired at Michigan City, then, exhibited many of the properties typically measured for bituminous coal/biomass blends. 
The tests were conducted in September 1997. Nine tests were conducted; 3 baseline tests and 6 cofiring tests made up the suite of runs available for analysis. The cofiring level was 10 percent (mass basis) in all cases. Variables included load, excess $\mathrm{O}_{2}$, and blend. Points examined included operational issues, efficiency, and emissions.

From an operational perspective, the practice of cofiring at Michigan City was a qualified success. The boiler operated stably. Cyclone temperatures increased slightly when cofiring, relative to firing the baseline coal blend. Furnace exit gas temperatures (FEGT) decreased slightly. Cofiring did not impact economizer exit temperatures. However the practice of cofiring did speed up the cyclone feeders as is shown in Figure S-13. Feeder speeds approached 95 percent. Essentially $425 \mathrm{MW}_{\mathrm{e}}$ was the maximum capacity that the unit could achieve with this fuel blend. While the boiler was not derated as a consequence of cofiring, the potential existed for such a derate condition.

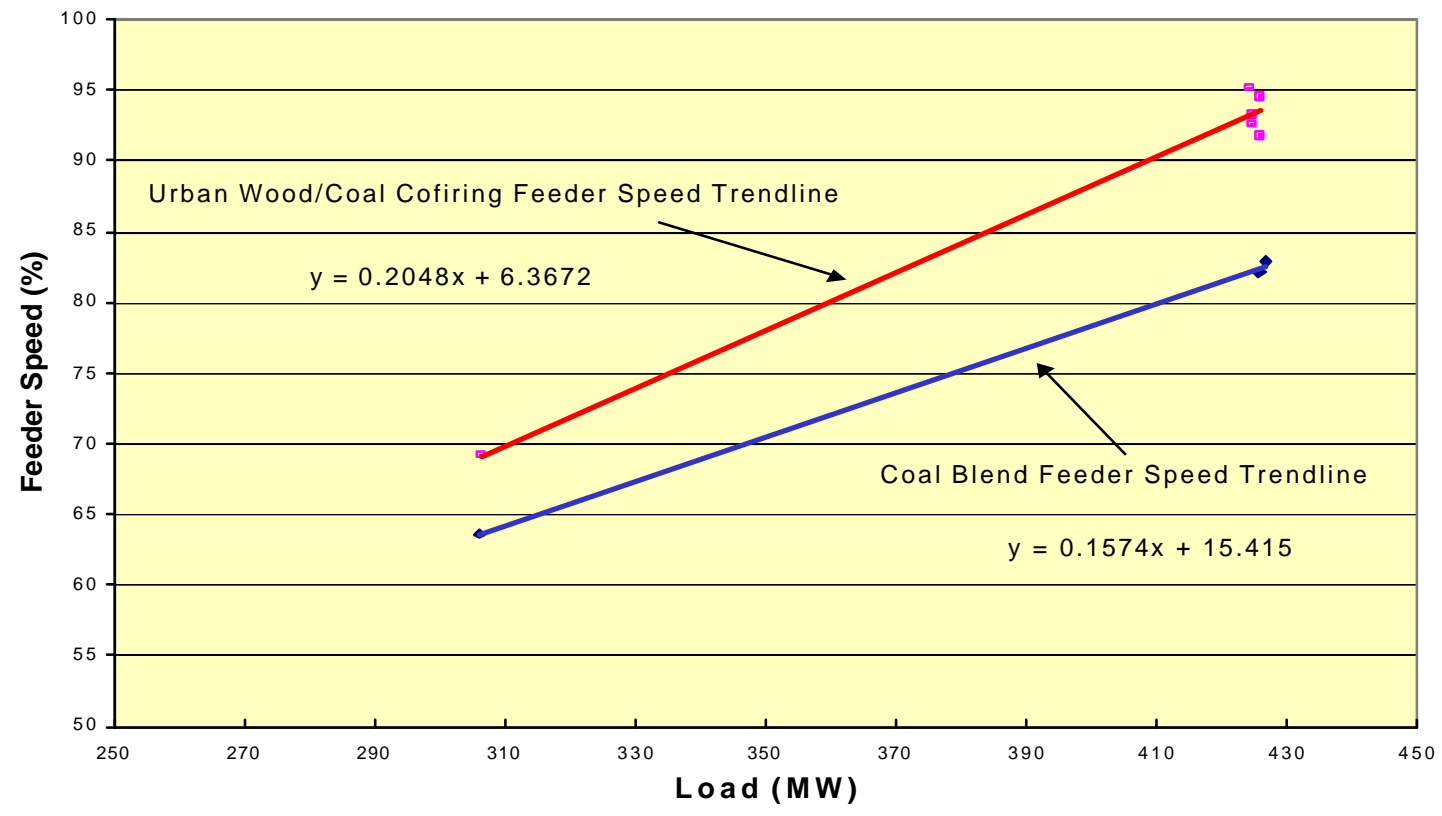

Figure S-13. Impact of Cofiring on Cyclone Feeder Speeds When Cofiring Wood Waste and PRB Coal at Michigan City Generating Station

The impact of cofiring on boiler efficiency was predictable, and consistent with all other cyclone cofiring tests. This impact is shown in Figure S-14. There was a modest decrease in efficiency as a consequence of urban wood waste cofiring. Efficiency calculations are made somewhat complex by the fact that NIPSCO switched from Caballo Rojo to Black Thunder PRB coal during the test program.

On average, the cofiring of 10 percent urban wood waste (mass basis) caused a decrease in boiler efficiency of about 0.3 percent. The efficiency decrease would have been larger if Black Thunder had 
been used throughout as the PRB coal. The efficiency decrease, further, was minimized by the fact that the average moisture content of the urban wood waste was 26 percent, rather than the typical $38-45$ percent for fresh green sawdust.

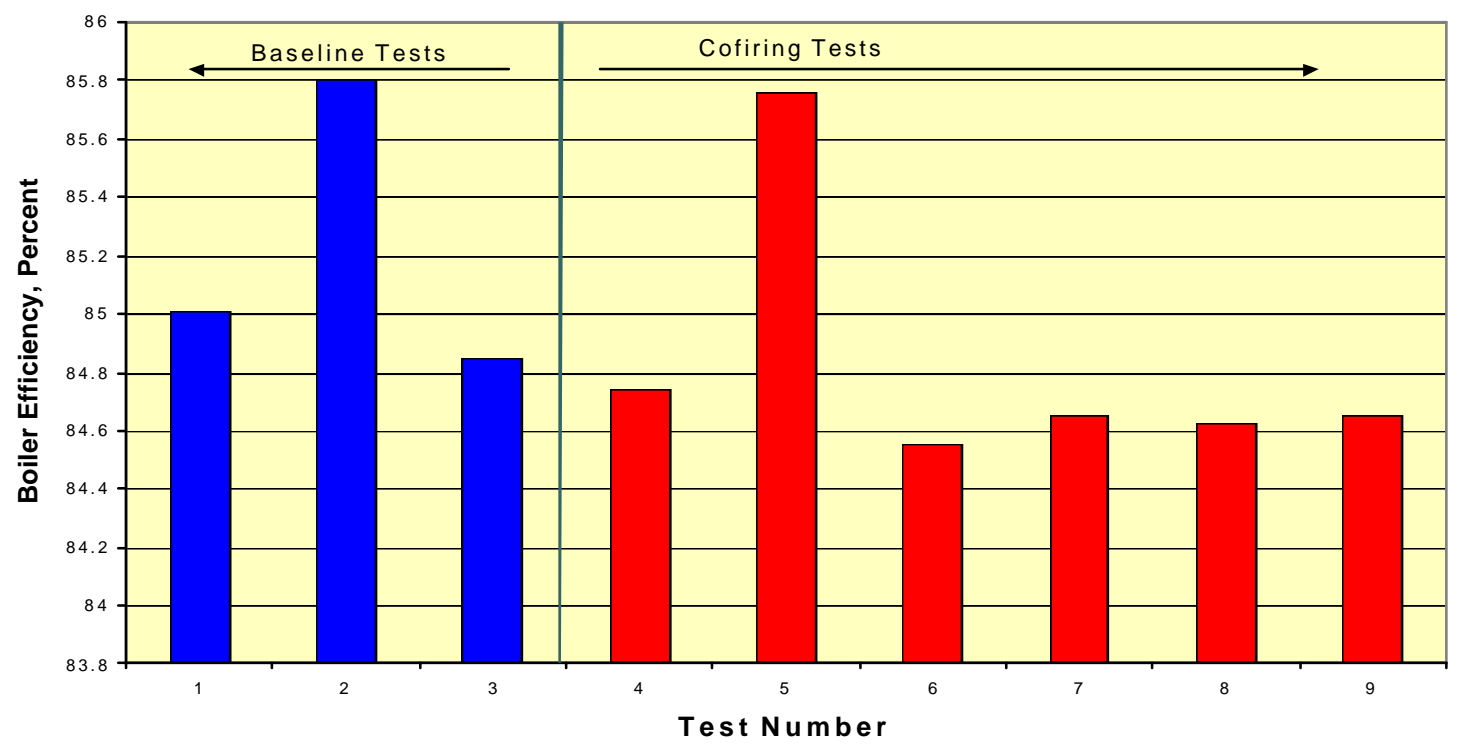

Figure S-14. Boiler Efficiencies Calculated for the Michigan City Generating Station Cofiring Tests

The environmental impact of cofiring at the Michigan City Generating Station was quite favorable. $\mathrm{SO}_{2}$ emissions decreased, although less than experienced in other tests due to the low sulfur content of the western and PRB coals. Opacity, on average, decreased modestly when cofiring — although the highest readings also occurred during one cofiring test. Most significantly, despite the fact that the western and PRB coals are low in nitrogen and high in volatile matter, cofiring achieved an average 9.5 percent reduction in $\mathrm{NO}_{\mathrm{x}}$ emissions while cofiring at 10 percent by mass or 6.5 percent on a heat input basis. Figure S-15 summarizes the $\mathrm{NO}_{\mathrm{x}}$ reduction achieved by cofiring at Michigan City.

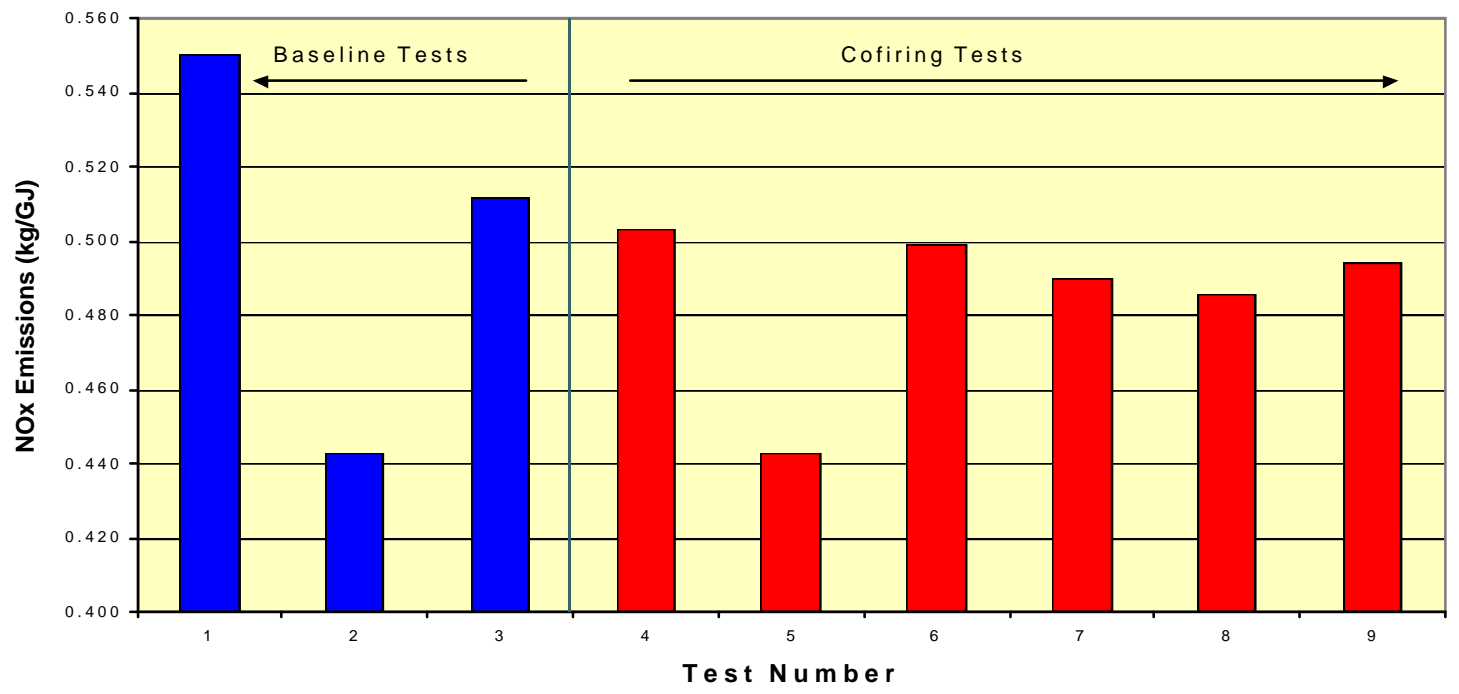


Figure S-15. $\mathrm{NO}_{\mathrm{x}}$ Emissions at the Michigan City Cofiring Tests

The equation which best describes the NOx results is as follows $\left(r^{2}=0.89\right)$ :

$$
\mathrm{NO}_{\mathrm{x}}=0.00039(\mathrm{FEGT})-0.0027\left(\mathrm{~W}_{\mathrm{m}}\right)-0.08
$$

Where $\mathrm{NO}_{\mathrm{x}}$ is measured in $\mathrm{kg} / \mathrm{GJ}$, furnace exit gas temperature or FEGT is measured in degrees $\mathrm{K}$, and $\mathrm{W}_{\mathrm{m}}$ is wood cofiring percentage on a mass basis. The probabilities that the calculated values for each term are random events are as follows: equation as a whole, 0.0012; FEGT, 0.00047; and $\mathrm{W}_{\mathrm{m}}$, 0.024. This is a reasonably significant equation despite the few observations. The English equivalent equation is as follows:

$$
\mathrm{NO}_{\mathrm{x}}=0.04-0.0063\left(\mathrm{~W}_{\mathrm{m}}\right)+0.00051(\mathrm{FEGT})
$$

Where $\mathrm{NO}_{\mathrm{x}}$ is measured in $\mathrm{lb} / 10^{6} \mathrm{Btu}$ and FEGT is measured in ${ }^{\circ} \mathrm{F}$.

The clear inference from the data is that the biomass increases the completeness of combustion in the cyclone barrel, reducing the combustion in the primary furnace and thereby reducing the FEGT. This appears to be the dominant mechanism from the Michigan City test program.

Fossil $\mathrm{CO}_{2}$ emissions also were reduced significantly during the Michigan City cofiring tests. Direct reductions of $25-27$ tonne/hr of fossil $\mathrm{CO}_{2}$ occurred during this program. The overall environmental results of the Michigan City cofiring tests were most favorable.

\section{The Bailly Generating Station Triburn Test Program}

Recognizing the potential for cofiring, yet mindful of the potential capacity limitations and efficiency issues, NIPSCO worked with EPRI and the Cooperative Agreement to define a project that would capture the benefits of cofiring without encountering some of the difficulties previously experienced. The Bailly Generating Station triburn program resulted from this assessment, as described by Tillman (1999), Tillman and Hus (2000), and Hus and Tillman (2000).

NIPSCO developed a demonstration of opportunity fuel cofiring at the Bailly Generating Station Boiler \#7. Boiler \#7 is a $160 \mathrm{MW}_{\mathrm{e}}$ (net) cyclone boiler generating about 545 tonne/hr $\left(1.2 \times 10^{6} \mathrm{lb} / \mathrm{hr}\right)$ of 16.5 $\mathrm{MPa} / 810 \mathrm{~K} / 810 \mathrm{~K}\left(2400 \mathrm{psig} / 1000^{\circ} \mathrm{F} / 1000^{\circ} \mathrm{F}\right)$ steam. It is fired with a blend of 70 percent Illinois Basin coal/30 percent Shoshone coal. It is equipped with a Pure Air scrubber for $\mathrm{SO}_{2}$ management. NIPSCO, working with Foster Wheeler, developed a program for testing the triburn concept: designing an opportunity fuel blend comprised of clean urban wood waste and petroleum coke. This opportunity fuel blend was then integrated with the coal blend for firing in the cyclones.

The triburn program was designed around multiple objectives including generating green powerenvironmentally friendly renewable energy-from clean (untreated) urban wood waste without 
decreasing unit capacity or increasing the cost of electricity generation. The objectives also included generating green power without increasing airborne emissions or other environmental impacts. If these were achieved, the total program sought improvements in unit performance. Specific targets were improved boiler efficiency, reduced fuel cost, reduced $\mathrm{NO}_{\mathrm{x}}$ emissions, and reduced metals emissions.

To achieve the overall programmatic goals, the design objective was to be able to fire at least 10 percent wood waste along with at least 20 percent petroleum coke (mass basis) in the fuel blend. From a mechanical engineering perspective, the program objectives were to develop a simple system that could be readily integrated into the total fuel handling scheme of the Bailly Generating Station. Simplicity, ease of control, and ease of maintenance were critical design objectives of the program.

The Bailly triburn program took advantage of two sets of testing that occurred previously: the Allen Fossil Plant triburn tests with wood and tire-derived fuel, and the Blount Station triburn tests with switchgrass and paper-derived fuel. In both of those cases the test periods were very short, and only hinted at the advantageous synergies that could be derived. The Bailly program explored those advantages with a full-scale effort.

The mechanical system designed for the Bailly demonstration included a wood waste preparation area and an opportunity fuel/coal blending system. The wood waste preparation area consisted of a pole building housing a $20 \mathrm{ton} / \mathrm{hr}$ trommel screen. The screen produced acceptable product sized to $<19.05$ $\mathrm{mm}(<3 / 4 ")$ particles. These biomass particles were then blended with petroleum coke in mass ratios of $1: 1,2: 1$, and 3:1. Blends were then trucked to a reclaim area where a Stamler reclaimer was installed. The Stamler reclaimer fed a short air-slide transition conveyor, bringing the opportunity fuel to the main coal belt for the plant. The Stamler reclaimer was equipped with variable speed drives; consequently the plant could "dial in" the appropriate blend of opportunity fuel/coal. Typical ratios ranged from 20 percent opportunity fuel/80 percent coal to 30 percent opportunity fuel $/ 70$ percent coal. The coal itself was maintained as a blend of Illinois basin/Shoshone western low sulfur coal.

The system was installed in 1999 and tested extensively that year. The demonstration was operated from March through July, with subsequent short-term testing in December of 1999. Figures S-16 - S17 depict this system. 


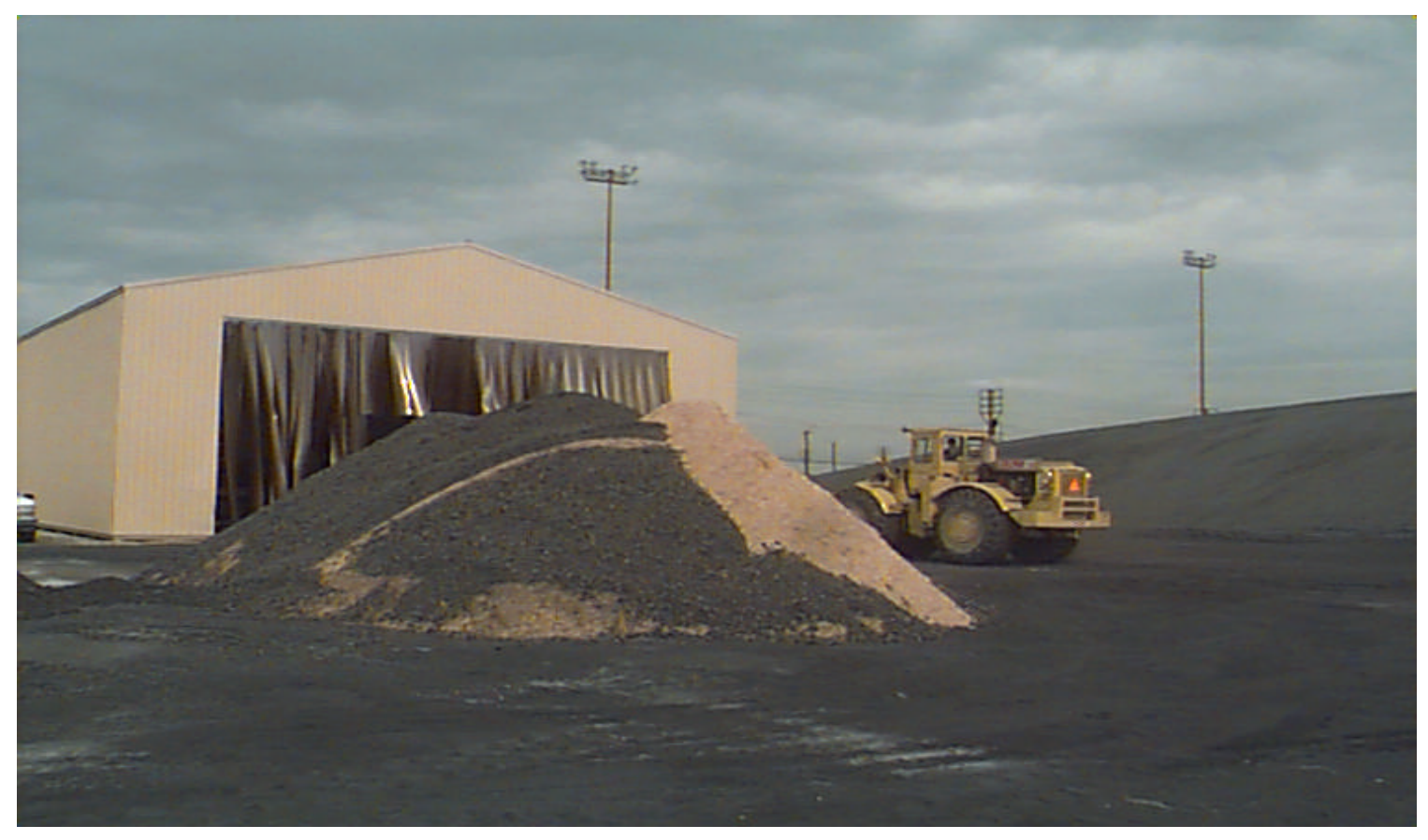

Figure S-16. The Pole Barn at Bailly Generating Station With a Pile of Blended Opportunity Fuel

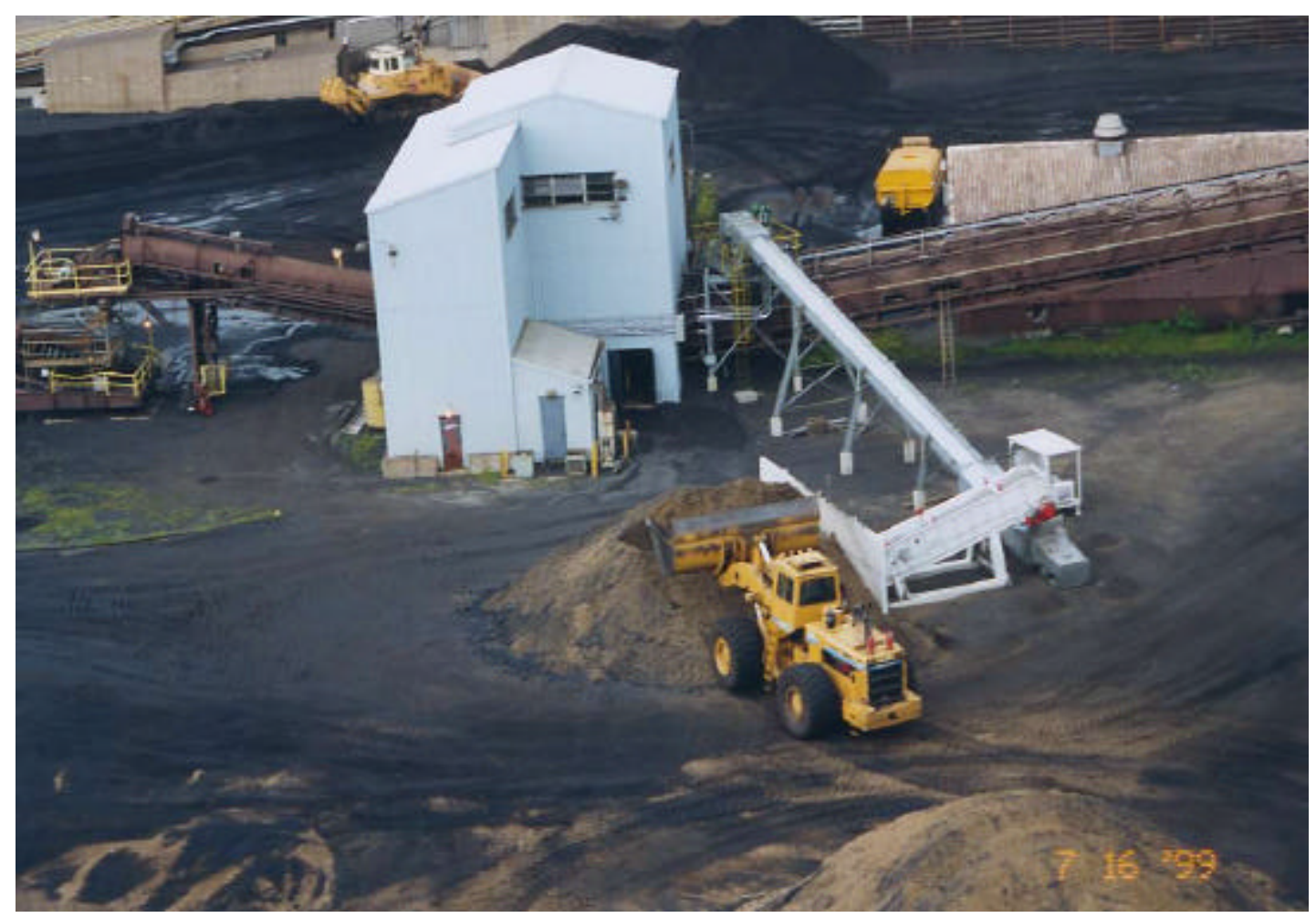

Figure S-17. Operation of the Reclaim and Opportunity Fuel/Coal Blending System at Bailly Generating Station 
Some 56 tests were conducted at the Bailly Generating Station, representing over 200 test hours. In total, over 1000 hours were logged on the system firing blends of wood waste and coal, petroleum coke and coal, and triburn blends of wood waste/petroleum coke/coal. The basic analytical tool used for testing was the construction of heat and material balances, complemented by measurement of emissions at the inlet of the air heater. Emissions measured included $\mathrm{NO}_{\mathrm{x}}, \mathrm{CO}$, and $\mathrm{SO}_{2}$. Stack testing was also performed by Clean Air Engineering, measuring $\mathrm{NO}_{\mathrm{x}}, \mathrm{CO}$, total hydrocarbons (HC's), and $\mathrm{SO}_{3}$.

Operationally there were no difficulties with the triburn project. The blends of opportunity fuels did not impact boiler capacity or operability; they did not decrease the temperatures in the cyclone or cause problems with slag tapping. From an efficiency perspective, the blends tended to improve operations since the most favorable blends were 2:1 and 3:1 petroleum coke/urban wood waste. Based upon all of the testing, the following efficiency equation was constructed:

$$
\eta=86.75-0.068(\% \mathrm{~W})+0.051(\% \text { PetC })
$$

$\% \mathrm{~W}$ is the mass percentage of wood waste in the blend, and \%PetC is the mass percentage of petroleum coke in the blend. The $r^{2}$ value for this equation, with 56 degrees of freedom, is 0.86 . The equation itself, and the individual terms in the equation, has significance values $\geq 99.99 \%$; the probability that it occurred randomly was $<0.0001$. The unburned carbon in the flyash increased with the addition of petroleum coke, and decreased with the addition of wood waste. What became obvious was the fact that the wood waste brought the volatiles to the new fuel, and the petroleum coke provided the heat content.

From an emissions perspective, the triburn project was a success. Figure S-18 depicts the emissions of $\mathrm{CO}, \mathrm{THC}$, and $\mathrm{SO}_{3}$ as measured by Clean Air Engineering. Note the very low emissions of all three pollutants. 


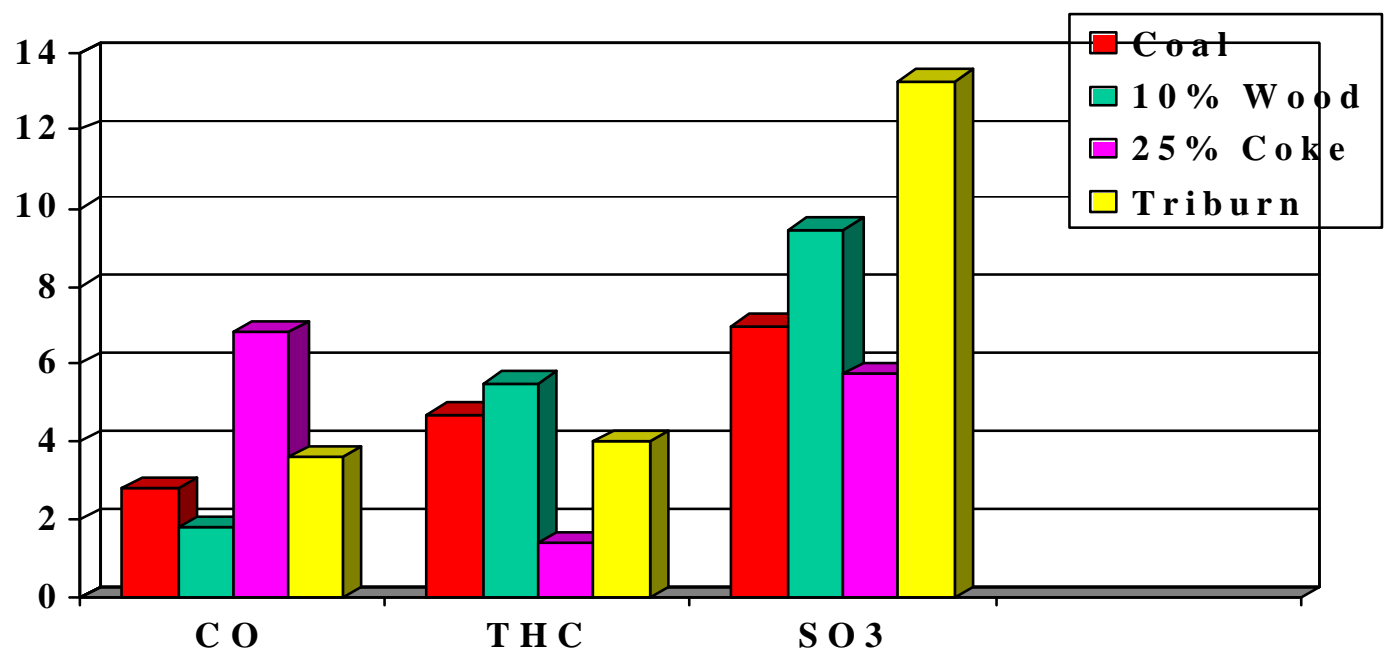

Figure S-18. Emissions of Carbon Monoxide, Total Hydrocarbons, and Sulfur Trioxide at the Bailly Generating Station Triburn Demonstration (values in ppmvd corrected to 3\% $\mathrm{O}_{2}$ )

$\mathrm{NO}_{\mathrm{x}}$ emissions decreased with every opportunity fuel, but particularly with the fuel blends. The equation describing the NOx reduction phenomenon is as follows:

$$
\mathrm{NO}_{\mathrm{x}(\mathrm{ppmvd} @ 3 \% \mathrm{O} 2)}=479-6.4(\% \mathrm{~W}),-6.8(\% \mathrm{PetC})+0.79\left(\mathrm{~L}_{\mathrm{m}}\right)+23.0\left(\% \mathrm{O}_{2}\right)
$$

$\mathrm{NO}_{\mathrm{x}}$ is expressed in ppmvd at 3\% $\mathrm{O}_{2}$ (dry basis). $\mathrm{L}_{\mathrm{m}}$ is load, or main steam flow, expressed as tonne/hr of main steam, and $\% \mathrm{O}_{2}$ is percent excess $\mathrm{O}_{2}$ on a total basis, recorded by plant instruments at the economizer exit.

Alternatively:

$$
\mathrm{NO}_{\mathrm{x}\left(\mathrm{lb} / 10{ }^{6}{ }_{\mathrm{Btu}}\right)}=0.691-0.0101(\% \mathrm{~W})-0.0098(\% \mathrm{PC})+0.0005\left(\mathrm{~L}_{\mathrm{e}}\right)+0.0255\left(\mathrm{EO}_{2}\right)
$$

Where $\mathrm{NO}_{\mathrm{x}}$ is measured in $\mathrm{lb} / 10^{6} \mathrm{Btu}$, and $\mathrm{L}_{\mathrm{e}}$ is load, expressed in $10^{3} \mathrm{lb} / \mathrm{hr}$ of main steam flow. All other terms are as defined in equation [S-11]. The load term is deceptively low; however the range of steam flows for the unit during the tests was typically 502 tonne/hr $\left(1.1 \times 10^{6} \mathrm{lb} / \mathrm{hr}\right.$ of main steam). The $\mathrm{r}^{2}$ for the equations is 0.70 . The significance of the $\% \mathrm{~W}$ is $99.999 \%$ (the probability that it is a random occurrence is $<0.00001$ ) and the significance of the \%PetC term is $99.9999 \%$ (the probability that it is a random occurrence is $<0.000001$ ). The significance of the total equation is about equal to that for the $\%$ PetC term. The fuel blend, with the fuels reported on an individual basis, and the load and excess $\mathrm{O}_{2}$ terms can be used to explain $70 \%$ of the $\mathrm{NO}_{\mathrm{x}}$ emissions. Included in the $30 \%$ unexplained impacts on $\mathrm{NO}_{\mathrm{x}}$ emissions are the synergies between the wood waste and the petroleum coke, as shown in Figure S-19. Note that the equation generated from the triburn test line shows that the minimum NOx 
formation will be generated at 40 percent cofiring of the designed opportunity fuel blend. The combination of the two fuels exceeds the additive value of the two fuels taken individually.

The Bailly program also documented that the triburn program could be used to reduce mercury, lead, and other metal emissions. The Bailly triburn test program, then, provided significant additional information regarding the process of cofiring.

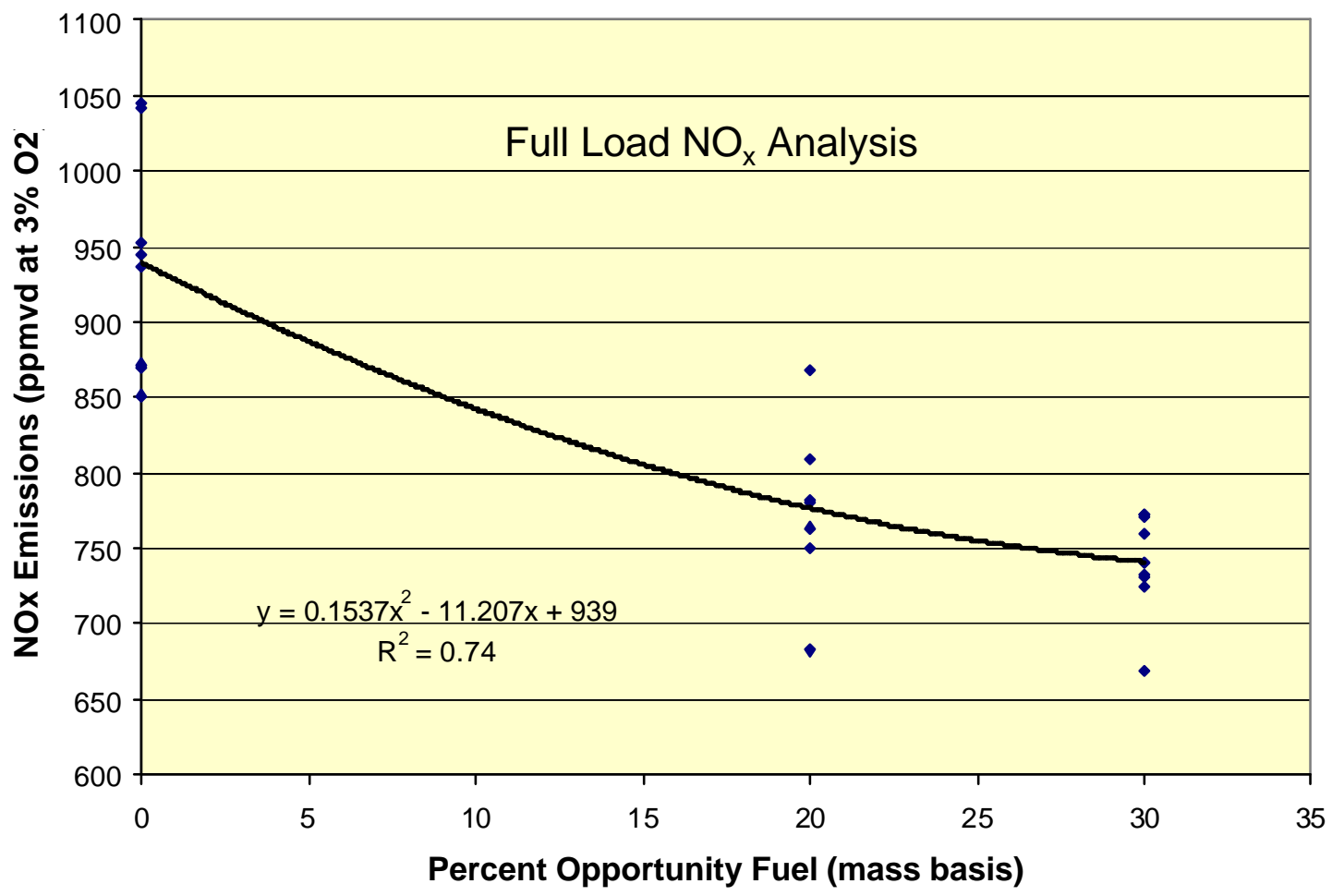

Figure S-19. $\mathrm{NO}_{\mathrm{x}}$ Emissions Measured During the Bailly Triburn Tests

\section{CONCLUSIONS FROM THE TEST PROGRAM OF THE COOPERATIVE AGREEMENT}

The testing and demonstration sponsored by EPRI, and then supported by the EPRI-USDOE Cooperative Agreement, documented the following:

- Cofiring can be used as a cost-effective means for reducing greenhouse gas emissions, providing utilities with a low capital cost option 
- Cofiring can be accomplished in a manner that does not negatively impact the operability or operations of a given power plant, provided that the most appropriate cofiring technology is applied

- Cofiring virtually always reduces the power plant boiler efficiency, however the reductions can be managed as an economic issue rather than as a technical barrier

- Cofiring can be used to reduce virtually all airborne emissions, and has a particularly beneficial impact on $\mathrm{NO}_{\mathrm{x}}$ emissions.

With respect to the $\mathrm{NO}_{\mathrm{x}}$ emissions, the evidence of impacts is substantial. Figure S-20 depicts the $\mathrm{NO}_{\mathrm{x}}$ emissions from all tests sponsored by the EPRI-USDOE Cooperative Agreement. Note the line indicating where a 1 percent cofiring percentage (heat input basis) would equal a 1 percent NOx reduction. This line represents the substitution effect of a low nitrogen fuel. Note that over 67 percent of all tests are well above that line. Figure S-20 shows considerable spread in the data. This spread is caused by variations in firing technology, biomass fuel used, percentage of biomass fuel used, base coal fired, and combustion conditions (e.g., load, excess $\mathrm{O}_{2}$ ). Despite this variability, however, the impact of cofiring on $\mathrm{NO}_{\mathrm{x}}$ emissions is highly significant.

\section{Average $\mathrm{NO}_{x}$ Emissions Reduction}

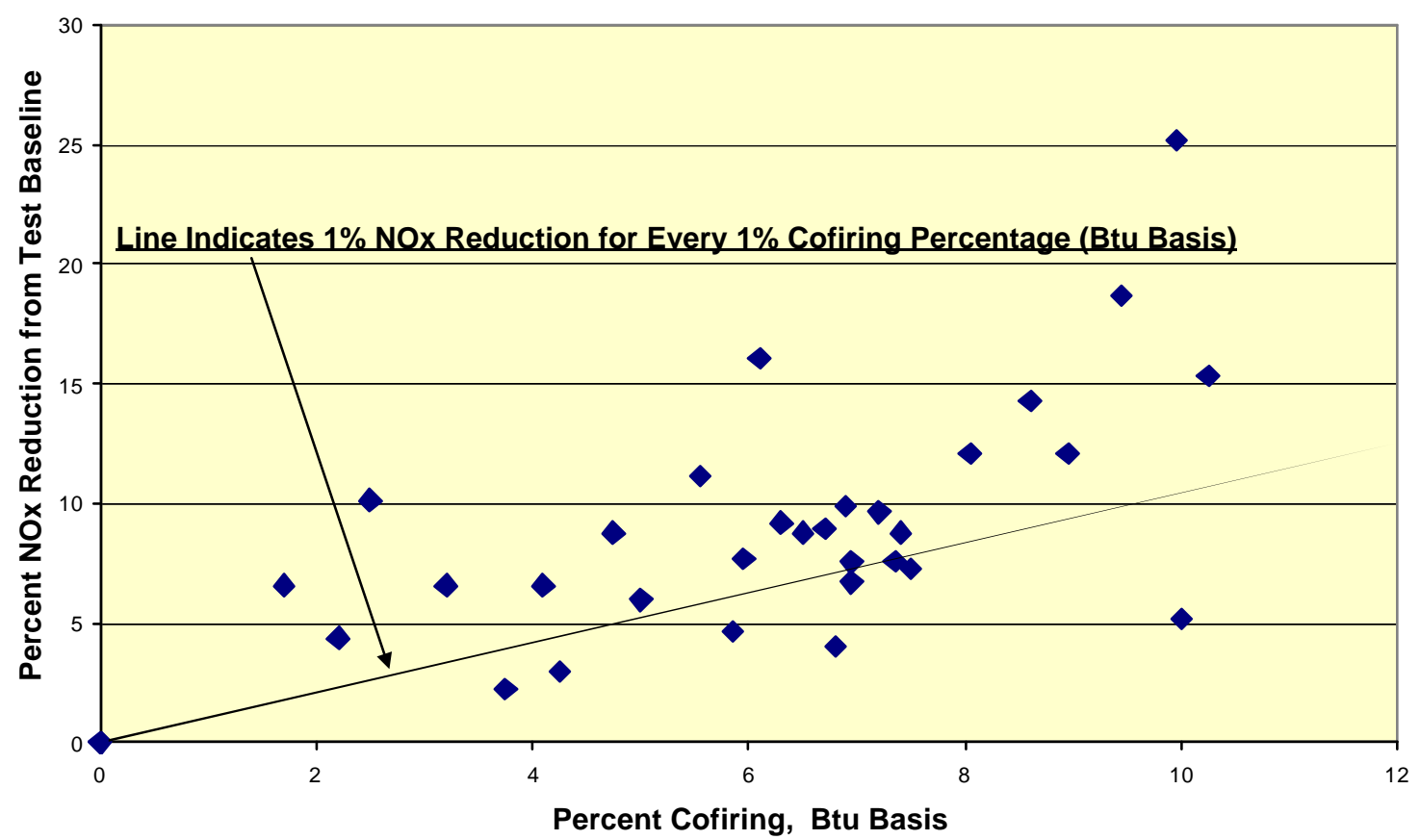

Figure S-20. $\mathrm{NO}_{\mathrm{x}}$ Reduction Caused by Cofiring-All Tests Sponsored by the EPRI-USDOE Cooperative Agreement 


\section{SPECIAL STUDIES ASSOCIATED WITH THE EPRI-USDOE COOPERATIVE AGREEMENT}

In addition to the cofiring tests and demonstrations, the EPRI-USDOE Cooperative Agreement was used to support significant engineering studies used to expand the potential of cofiring. These studies included:

- An assessment of gasification-based cofiring at the Allen Fossil Plant, evaluating the ability of gasification to address issues of flyash contamination from biomass, the ability of gasification to further promote $\mathrm{NO}_{\mathrm{x}}$ reduction, and the ability of gasification to broaden the base of appropriate biomass resources (Foster Wheeler Development Corporation, 1998). The fuel supply data developed during this study included not only sawdust but also non-recyclable paper, clean urban wood waste, bark, cotton gin trash, and other locally available materials. The study considered integrating biomass gasification with the use of wastewater treatment gas to be supplied to the plant. This was followed by a Request for Proposals by TVA to construct and test gasificationbased cofiring. The project was not pursued beyond the RFP stage.

- The development of detailed fuels databases, including some rudimentary modeling of cofiring combustion (see Prinzing, 1996). This database development included information on biomass and various types of coal, sufficient for initial analyses of cofiring.

- The development of a survey of all cofiring testing by utilities - including those that did not participate in the EPRI-USDOE Cooperative Agreement (see Battista, 2001). A previous study (Wiltsee, 1998) included cofiring in a broader survey of biomass technologies.

\section{FUTURE RESEARCH REQUIREMENTS TO COMMERCIALIZE COFIRING}

The current status of cofiring has been well documented (see Plasynski, Goldberg, and Chen, 2001; Tillman, 2000; Tillman, Plasynski, and Hughes, 1999; Tillman, Hughes, and Plasynski, 1999; Freeman, Goldberg, and Plasynski, 1998). The EPRI-USDOE Cooperative Agreement has moved the technology towards full commercial deployment. Certain issues remain that must be addressed by additional demonstrations, testing, or research. These include:

- Broadening the useful biomass fuel base either by technologies to make more difficult residues more useful (e.g., gasification, fluidized bed combustion) or by pre-treatment technologies

- Addressing the issues associated with biomass ash including the potential for catalyst deactivation in selective catalytic reduction (SCR) systems, the problems associated with marketing flyash, and related considerations 
- Integrating biomass cofiring into gas-fired technologies, particularly combined cyclecombustion turbine generation, as a means to ensure long-term viability of this fuel source

- Developing a deeper understanding of the properties of biomass fuels-including crops proposed as fuels - to ensure compatibility with coal and to ensure the ability to maximize the benefits from these biofuels

- Developing and demonstrating technologies that have special applications for biomass (e.g., the use of biomass or producer gas from biomass as a reburn fuel)

While the Cooperative Agreement has served a highly useful purpose of advancing cofiring to the point of initial commercialization, additional research can profitably be employed to broaden the application of this technology. And, given the role of electricity in the US energy arena, broadening the application of cofiring may be the best near-term approach to increasing the contribution and role of biomass as a renewable energy resource. 


\subsection{INTRODUCTION}

\subsection{THE BASIS FOR FOCUSING ON COFIRING}

Increasing the use of renewable fuels in the US economy — both in absolute and relative contributionshas long been a goal of energy planners and policy makers in both the public and private sectors. Achieving such increases requires recognizing long term trends shown in Figures 1-1 and 1-2, indicating that the US economy increasingly has focused upon energy dense fossil fuels to meet the economy's need for low cost, abundant energy supplies. It also recognizes the need to continue the trends shown in Table 1-1, documenting the fact that biomass fuels have consistently increased their contribution to the US economy since 1970, both in absolute and relative terms.

The goal or objective of increasing the use of renewable fuels in the US economy also requires recognition of trends within the distribution of energy use in the US. The dominant trend is increased electrification, as shown in Figure 1-3. Energy use for electricity generation has grown dramaticallyparticularly as a percentage of total energy use. On an absolute basis, fuel use for non-electricity and non-transportation applications has remained somewhat static and, in many sectors, has declined. In 1970 the US consumed $51.9 \times 10^{15} \mathrm{Btu} / \mathrm{yr}$ for non-electricity uses and $16.4 \times 10^{15}$ Btu for electricity generation. In the year 2000, energy consumption for non-electricity purposes grew to $61.3 \times 10^{15}$ Btu/yr, with most of the growth coming in the transportation sector. Energy consumption for electricity generation in the year 2000 was $35.1 \times 10^{15} \mathrm{Btu} / \mathrm{yr}$. Biomass, which now supports some 7,000 $\mathrm{MW}_{\mathrm{e}}$ of electricity generating capacity, has grown slowly in this marketplace. In 1960 and 1970, some $0.3 \times 10^{15}$ Btu/yr of wood, agricultural materials, and municipal refuse was used to generate electricity. In 1980 that number had increased to $0.4 \times 10^{15} \mathrm{Btu}$, in 1990 it was $0.6 \times 10^{15} \mathrm{Btu}$, and at the turn of the century it had increased to $0.7 \times 10^{15} \mathrm{Btu}$. Much of that biomass was fired in cogeneration applications within the pulp and paper industry, although small stand-alone wood-fired power plants have been built in Vermont, Washington, Maine, California, Virginia, and other locations.

Electricity generation, then, provides a highly useful target market for increasing the use of renewable energy resources within the US. Further, electricity generating stations firing, or cofiring biomass can be dispatched to meet demand; dispatchability makes biomass a useful energy source for utilities. Biomass cofiring in existing power plants is one of two general pathways for increasing the use of this family of fuels in the electricity sector. The other pathway is the construction of stand-alone biomass-fired power plants. Trends in the construction of generating stations favor cofiring. Individual steam boiler-steam turbine combinations have increased in capacity over time, as shown in Figure 1-4. By 1996, the average new boiler ordered was $650 \mathrm{MW}_{\mathrm{e}}$ (UDI, 2000). Typically boilers constructed since 1980 are either $2400 \mathrm{psig} / 1000^{\circ} \mathrm{F} / 1000^{\circ} \mathrm{F}$ drum boilers or $3500 \mathrm{psig} / 1000^{\circ} \mathrm{F} / 1000^{\circ} \mathrm{F}$ supercritical boilers. These are very large installations. Comparable trends are being experienced in the combustion turbinecombined cycle (CCCT) arena, where new installations $>500 \mathrm{MW}_{\mathrm{e}}$ are now common as well. Biomass installations $>70$ MWe are not practical due to logistical and fuel supply issues; at such low capacities it is virtually impossible to justify, economically, the efficiency enhancements associated with reheat cycles. 
Reheat is virtually always installed on new steam power plants, and is being designed into heat recovery steam generators (HRSG's) for CCCT installations as well.

\section{Energy Consumption in the US}

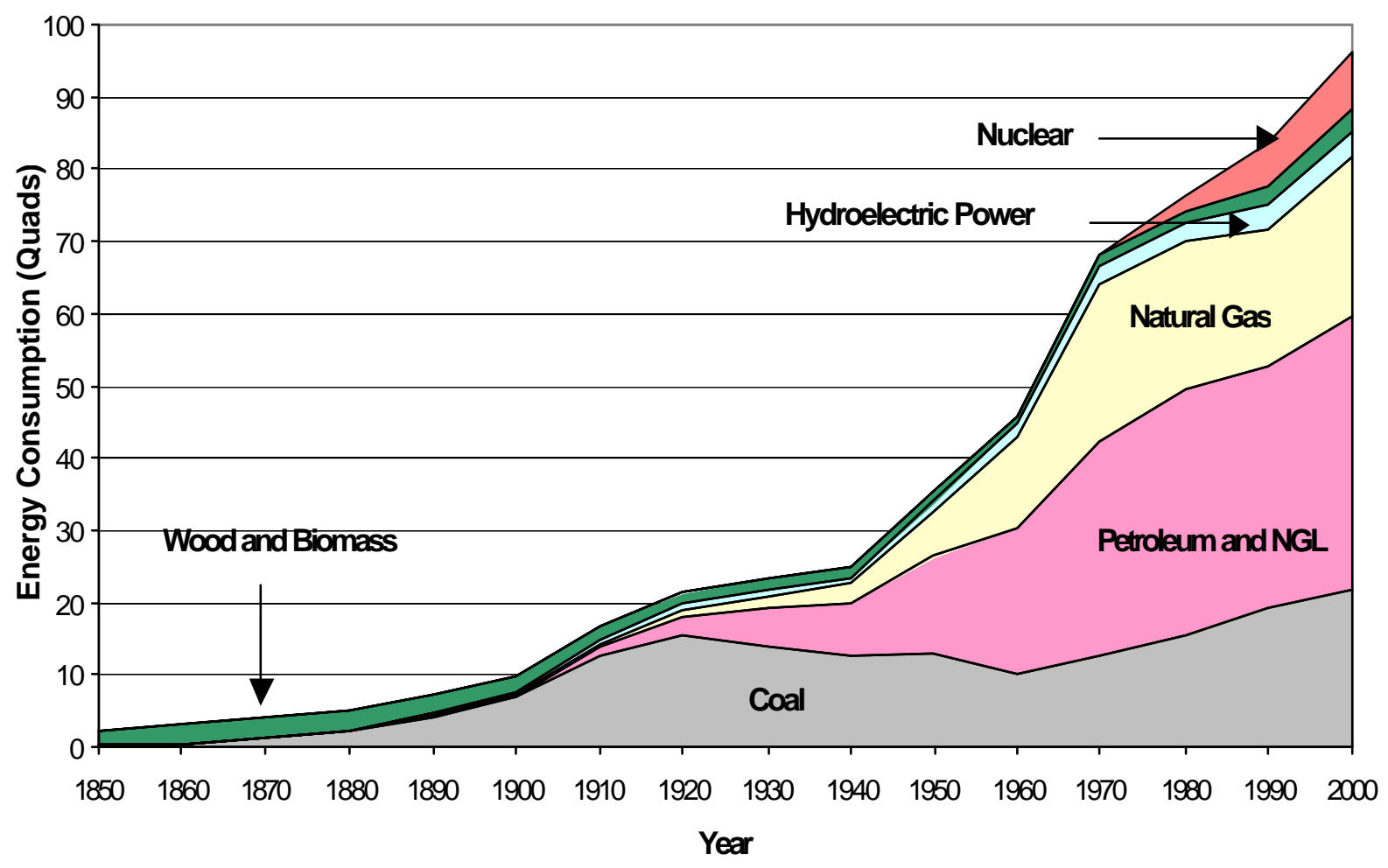

Figure 1-1. Historical Trends in US Energy Consumption by Fuel (Sources: Energy Information Agency; 2000; Enzer, Dupree, and Miller, 1975) 


\section{Energy Consumption Percentage by Fuel}

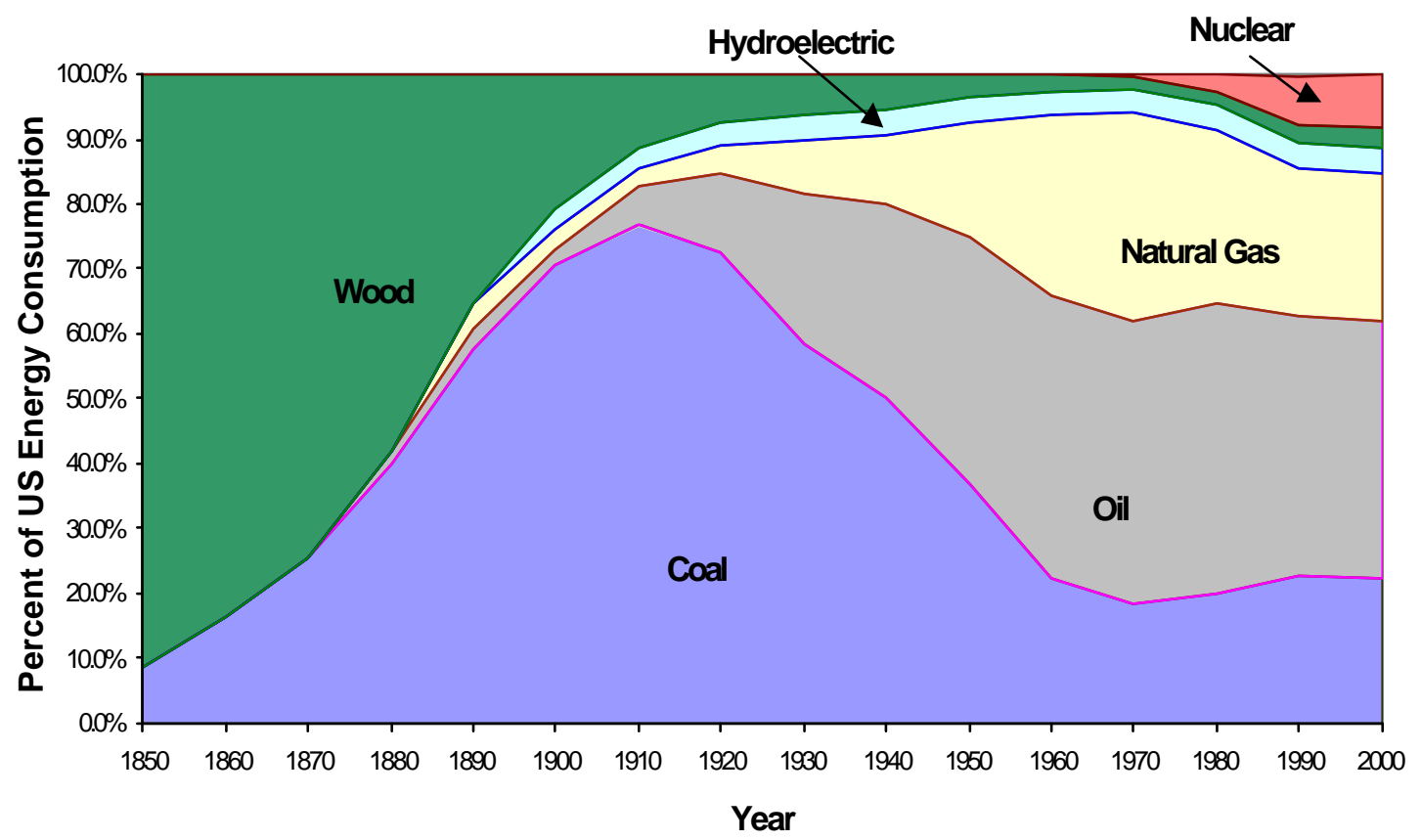

Figure 1-2. Historical Trends in Percentage Distribution of US Energy Consumption (Sources: Energy Information Agency, 2000; Enzer, Dupree, and Miller, 1975)

Table 1-1. Biomass Contribution to US Energy Production and Consumption

\begin{tabular}{|l|l|l|l|l|l|}
\hline Year & $\begin{array}{l}\text { US Energy } \\
\text { Production } \\
\left(10^{15} \mathrm{Btu}\right)\end{array}$ & $\begin{array}{l}\text { US Energy } \\
\text { Consumption } \\
\left(10^{15} \mathrm{Btu}\right)\end{array}$ & $\begin{array}{l}\text { Energy } \\
\text { Production } \\
\text { and } \\
\text { Consumption } \\
\text { From Biomass } \\
\left(10^{15} \mathrm{Btu}\right)\end{array}$ & $\begin{array}{l}\text { Biomass } \\
\text { Energy as a } \\
\text { Percentage of } \\
\text { Total US } \\
\text { Energy } \\
\text { Production }\end{array}$ & $\begin{array}{l}\text { Biomass } \\
\text { Energy as a } \\
\text { Percentage of } \\
\text { Total US } \\
\text { Energy } \\
\text { Consumption }\end{array}$ \\
\hline 1960 & 42.0 & 45.8 & 1.2 & 2.9 & 2.6 \\
\hline 1970 & 61.4 & 68.3 & 1.2 & 2.0 & 1.8 \\
\hline 1980 & 58.2 & 76.4 & 1.8 & 3.1 & 2.4 \\
\hline 1990 & 70.7 & 84.1 & 2.7 & 3.8 & 3.2 \\
\hline 2000 & 71.8 & 96.4 & 3.4 & 4.7 & 3.5 \\
\hline
\end{tabular}

Sources: Energy Information Agency 2000; Energy Information Agency, 2001; Norwood and Warnick, 1982; Schreuder and Tillman, 1980; Tillman, 1977; Tillman, 1978; Enzer, Dupree, and Miller, 1975 


\section{Fuel Consumption by Use}

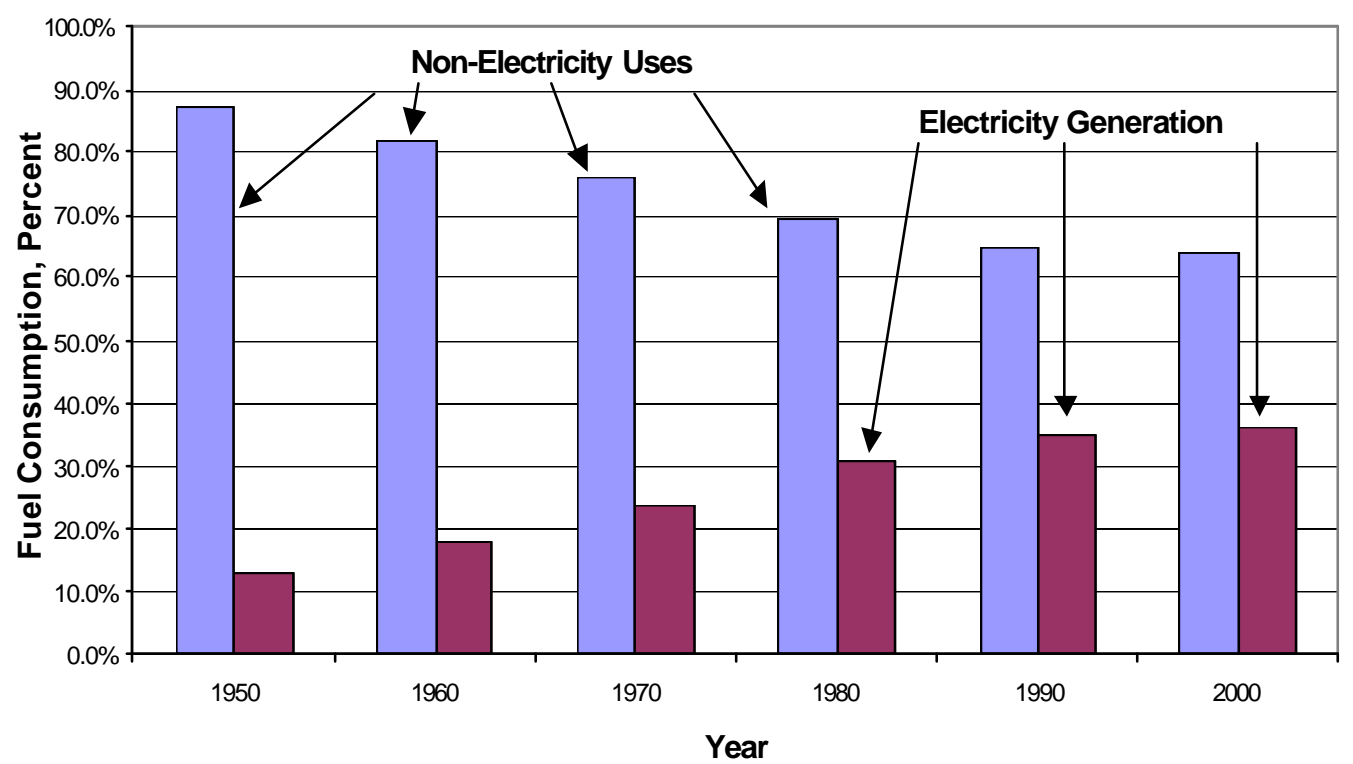

Figure 1-3. Importance of Electricity Generation in US Fuel Consumption (Source: Energy Information Agency, 2000)

\section{Average MW per Boler}

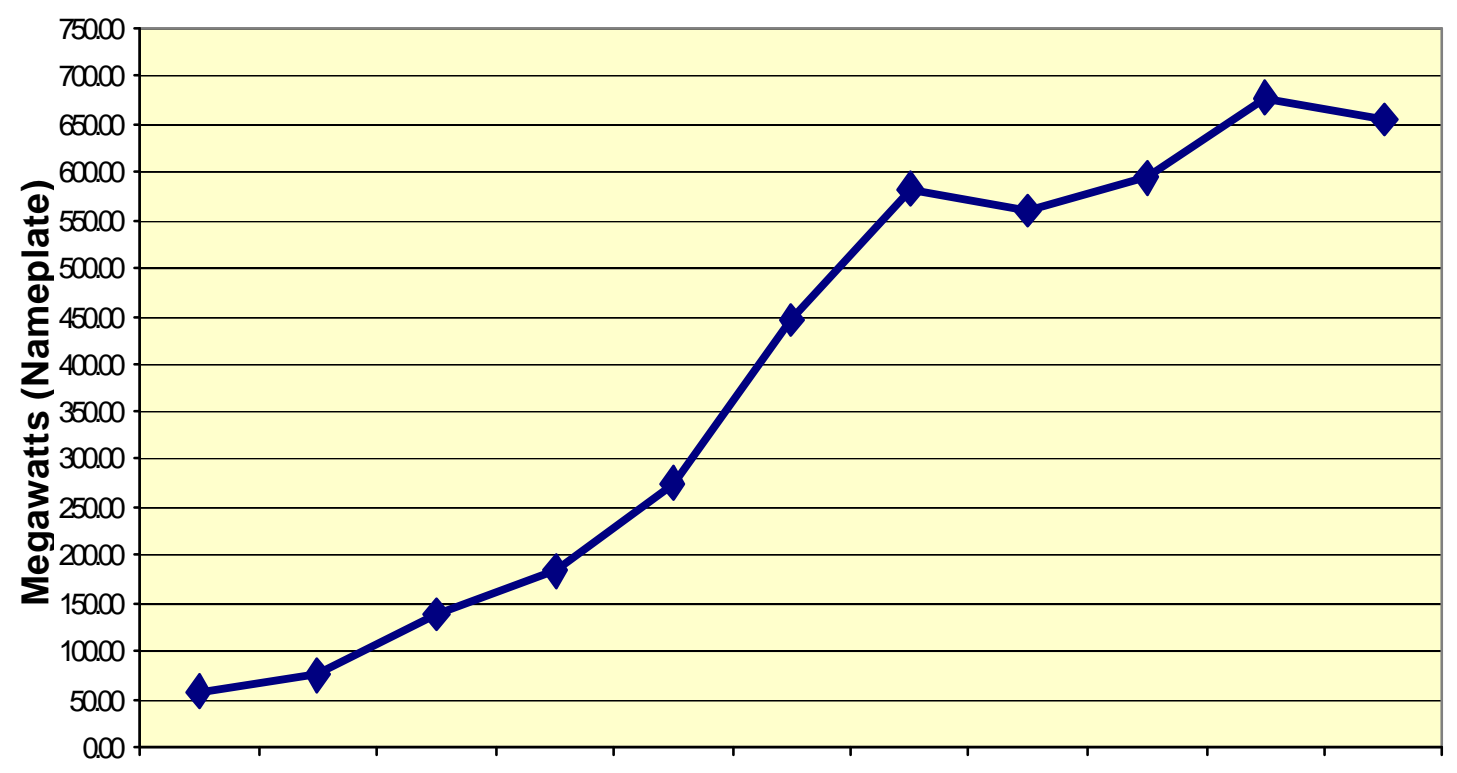

1940-1945 1946-1950 1951-1955 1956-1960 1961-1965 1966-1970 1971-1975 1976-19801981-1985 1986-19901991-1996

Time Period

Figure 1-4. Average Capacity of Steam-Electric Generating Systems Installed, 1940 - 1995. (Source: Utility Data Institute, 1996) 
Cofiring offers the advantages of being able to use biomass in acceptable quantities, where logistics can be accommodated. Cofiring can capitalize upon the efficiencies of existing fossil fuel-fired generating stations, thereby improving the efficiency with which electricity is generated from wood and other biofuels. Cofiring can capitalize upon the existing infrastructure-switchyards, transmission systems, dispatch systems and techniques - and it capitalizes upon the existing, highly skilled and trained labor force in the current fleet of US power plants. Consequently it offers a near-term approach to increasing the role of biomass and renewable energy supplies in the US economy.

\subsection{THE EPRI - USDOE COFIRING PROGRAM}

The Electric Power Research Institute (EPRI), working with the Tennessee Valley Authority (TVA) and supported partially by the US Department of Energy (USDOE) initiated a cofiring program in 1992. Beginning with engineering studies and expanding through tests and demonstrations, this program was designed to evaluate, demonstrate, and commercialize cofiring as a strategy for immediately increasing the use of biomass in utilities. The program was based upon recognition that the utility fleet of electricity generating stations had the potential to support significant cofiring. The UDI Equipment Database, covering about 65 percent of all electric utility generating stations, illustrates this point. This database, summarized in Table 1-2, shows that of the 1101 utility boilers built between 1940 and 1995-and documented by UDI-nearly two thirds are coal-fired. Further, during every time period between 1950 and 1995, more coal-fired boilers were constructed than any other type of steam generator.

Table 1-2. The Distribution of Utility Boilers by Fuel Type in the UDI Database

\begin{tabular}{|l|c|c|c|c|c|}
\hline Time Period & $\begin{array}{c}\text { Number of } \\
\text { Boilers Built }\end{array}$ & $\begin{array}{c}\text { Number of } \\
\text { Coal-Fired } \\
\text { Boilers Built }\end{array}$ & $\begin{array}{c}\text { Number of Oil- } \\
\text { Fired Boilers } \\
\text { Built }\end{array}$ & $\begin{array}{c}\text { Number of Gas- } \\
\text { Fired Boilers } \\
\text { Built }\end{array}$ & $\begin{array}{c}\text { Coal-Fired Boilers } \\
\text { as a Percentage of } \\
\text { All Boilers }\end{array}$ \\
\hline $1940-1945$ & 11 & 3 & 3 & 5 & $27.3 \%$ \\
\hline $1946-1950$ & 52 & 18 & 9 & 25 & $34.6 \%$ \\
\hline $1951-1955$ & 161 & 120 & 5 & 36 & $74.5 \%$ \\
\hline $1956-1960$ & 179 & 106 & 19 & 54 & $59.2 \%$ \\
\hline $1961-1965$ & 140 & 73 & 17 & 50 & $52.1 \%$ \\
\hline $1966-1970$ & 155 & 93 & 18 & 44 & $60.0 \%$ \\
\hline $1971-1975$ & 172 & 97 & 32 & 43 & $56.4 \%$ \\
\hline $1976-1980$ & 129 & 101 & 13 & 15 & $78.3 \%$ \\
\hline $1981-1985$ & 72 & 69 & 1 & 2 & $95.8 \%$ \\
\hline $1986-1990$ & 22 & 22 & 0 & 0 & $100.0 \%$ \\
\hline $1991-1996$ & 8 & 8 & 0 & 0 & $100.0 \%$ \\
\hline \multicolumn{7}{|l|}{} & 1101 & 710 & 117 & 274 & $64.5 \%$ \\
\hline TOTAL & & & & & \\
\hline Source: Utility Data Institute, 1996 & & & \\
\hline
\end{tabular}


The approximate distribution of boiler capacity by combustion technology is as follows (Utility Data Institute, 1996):

- Wall-fired pulverized coal: 47 percent

- Tangentially-fired pulverized coal: 42 percent

- Cyclone boilers: 9 percent

- Other (fluidized bed, circulating fluidized bed, stoker): 2 percent

The coal-fired boilers have materials handling systems and firing systems that can be readily adapted to the addition of another solid fuel. Firing systems include front wall fired boilers, opposed wall fired boilers; single furnace tangentially fired (T-fired) boilers, twin furnace T-fired boilers, and front wall cyclone boilers and opposed wall cyclone boilers. All of these firing systems can be readily adapted to biomass cofiring.

Beyond materials handling and firing systems, these coal-fired boilers have sootblowing capability along with ash removal and ash handling systems. Their post-combustion pollution controls-typically electrostatic precipitators (ESP's) and, to a lesser extent fabric filters or baghouses - can manage the particulates that form the primary airborne emissions from the combustion of biomass.

The EPRI Cofiring program expanded to incorporate other utilities: GPU Genco, Northern Indiana Public Service Company (NIPSCO), Madison Gas \& Electric, New York State Electric and Gas (NYSEG), Northern States Power, Duquesne Light, Central and Southwest Utilities, Delmarva, Allegheny Energy Supply Co., LLC, and many others. These utilities considered cofiring with conceptual engineering studies, test programs, or other related activities. The EPRI Cofiring program was part of an overall thrust towards increased biomass usage, and it included the design and assessment of alternative generating technologies as well. Cofiring quickly became the focus of the program, as it offered utilities the most readily developed technology for the use of biomass residues and, potentially, crops grown for their energy content.

The EPRI Cofiring program was designed specifically to develop cofiring - the incorporation of a modest stream of an alternative energy source into the total fuel supply of a given boiler. Cofiring was considered as a means for addressing the generation of greenhouse gases either from the combustion of fossil fuels or the production of methane in landfills. It was also viewed as a means for modestly reducing other airborne emissions including $\mathrm{SO}_{2}$ and $\mathrm{NO}_{\mathrm{x}}$. These emissions reductions were projected based upon the substitution of biomass for fossil fuel, thereby not increasing the quantity of carbon in the biosphere (see Figure 5). Carbon not in the current global carbon cycle, such as carbon from use of fossil fuels, only adds to the tonnages being utilized and emitted. These emissions reductions from cofiring were also projected on the basis that the most promising biofuels have very low concentrations of sulfur, and many such as the woody biomass fuels have relatively little nitrogen. 


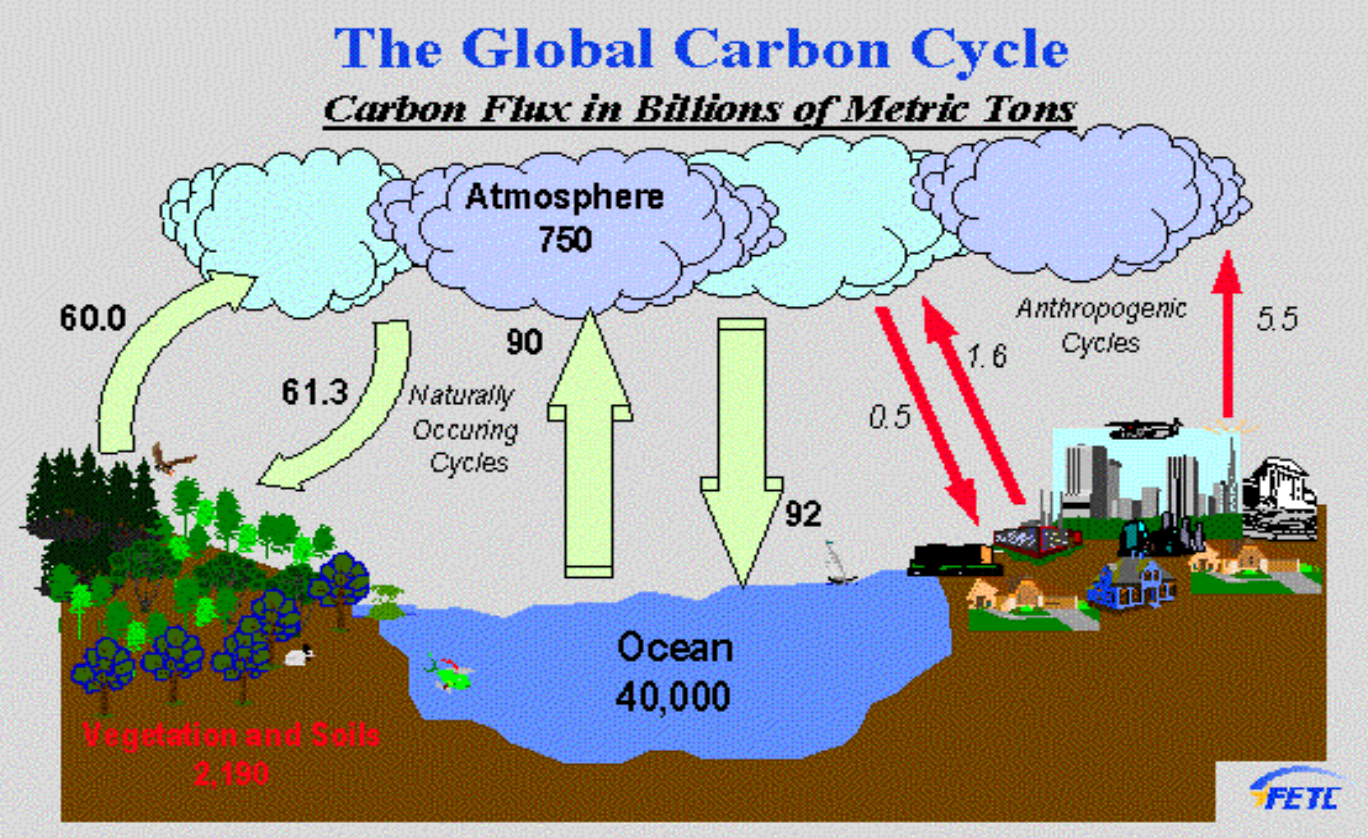

Figure 1-5. The Global Carbon Cycle

(Source: National Energy Technology Laboratory)

Because of the near-term potential of biomass cofiring, it was also seen as having the benefit of developing a biomass supply/delivery infrastructure. Currently biomass fuels are outside the normal commercial energy arena; a strong cofiring technology was viewed as having the potential to develop that commercial trade in wood fuels and other biomass fuels.

The National Energy Technology Laboratory (NETL), then the Federal Energy Technology Center (FETC) became an active partner with EPRI in 1994, bringing an infusion of funding capability and project management to the program. The Office of Energy Efficiency and Renewable Energy (EE-RE) of USDOE became an active partner in 1997, providing further momentum to the cofiring initiative of EPRI and NETL. The entire effort became a Cooperative Agreement between EPRI and USDOE. EPRI brought a technology to be commercialized—cofiring — along with significant industrial partners such as TVA, GPU Genco, NIPSCO, Allegheny Energy Supply Co., LLC, NYSEG, Southern Company, and others to the cooperative effort. EPRI also brought a technology development company-Foster Wheeler-to the cofiring development program. Ebasco Environmental began working with EPRI at the inception of the cofiring effort. Ebasco Environmental ultimately was acquired by Foster Wheeler, and became Foster Wheeler Environmental. Foster Wheeler Environmental, and then Foster Wheeler Development Corporation, served as the primary contractor throughout the 9-year development period. Foster Wheeler Development Corporation and Foster Wheeler Energy Corporation became involved when the projects reached the demonstration phase. USDOE, through NETL and EERE, brought an infusion of financial resources and project management resources to the program. Such resources became critical to the transition of the cofiring commercialization effort from engineering studies and short term testing to the long term testing and demonstration required to commercialize this biomass technology. 


\subsection{SPECIFIC PROJECTS FOR THE COOPERATIVE AG REEMENT}

The cooperative agreement, as it was originally configured, contained numerous projects. Some of these projects did not relate to cofiring. Some of these projects did not materialize. The projects that did relate to cofiring, and that proceeded to maturity were as follows:

- Testing and demonstrating the cofiring of sawdust in pulverized coal boilers, using separate injection of the sawdust into the boiler (rather than blending the sawdust with coal on the coal pile) at Seward Generating Station of GPU Genco and, later, at the Albright Generating Station of Allegheny Energy Supply Co., LLC.

- Testing and demonstrating the cofiring of sawdust in wall-fired pulverized coal boilers blending the sawdust with coal in the coal yard, at the Colbert Fossil Plant of TVA.

- Testing and demonstrating the cofiring of urban wood waste with western coal (including Powder River Basin coal) at Michigan City Generating Station of NIPSCO, and the trifiring of urban wood waste with Illinois Basin and western coal along with petroleum coke at the Bailly Generating Station \#7 boiler of NIPSCO; both boilers employ cyclone combustion technology.

- Developing fuel preparation systems for cofiring wood waste with coal, using separate injection, at the T-fired boiler at Greenidge Station of NYSEG

- Testing the cofiring of switchgrass with coal at the Blount St. Station of Madison Gas \& Electric, a front wall fired pulverized coal boiler.

- Testing the cofiring of switchgrass with coal at the T-fired boiler at Gadsden Station of Alabama Power, a Southern Company project.

- Evaluating gasification-based cofiring at the Allen Fossil Plant of TVA, a cyclone boiler station.

- Performing supporting studies including developing detailed analyses of biomass fuels to be cofired along with base coals, developing a fuels database, and developing a cofiring experience database.

In addition to these programs within the framework of the cooperative agreement, EPRI brought significant previous projects that had been conducted prior to the cooperative agreement; several of these also had USDOE participation. These included:

- Engineering evaluations of cofiring potentials and costs at all TVA fossil plants

- Extensive cofiring testing with sawdust, Illinois Basin coal, western bituminous coal, and other fuels at the Allen Fossil Plant of TVA 
- Cofiring testing with sawdust, using blended feed, at the Kingston Fossil Plant of TVA

- Cofiring testing with sawdust, logging residue, and hybrid poplar, using blended feed, at the Shawville Generating Station of GPU Genco

- Fuel bunker performance studies, conducted by Reaction Engineering International, regarding the ability of blends of coal and sawdust to retain their blend characteristics and to flow through bunkers

- Fuel storage safety studies focusing upon self-heating and spontaneous combustion, sponsored by TVA and supported by EPRI

- Development of simplified cofiring models to provide for rapid evaluation of the applicability of this technology at any given power plant site

- Application of alternative combustion technologies - particularly slagging combustionas a way to increase the cofiring percentage and to manage biomass fuels with high slagging potential.

The EPRI program also took advantage of extensive cofiring research that was being conducted simultaneously at Southern Company. This research included testing at Plant Hammond, Plant Kraft, and other locations (see Boylan, 1993), alkali deposit research at Sandia National Laboratories (see, for example, Baxter et. al., 1996a; Baxter et. al., 1996b), and other related research programs. The program capitalized upon feedstock research at the Oak Ridge National Laboratory (see, for example, Downing et. al., 1998; Wright and Cushman, 1997; Walsh and Becker, 1996) to evaluate potential additions to the biomass fuel supply.

While there was a breadth of research involved in the cooperative agreement, in the studies that EPRI brought to the cooperative agreement, and in the parallel research by other organizations; the focus of the cooperative agreement was on the cofiring combustion tests and demonstrations. All of the studies and tests, however, contributed significantly to the launching of cofiring as a biomass technology that could significantly increase the use of this renewable energy source in the US economy.

Because of the breadth of the cooperative agreement, there is extensive coverage of numerous cofiring issues. Fuels covered by the research include sawdust from primary sawmills and wood processing facilities; urban wood waste from mobile home and recreational vehicle manufacturing, tree trimming activities, and utility poles and crossarms; short rotation woody crops (SRWC) including hybrid poplar and willow; herbaceous crops focusing upon switchgrass; and other biofuels. The introduction of designer opportunity fuels brought project coverage to petroleum coke and tire-derived fuel (TDF) as well, and petroleum coke-wood blends plus TDF-wood blends.

The program provided coverage of all types of combustion systems including cyclone boilers (Allen Fossil Plant, Michigan City Generating Station, Bailly Generating Station), wall-fired pulverized coal boilers (Seward Generating Station, Blount St. Station, Colbert Fossil Plant) and tangentially-fired 
pulverized coal boilers (Albright Generating Station, Plant Gadsden, Greenidge Station). Some attention was given to fluidized bed combustion and stoker firing as well. One boiler, Michigan City \#12 cyclone boiler, was a supercritical unit $\left(3500 \mathrm{psig} / 1000^{\circ} \mathrm{F} / 1000^{\circ} \mathrm{F}\right.$ steam). All other boilers were subcritical, with pressures ranging from 850 psig to $2400 \mathrm{psig}$. Both reheat and non-reheat boilers were tested.

The supporting studies provided coverage of materials handling issues, safety issues, and environmental consequences of cofiring, and related considerations. Both long-term and short-term issues were addressed. These supporting studies were geared to addressing the questions of power plant managers, and to addressing long-term issues of policy makers as well.

\subsection{ORGANIZATION OF THIS REPORT}

The focus of the EPRI-USDOE cooperative agreement program has been on bringing cofiring towards commercial implementation. It capitalized upon prior research by EPRI and member utilities, and upon a momentum that had been built up by the EPRI program. The breadth of the research, development, and demonstration associated with the program has been focused upon addressing the practical and theoretical technical issues along with the economic and environmental considerations. The final report is organized, therefore along the following lines:

- Review of the EPRI Cofiring Research and Testing Conducted Prior to the Cooperative Agreement

- Review of the GPU Genco Cofiring Testing at Seward Generating Station Boiler \#12 and other Wall-Fired PC Boiler Tests

- Review of the Allegheny Energy Supply Co., LLC Cofiring Testing at the Albright Generating Station Boiler \#3 and other Tangentially-Fired PC Boiler Tests

- Review of the NIPSCO Cofiring Testing and Demonstration at Michigan City Station Boiler \#12 and Bailly Station Boiler \#7 for Cyclone Combustion

- Review of Supporting Research and Collateral Studies

From these data conclusions regarding the cofiring program can be drawn. Further, the final research efforts required to fully commercialize this technology can be identified. 


\subsection{EPRI COFIRING RESEARCH PRIOR TO THE COOPERATIVE AGREEMENT WITH USDOE}

\subsection{THE EPRI BIOMASS COFIRING PROGRAM}

EPRI initiated its cofiring program with a Request for Proposals and subsequent award to Ebasco Environmental in 1992. The concept of cofiring various residue biomass fuels with coal in cyclone and pulverized coal boilers was viewed as having the following benefits (see McGowin and Gold, 1992; McGowin and Hughes, 1992):

- Providing efficient generation of electricity from biomass by capitalizing upon larger boilers with highly efficient high pressure reheat cycles, having typical steam conditions of $2400 \mathrm{psig} / 1000^{\circ} \mathrm{F} / 1000^{\circ} \mathrm{F}$ or $3500 \mathrm{psig} / 1000^{\circ} \mathrm{F} / 1000^{\circ} \mathrm{F}$

- Providing a means for utilities to reduce greenhouse gas emissions, substituting carbonneutral biomass for coal

- Providing a means to develop infrastructures necessary for the introduction of biomass crops grown for energy purposes, including hybrid poplar, willow, and switchgrass

- Providing utilities with sulfur-free and low nitrogen fuels to begin addressing criteria pollutants

\subsubsection{Industry Experience With Cofiring When Program Was Initiated}

At the time when EPRI initiated its cofiring program, there was little utility industry experience with the concept. Utilities were evaluating blending dissimilar coals-e.g., Powder River Basin (PRB) coals and eastern bituminous coals - with varying degrees of success (see, for example, Bryers and Harding, 1994). This practice was replete with problems of boiler derating, mill difficulties, slagging and fouling, and reduced boiler efficiency. At the time when EPRI initiated its cofiring program, however, utilities were regulated and costs of such programs could be recovered in the rate structures.

Few utilities pursued fuel blending and cofiring beyond the blending of dissimilar coals to the blending or cofiring of unusual fuels. The experience of cofiring refuse-derived fuel (RDF) with coal at Union Electric, Wisconsin Electric Power Company, Baltimore Gas \& Electric, and other locations had not been universally successful. Otter Tail Power Co. had some success cofiring up to 12 percent RDF (mass basis) with $6200 \mathrm{Btu} / \mathrm{lb}$ lignite at its Big Stone cyclone boiler, although they experienced a 1.8 percent decrease in boiler efficiency due to handling problems and their consequence for cyclone operation (Pawlowski, 1993). Northern States Power had more favorable experience with RDF, however most was fired in dedicated boilers (Brobjorg, 1993). Tacoma City Light in Tacoma, WA, successfully fired a blend of RDF and wood waste with coal in two bubbling fluidized bed boilers (Gamble, 1993; Tillman and Leone, 1990). 
Otter Tail Power had successfully experimented with cofiring of sunflower seeds and other available biofuels. Associated Electric Cooperative conducted a very brief test cofiring railroad ties at a cyclone boiler. Utilities such as Illinois Power, Wisconsin Power and Light, Ohio Edison, New York State Electric and Gas (NYSEG) and TVA experimented with cofiring tire-derived fuel (TDF) in cyclone boilers, stoker-fired boilers, and in on PC boiler as well (for more information see Gillen and Szempruch, 1993; Stopek, et. al., 1993; Nast, 1993; Murphy and Tesla, 1993). Wisconsin Power \& Light constructed their own TDF production facility supporting this effort.

Northern States Power (NSP) had developed a successful biomass cofiring program with Andersen Windows. At this location, dry (e.g., <10 percent moisture) finely divided sawdust was pneumatically transported from the Andersen factory to the Allen S. King Generating Station in Bayport, MN. The King station is a 598 MWe cyclone boiler installation fired with PRB coal. The sawdust was pneumatically introduced into the secondary air location on three of the 12 cyclone barrels. The biomass being cofired contained $>7500 \mathrm{Btu} / \mathrm{lb}$ and was not a major fuel supply. It had very little, if any, impact on operations. NSP also experimented with blending small amounts of crushed pallets and other materials into the coal supply on the coal pile. They evaluated other cofiring fuels as well.

Southern Company initiated biomass cofiring testing at Plant Hammond Unit 1. This $100 \mathrm{MWe}$ Babcock \& Wilcox boiler was fired with 9.7 to 13.5 percent (mass basis) sawdust and ground tree trimming waste. Bark was initially, and unsuccessfully, attempted as well. The cofiring levels were equivalent to 6.5 percent on a heat input basis. The wood had a heat content of $6946 \mathrm{Btu} / \mathrm{lb}$ compared to the coal heat content of $12,877 \mathrm{Btu} / \mathrm{lb}$. There was only a minor loss in boiler efficiency measured during these tests-largely as a result of moisture in the wood waste. There was a 5 percent reduction in $\mathrm{SO}_{2}$ emissions, however there was no decrease in $\mathrm{NO}_{\mathrm{x}}$ emissions. Mill performance was significantly impacted. Mill amps were increased by 15 percent, and mill fineness deteriorated slightly (see Boylan, 1993 for details). The tests were sufficiently successful that Southern Company continued cofiring at Plant Hammond and Plant Yates on a limited basis.

Santee Cooper also experimented with cofiring at Jeffries Station, burning wood chipped from its forests. The wood burned was downed timber as a result of Hurricane Agnes. The boiler where cofiring occurred was a Riley boiler equipped with Atrita pulverizers. Atrita mills are essentially hammer mills, and somewhat suited to combined feed of wood chips and coal. However officials of Santee Cooper indicated that, at $>8$ percent biomass (mass basis) the unit suffered significant derating as a consequence of cofiring.

The experience base for cofiring, then, was very limited. EPRI recognized these limitations and, with support from numerous utilities led initially by TVA, structured a program to achieve widespread commercialization of the cofiring technology.

\subsubsection{Structuring the Initial EPRI Cofiring Program}

The initial program, focusing upon TVA Fossil Plants, was designed to identify the critical issues associated with cofiring and then to address those issues. At the time it was constructed, the TVA 
program was based upon a 5-year commercialization timetable. Consequently it was developed around initial engineering studies followed by detailed studies and short cofiring test programs. The initial EPRITVA cofiring program was developed with a competitive solicitation; Ebasco Environmental (now part of Foster Wheeler) won the competition with a team including Reaction Engineering International.

Subsequent to the TVA studies and tests, EPRI sponsored or participated in cofiring assessments and short cofiring tests at other utilities including GPU Genco, Union Electric, and Northern Indiana Public Service Company (NIPSCO). Of these, the most significant effort was the cofiring testing at the Shawville Generating Station of GPU Genco. The Shawville test was sponsored largely by GPU, with support from EPRI and USDOE-FETC (now USDOE-NETL). Simultaneously, EPRI met with and surveyed cofiring possibilities with other utilities including the following:

- Central Louisiana Electric Co

- Arkansas Power \& Light

- Northern States Power

- Delmarva

- East Kentucky Cooperative

- Northeast Utilities

EPRI also cooperated closely with Southern Company. This experience provided considerable impetus to the overall cofiring initiative.

\subsection{THE EPRI-TVA COFIRING PROGRAM}

The initial EPRI program, cosponsored by Tennessee Valley Authority (TVA) and partially supported by USDOE, included an assessment of the TVA generating stations. From these assessments, one cyclone boiler was selected for detailed engineering analysis. At the same time one wall-fired pulverized coal (PC) boiler was selected along with one tangentially-fired (T-fired) PC boiler. The overall program is summarized by Tillman, Hughes, and Gold (1993). Engineering was performed by Ebasco, supported by Reaction Engineering. Fuel supply studies were performed in complementary research for TVA by the University of Tennessee (see Noon, 1993) and by Oak Ridge National Laboratory (see Downing and Graham, 1993).

The initial engineering experimentation led to the development of supporting studies and to short term testing at the Allen Fossil Plant, the Kingston Fossil Plant, and the Colbert Fossil Plant of TVA. These plants included a cyclone boiler, a T-fired boiler, and a wall-fired boiler.

\subsubsection{The Engineering Studies}

The initial engineering studies were divided into two parts: 1) evaluating cofiring in coal-fired boilers and 2) evaluating cofiring using gasification as the biomass technology and cofiring (or firing producer gas exclusively) in combined cycle combustion turbine (CCCT) applications. The general engineering parameters used to select boilers for engineering evaluation included the program objectives: cofire at 
$10-15$ percent (heat input basis, equal to $\sim 20-30$ percent on a mass basis), design systems for a 20 year project life, and design systems to handle unprocessed wood residues. Taking a conservative design approach (requiring <1/16" x 0 " fuel particles < 15 percent moisture for PC firing, and <1/4" particles at $<50$ percent moisture for cyclone firing) the capital cost estimates were $\$ 517-\$ 640 / \mathrm{kW}$ for PC boilers using separate injection of the biomass into the boiler, and $\$ 150$ - $\$ 200 / \mathrm{kW}$ for cyclone boilers. These estimates were in 1993 dollars (see Tillman et. al., 1993). Given the economic assumptions, cofiring at the Allen Fossil Plant-the cyclone installation-was considered most favorable.

What was more important than the calculated economics was the identification of unresolved issues. Recognizing that the practice of biomass cofiring was in its infancy, questions arose including the following:

- The ability of fuel blends to be stored successfully in bunkers without stratification

- The ability of biomass/coal blends to flow from bunkers without hanging up

- The ability of biomass to be stored in bunkers, or in fuel yards, without spontaneous combustion

- The consistency of biomass fuel quality (Btu/lb, moisture, ash, chemistry)

- The potential for special uses of biomass in cofiring settings

The biomass material of choice was sawdust. Given the infancy of cofiring, each of the issues identified was addressed by a short study. To evaluate the storage issues, Reaction Engineering International built a cold flow bunker. This bunker was used to resolve the issues of stratification and the ability to discharge blends of coal/wood chips, coal/sawdust, and coal/sawdust/TDF without difficulty. The research was successful.

The issue of spontaneous combustion was addressed explicitly by research sponsored by TVA (Foster Wheeler Environmental, 1994a). Initially an extensive literature search was performed. This was followed by experimental research. Blends of various bituminous coals and woods were used; both green (52 percent moisture) and dry (5 percent moisture) wood ground to <1/4" x 0" particle size was used in the testing. Table 2-1 identifies the fuels selected. Table 2-2 identifies the fuel blends tested. Note that the coals employed were varied as a function of sulfur content and moisture content. Samples indicated in the table document that the self-heating tests were performed on coal alone (pure), coal/wood blends, and wood alone.

In this test, a sample was placed in a reaction chamber and subjected to a stream of moist oxygen heated to $165^{\circ} \mathrm{F}\left(74^{\circ} \mathrm{C}\right)$ for time periods ranging from 6 hours to 24 hours. The temperature of the fuel blend along with the off-gas composition was measured. In the off-gas, the experiment measured concentrations of $\mathrm{O}_{2}, \mathrm{CO}$, and $\mathrm{CO}_{2}$. The tests, conducted by Hazen Research of Golden, $\mathrm{CO}$, provided a relative measure of storage reactivity of fuels. They measure reactivity under the most severe conditions. The standard-PRB coal—typically ignites in 1 hour under the test conditions. 
Table 2-1. Fuels Used in Assessment of Spontaneous Combustion Assessment

\begin{tabular}{|l|l|c|c|c|}
\hline Fuel & Source & Sulfur & Moisture & Samples \\
\hline Utah Basin Coal & Allen Fossil Plant & $0.6 \%$ & $3.9 \%$ & Pure, Blends \\
\hline Eastern Tenn. Coal & Kingston Fossil Plant & $1.3 \%$ & $5.5 \%$ & Unused \\
\hline "Low-Sulfur" Coal & Colbert Fossil Plant & $1.0 \%$ & $10.6 \%$ & Unused \\
\hline "High-Sulfur" Coal & Colbert Fossil Plant & $2.2 \%$ & $5.7 \%$ & Pure, Blends \\
\hline W. Kentucky Coal & Gallatin Fossil Plant & $2.8 \%$ & $10.1 \%$ & Pure, Blends \\
\hline Green Wood & Memphis-Area Sawmill & $0.05 \%$ & $51.6 \%$ & Pure, Blends \\
\hline "Dry" Wood & Memphis-Area Manufacturing Facility & $0.07 \%$ & $28.4 \%$ & Pure \\
\hline Kiln-Dried Wood & $\begin{array}{l}\text { Memphis Hardwood Flooring } \\
\text { Company }\end{array}$ & $0.06 \%$ & $5.5 \%$ & Pure \\
\hline
\end{tabular}

Source: Foster Wheeler Environmental, 1994a.

The results of this test program were most significant, and favorable. Although the conditions of the test constitute a severe, worst-case self-heating environment, none of the samples, either the pure fuels or the fuel blends, exhibited a tendency to self-heat under the test conditions. Slight temperature fluctuations in the bed were observed, and determined to be insignificant. They were likely associated with fluctuations in the oven temperature. Similarly, only trace amounts of $\mathrm{CO}$ and $\mathrm{CO}_{2}$ were detected during the test, and these levels were determined to be insignificant. With the exception of the pure green sawdust sample (52 percent moisture), each sample was tested for a duration of six hours. The analysis of the green sawdust sample was extended to 24 hours, which is the expected duration in a day-bin or fuel storage bunker at a power plant. Even over the extended duration, the wood sample did not exhibit a tendency to self-heat under the severe test conditions.

The greatest temperature increases were observed with the driest fuels. A $13^{\circ} \mathrm{F}$ rise was observed for the pure Allen Utah bituminous coal with 4 percent moisture, and a $14^{\circ} \mathrm{F}$ rise was observed for the pure kiln-dried sawdust with 6 percent moisture. These slight temperature increases are not considered to be significant indications of self-heating tendencies under the test conditions, particularly when compared with responses from fuels like the Powder River Basin coal. Again this research was confined to woody biomass, and did not include herbaceous biomass. However it demonstrated the potential for successful storage of biomass_-and biomass/coal blends_-in power plant settings.

Studies of fuel consistency among the woody biofuels available in the Tennessee Valley demonstrated that the inherent properties of the softwoods and hardwoods were sufficiently similar that the primary concern would be the wood processing technologies applied to the incoming logs. Sawmills vary in their use of water for cooling headrigs, with bandsaws producing the finest—and wettest—dust. Residues from secondary processes (hardwood flooring, furniture manufacturing) also showed 
significant variation in moisture and ash content when compared to sawmill residues. However, on a moisture and ash free (MAF) basis, the woody biomass was sufficiently consistent that species or genera posed no issues for biomass cofiring (Prinzing, Harding, and Tillman, 1993; Tillman and Prinzing, 1994).

Table 2-2. Fuel Blends Used in Spontaneous Combustion Assessment

\begin{tabular}{|l|l|l|}
\hline Coal/Power Plant Source & Wood & Blend (Percent Heat Input) \\
\hline Allen 0.6\% Sulfur & --- & $100 \%$ Coal \\
\hline Allen 0.6\% Sulfur & Sawdust 52\% Moisture & $5 \%$ Wood \\
\hline Allen 0.6\% Sulfur & Sawdust 52\% Moisture & $10 \%$ Wood \\
\hline Allen 0.6\% Sulfur & Sawdust 52\% Moisture & $15 \%$ Wood \\
\hline Allen 0.6\% Sulfur & Sawdust 52\% Moisture & $50 \%$ Wood \\
\hline Colbert 2.2\% Sulfur & --- & $100 \%$ Coal \\
\hline Colbert 2.2\% Sulfur & Sawdust 52\% Moisture & $2.5 \%$ Wood \\
\hline Colbert 2.2\% Sulfur & Sawdust 52\% Moisture & $5 \%$ Wood \\
\hline Colbert 2.2\% Sulfur & Sawdust 52\% Moisture & $10 \%$ Wood \\
\hline Gallatin 2.8\% Sulfur & --- & $100 \%$ Coal \\
\hline Gallatin 2.8\% Sulfur & Sawdust 52\% Moisture & $2.5 \%$ Wood \\
\hline Gallatin 2.8\% Sulfur & Sawdust 52\% Moisture & $5 \%$ Wood \\
\hline Gallatin 2.8\% Sulfur & Sawdust 52\% Moisture & $10 \%$ Wood \\
\hline Gallatin 2.8\% Sulfur & Sawdust 52\% Moisture & $15 \%$ Wood \\
\hline Gallatin 2.8\% Sulfur & Sawdust 52\% Moisture & $50 \%$ Wood \\
\hline--- & Sawdust 6\% Moisture & $100 \%$ Wood \\
\hline--- & Sawdust 22\% Moisture & $100 \%$ Wood \\
\hline--- & Sawdust 52\% Moisture & $100 \%$ Wood \\
\hline Source: Foser Wheer Env & Sonent 294 & 5 Ma \\
\hline
\end{tabular}

Source: Foster Wheeler Environmental, 1994a.

The issue of special applications of biomass in cofiring settings focused upon using biofuels in reburn systems for $\mathrm{NO}_{\mathrm{x}}$ control. The Southeast Regional Biomass Energy Program (SERBEP), along with TVA and EPRI, funded research on woody biomass as a reburn fuel. This research, conducted by Reaction Engineering International, was reported by Brouwer et. al. (1995), Brouwer et. al. (1994), Adams and Harding (1996) and more recently updated by Harding and Adams (2000). This research preceded, and then paralleled research at Iowa State University (see Sweterlitsch and Brown, 1999) and EER-GE Corporation (see Zamanski et. al., 1998) conducted outside of the EPRI program. Their research demonstrated that woody biomass could be about as effective as natural gas or coal in reburn 
applications, as shown in Figures 2-1 and 2-2. Further, biomass reburn is not very sensitive to particle size, carrier gas, or moisture content when the particles are $<12$ mesh $(<1.68 \mathrm{~mm})$. The carrier gas issue shows a preference for an inert gas (either nitrogen or flue gas) in order to maintain appropriate stoichiometries; however the use of air is influential only in the sense that it can impact the local stoichiometric ratio used to drive reburn reactions. Softwood appeared to be somewhat more effective as a reburn fuel than hardwood, largely as a result of higher nitrogen in the hardwood samples. Special applications can be useful cofiring strategies.

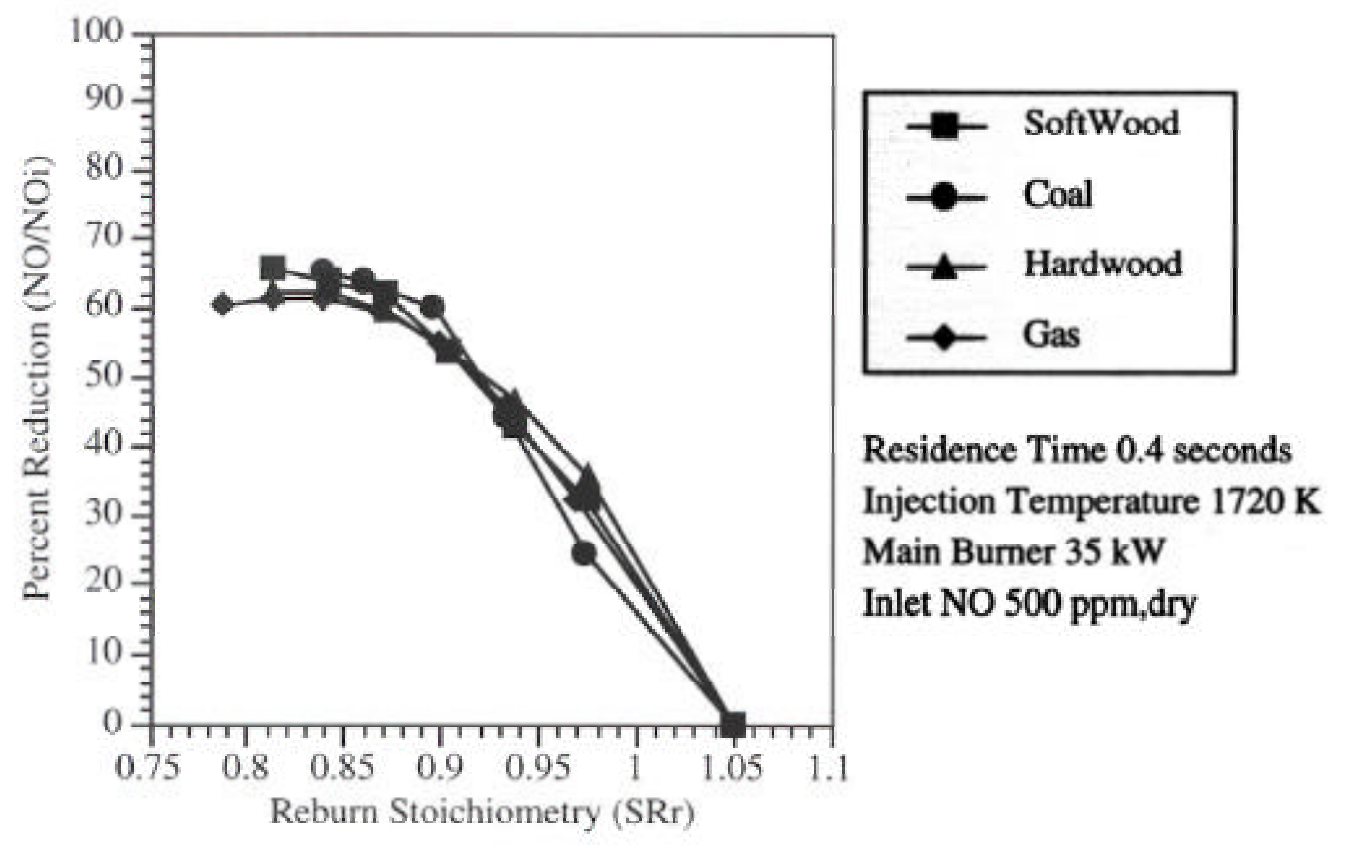

Figure 2-1. Reburn Effectiveness of Wood Fuel Relative to Coal and Natural Gas at $2600^{\circ} \mathrm{F}(1720 \mathrm{~K})$
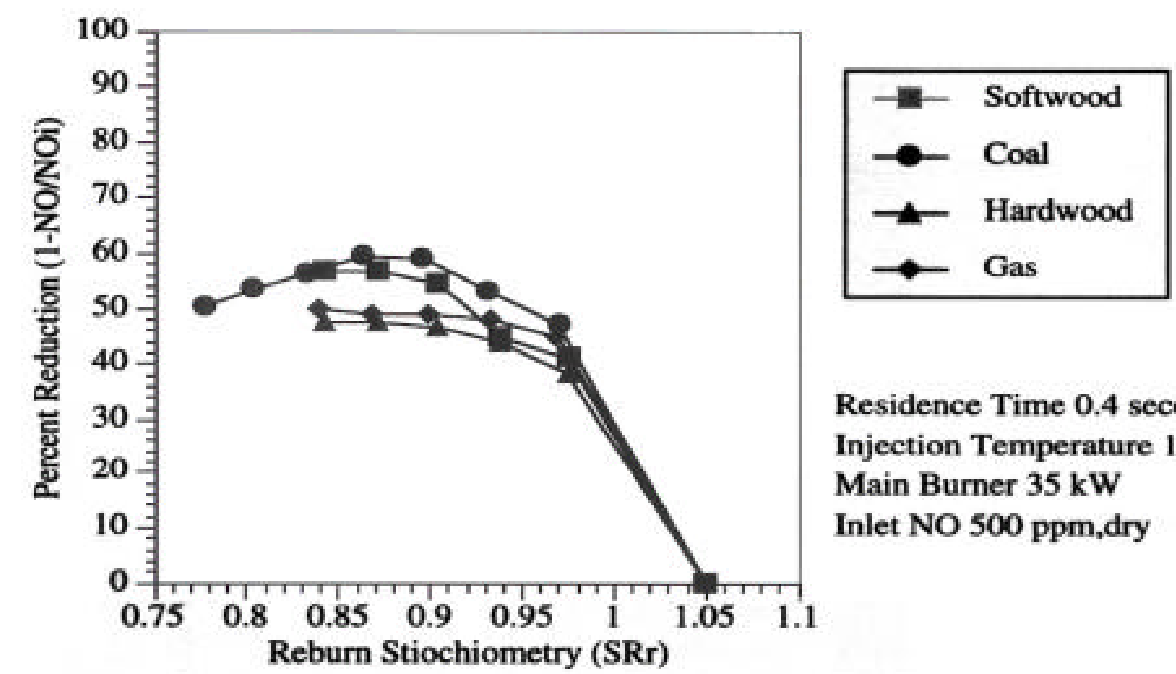

Residence Time 0.4 seconds Injection Temperature $1400 \mathrm{~K}$ Main Burner 35 kW Inlet NO 500 ppm,dry

Source: Harding and Adams, 2000 
Figure 2-2. Reburn Effectiveness of Wood Fuel Relative to Coal and Natural Gas at $2060^{\circ} \mathrm{F}(1400 \mathrm{~K})$ Source: Harding and Adams, 2000.

\subsubsection{Cofiring Testing at the Allen Fossil Plant}

Given the assessment of cofiring at the Allen Fossil Plant and the favorable resolution of questions concerning fuel quality, fuel storage, and fuel transport, EPRI and TVA developed a test program for this cyclone installation. Because the Allen Fossil Plant uses cyclone combustion technology, the sawdust was screened and then blended with the coal on the main belt feeding the bunkers. The blends of fuel then were transported from the bunkers through the Stock feeders and to the cyclone barrels. The results of this Allen Fossil Plant cofiring test program have been well documented in the literature (see Foster Wheeler Environmental Corporation, 1995a; Foster Wheeler Environmental Corporation, 1994b; Tillman et. al., 1995; Tillman, Reardon, and Rollins, 1996; Tillman, et. al., 1996a; Tillman, Rollins, Reardon, and Hughes, 1997; Foster Wheeler Environmental Corporation, 1997a). The testing was extensive, considering the following variables:

- Percentage of biomass fired on a mass and heat input basis

- Base coal for the power plant (Illinois basin coal and Utah bituminous coal)

- Particle size of the biomass being fired

- Power plant operating parameters (load, excess $\mathrm{O}_{2}$ )

The test program addressed the issues of capacity, efficiency, operability, and emissions. Emissions of concern included $\mathrm{SO}_{2}$ emissions reductions and greenhouse gas-fossil $\mathrm{CO}_{2}$ emissions reductions. It demonstrated that capacity could be maintained when cofiring up to 20 percent biomass. Operability problems such as boiler stability and temperatures were virtually non-existent. Efficiency reductions associated with cofiring biomass in cyclone boilers were modest, and could be managed as an economic issue. $\mathrm{SO}_{2}$ emissions reductions were typically about 0.5 percent when cofiring at $10-15$ percent (mass basis).

The test effort quickly demonstrated the ability to reduce $\mathrm{SO}_{2}$ and fossil $\mathrm{CO}_{2}$ emissions. These provided an economic and policy incentive to continue pursuing cofiring. The focus of the program, however, became the ability of biomass cofiring to reduce $\mathrm{NO}_{\mathrm{x}}$ emissions from cyclone boilers. This resulted from the fact that, when firing eastern coal and sawdust, $\mathrm{NO}_{\mathrm{x}}$ reductions as shown in Table 2-3 resulted.

Table 2-3. $\mathrm{NO}_{\mathrm{x}}$ Reductions at the Allen Fossil Plant When Firing Illinois Basin Coal and Sawdust

\begin{tabular}{|c|c|c|c|}
\hline $\begin{array}{l}\text { Percent } \\
\text { Sawdust } \\
\text { (mass basis) }\end{array}$ & $\begin{array}{l}\text { Percent Sawdust } \\
\text { (Btu basis) }\end{array}$ & $\mathrm{NO}_{\mathrm{x}}$ Emissions (lb/10 $\left.{ }^{6} \mathrm{Btu}\right)$ & Percent $\mathrm{NO}_{\mathrm{x}}$ Reduction \\
\hline 0 & 0 & 1.973 & 0 \\
\hline 5 & 2.5 & 1.862 & 5.6 \\
\hline 5 & 2.5 & 1.915 & 2.9 \\
\hline 10 & 5 & 1.710 & 13.3 \\
\hline
\end{tabular}




\begin{tabular}{|c|c|c|c|}
\hline $20(*)$ & 10 & 1.374 & 30.4 \\
\hline
\end{tabular}

(*) Minor loss of load

Source: Foster Wheeler Environmental, 1994b

Tests when cofiring with Utah bituminous coal in 1995 showed $\mathrm{NO}_{\mathrm{x}}$ reductions up to 25 percent when cofiring 15 percent sawdust (mass basis) with lesser reductions when cofiring at higher percentages (Foster Wheeler, 1997). Such reductions have significant economic value and therefore became the focus of much of the test effort described below.

The Allen Fossil Plant consists of three identical cyclone boilers, each with a nominal capacity of 275 MWe (gross), or about 260 MWe (net). The design of the plant includes stacked boilers for space management. Each boiler has seven cyclones in an opposed firing configuration: three barrels are located on the north side and four are located on the south side. All cyclones are on a single elevation. The cyclones employ vortex feeders and are consequently sensitive to fines in the fuel supply. Airborne emissions are controlled with electrostatic precipitators. Each boiler has its own stack. Each stack is equipped with a continuous emissions monitor (CEM) which logs data concerning flue gas flow plus $\mathrm{NO}_{\mathrm{X}}, \mathrm{SO}_{2}$, and opacity emissions. Each boiler is equipped with a distributed computer control (Bailey) system, and with an on-line diagnostic monitoring system (OLDMS) for information gathering.

Between 1994 and 1995, TVA began the process of converting from eastern bituminous coal to western bituminous coal as a means of reducing $\mathrm{SO}_{2}$ emissions. This switch occurred while the plant was evaluating both wood waste and TDF as alternate fuels. Consequently the cofiring testing capitalized upon the opportunity to evaluate differences in the base coal. During this period of time TVA also evaluated cofiring TDF with coal; some initial testing of tri-firing sawdust, TDF, and coal was briefly tried(see Tillman et. al., 1996b).

Tests of the Allen Fossil Plant were conducted in boilers \#1 and \#2, over a range of load, fuel blend, and firing rate conditions. Typically these tests occurred over 3 to 4 hour periods. During these tests, the fuels varied in composition and heating value. Data acquired during each test were sufficient to calculate heat and material balances and to evaluate airborne emissions.

During all tests, sawdust was received in the coal yard, screened through a trommel screen, and then metered onto the coal belts through metering conveyors (see Figures 2-3 and 2-4). Table 2-4 provides analyses of the fuels burned. During the tests, load was varied between full bad $\left(272 \mathrm{MW}_{\mathrm{e}}\right)$ and minimum load $\left(\sim 100 \mathrm{MW}_{\mathrm{e}}\right)$. Excess $\mathrm{O}_{2}$ was varied between 2.4 percent and 3.3 percent. Cofiring percentages were varied between 5 percent and 20 percent (mass basis) with a high concentration of tests between 10 and 15 percent cofiring. In all, over 40 individual tests were conducted representing some 140 test hours. Of these, 2 days of trifiring tests with sawdust and TDF were performed to obtain a perspective on what might occur by blending these two opportunity fuels. 


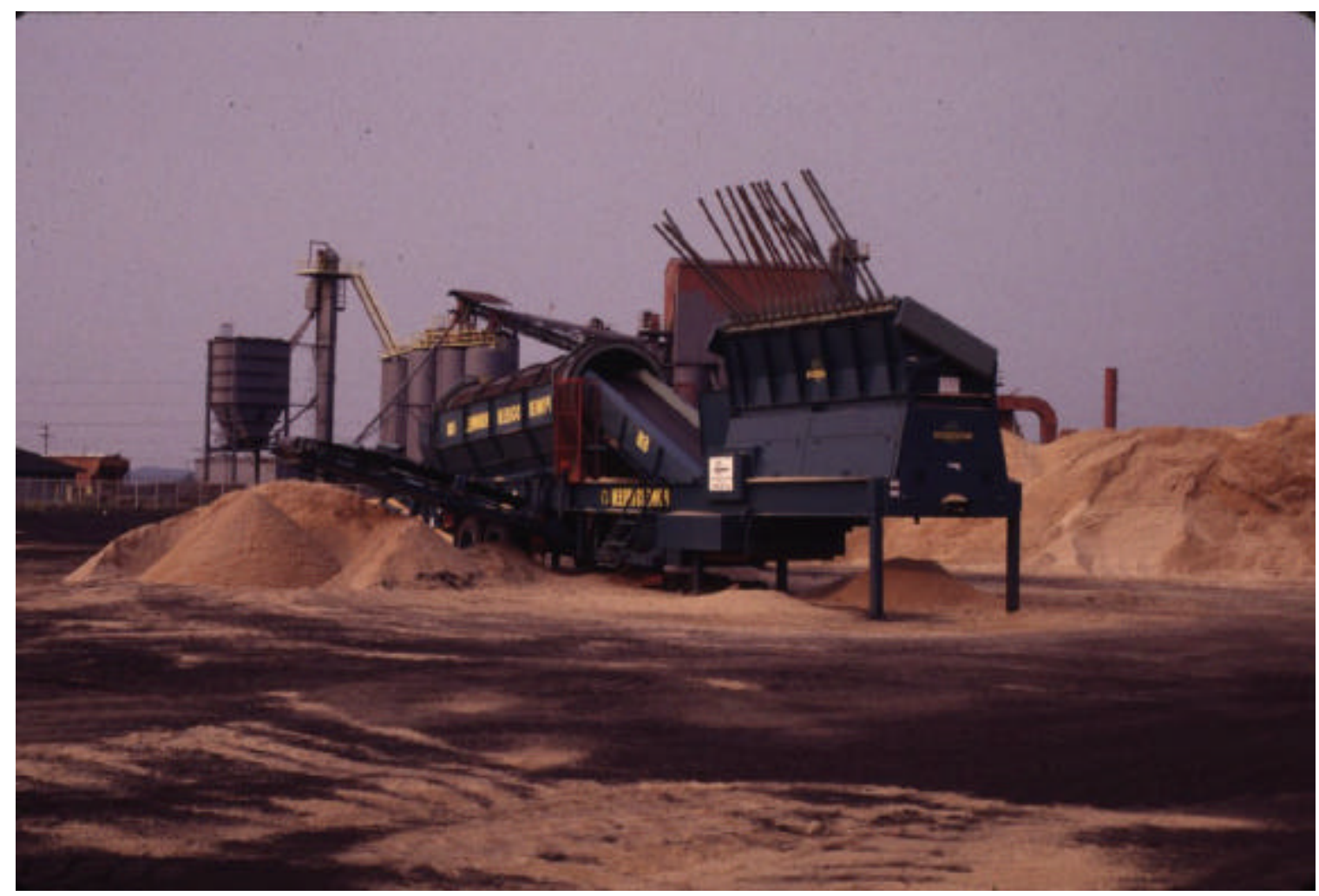

Figure 2-3. The Trommel Screen Installed at the Allen Fossil Plant 


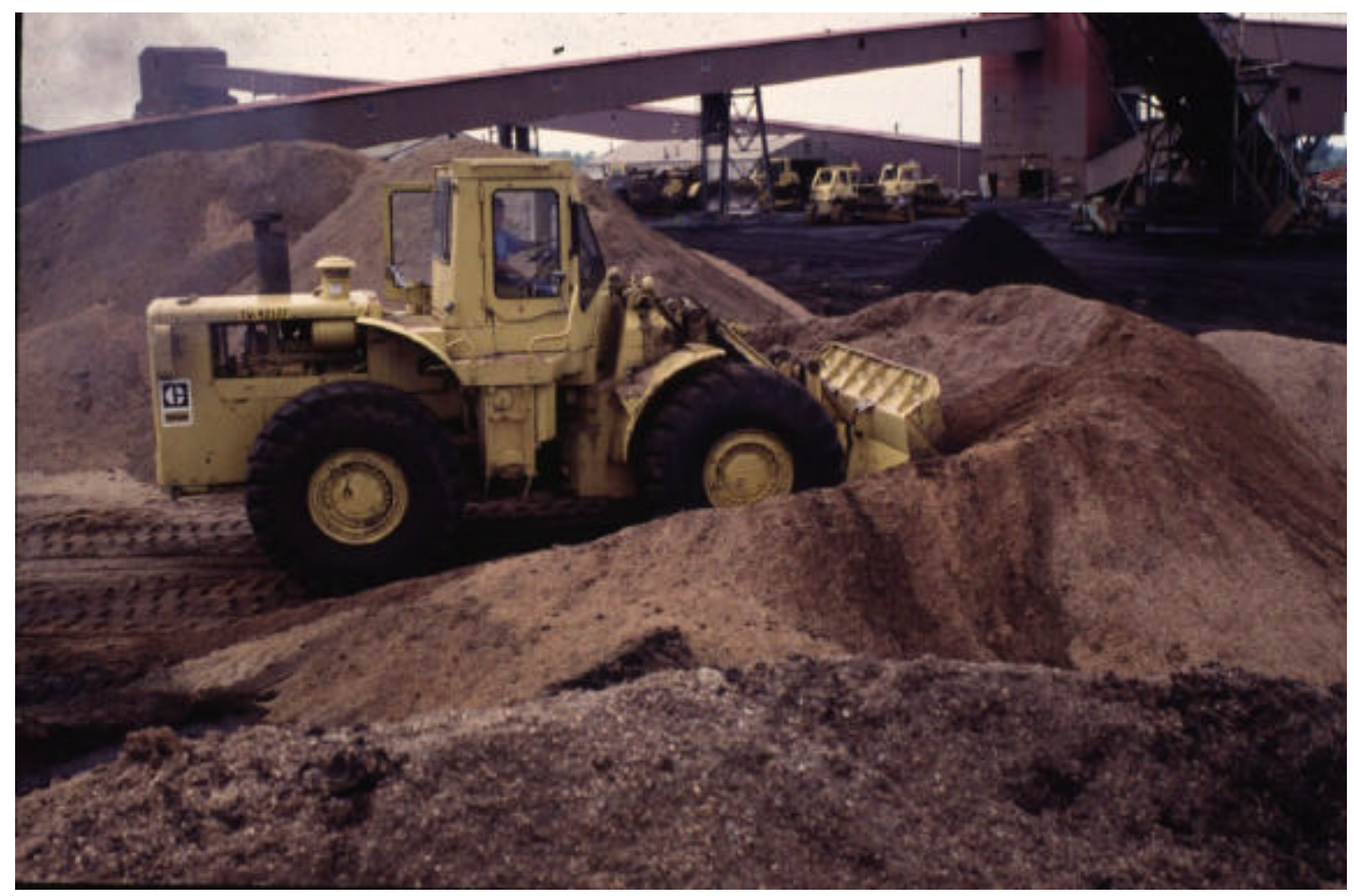

Figure 2-4. Managing the Biomass Fuel Supply at the Allen Fossil Plant

Table 2-4. Fuels Used for Cofiring Tests at the Allen Fossil Plant

\begin{tabular}{|r|c|c|c|c|c|}
\hline \multicolumn{1}{|c|}{ Analytical Parameter } & $\begin{array}{c}\text { Illinois Basin } \\
\text { Coal }\end{array}$ & Utah Coal & $\begin{array}{c}\text { Sawdust } \\
\text { Burned with } \\
\text { Illinois Coal }\end{array}$ & $\begin{array}{c}\text { Sawdust } \\
\text { Burned With } \\
\text { Utah Coal }\end{array}$ & $\begin{array}{c}\text { Tire } \\
\text { Derived } \\
\text { Fuel }\end{array}$ \\
\hline $\begin{array}{r}\text { Proximate Analysis } \\
\text { (Wt percent) }\end{array}$ & & & & & \\
\hline Moisture & 8.79 & 9.60 & 45.49 & 40.84 & 2.95 \\
\hline Ash & 8.26 & 7.33 & 0.63 & 3.70 & 4.79 \\
\hline Folatiles & 33.22 & 39.06 & 45.85 & 46.36 & 60.82 \\
\hline $\begin{array}{r}\text { Ultimate Analysis Carbon } \\
\text { (Wt percent) }\end{array}$ & 49.73 & 44.01 & 8.03 & 9.10 & 31.44 \\
\hline Carbon & 68.60 & 66.91 & 27.16 & 28.50 & 81.63 \\
\hline Hydrogen & 4.64 & 4.86 & 3.29 & 3.32 & 7.03 \\
\hline Oxygen & 6.23 & 9.58 & 23.32 & 23.53 & 1.06 \\
\hline Nitrogen & 1.23 & 1.15 & 0.09 & 0.08 & 0.54 \\
\hline Sulfur & 2.24 & 0.58 & 0.03 & 0.05 & 2.02 \\
\hline Moisture & 8.79 & 9.60 & 45.49 & 40.84 & 2.95 \\
\hline Ash & 8.26 & 7.33 & 0.63 & 3.70 & 4.79 \\
\hline Value & & & & & \\
\hline Heating & & & & & \\
\hline
\end{tabular}




\begin{tabular}{|l|l|l|l|l|l|}
\hline (Btu/lb) & 12305 & 12029 & 4563 & 4739 & 15332 \\
\hline
\end{tabular}

All tests from three years of testing have been accumulated into a single database of inputs and results. Critical variables were then analyzed over the entire range of tests, with particular emphasis on the factors influencing $\mathrm{NO}_{\mathrm{x}}$ emissions. The analytical techniques employed included multiple linear regression analyses and curve fitting analyses. Fuel variables considered included fuel volatility expressed as volatile/fixed carbon (V/FC) ratio derived from the proximate analysis, heat content in $\mathrm{Btu} / \mathrm{lb}$, fuel nitrogen content in $\mathrm{lb} \mathrm{N} / 10^{6} \mathrm{Btu}$ fuel, fuel ash and moisture contents in $\mathrm{lb} / 10^{6} \mathrm{Btu}$, and fuel oxygen content expressed as stoichiometric $\mathrm{lb}$-moles $\mathrm{O}_{2}$ from air required per million Btu fuel fired. Firing conditions evaluated included excess $\mathrm{O}_{2}$ at the outlet of the economizer, firing rate expressed as $10^{6} \mathrm{Btu} / \mathrm{hr}$, and furnace exit gas temperature (FEGT). Special tests were also conducted to determine the influence of biomass particle size on the $\mathrm{NO}_{\mathrm{x}}$ reduction mechanisms.

The variables selected for analysis were based on considering two fundamental pathways for formation of $\mathrm{NO}_{\mathrm{X}}$ in cyclone boilers: 1) conversion of the fuel nitrogen to $\mathrm{NO}$; and 2) conversion of nitrogen in the combustion air to NO through thermal processes. The analysis produced provides an explanation of why the alternate fuels reduced $\mathrm{NO}_{\mathrm{X}}$ emissions, expressed in $\mathrm{lb} \mathrm{NO}_{\mathrm{X}} / 10^{6}$ Btu fuel input. Further, it provides analytical tools to evaluate means of optimizing the contributions of alternate fuels to control oxides of nitrogen emissions.

Two influences dominate the issue of $\mathrm{NO}_{\mathrm{X}}$ control through fuel blending and fuel switching - fuel influences and firing condition influences. These two influences are treated separately, and are followed by consideration of combined influences.

\subsubsection{Fuel Influences on $\mathrm{NO}_{\mathrm{x}}$ Emissions}

Fuel influences include fuel nitrogen content and fuel volatility. Figure 2-3 presents the impact of fuel nitrogen on $\mathrm{NO}_{\mathrm{X}}$ emissions at the Allen Fossil Plant. Note the following observations with respect to Figure 2-5: 1) fuel nitrogen is a dominant force $\left(\mathrm{r}^{2}=0.63\right)$, but not the complete cause of $\mathrm{NO}_{\mathrm{X}}$ emissions; and 2) there appears to be a lower limit of about $0.9 \mathrm{lb} \mathrm{N} / 10^{6}$ Btu fuel, below which reducing fuel nitrogen has virtually no further impact. At this base low point, other mechanisms may dominate the $\mathrm{NO}_{\mathrm{x}}$ emissions. 


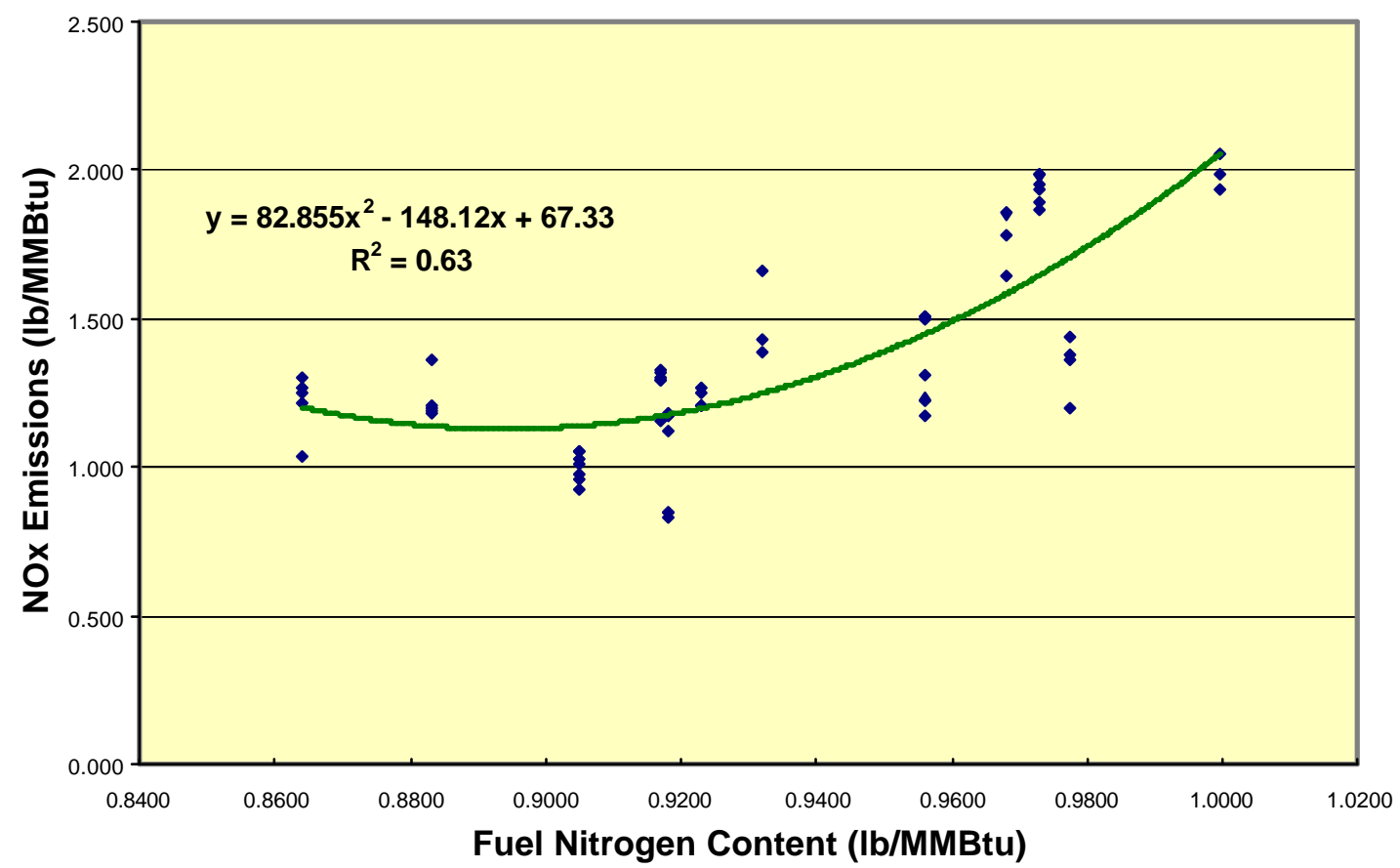

Figure 2-5. The Influence of Fuel Nitrogen Content on NOx Emissions at the Allen Fossil Plant Cofiring Tests

Fuel volatility is the second force of significance, as this governs the way the fuel burns. Volatility, coupled with the temperature at which pyrolysis is initiated, governs the mechanisms of combustion in the cyclone barrel. Typically, about 15 percent of the combustion air going to the cyclone is primary and tertiary air and 85 percent is secondary air. Volatiles evolved in the burner section of the cyclone exist, at least temporarily, in a reducing environment. The extent to which fuel $\mathrm{N}$ evolves in volatiles in this environment influences the NOx reduction pathways, with creation of reducing environments becoming more prominent with highly volatile fuels where pyrolysis is easily initiated.

Wood waste is a highly volatile fuel that readily devolatilizes at relatively low temperatures. The temperature at which devolatilization is initiated in wood is about $700^{\circ} \mathrm{F}$ to $1,000^{\circ} \mathrm{F}(648-811 \mathrm{~K})$ depending on wood component (e.g., extractives, hemicelluloses, cellulose, lignin) and depending upon the particle size. Devolatilization is facilitated by smaller particles with higher surface/mass ratios and with low aromaticity. The temperature of devolatilization is lower than the temperature at which coal devolatilization is initiated. Further, devolatilization is essentially completed when wood particles reach internal temperatures of $1830^{\circ} \mathrm{F}(1273 \mathrm{~K})$.

Subsequent research by Pennsylvania State University on the kinetics of devolatilization provides kinetic parameters for low and high temperature devolatilization of sawdust and Illinois basin coal, as shown in Table 2-5. The kinetics were developed to conform to the Arrhenius equation. 
Table 2-5. Kinetic Parameters for Devolatilization of Sawdust and Illinois Basin Coal

\begin{tabular}{|l|l|l|l|l|}
\hline Fuel & Regime & $\begin{array}{l}\text { Temperature Range } \\
(\mathrm{K})\end{array}$ & $\begin{array}{l}\text { Pre-Exponential } \\
\text { Constant }(1 / \mathrm{sec})\end{array}$ & $\begin{array}{l}\text { Activation } \\
(\mathrm{kcal} / \mathrm{mol} \mathrm{K})\end{array}$ \\
\hline Sawdust & Low Temp & $673-873$ & 1.17 & 0.681 \\
\hline Sawdust & High Temp & $873-1273$ & 5.74 & 3.42 \\
\hline Illinois coal & Low Temp & $873-1273$ & 5.88 & 4.08 \\
\hline Illinois coal & High Temp & $1273-1773$ & 338 & 14.6 \\
\hline
\end{tabular}

Source: Johnson et. al., 2001

Figure 2-6 shows the influence of fuel blend volatility on $\mathrm{NO}_{\mathrm{X}}$ emissions when sawdust is the biomass source, and using the volatile/fixed carbon (V/FC) ratio from the proximate analysis to measure volatility. Note again that the function is non-linear, and there is a minimum value. That minimum value appears to be when $\mathrm{V} / \mathrm{FC} \cong 1.0$. Again, the increase where $\mathrm{V} / \mathrm{FC}>1.0$ appears to be caused by the efficiency consequences of wood fuel addition to the coal, resulting in somewhat higher firing rates. Note, also, that the coefficient of determination, $\stackrel{2}{\mathrm{r}}$, is not totally dominant; however it represents a significant force in managing emissions of oxides of nitrogen.

Clearly the increase in volatility comes from the biomass and, in sawdust form, it contributes to $\mathrm{NO}_{\mathrm{x}}$ reduction. The research on particle size influences included cofiring chips at $1 / 2$ " $\mathrm{x} 0$ " with sawdust and coal, and cofiring 1" x 0" chips with sawdust and coal. Chips made up 25 to 50 percent of the biomass feed. Under those conditions, the Foster Wheeler (1997) report concludes:

"With the exception of the test on June 28, the data suggest that the use of larger wood particles reduces if not eliminates the benefits of cofiring biofuels with coal in achieving $\mathrm{NO}_{\mathrm{x}}$ reductions."

Apparently the diffusion effects associated with larger particles effectively reduced the rate of volatiles released in the combustion process, thereby minimizing their benefit in $\mathrm{NO}_{\mathrm{x}}$ reduction. A one-cyclone

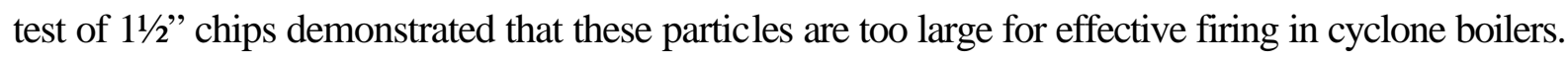

Prior work has shown that nitrogen evolution in volatile compounds from sawdust and other small wood particle pyrolysis proceeds more rapidly than that of carbon evolution in volatile compounds or of total volatile release (Tillman and Smith, 1982; Tillman, 1991). Figure 2-7 shows more recent data developed by Pennsylvania State University confirming this phenomenon. Such wood particles release virtually all of their nitrogen as volatile matter, and release it under fuel rich conditions. This contributes to $\mathrm{NO}_{\mathrm{x}}$ reduction, rather than $\mathrm{NO}_{\mathrm{x}}$ formation. 


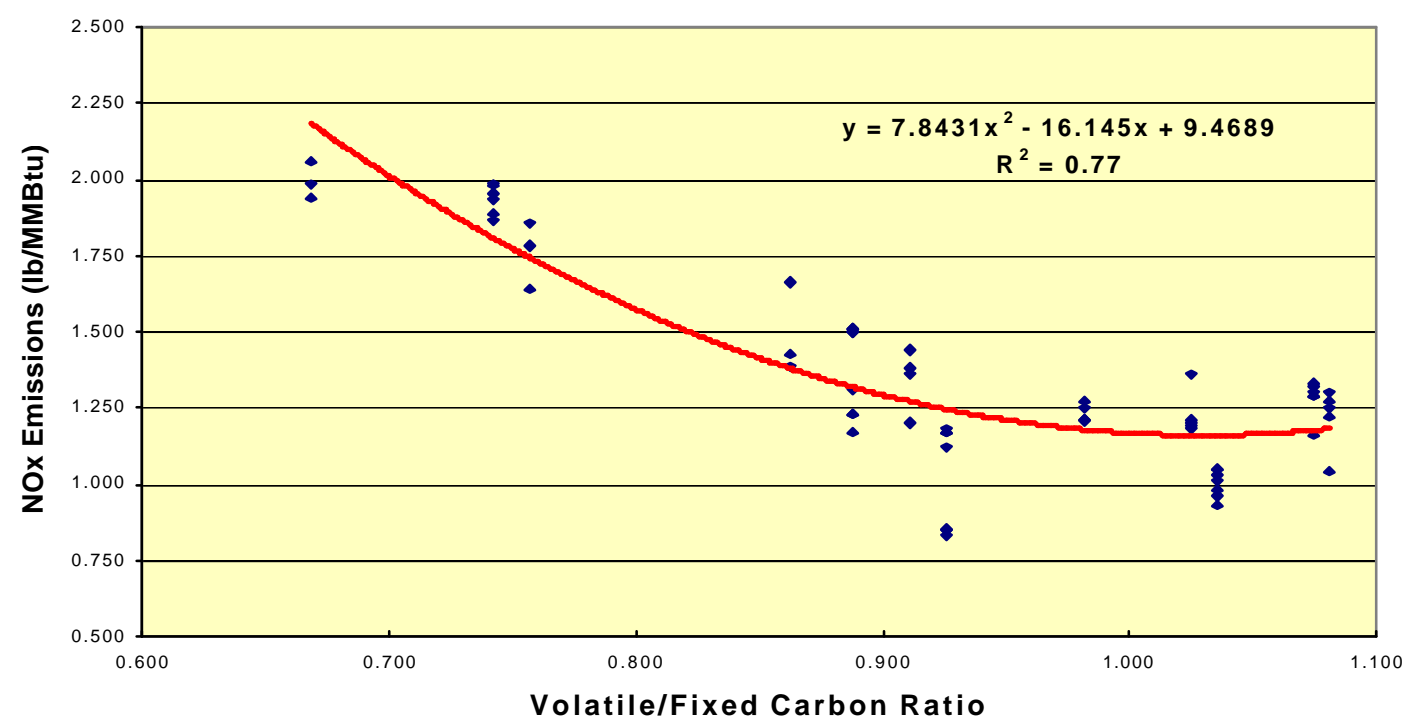

Figure 2-6. Influence of Volatility on $\mathrm{NO}_{\mathrm{x}}$ Emissions at the Allen Fossil Plant.

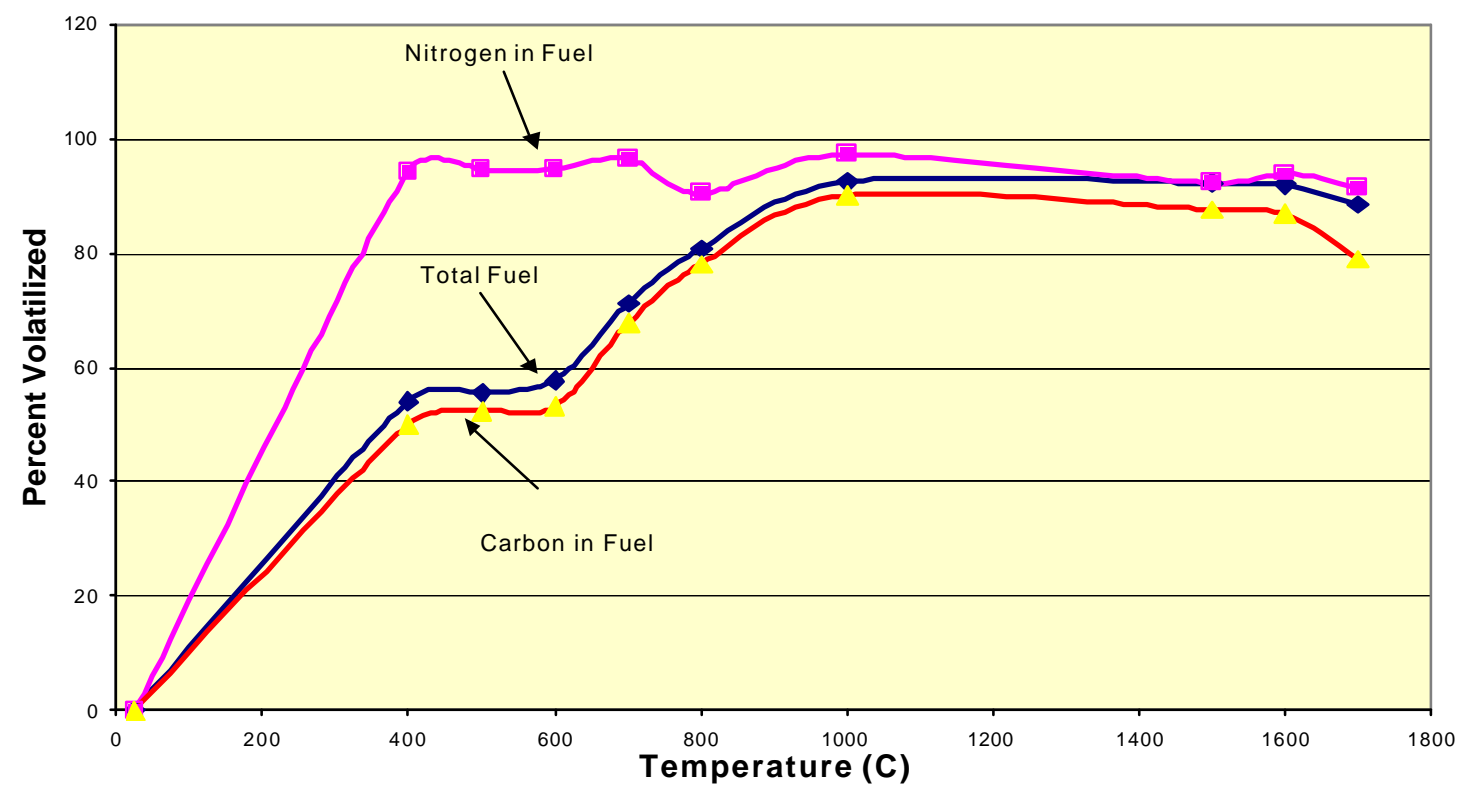

Figure 2-7. Release of Nitrogen Volatiles Relative to Carbon Vlatiles and Total Volatiles from Sawdust based upon data from Pennsylvania State University.

Source: Payette and Tillman, 2001. 


\subsubsection{Firing Condition Impacts on $\mathrm{NO}_{\mathrm{x}}$ Emissions During Allen Fossil Plant Tests}

Firing conditions of significance include furnace exit temperatures, firing rate, and excess air use. These relate to driving the Zeldovich mechanism. Furnace exit gas temperature (FEGT) provides measurement of the activation energy available for driving the formation of thermal $\mathrm{NO}_{\mathrm{x}}$. Measurements of furnace exit temperatures at the Allen Fossil Plant were made using optical pyrometry. Optical pyrometry is used to measure the temperature of a solid surface, and the furnace exit temperature as measured is estimated to be 50 to $75^{\circ} \mathrm{F}$ lower than the furnace exit gas temperature (FEGT).

$\mathrm{NO}_{\mathrm{X}}$ emissions are a curvilinear function of FEGT at the Allen Fossil Plant, as shown in Figure 2-8. Note that the combustion of Illinois basin coal results in higher FEGT values than the combustion of western bituminous coal. Note, also, that the NOx emissions are relatively uninfluenced by FEGT below about $2000^{\circ} \mathrm{F}$; however when FEGT temperatures exceed about $2200^{\circ} \mathrm{F}, \mathrm{NO}_{\mathrm{x}}$ emissions rise sharply. The testing indicated that cofiring sawdust with coal could drop FEGT values by $100-200^{\circ} \mathrm{F}$, when firing either Illinois Basin or western coal.

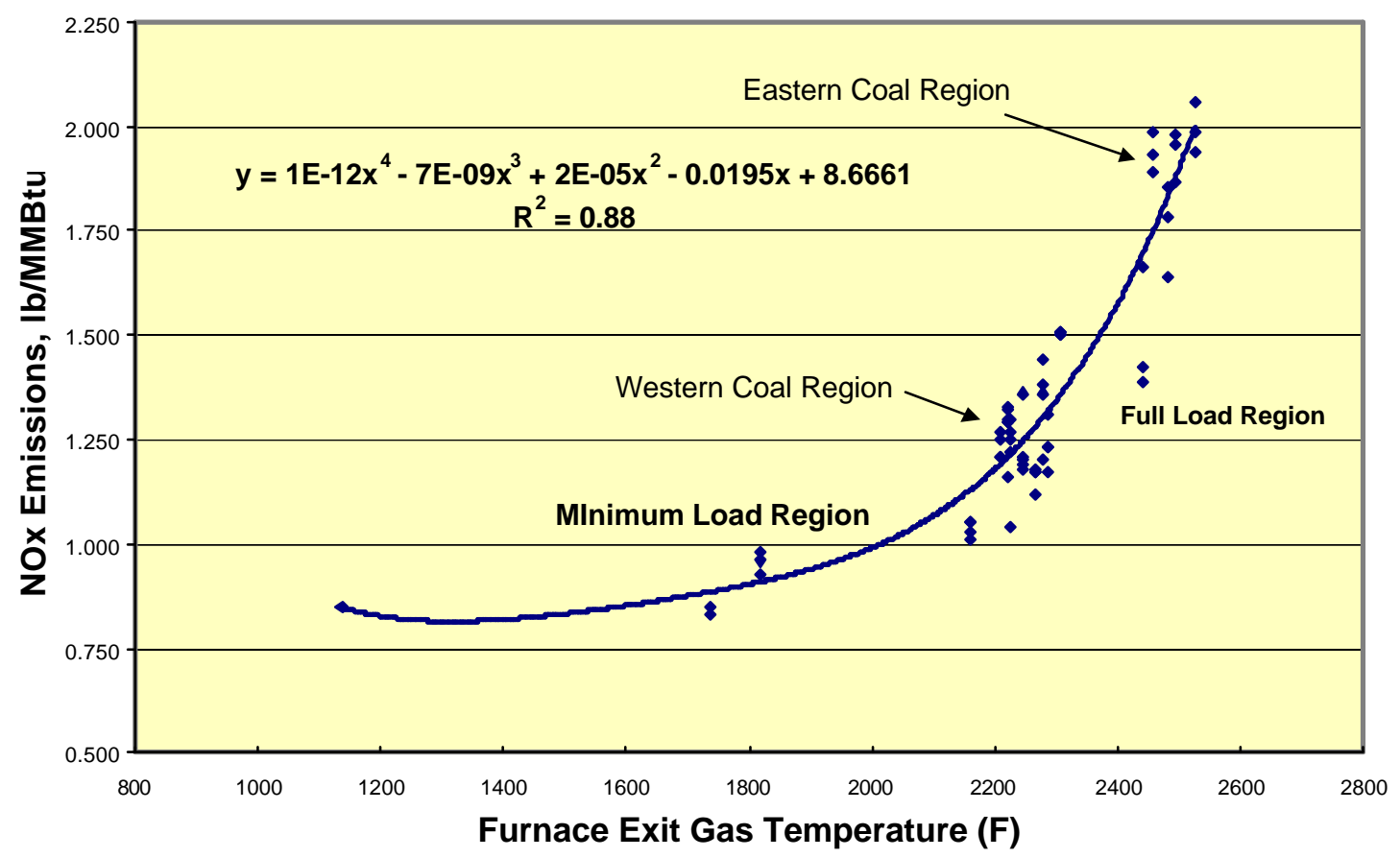

Figure 2-8. $\mathrm{NO}_{\mathrm{x}}$ Emissions at the Allen Fossil Plant as a Function of Furnace Exit Gas Temperature

Firing rate, expressed as $10^{6} \mathrm{Btu} / \mathrm{hr}$ of fuel input, is a second variable of significance. Firing rate clearly influences furnace exit temperature, and the various fuel variables as previously shown. It is, in turn, a function of boiler efficiency and capacity requirement. Because of the many interrelationships between firing rate and fuel selection, overall regression calculations are meaningless. However, there is general 
recognition that increased firing rates cause increased $\mathrm{NO}_{\mathrm{X}}$ emissions in cyclone boilers, and that small changes in firing rates at or near maximum continuous rating (MCR) can cause dramatic increases or decreases in emissions of this pollutant. The firing rate, however, is as much a consequence of fuel selection and boiler efficiency as it is an independent parameter. Similarly, boiler efficiency is a function of fuel composition, excess air usage, air heater exit temperature, and related parameters; it, too, is a consequence of conditions rather than an independent parameter.

Excess air, measured as excess $\mathrm{O}_{2}$ at the outlet of the economizer, is the second firing condition of significance. Higher percentages of excess $\mathrm{O}_{2}$ resulted in higher concentrations of $\mathrm{NO}_{\mathrm{X}}$ since there were increasing oxygen available. The statistical relationship was as follows, as shown in Figure 2-9:

$$
\mathrm{NO}_{\mathrm{x}(\mathrm{lb} / \mathrm{MMBtu})}=183.24\left(\mathrm{O}_{2}\right)-3.325
$$

Where $\mathrm{O}_{2}$ is the excess oxygen measured at the exit of the economizer, and expressed as a decimal. The statistical relationship is sufficiently strong that a coefficient of determination of 0.94 was achieved.

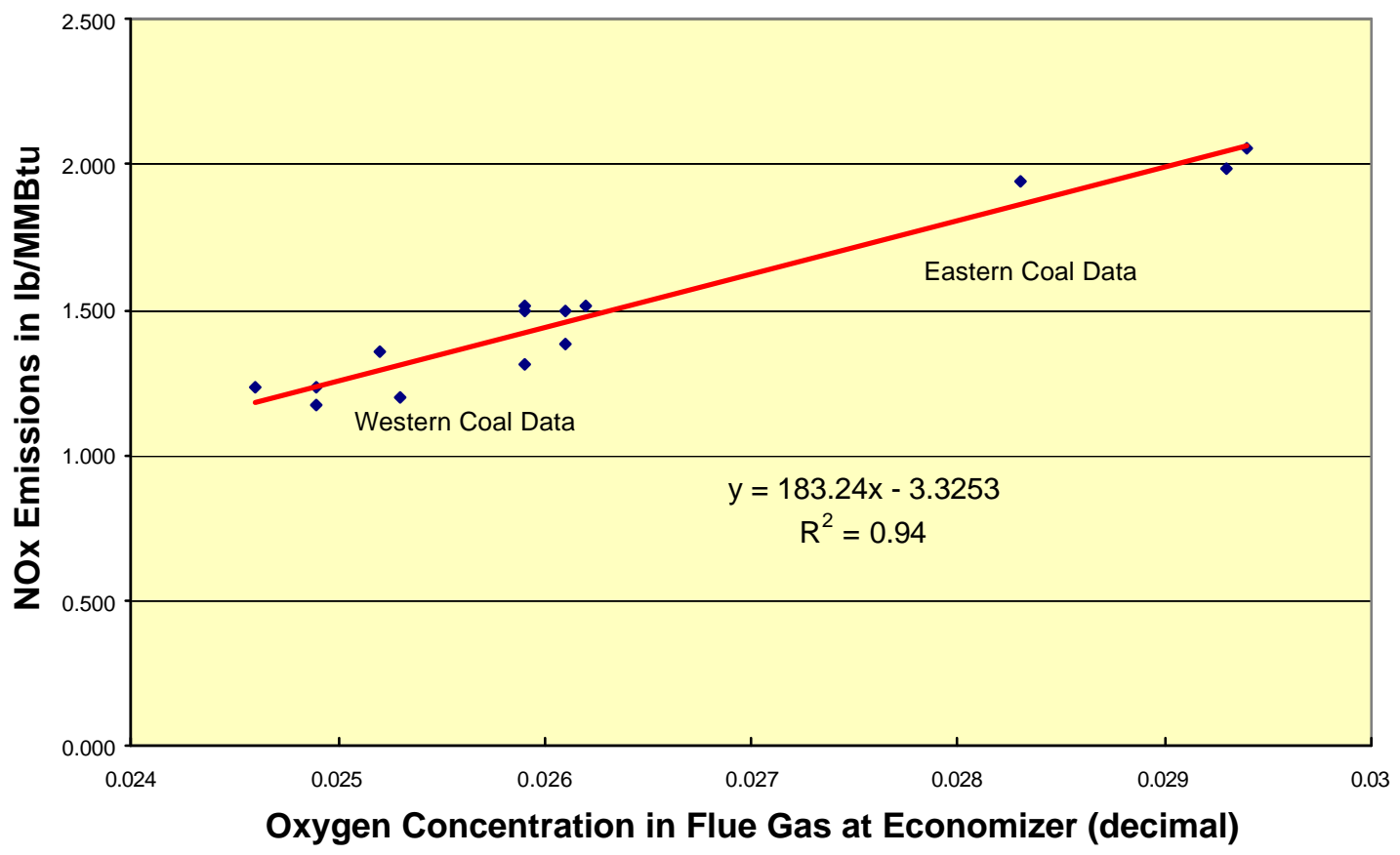

Figure 2-9. $\mathrm{NO}_{\mathrm{x}}$ Emissions as a Function of Excess Oxygen at Allen Fossil Plant

\subsubsection{Combined Influences of Fuel and Firing Conditions on $\mathrm{NO}_{\mathrm{x}}$ Generation at the Allen Fossil Plant Tests}

The combined impacts of coal switching plus alternative fuels with coal were analyzed through the use of multiple linear regression technique. The regression equation developed depicted the various influences, 
as they are interrelated, recognizing that many of the factors, by themselves, exert non-linear influences on $\mathrm{NO}_{\mathrm{X}}$ formation. Note that regression analysis was not used to deal with the influence of particle size.

The most useful regression equation resulting from the Allen Fossil Plant testing, and related to the test conditions experienced, is presented below:

$$
\mathrm{NO}_{\mathrm{x}, \mathrm{lb} / \mathrm{MMBtu}}=5.73\left(\mathrm{O}_{2} \mathrm{E}\right)+1.62\left(\mathrm{O}_{2} \mathrm{~A}\right)+0.0007(\mathrm{FEGT})-1.34(\mathrm{~V} / \mathrm{FC})-7.83
$$

Where $\mathrm{O}_{2} \mathrm{E}$ is the oxygen content of the flue gas at the economizer exit, expressed as a decimal, and $\mathrm{O}_{2} \mathrm{~A}$ is the stoichiometric lb-moles of oxygen required per $10^{6} \mathrm{Btu}$ of fuel input. The coefficient of determination for this equation is relatively high: $r^{2}=0.83$. Essentially, this equation suggests that decreasing the excess air, increasing the oxygenation (hence reactivity) of the fuel, decreasing the furnace exit temperature, and increasing the fuel volatility will, in combination, cause a reduction in $\mathrm{NO}_{\mathrm{X}}$ emissions. The cofiring of biomass with coal does increase the oxygenation of the fuel while it increases the V/FC ratio and decreases the FEGT. Cofiring does not require increasing the excess oxygen associated with firing a cyclone. Consequently it can drive three of the four terms while not negatively impacting the fourth term.

The combined influences of cofiring biomass on $\mathrm{NO}_{\mathrm{x}}$ emissions at the Allen Fossil Plant also can be represented graphically, as shown in Figure 2-10. Note the more pronounced impact when cofiring against Illinois Basin Coal.

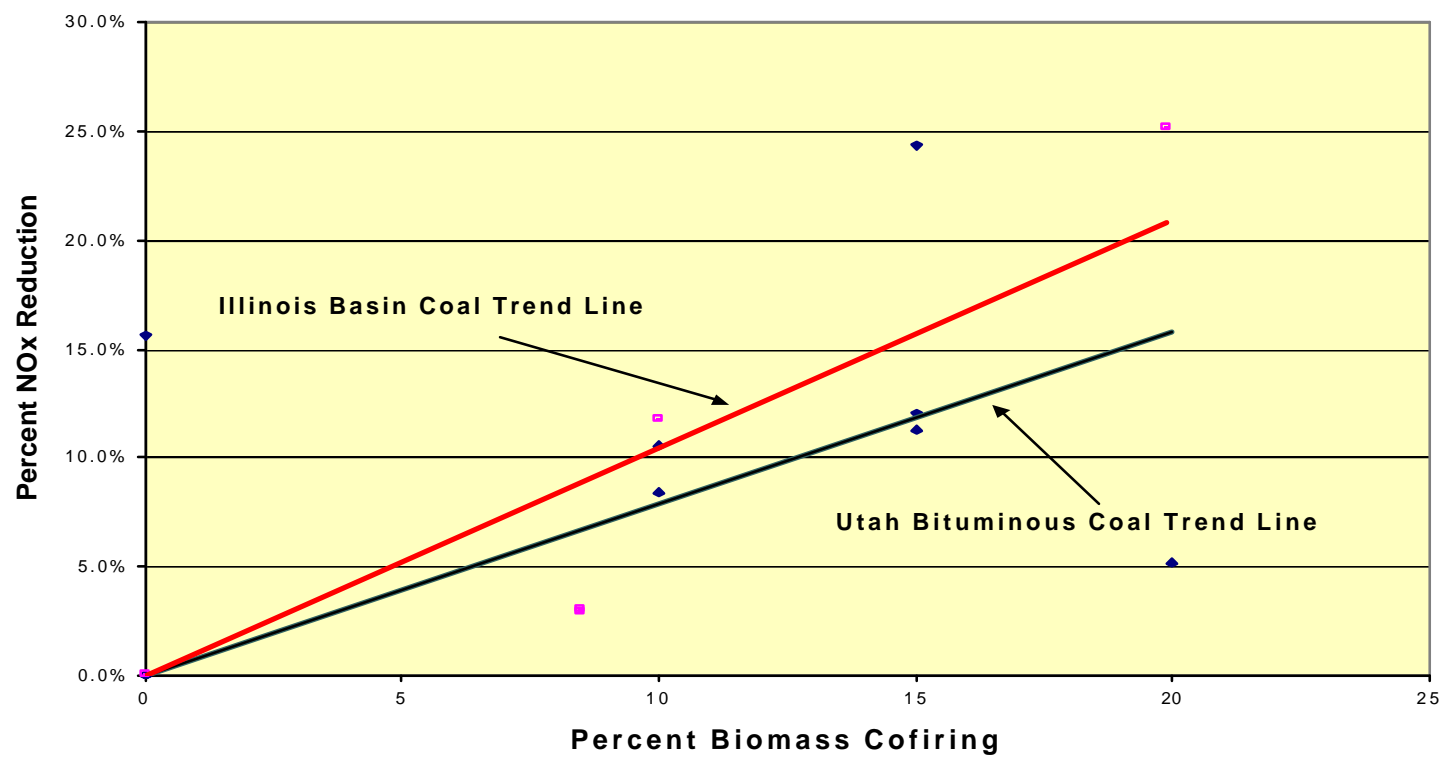

Figure 2-10. Summary Impacts of Cofiring on $\mathrm{NO}_{\mathrm{x}}$ Emissions at the Allen Fossil Plant

The parametric tests at the Allen Fossil Plant suggested that the impact of cofiring biomass fuels provided some potential for reducing the formation of oxides of nitrogen emissions in cyclone boilers. Cofiring biomass can be coupled with changes in firing conditions to minimize the formation of $\mathrm{NO}_{\mathrm{X}}$. 
These benefits were achieved while reducing $\mathrm{SO}_{2}$ emissions, fossil $\mathrm{CO}_{2}$ emissions, and achieving other environmental benefits. Further, they demonstrated that cofiring could be successfully deployed in cyclone boilers under the right economic conditions.

The cofiring tests at the Allen Fossil Plant were significant as a starting point for all cofiring testing. They established a basis for other tests within and outside TVA in both cyclone and PC boilers. Further, the 2-days of tri-firing testing with sawdust and TDF gave impetus to the concept of designing an opportunity fuel blend for cyclone boilers by using biomass in combination with other alternative fuels.

\subsubsection{Cofiring Testing at the Kingston Fossil Plant}

The cofiring testing at the Kingston Fossil Plant of TVA also employed blending wood waste with coal prior to its introduction into the fuel supply system of the boiler. The sawdust was blended with coal on the primary belt feeding the crusher and the bunkers. The blend of fuels then was introduced into the pulverizers on their way to the boiler. In all, nine cofiring tests were conducted.

The Kingston Fossil Plant has nine T-fired boilers. Units \#1 - \#4 are 136 MWe single furnace boilers with four elevations of burners; Units \#5 - \#9 are 200 MWe twin furnace boilers. Coal is received by rail and truck, crushed, and either sent to the bunkers or to reclaim. Either directly received coal or reclaimed coal is bunkered. Upon demand, the coal is discharged from the bunkers into CE Raymond bowl mills and then exhausted into the boiler. The bowl mills are operated under negative pressure.

The results of this program are documented in Foster Wheeler Environmental Corporation (1995b). During this test approximately 600 tons of hardwood sawdust were cofired with coal in Kingston Unit \#5, a twin furnace boiler. The boiler has ample pulverizer capacity, necessary to support this type of testing. Tests were conducted at biomass cofiring levels of 0 to 4.6 percent (mass basis). Tests were conducted under full capacity (e.g., up to192 $\mathrm{MW}_{\mathrm{e}}$ generation) and low load conditions (101 - 103 $\mathrm{MW}_{\mathrm{e}}$ ). The low cofiring percentage was based upon previous one-pulverizer tests suggesting potential problems with Hardgrove Grindability Index and sieve analyses of the pulverized coal.

The low percentages of cofiring resulted in no impact of firing wood waste with coal on boiler capacity and operability. There were inconclusive, and minimal, impacts on boiler efficiency. However these tests documented pulverizer problems when blending wood waste with coal and then pulverizing the blended fuel. These problems include reduction in the Hardgrove Grindability Index (HGI), indicating increasing difficulties with the pulverizer process. The tests also documented problems with the sieve analysis of the fuel from the pulverizers when cofiring was practiced.

Samples of the blended feed to each of the pulverizers were obtained and subjected to HGI testing by TVA laboratories. The results of the average among pulverizers for any given test are shown in Figure 2-11. Note that the HGI was highest when only coal was fed to the pulverizers, and that modest decreases in HGI occurred beyond that point. Wood and sawdust, being fibrous, does not pulverize well in traditional bowl mills or ball-and-race mills. 


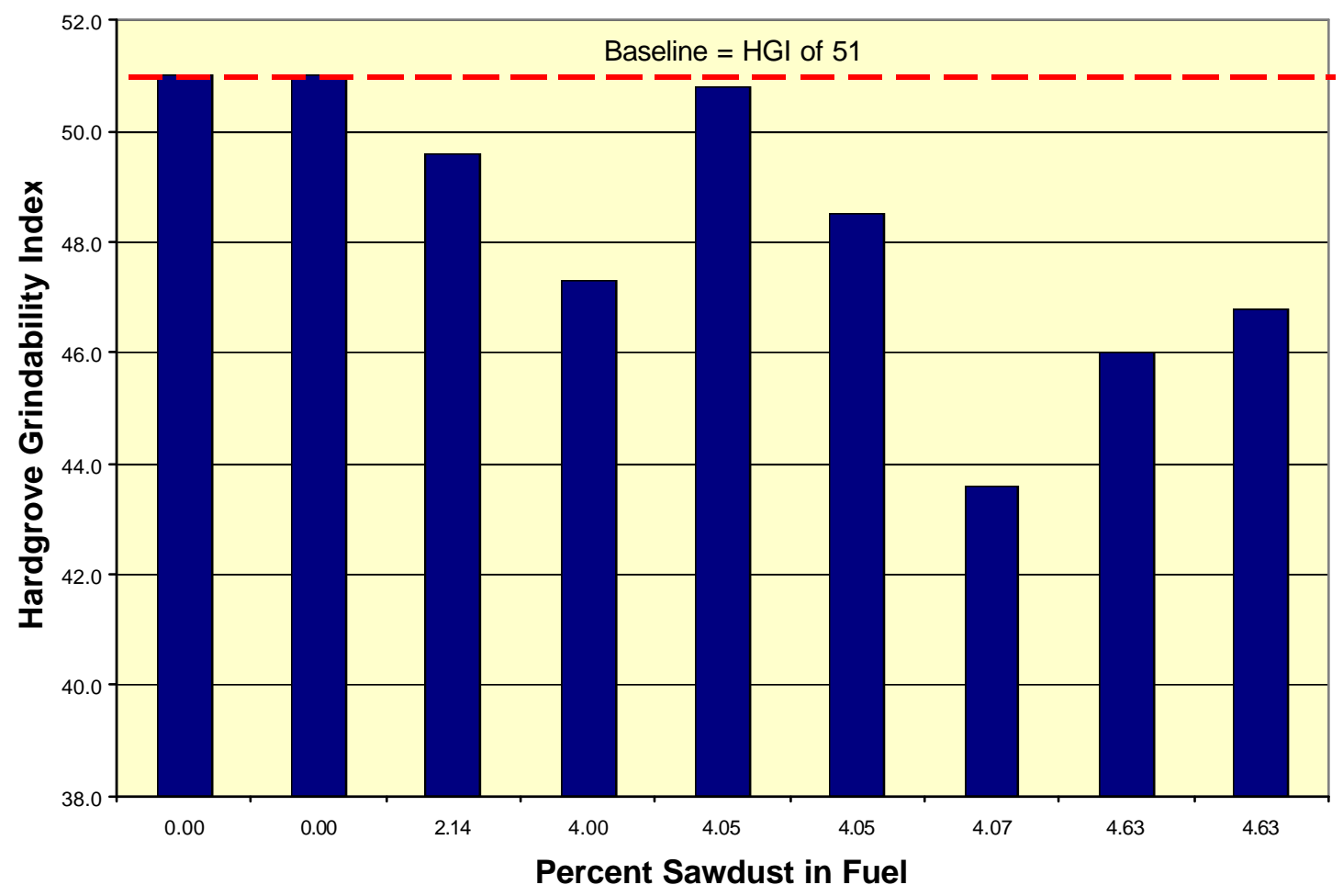

Figure 2-11. Hardgrove Grindability Index for Cofiring Tests at Kingston Fossil Plant

Sieve analyses were performed on samples of the pulverized fuel from three mills-A mill, C mill, and E mill—during each of the tests. The sieve analyses were made measuring the percentage of fuel passing 50 mesh, 100 mesh, and 200 mesh. Figures 2-12 through 2-14 document the results. Note that, with a standard specification of 70 percent of the fuel passing 200 mesh, cofiring caused serious failure on one mill and the start of failure on a second mill before 5 percent mass basis cofiring-equivalent to 2.5 percent cofiring on a heat input basis-was achieved. The loss of pulverizer product quality experienced by TVA was consistent with the experience of Southern Company at Plant Hammond (Boylan, 1993).

Interesting, the degraded grind did not cause a significant increase in the reject rate from the mills. The unburned carbon in the flyash did increase, however. When cofiring at 2 to 4 percent biomass (mass basis), the unburned carbon or loss on ignition (LOI) increased by slightly greater than 2 percent. When cofiring at 4.6 percent at full load, the LOI increased by 4.5 percent. While the sample of tests is sufficiently small that the results are not statistically significant, they indicate the potential for a significant problem when blending biomass with coal for firing in PC boilers. Further, these results are the predictable consequence of the sieve analyses measured.

The Kingston tests, then, demonstrated that low percentage cofiring could be performed by blending the sawdust with coal prior to pulverizing the fuel; however this approach is limited and could cause 
problems with the mills as cofiring approaches 5 percent (mass basis). The mill problems can cause degradation of other performance measures.

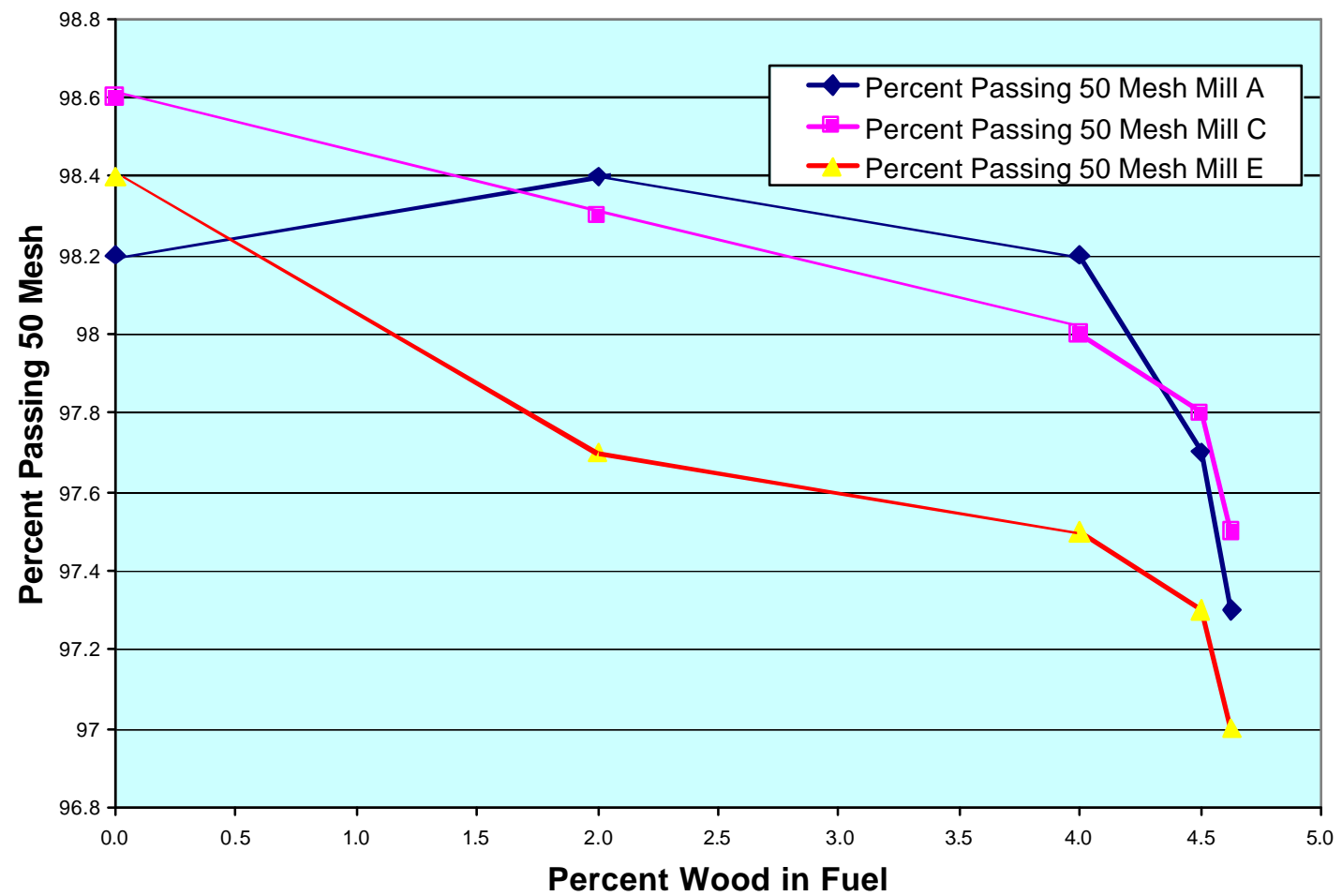

Figure 2-12. Percent Fuel Passing 50 Mesh at Kingston Fossil Plant as a Function of Cofiring Level 


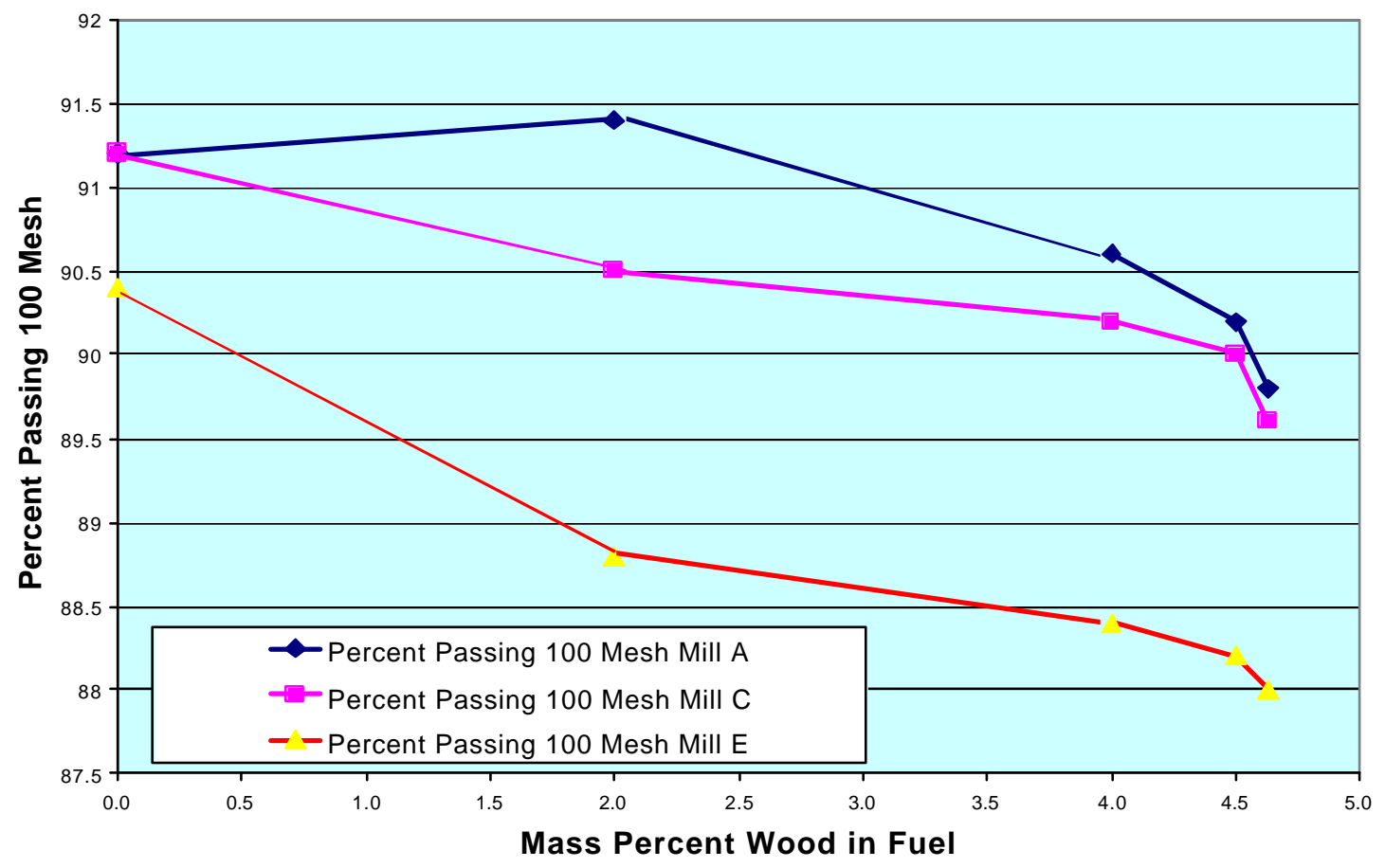

Figure 2-13. Percent Fuel Passing 100 Mesh at Kingston Fossil Plant as a Function of Cofiring Level. 


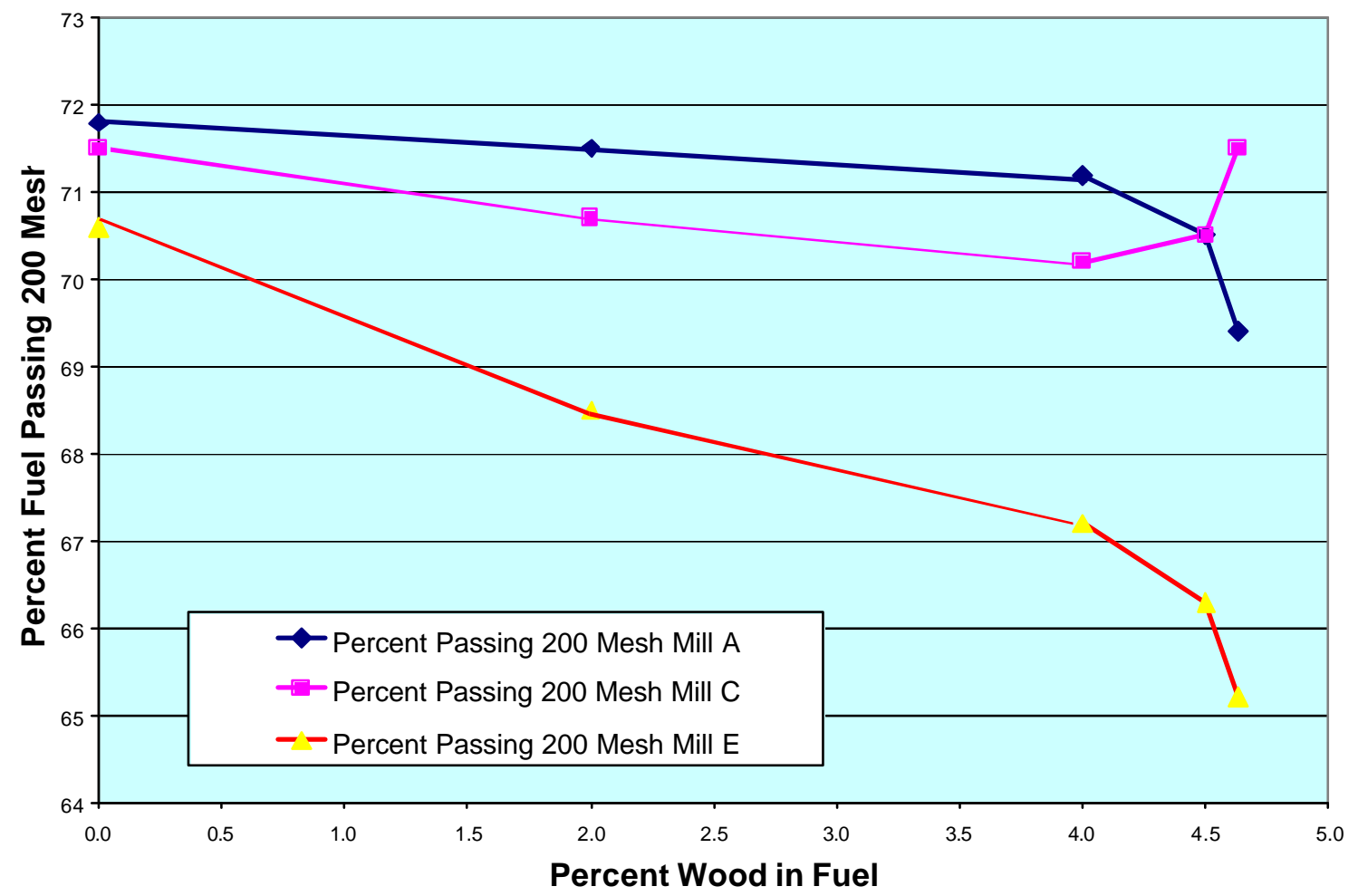

Figure 2-14. Percent Fuel Passing 200 Mesh at Kingston Fossil Plant as a Function of Cofiring Level.

\subsubsection{Conclusions Regarding the EPRI-TVA Program}

The EPRI-TVA program, then, was a significant pioneering effort in cofiring. It elucidated many of the opportunities, issues, and constraints impacting cofiring of biomass with coal. While it focused only on the woody biofuels - and only on residues - it highlighted opportunities for emissions reductions and plant operations. At the same time it began to identify some of the problems with cofiring in PC boilers by feeding a blend of fuels to the pulverizers.

The EPRI-TVA program also permitted the integration of science with engineering in evaluating selfheating and spontaneous combustion. It highlighted the benefits of certain analytical techniques including extensive computational fluid dynamics modeling (CFD) of boilers (see Tillman, Rollins, Reardon, and Hughes, 1997) and made extensive use of in-furnace video camera analysis. These techniques provided significant insights into the impacts of cofiring, and benefited subsequent test programs funded under the USDOE-EPRI Cooperative Agreement.

\subsection{COFIRING RESEARCH AT GPU GENCO}

Prior to the initiation of the Cooperative Agreement between USDOE-FETC and EPRI-which became the USDOE-EPRI Cooperative Agreement administered by NETL—GPU Genco initiated a cofiring research program complementing the efforts of TVA. The motivation for this program was an evaluation of cofiring to address voluntary $\mathrm{CO}_{2}$ reduction targets in a cost-effective manner. Secondary 
benefits of customer service also were considered as motivating factors in the development of the GPU cofiring program.

\subsubsection{Initial Research Efforts}

The initial research at GPU was an assessment of the cofiring potential at its three smaller western generating stations: Seward, Shawville, and Warren. Plants were evaluated with respect to the following parameters:

- Fuel availability within a radius of 50 miles

- Plant layout

- Ability to integrate cofiring into the overall operations

Both the Seward and Shawville generating stations showed significant potential for cofiring. Further the economics of cofiring were not considered prohibitive when initial engineering and associated cost estimates were made. The resource base around Shawville was considered to be somewhat stronger, initially, resulting in the design of a test program for that facility.

\subsubsection{The Shawville Generating Station Test Program}

The Shawville Generating Station test program has been well documented in the literature (Prinzing, Hunt, and Battista, 1996; Prinzing and Hunt, 1996; Battista, Tillman, Prinzing, and Hunt, 1996). In this program, 3 percent (mass basis) sawdust, right-of-way (ROW) trimmings, and ground hybrid poplar was blended with coal for firing in Shawville Units \#2 and \#3.

The Shawville Generating Station is comprised of four units and has a total generating capacity of 623 megawatts electric $\left(\mathrm{MW}_{\mathrm{e}}\right)$. This station has certain distinctive features, however, impacting cofiring potential:

- it has a small coal yard, with tight fuel management requirements and significant physical constraints

- it has low- $\mathrm{NO}_{\mathrm{x}}$ burners on all boilers

- it uses coal from both surface and underground mines, and the surface mines are typically reclaimed by planting trees; this facilitates the concept of coal industry/biofuel industry alliances

- it is operated at the limit of physical capacity, in this case set by pulverizer capacity; as such it is operated at production levels well in excess of the nominal design capacity originally reported for the individual boilers of the plant

Shawville Unit 2 is a $130 \mathrm{MW}_{\mathrm{e}}$ (net) Babcock and Wilcox (B\&W) front wall-fired pulverized coal boiler that typically generates $900,000 \mathrm{lb} / \mathrm{hr}$ of $1850 \mathrm{psig} / 1020^{\circ} \mathrm{F}$ steam at full load. It also typically 
generates $390 \mathrm{psig} / 950^{\circ} \mathrm{F}$ reheated steam. The unit is equipped with four rows of four low- $\mathrm{NO}_{\mathrm{x}}$ burners situated on the front wall of the boiler. There are four B\&W Ball and Race mills, each supplying pulverized coal to four burners. There is essentially no spare capacity in the mills. If one mill is out of service, boiler capacity declines from 130 to $103 \mathrm{MW}_{\mathrm{e}}$. Shawville Unit 3 is a $180 \mathrm{MW}_{\mathrm{e}}$ (net) Combustion Engineering (CE) tangentially-fired, twin-furnace pulverized coal boiler that typically generates $1,200,000 \mathrm{lb} / \mathrm{hr}$ of $2450 \mathrm{psig} / 1020^{\circ} \mathrm{F}$ steam at full load. It also typically generates 475 $\mathrm{psig} / 980^{\circ} \mathrm{F}$ reheated steam. The unit is equipped with four rows of eight low- $\mathrm{NO}_{\mathrm{x}}$ burners situated at the corners of the twin furnaces. There are four CE Raymond Bowl mills, each supplying pulverized coal to eight burners. There is essentially no spare capacity in the mills. If one mill is out of service, the boiler capacity declines from 180 to $135 \mathrm{MW}_{\mathrm{e}}$. If two mills are out of service, oil is used to maintain capacity in the unit (Prinzing and Hunt, 1996).

The test program was designed to test the following issues:

- The economics of off-site blending of coal and woody biofuels rather than incorporating blending into plant operations

- The impacts of ground right-of-way trimmings, and ground hybrid poplar grown on reclaimed coal strip mines as biomass feedstocks

- Potential impacts on the pulverizer circuit and consequences for the operation of the power plant

- Impacts—if any—on low NOx burners installed in Shawville Generating Station

The tests were conducted in 1995 with primary funding from GPU Genco, supported by EPRI and by USDOE-FETC. Wood was procured from three different sources, ground and screened at an off-site location. It was brought from this location to the Tanoma Coal Tipple, and blended with coal to make up the fuel supply to Shawville Generating Station.

Biofuels were processed prior to blending with coal by grinding (if necessary) in a tub grinder and screening with a combination auger screen/trommel screen to ensure a particle size of less than $1 / 4$ inch. The processed sawdust had a bulk density of $19 \mathrm{lbs} / \mathrm{ft}^{3}$ and the processed ROW material had a bulk density of $20 \mathrm{lbs} / \mathrm{ft}^{3}$. The processed short rotation woody crop (SRWC) hybrid poplar had a bulk density of $12 \mathrm{lbs} / \mathrm{ft}^{3}$, indicative of a rapid growth species. The coal had a bulk density of approximately $50 \mathrm{lbs} / \mathrm{ft}^{3}$. Chemical compositions of the fuels are shown in Table 2-6. 
Table 2-6. Characteristics of Individual Fuels Burned During the Shawville Tests

\begin{tabular}{|c|c|c|c|c|}
\hline Parameter & Coal & Sawdust & ROW & SRWC \\
\hline \multicolumn{5}{|c|}{ Proximate Analysis (Weight Percent) } \\
\hline Moisture & $7.5 \%$ & $38.6 \%$ & $42.3 \%$ & $45.4 \%$ \\
\hline Ash & $13.0 \%$ & $0.4 \%$ & $14.5 \%$ & $5.4 \%$ \\
\hline Volatile Matter & $22.7 \%$ & $52.5 \%$ & $35.7 \%$ & $41.4 \%$ \\
\hline Fixed Carbon & $56.8 \%$ & $8.5 \%$ & $7.5 \%$ & $7.9 \%$ \\
\hline \multicolumn{5}{|c|}{ Ultimate Analysis (Weight Percent) } \\
\hline Carbon & $69.4 \%$ & $31.0 \%$ & $22.5 \%$ & $25.5 \%$ \\
\hline Hydrogen & $4.0 \%$ & $3.6 \%$ & $2.6 \%$ & $3.0 \%$ \\
\hline Oxygen & $2.5 \%$ & $26.4 \%$ & $17.8 \%$ & $20.6 \%$ \\
\hline Nitrogen & $1.2 \%$ & $0.0 \%$ & $0.3 \%$ & $0.1 \%$ \\
\hline Sulfur & $2.1 \%$ & $0.0 \%$ & $0.0 \%$ & $0.1 \%$ \\
\hline Chlorine & $0.1 \%$ & $0.0 \%$ & $0.0 \%$ & $0.0 \%$ \\
\hline Ash & $13.0 \%$ & $0.4 \%$ & $14.5 \%$ & $5.4 \%$ \\
\hline Moisture & $7.5 \%$ & $38.6 \%$ & $42.3 \%$ & $45.4 \%$ \\
\hline \multicolumn{5}{|c|}{ Higher Heating Value (Btu/lb): } \\
\hline $\mathrm{HHV}$ & 12,035 & 5,046 & 3,659 & 4,172 \\
\hline
\end{tabular}

The test program evaluated the impact of cofiring on pulverizer performance; and on boiler capacity, efficiency, operability, and airborne emissions. These results have been developed for both Unit \#2 and Unit \#3. Institutional results included the following:

There was significant evidence that the coal and biofuel industries could team in the arena of fuel supply, producing a blended feedstock; this process, involving blending the wood with the coal, was analogous to blending of different coals to meet a specific specification, however this would provide for a more expensive biomass supply due to the multiple handling operations the "just-in-time" delivery system required by the tight fuel yard impacted the test through more complex and intricate logistics, and this created test limitations; it had significant impacts on the operation of the coal yard as well as the biomass delivery system.

The main impact of cofiring occurred in the pulverizers, both with respect to Unit \#2 and Unit \#3. Mill fineness was largely not impacted by cofiring at 3 percent by mass biofuel/97 percent coal. Despite difficulties in grinding wood waste, about 80 percent of the pulverized blended fuel always passed 200 mesh, and there was little difference between the coal alone and the wood/coal mixtures.

Mill Amps were impacted both by load and by fuel blend. Three regression equations define these impacts for Unit \#2:

$$
\mathrm{TMA}, \# 2_{\text {coal }}=0.0194 \mathrm{FR}+105.6
$$


TMA, \# $2_{\text {coal }}$ ROw $=0.0143 \mathrm{FR}+117.6$

TMA, $\# 2_{\text {coal } \& \text { sawdust }}=0.206 \mathrm{FR}+110.7$

Where TMA is total mill amps for four mills, and FR is unit firing rate in $10^{6} \mathrm{Btu} / \mathrm{hr}$. Similar regressions exist for Unit \#3, as shown below:

$\mathrm{TMA}, \# 3_{\text {coal }}=0.0524 \mathrm{FR}+76.3$

TMA, $\# 3_{\text {coal\&sawdust }}=0.0482 \mathrm{FR}+83.6$

TMA,\#3 coal,ROW,sawdust,poplar $=0.061 \mathrm{FR}+67.1$

In all cases the coefficient of determination $\left(r^{2}\right)$ exceeds 0.92 and in most cases the $r^{2}$ exceeds 0.98 . The impact of cofiring on mill amps for Unit \#2, as an example, is shown in Figure 2-15

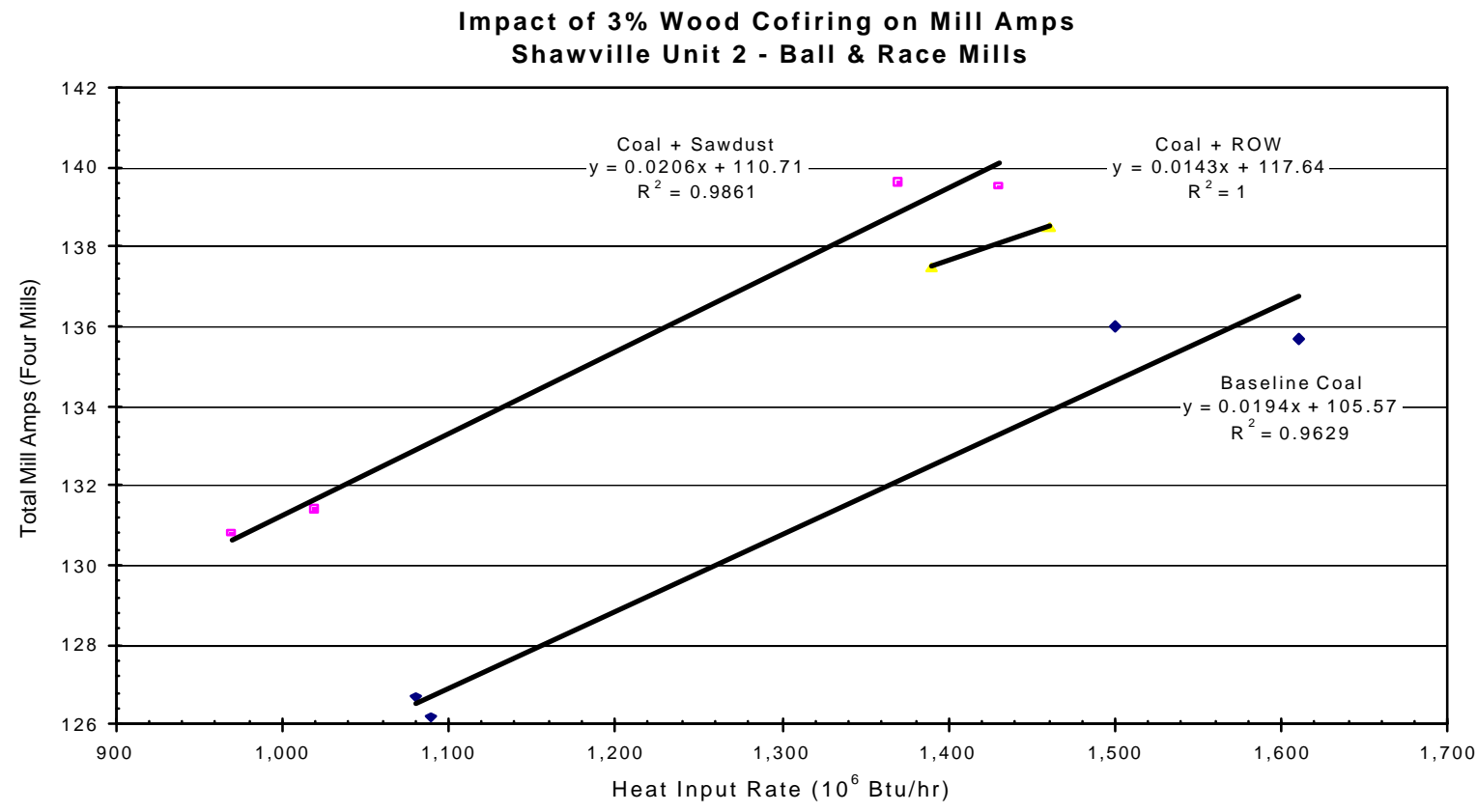

Figure 2-15. Impact of Cofiring on Mill Amps at Shawville Unit \#2 During Cofiring

For Unit \#2, the more significant impact of the cofiring process was to impact mill feeder capacity, as is shown in Table 2-7. Note that mill feeder capacity, reflected in feeder speeds, in turn impacted steam flow and gross unit load. The biofuel, in effect, made the blended fuel behave like very wet coal and reduced overall boiler capacity as a function of mill feeder performance and feeder capacity. 
Table 2-7. Unit 2 Average Feeder Speeds and Boiler Capacities Achieved at the Shawville Test

\begin{tabular}{|l|c|c|c|c|c|}
\hline Fuel Blend & $\begin{array}{c}\text { Test } \\
\text { Number }\end{array}$ & $\begin{array}{c}\text { Gross Load } \\
(\mathrm{MW})\end{array}$ & $\begin{array}{c}\text { Steam Flow } \\
(\mathrm{kpph})\end{array}$ & $\begin{array}{c}\text { Heat Input } \\
\left(10^{6} \mathrm{Btu} / \mathrm{hr}\right)\end{array}$ & $\begin{array}{c}\text { Feeder Speed } \\
(\%)\end{array}$ \\
\hline \multicolumn{2}{|l|}{ Full Load Tests: } & & & & \\
\hline Baseline Coal (100\%) & 1 & 132.6 & 895.7 & 1,500 & 72.0 \\
\hline Baseline Coal (100\%) & 2 & 133.1 & 899.9 & 1,610 & 78.6 \\
\hline Coal + 3\% Sawdust & 5 & 129.0 & 877.3 & 1,430 & 88.3 \\
\hline Coal + 3\% Sawdust & 6 & 128.8 & 880.6 & 1,370 & 93.9 \\
\hline Coal + 3\% Right-of-Way & 9 & 130.0 & 874.1 & 1,460 & 101.6 \\
\hline Coal + 3\% Right-of-Way & 10 & 128.7 & 858.0 & 1,390 & 105.1 \\
\hline
\end{tabular}

The maximum capacity against which the final two tests should be compared is 138 MWe for Unit \#2. Cofiring with the biofuel, then, reduced unit capacity by about $9 \mathrm{MW}_{\mathrm{e}}$, or about 6 percent. This is depicted in Figure 2-16.

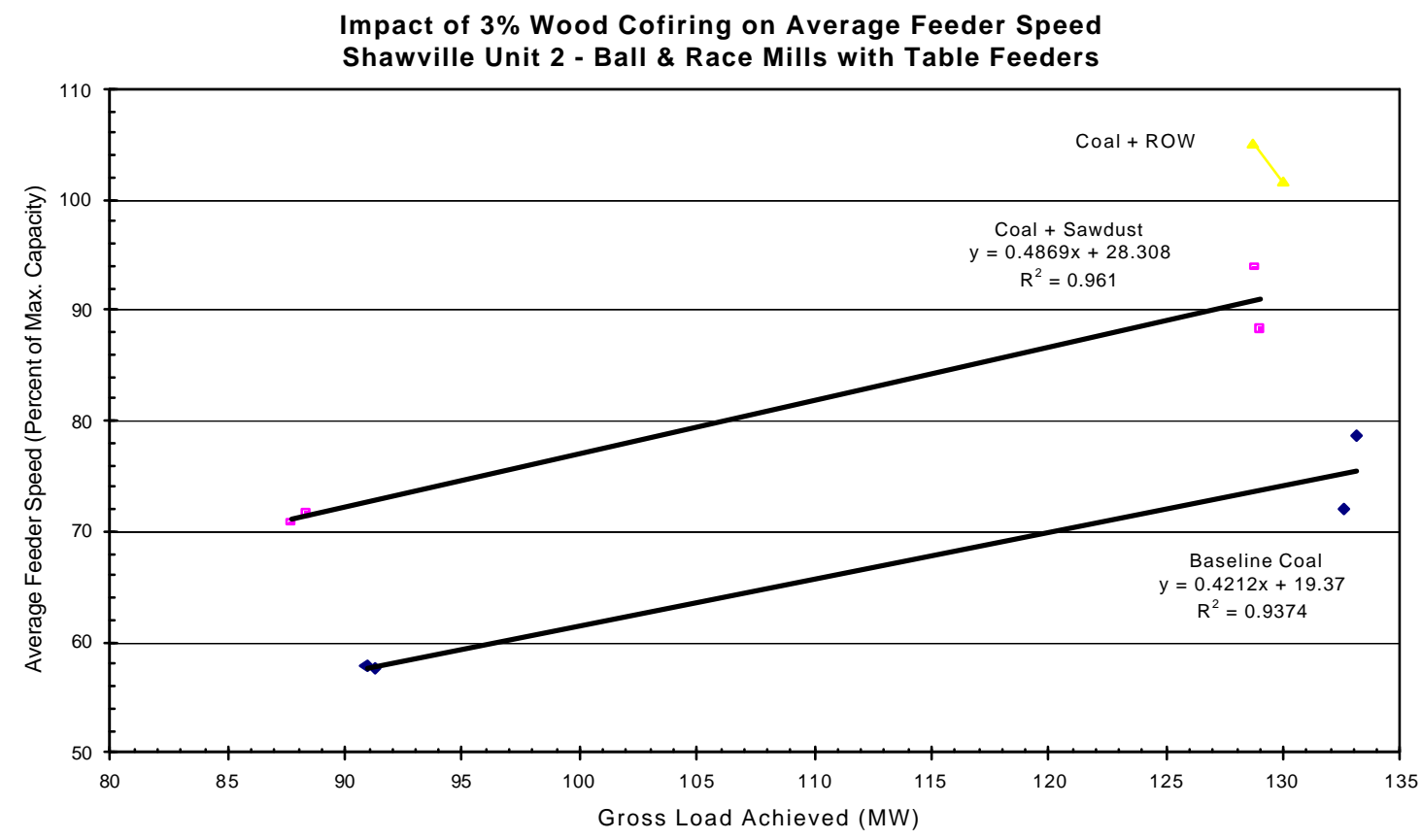

Figure 2-16. Impact of Cofiring on Ball-and-Race Mill Feeder Speeds at Shawville Generating Station Unit \#2

A similar capacity limitation occurred with the mills when firing Unit \#3, although the phenomenon causing the limitation was a reduction in mill outlet temperature rather than maximizing feeder speed. This outcome is shown in Figure 2-17 and Table 2-8. The desired mill outlet temperature for Unit \#3 is $154^{\circ} \mathrm{F}$. At this temperature, the mill accomplishes the requisite fuel drying, while maintaining negative pressure in the pulverizer. Losses in temperature impact the pressure in the pulverizer, and cause the fuel carrier gas (air) to approach dew point. When the carrier gas is below dew point, feeders plug and the unit shuts down. 


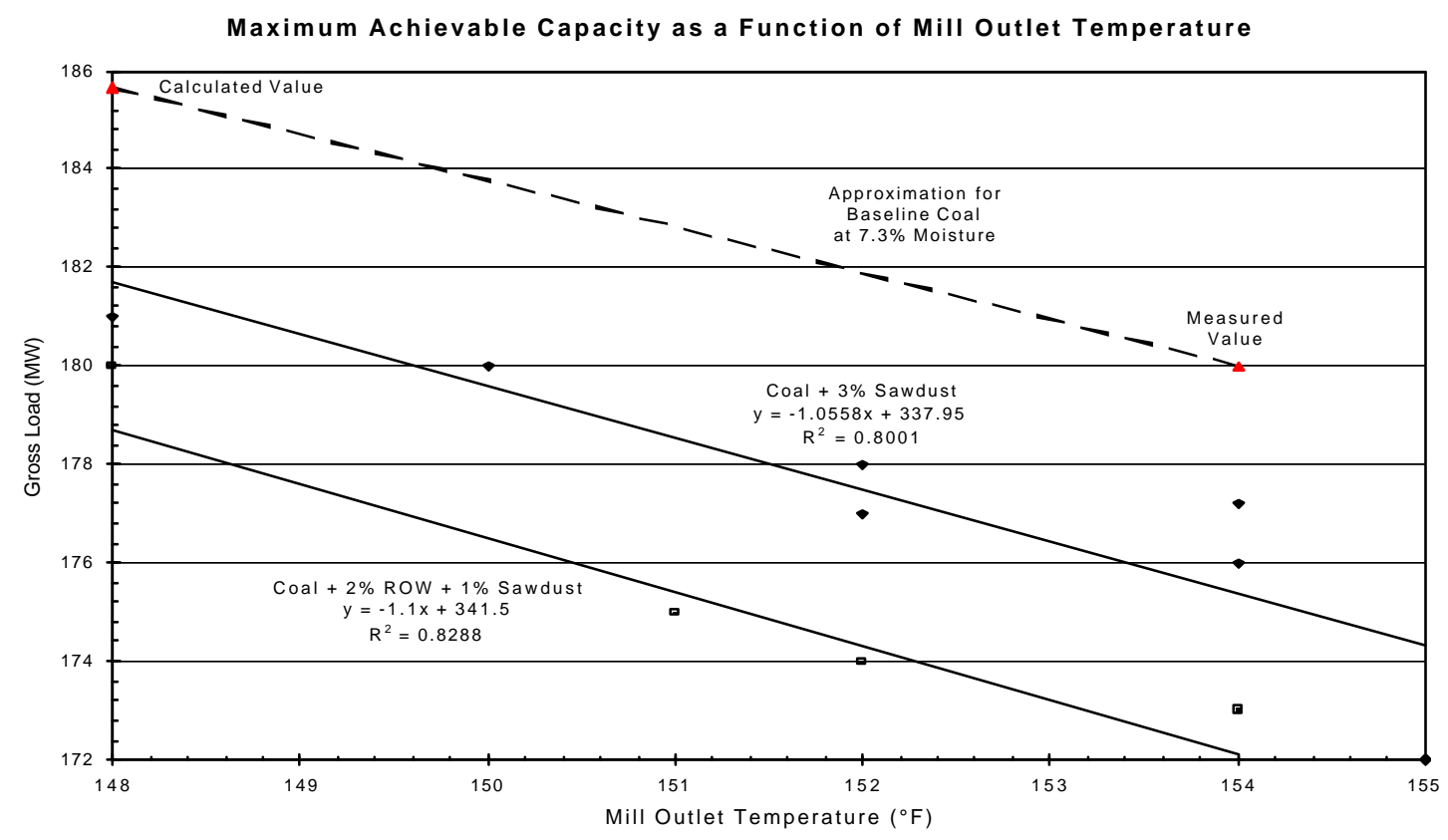

Figure 2-16. Impact of Cofiring on Mill Outlet Temperatures and Capacities at Shawville Unit \#3

Table 2-8. Unit 3 Mill Outlet Temperatures at the Shawville Cofiring Test.

\begin{tabular}{|l|c|c|c|}
\hline Fuel Blend & Gross Load (MW) & $\begin{array}{c}\text { Fuel Moisture } \\
(\%)\end{array}$ & Mill Outlet Temp. $\left({ }^{\circ} \mathrm{F}\right)$ \\
\hline Baseline Coal $(100 \%)$ & 180.0 & 7.3 & 154 \\
\hline Coal + 3\% Sawdust & 177.2 & 8.0 & 154 \\
\hline Coal + 2\% ROW + 1\% Sawdust & 175.0 & 9.1 & 151 \\
\hline
\end{tabular}

Note that the blended fuel with ROW material in it caused about a $5 \mathrm{MW}_{\mathrm{e}}$ loss in capacity, or a $3 \%$ loss in capacity. This reduction is proportional to the percentage biofuel in the fuel blend. The reduction in capacity caused by sawdust, $3 \mathrm{MW}_{\mathrm{e}}$ or 1.6 percent of capacity, is less severe. Alternatively, the capacity function can be expressed as two regression equations:

$$
\begin{aligned}
\mathrm{GC}_{\mathrm{MW}} & =1.056 \mathrm{MOT}_{\mathrm{F}}+338.0 \\
\mathrm{GC}_{\mathrm{MW}} & =1.1 \mathrm{MOT}_{\mathrm{F}}+341.5
\end{aligned}
$$

Where GC is gross capacity of the unit expressed in $\mathrm{MW}_{\mathrm{e}}$ and MOT is mill outlet temperature expressed in ${ }^{\circ} \mathrm{F}$. Equation 9 relates to the coal/sawdust blend while equation 10 relates to the coal/sawdust-ROW-poplar blend. Through these equations, one can observe that maintaining $154^{\circ} \mathrm{F}$ mill outlet temperature reduces unit capacity by $3 \mathrm{MW}_{\mathrm{e}}$, or 1.6 percent, when cofiring with 3 percent sawdust; and maintaining $154^{\circ} \mathrm{F}$ mill outlet temperature while cofiring a 3 percent blend including ROW and hybrid poplar causes an $8 \mathrm{MW}_{\mathrm{e}}$ reduction in capacity or a 4.4 percent reduction in unit capacity. 
The Shawville tests also demonstrated that there could be modest impacts on sieve analysis. However the cofiring percentage - 3 percent by mass - was sufficiently low that these impacts were limited.

Boiler performance of the Unit \#2 and Unit \#3 boilers was largely unaffected by the cofiring of a biofuel/coal blend. Boiler efficiencies were calculated within 0.1 percent of the baseline cases, and this is well within the error of estimate. Furnace exit gas temperatures did not decrease significantly. The reduction in $\mathrm{SO}_{2}$ emissions was proportional to the change in fuel, however the 3 percent biofuel/97 percent coal blend was sufficiently close to the baseline that measurement was within the statistical accuracy of the instruments. $\mathrm{NO}_{\mathrm{x}}$ emissions were largely not impacted by firing the blend, although there was one test where indications were that the biofuel supported early ignition of the coal, increasing the oxides of nitrogen concentration in the flue gas slightly. $\mathrm{CO}$ emissions did not change with the cofiring testing.

The conclusion of the Shawville test, then, was to provide the final evidence that the most appropriate method for cofiring woody biofuels in PC boilers is to employ separate injection of the biomass into the boiler. The practice of blending the biomass with the coal prior to introducing it into the pulverizers has significant consequences for mill amps and boiler capacity. Further, these tests demonstrated the high costs associated with off-site blending of the biomass and coal, when double handling is involved.

\subsection{OTHER ELEMENTS OF THE INITIAL EPRI COFIRING PROGRAM}

The test programs formed the major elements of the EPRI cofiring program, however other research was pursued simultaneously. Further, the EPRI cofiring effort coordinated its analyses with other independent cofiring research.

Under contract to EPRI, Foster Wheeler Environmental evaluated slagging combustion as a means for achieving high percentage ( $>25$ percent, Btu basis) cofiring, and as a means for using biofuels with a high slagging potential. Such fuels include switchgrass and the fertilized energy crops. Miles et. al. (1993) identify biomass materials with high slagging potential as having an alkali content $>0.8 \mathrm{lb} / 10^{6}$ Btu and biomass materials with probable slagging potential as having an alkali content $>0.4 \mathrm{lb} / 10^{6} \mathrm{Btu}$. Among those with the highest slagging potential as identified by Miles et. al. (1993) are almond shells, refuse derived fuel, switchgrass, wheat straw, and rice straw. Whole tree hybrid poplar chips, urban wood waste, and tree trimmings are among those biomass energy sources identified as having probable slagging problems. The problem is the focal point of research by Baxter (1996a, 1996b) collaborating with Miles and others in analyzing slagging and fouling from biomass combustion.

The concept behind the slagging combustion investigation was to capitalize upon the slagging tendencies of such fuels, using either Babcock \& Wilcox cyclones modified to manage a high percentage of biomass in the feed or using one of the more recently proposed slagging combustion technologies. Investigations were made into the use of Coal Tech technology, slagging technology owned by TransAlta of Canada, TRW, and other technology developers. 
The technology was proposed in combination with biomass-based reburning for NOx control. It was proposed both fr repowering existing generating stations and for construction of new stand-alone generating stations. Unfortunately the analyses led to the conclusion that slagging combustion of biomass is not economically feasible at this time.

Additional research included developing the initial screening models for evaluating cofiring at existing power plants. These models were based upon the engineering studies and tests performed from $1992-$ 1995. They provided screening tools, however the unique features of each candidate power plant led to the conclusion that such screening tools would not be profitable to pursue. As part of the screening modeling effort, however, Foster Wheeler began the development of a biomass fuels database. This database was completed under the USDOE-EPRI Cooperative Agreement (Prinzing, 1996).

The initial EPRI Cofiring program also involved discussions with a wide range of utilities to summarize their experiences in cofiring, and to pursue potential opportunities in this area. Utilities that were involved in this phase of the program included Northern States Power, Minnesota Power, Central Louisiana Electric Co., Arkansas Power \& Light, Union Electric, Delmarva, East Kentucky Electric Cooperative, Northeast Utilities, and Colorado Public Service. EPRI coordinated its efforts with Southern Company in the cofiring testing at Plant Kraft. EPRI also coordinated its efforts with the initial design studies and programs of New York State Electric and Gas (NYSEG) at Greenidge Generating Station. EPRI also maintained involvement with researchers evaluating and developing biomass feedstocks at Oak Ridge National Laboratory and State University of New York at Syracuse.

\subsection{CONCLUSIONS CONCERNING THE INITIAL EPRI PROGRAM}

The EPRI program in cofiring developed prior to the cooperative agreement with USDOE, but with the support of USDOE, achieved numerous objectives:

- It developed necessary engineering concepts to design and construct either test or permanent cofiring facilities at cyclone and pulverized coal boilers.

- It developed sufficient background data on fuel properties, fuel transport and storage issues, and on spontaneous combustion-safety issues to provide a basis for promoting testing of cofiring.

- It sponsored or participated in many of the initial test programs of cofiring, and documented the benefits and limitations of various cofiring approaches; this included documenting problems associated with blending biomass and coal for transport into PC boilers through pulverizers, which showed that this technology has limited potential.

- It developed research programs investigating additional approaches to cofiring including gasification-based cofiring, slagging combustion-based cofiring, and related approaches.

- It initiated the development of screening modeling tools that ultimately led to the development of a biomass fuels database. 
EPRI, through this aggressive program, developed numerous active utility partnerships with such organizations as TVA, GPU Genco, Northern States Power, Southern Company, Northern Indiana Public Service Company (NIPSCO), and other strong utilities investigating cofiring as a means for costeffective greenhouse gas emissions reduction, $\mathrm{SO}_{2}$ reduction, and other emissions management. The research results, and the utility partnerships, provided a strong base for commercializing the biomass cofiring technology. 


\subsection{COOPERATIVE AGREEMENT DEVELOPMENT OF COFIRING IN WALL FIRED PULVERIZED COAL BOILERS}

\subsection{OVERVIEW}

With the initiation of the cooperative agreement between the Federal Energy Technology Center (FETC)—now the National Energy Technology Center (NETL) — and EPRI, a cooperative agreement joined by the Office of Energy Efficiency and Renewable Energy (EE-RE) of USDOE, cofiring commercialization proceeded. EE-RE would become a major partner in this cooperative agreement, providing the necessary funds for cofiring commercialization. Because wall fired PC boilers are more common than any other type of coal-fired boiler, they became a focus for cooperative agreement activity. Test and demonstration activities occurred at the following locations:

- Colbert Fossil Plant, TVA

- Seward Generating Station, GPU Genco

- Blount St. Station, Madison Gas \& Electric

These three test and demonstration sites completed commercialization of low percentage cofiring (e.g., $<5$ percent biomass, mass basis) of woody biomass by blending sawdust and coal in the coal yard, demonstrating the benefits of $10-20$ percent cofiring of woody biomass on emissions management, and demonstrating the cofiring of switchgrass as a biofuel in PC boilers. EPRI and the cooperative agreement played a dominant role in the Colbert and Seward demonstrations, and played a supporting role in the Blount St. Station switchgrass demonstration.

\subsection{THE COLBERT FOSSIL PLANT COFIRING INSTALLATION}

The commercialization of low percentage cofiring at the Colbert Fossil Plant has been documented in several publications (see, for example, Tillman, Stahl, and Therkelsen, 1997; Rollins, Reardon, and Tillman, 1998). This represented the final step in blending wood waste with coal on the coal pile-using this approach in a boiler where sufficient excess pulverizer capacity exists and where cofiring percentages are held sufficiently low to avoid causing problems with the sieve analysis.

The Colbert Fossil Plant (see Figure 3-1), located near Muscle Shoals, AL, is located near one of the Tennessee Valley's larger sources of wood waste from the furniture industry. This is both green hardwood sawdust from primary sawmills and dry wood waste from the furniture manufacturers. Key to this cofiring installation was adequate integration of the cofiring system into the coal yard. This plant has five boilers; four are $192 \mathrm{MW}_{\mathrm{e}}$ Babcock \& Wilcox subcritical units and the fifth is a $550 \mathrm{MW}_{\mathrm{e}}$ wallfired supercritical boiler. Cofiring was demonstrated and commercialized in Boiler \#3, one of the 192 $\mathrm{MW}_{\mathrm{e}}$ units. 


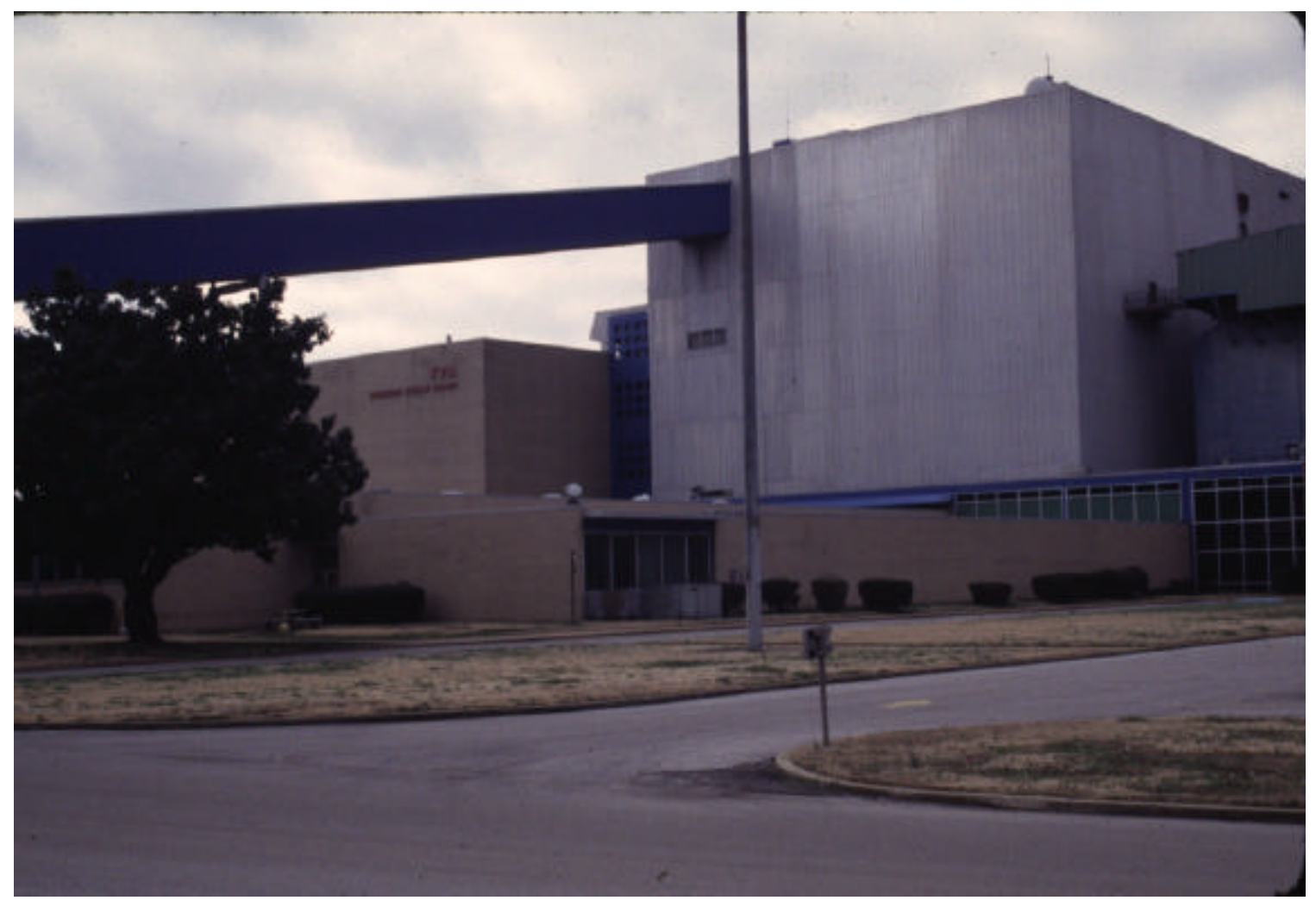

Figure 3-1. The Colbert Fossil Plant of TVA

The Colbert coal yard is stocked with coal supplied from single conveyors that deliver coal from each of two barge unloaders. There is no coal crusher and all sizing is done on the coal belt that moves coal from the barge unloader to either the stockpile or directly to the belt lines supplying the coalbunkers. Two stockpiles of coal are maintained. One is a low sulfur coal stockpile for the $192 \mathrm{MW}_{\mathrm{e}}$ units, while a separate high sulfur coal stockpile is maintained for Unit $5\left(550 \mathrm{Mw}_{\mathrm{e}}\right)$. A reclaim hopper is also provided for each stockpile. Each of the reclaim hoppers consist of two adjacent hoppers covered by a grizzly or steel grate with a vibrating feeder located under each hopper. Each of the two feeders for the reclaim hopper feeds a common reclaim conveyor belt. This conveyor belt then feeds either one of two parallel coal belt lines on the North side of the coal yard. Each of the two coal belt lines is designed to provide 700 tons of coal per hour. They may be used one at a time or together.

\subsubsection{Cofiring Materials Handling Design}

The location chosen for wood fuel storage, processing, and handling was on the Northeast corner of the coal yard adjacent to the high sulfur coal stockpile and reclaim hopper. It was next to a roadway that allowed easy routing of delivery trucks from the truck scales. Introduction of the wood fuel was through the reclaim hopper where, it could be easily conveyed to either coal belt line. 
When cofiring is practiced, sawdust is delivered to the Colbert Plant via trucks with walking floor van trailers. The trucks were weighed on truck scales located at the plant. They were then unloaded in the coal yard. Unloading was accomplished in about ten minutes. A 40' x 200' pole barn was constructed next to the reclaim hopper as shown in Figure 3-2. It was covered on three sides and the top with galvanized siding. This allowed for easy access by the front-end loader and trucks. The height of the building was designed to permit operation of a front-end loader inside of the building and to allow trucks to back into the building. Concrete barriers were used along the sides of the building. This provided some protection to the building sides and provided a backing surface for the front-end loader when it was picking up sawdust. Lights were provided to support operations during the non-daylight or cloudy conditions. The West Side of the pole building had an opening for a wood fuel conveyor. The wood fuel conveyor angle was adjusted such that wood fuel could be placed into the reclaim hopper or the reclaim hopper could still be used for its primary design function of feeding coal to the plant.

The material handling design placed the delivered fuel on the coal yard. A front-end loader then placed the sawdust in a $60 \mathrm{ton} / \mathrm{hr}$ trommel screen fitted with $1 / 4$ " screens placed parallel to the open side of the pole building. A conveyor was located between the sawdust discharge conveyor of the trommel screen and the South feeder. The trommel screen hydraulic pump powered the conveyor. This allowed direct feeding of the coal belts from the trommel screen. The delivery trucks delivered the fuel directly into the pole building. From the pole building, the material was handled only once and placed directly into the trommel screen for processing and feeding into the reclaim hopper. This design allowed for operation during periods of light rain. The wood fuel was only moved outdoors for screening and feeding to the reclaim hopper. 


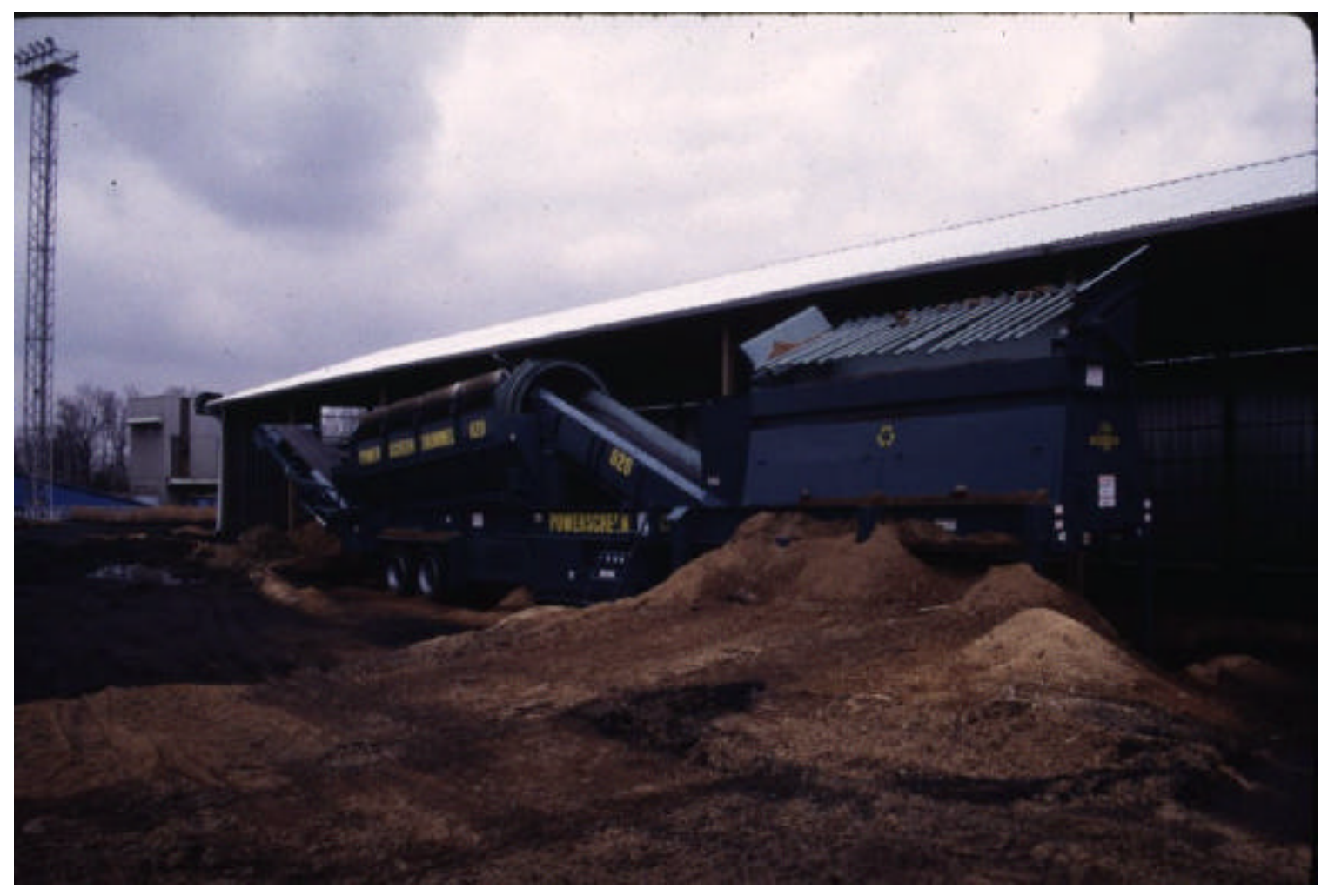

Figure 3-2. Colbert Fossil Plant Cofiring Installation

\subsubsection{Cofiring at Colbert-Test Results}

A test program was configured to determine the results of this approach at Colbert. The test program was designed to evaluate the impacts of cofiring on boiler operations and on the formation of emissions. Mill performance, along with boiler capacity, efficiency, and emissions formation became the focus of the effort.

The test approach was to have the plant firing wood waste on a continuous basis, and to conduct periodic parametric tests to determine the impact of cofiring. Parametric tests included sampling the fuels, obtaining control room and CEMS data, and analyzing these data with respect to the critical parameters. A blend of 4 percent biofuel/96 percent coal (by mass) was chosen as the target cofiring level.

The test results documented that there was no impact of low percentage cofiring on boiler capacity. The boiler had sufficient pulverizer capacity to overcome any impacts of sawdust on total system capacity.

\subsubsection{Pulverizer Impacts}

While total plant capacity was not impacted, pulverizers did experience some consequences of cofiring. Mill amps did increase by about 8 percent when cofiring, and mill feeder speeds also increased when 
cofiring. The plant had sufficient spare pulverizer capacity to handle the biofuel/coal blend without problems.

While mill amps and feeder speeds increased, cofiring had no significant impact on sieve analysis of the product fuel, as shown in Table 3-1. This result may be the result of using ball and race mills. Tests at Kingston Fossil Plant, where bowl mills are employed, indicated some deterioration of sieve analysis with increasing percentages of wood waste firing, even at low percentages.

Table 3-1. Impact of Cofiring on Sieve Analysis at Colbert Fossil Plant

\begin{tabular}{|r|c|c|}
\hline Screen Size & Baseline Test & 4 Percent Cofiring Test \\
\hline Passing 50 mesh & $99.6 \%$ & $99.7 \%$ \\
\hline Passing 100 mesh & $95.2 \%$ & $95.9 \%$ \\
\hline Passing 200 mesh & $67.1 \%$ & $67.8 \%$ \\
\hline
\end{tabular}

\subsubsection{Cofiring Impacts on Boiler Efficiency at Colbert Fossil Plant}

Cofiring did not impact boiler efficiencies. Table 3-2 shows efficiencies measured during some parametric tests. It illustrates the fact that low percentage cofiring did not degrade boiler efficiency relative to coal-only firing at this location. The impacts at 4 percent cofiring are below accurate and precise measurement.

Table 3-2. Impact of Cofiring on Boiler Efficiency at Colbert Fossil Plant

\begin{tabular}{|c|c|c|c|c|}
\hline Test Number & Date & Percent Wood & Main steam flow (kpph) & Efficiency (\%) \\
\hline 0 & $2 / 10$ & 0 & 870,9 & 82.6 \\
\hline 1 & $3 / 6$ & 4 & $1,236.2$ & 83.5 \\
\hline 2 & $3 / 6$ & 4 & $1,087.3$ & 82.9 \\
\hline 3 & $3 / 7$ & 4 & 927.8 & 83.5 \\
\hline 4 & $3 / 7$ & 0 & 925.8 & 83.6 \\
\hline 5 & $3 / 8$ & 0 & 695.0 & 81.9 \\
\hline
\end{tabular}

Subsequent parametric tests also demonstrated that the variability in efficiencies caused by other factors such as coal moisture, excess $\mathrm{O}_{2}$, and air heater exit temperatures was greater than the variability induced by cofiring 4 percent biomass.

Cofiring did not impact emissions. $\mathrm{NO}_{\mathrm{x}}$ and $\mathrm{SO}_{2}$ emissions were monitored through the CEMS system, along with opacity. Variability in these emissions was sufficient to bracket the results obtained during the cofiring tests. Further, there was insufficient biomass in the fuel supply to create the types of combustion mechanisms conventionally associated with $\mathrm{NO}_{\mathrm{x}}$ reduction through cofiring. An evaluation was made concerning the impact of cofiring on the Toxic Release Inventory, with favorable results. 
Based upon the cofiring results experienced at Colbert Fossil Plant, TVA commercialized the cofiring operation at that location. Such commercialization has provided TVA with benefits in the area of fuel diversity and fuel cost management, customer service, and the ability to initiate programs associated with portfolio standards. Cofiring is now practiced when biomass can be obtained at favorable prices.

\subsection{COFIRING AT THE SEWARD GENERATING STATION}

The Seward Generating Station was used to pioneer cofiring using separate injection of sawdust into a wall fired PC boiler, with cofiring percentages reaching 20 percent (mass basis). Initial parametric testing of this concept was performed in December 1996. Subsequent parametric testing in July 1997 led to the design, construction, and testing of a demonstration facility.

The Seward testing and demonstration program has been well documented (see, for example, Foster Wheeler Environmental Corporation, 1997b; Battista, Tillman, and Hughes, 1998; Tillman, Battista, and Hughes, 1998; Battista, Tillman, and Hughes, 1999; Tillman, 1999a; and Battista, Hughes, and Tillman, 2000; Battista, Tillman, and Hughes, 2000; Battista, Hughes, Tillman, and Prinzing, 1996). It involved designing and developing a materials handling system, modifications to the coal burners, and controls integrated into the total boiler controls package. It then involved extensive testing of the system, and its impacts on plant operations.

The Seward Generating Station located in Seward, PA and shown in Figure 3-3, consists of three boilers; two (Boilers \#12 and \#14) are 330,000 lb/hr font-fired units supplying steam to a single 64 $\mathrm{MW}_{\mathrm{e}}$ turbine; the third (Boiler \#15) is a $147 \mathrm{MW}_{\mathrm{e}} \mathrm{T}$-fired boiler. 


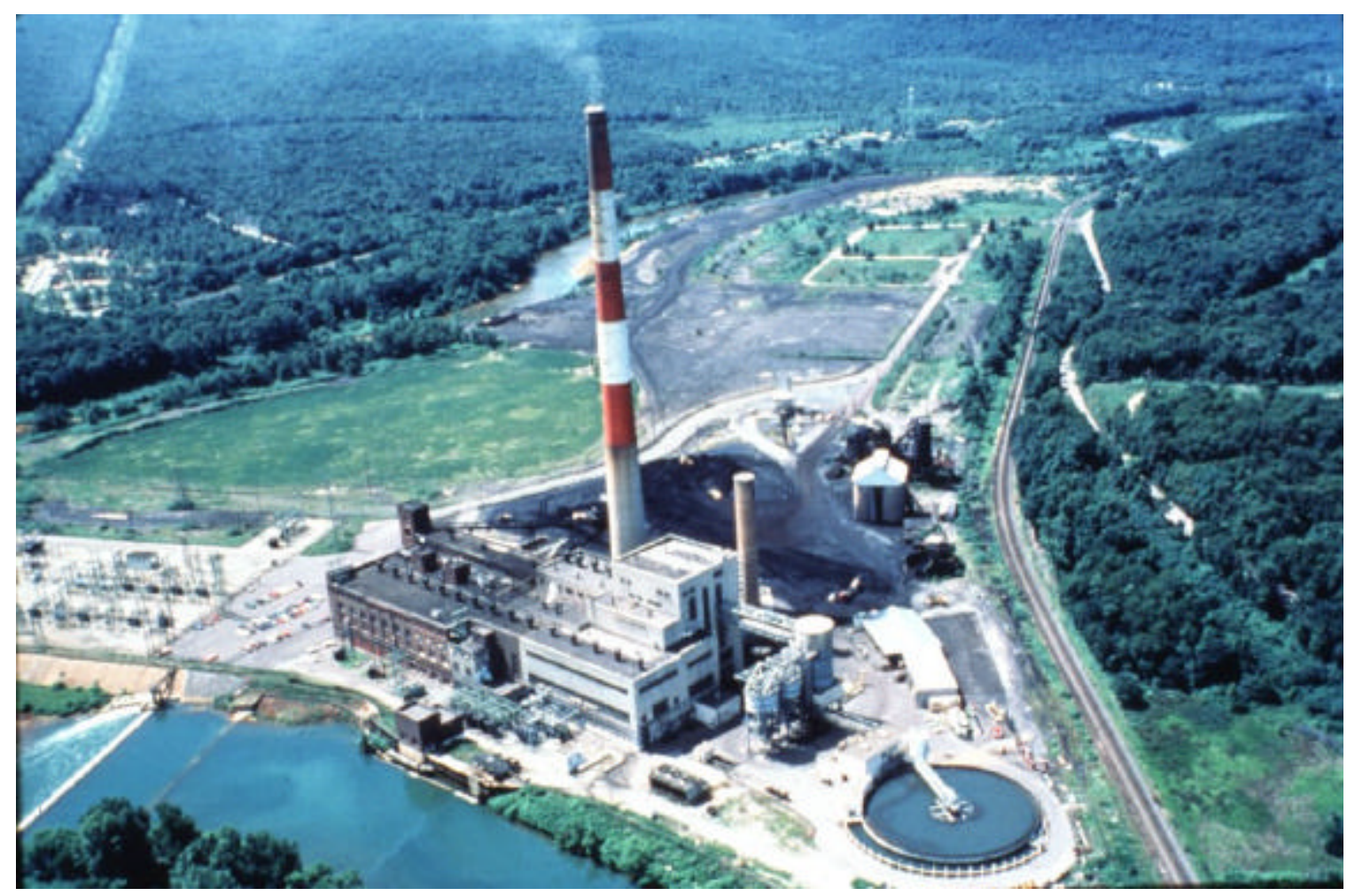

Figure 3-3. Seward Generating Station

Seward \#12 boiler, a 330,000 lb/hr wall-fired unit with two rows of burners, was chosen for testing and demonstration. Each row of burners contained 3 conventional PC burners with Eagle Air registers. The concept of cofiring involved selecting the top row of burners and modifying those burners to accept sawdust prepared separately and pneumatically transported separately to the boiler.

\subsubsection{The Parametric Test Program at Seward Generating Station}

The concept of the cofiring system designed for parametric testing at Seward Generating Station involved screening the wood in a trommel screen to ensure $<1 / 4$ " biofuel particles. The sawdust was then loaded into a surge bin. From the surge bin it was metered into 3 rotary airlocks, and these rotary airlocks supplied known quantities of biomass to 3 transport lines. An individual blower supported each transport line. Each blower transported the biofuel from a single rotary air lock to a burner on the top row of coal burners.

\subsubsection{System Design for Parametric Testing}

The biomass was not mixed with coal in the burner. Rather, the sawdust was blown down the center pipe of the burner and then diffused into the coal flame in the furnace. The modifications to the burner included flexible piping to connect the wood transport system to the center pipe of the burner, and diffusers in the end of the center pipe to transport the sawdust into the coal flame. Air flow was held constant, to achieve a velocity of 5,000 ft/min. Biofuel feed rates were changed using variable speed 
screws in the surge bin, feeding the rotary air locks. Figures 3-4 and 3-5 show the design of the transport system and burner modification. Figure 3-6 is a photograph of the burner tip modification.

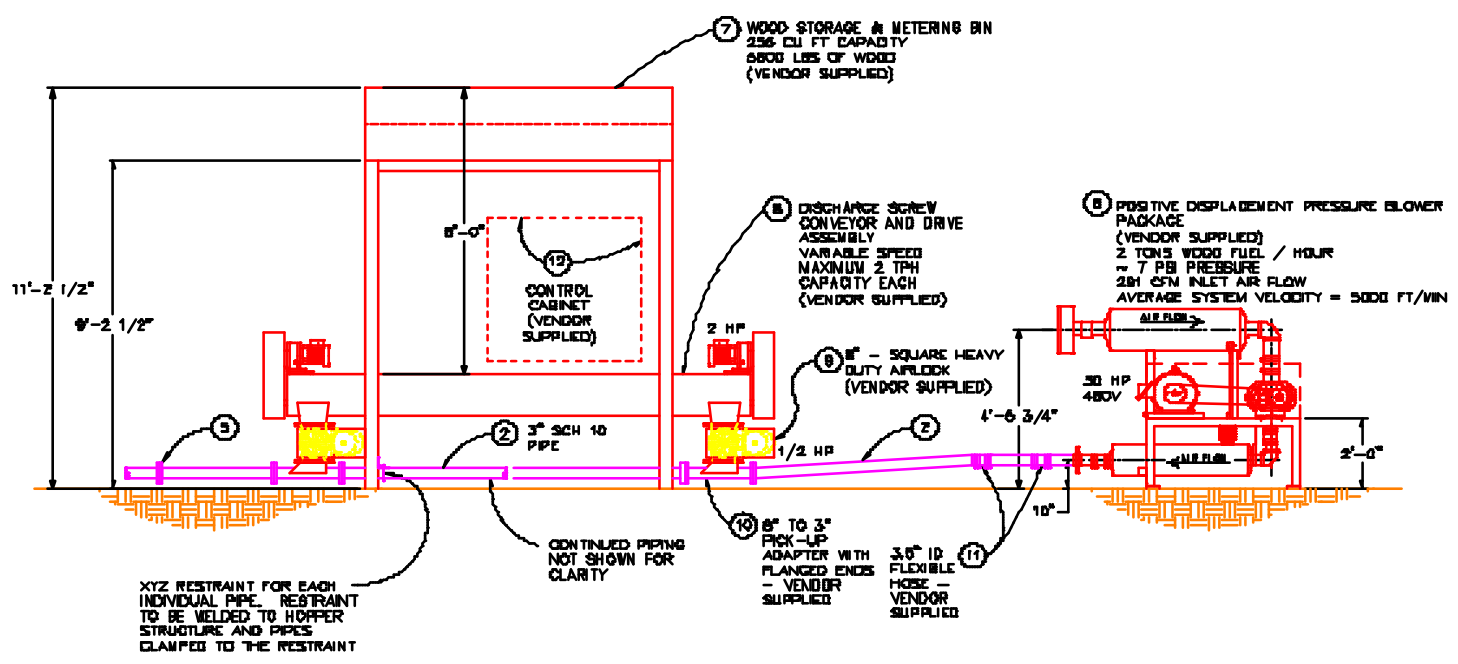

Figure 3-4. Elevation View of the Original Pneumatic Transport System at Seward

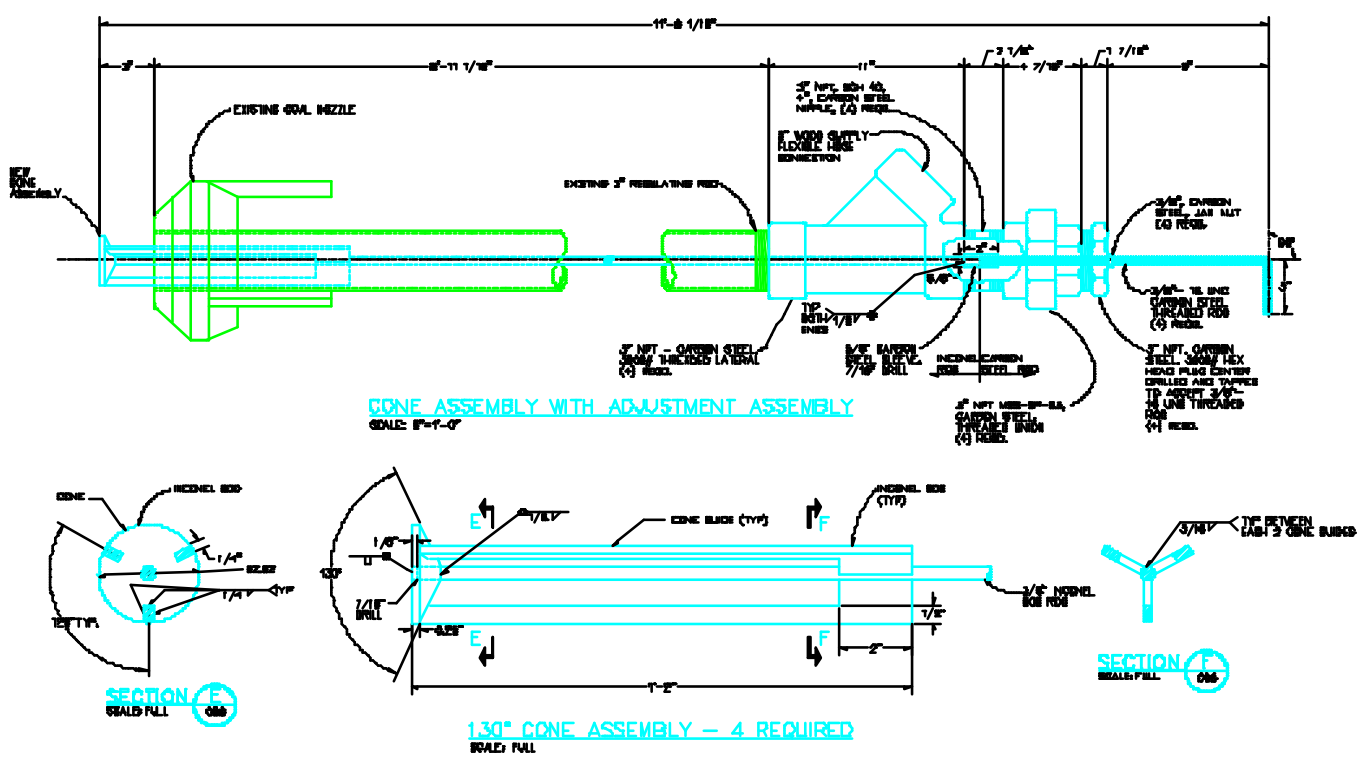

Figure 3-5. Design of the Burner Tip Modifications at Seward 


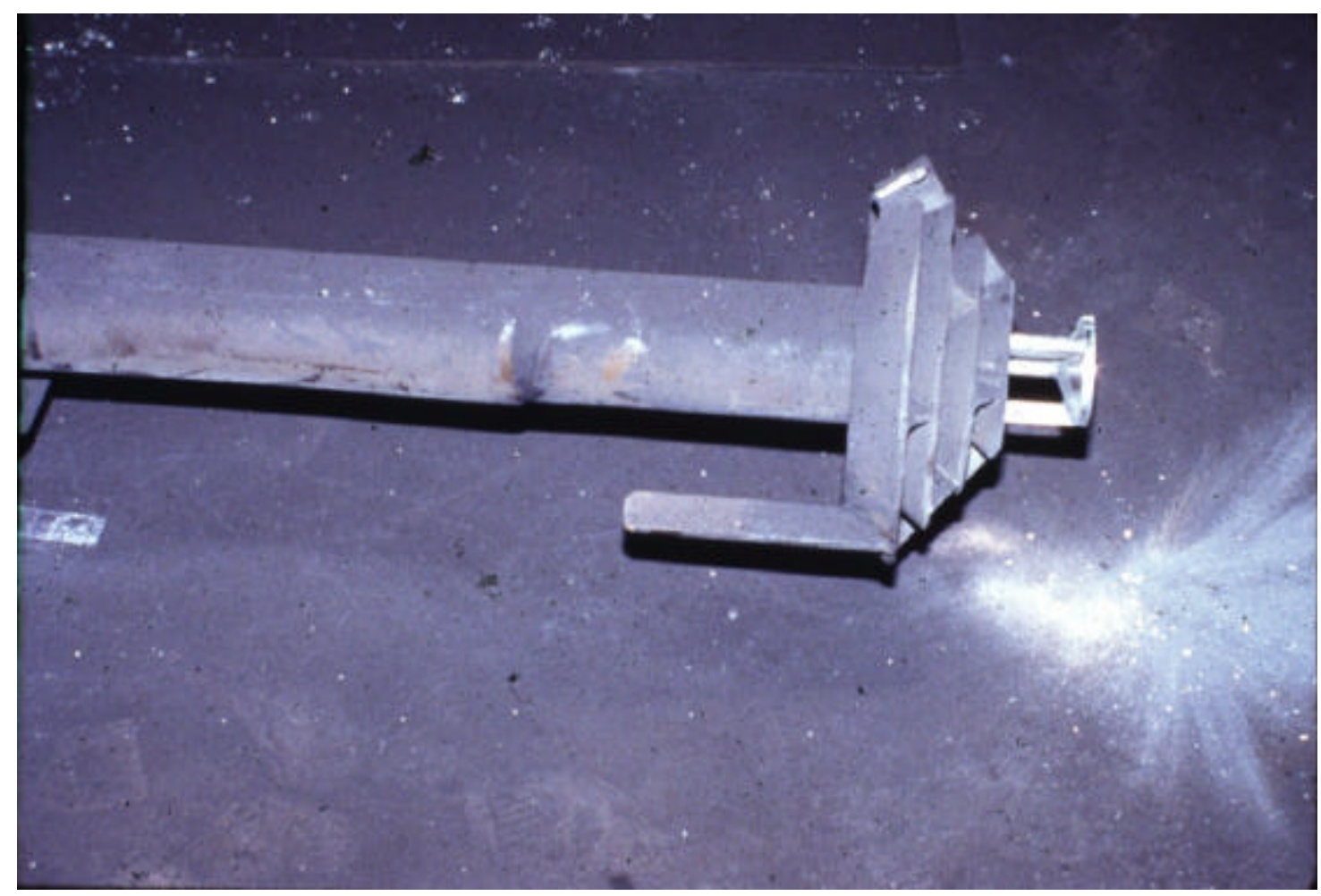

Figure 3-6. Photograph of the Burner Tip Insert for Biomass Cofiring at Seward

During the initial testing in December 1996, the trommel screen was installed in a paved area adjacent to the power plant, outside. The sawdust, once screened, was stored under a large tent and reclaimed by a bobcat. In July of 1997, the testing used the same trommel arrangement but did not store the sawdust under a tent. Rather, open piles were used. Tables 3-3 and 3-4 are the original equipment and motor lists for the parametric tests.

Table 3-3. Equipment List for Parametric Testing at Seward Generating Station

\begin{tabular}{|l|c|l|}
\hline Equipment & Quantity & Capacity/Basis/Data \\
\hline Truck scale and scale house & 1 & Existing \\
\hline Front-end loader & 1 & Existing \\
\hline Fuel storage and reclaim tent & 1 & Tent - 100'L x 80' W \\
\hline Trommel Screen & 1 & $<1 / 4$ screening, 20-30 tons per hour output \\
\hline Fines conveyor & 1 & 20-30 tons per hour output \\
\hline Fuel Storage \& Metering Bin & 1 & 256 cu ft capacity, 5600 lbs. \\
\hline Discharge Screws & 3 & $\begin{array}{l}\text { 9' - variable speed, 2 tons of wood fuel } \\
\text { per hour each }\end{array}$ \\
\hline Rotary Airlock & 3 & 2 tons of wood fuel per hour each \\
\hline $\begin{array}{l}\text { Positive Displacement Blower } \\
\text { Package }\end{array}$ & 3 & $\begin{array}{l}\text { 291 cfm, 2 tons of wood fuel per hour } \\
\text { each }\end{array}$ \\
\hline
\end{tabular}


Table 3-4. Motor List for the Original Seward Cofiring Tests

\begin{tabular}{|l|c|c|c|c|}
\hline Equipment & Quantity & $\begin{array}{c}\text { Number of } \\
\text { Motors }\end{array}$ & $\begin{array}{c}\text { HP } \\
\text { Each }\end{array}$ & $\begin{array}{c}\text { Total } \\
\text { HP }\end{array}$ \\
\hline Truck scale and scale house & 1 & N/A & & \\
\hline Front-end loader & 1 & N/A & & \\
\hline Fuel storage and reclaim tent & 1 & N/A & & \\
\hline Trommel Screen & 1 & N/A & & \\
\hline Fines conveyor & 1 & N/A & & \\
\hline Fuel Storage \& Metering Bin & 1 & N/A & & \\
\hline Discharge Screws & 3 & 3 & 2 & 6 \\
\hline Rotary Airlock & 3 & 3 & $1 / 2$ & 1.5 \\
\hline Positive Displacement Blower Package & 3 & 3 & 30 & 90 \\
\hline \multicolumn{1}{|r|}{ TOTAL } & & & & $\mathbf{9 7 . 5}$ \\
\hline
\end{tabular}

\subsubsection{Seward Generating Station Parametric Test Results}

The Seward tests conducted in December 1996 and July 1997 documented the benefits and impacts of separate injection cofiring. These impacts occurred with respect to capacity, efficiency, and emissions reduction. In order to evaluate these impacts it is important to consider the fuels burned, as shown in Table 3-5.

Table 3-5. Composition of Fuels Burned at Seward Generating Station

\begin{tabular}{|l|c|c|c|c|}
\hline Parameter & \multicolumn{4}{|c|}{ Fuel } \\
\hline $\begin{array}{l}\text { Proximate } \\
\text { Analysis (wt \%) }\end{array}$ & Fresh Sawdust & Dry Sawdust & Old Sawdust & Coal \\
\hline Moisture & 38.82 & & & \\
\hline Ash & 0.37 & 13.47 & 48.47 & 5.04 \\
\hline Volatile Matter & 51.86 & 68.16 & 41.35 & 17.01 \\
\hline Fixed Carbon & 8.96 & 10.56 & 7.46 & 58.62 \\
\hline & & & & \\
\hline $\begin{array}{l}\text { Ultimate Analysis } \\
\text { wt \%) }\end{array}$ & & & & \\
\hline Moisture & 38.82 & 13.47 & 48.47 & 5.04 \\
\hline Carbon & 31.66 & 40.90 & 26.09 & 70.06 \\
\hline Hydrogen & 3.46 & 4.43 & 2.67 & 3.60 \\
\hline Nitrogen & 0.09 & 0.10 & 0.10 & 1.20 \\
\hline
\end{tabular}




\begin{tabular}{|l|c|c|c|c|}
\hline Sulfur & 0.02 & 0.02 & 0.02 & 1.74 \\
\hline Ash & 0.37 & 7.81 & 2.72 & 17.01 \\
\hline Oxygen & 25.60 & 33.27 & 19.93 & 1.29 \\
\hline Chlorine & 0 & 0 & 0 & 0.07 \\
\hline HHV (Btu/lb) & 5048 & 6496 & 4137 & 11778 \\
\hline
\end{tabular}

The capacity impacts of cofiring at Seward Generating Station were favorable, with particular attention to firing with wet coal. Under normal conditions, cofiring had no impact on capacity. However the unit experienced forced capacity reductions in winter when firing with wet coal. During the December 1996 tests, the unit experienced a significant "wet coal" occurrence. On that day the unit was brought to maximum capacity on coal only $-240,000 \mathrm{lb} / \mathrm{hr}$ of steam. This compared to a normal maximum capacity of $330,000 \mathrm{lb} / \mathrm{hr}$ of steam. After being brought to maximum capacity with wet coal, sawdust was added to the fuel supply. The steaming capacity of the Seward Boiler \#12 increased to 280,000 $\mathrm{lb} / \mathrm{hr}$. No capacity was added to the boiler. However some capacity lost due to wet coal was recovered. The capacity recovered represented nearly $4 \mathrm{MW}_{\mathrm{e}}$.

The efficiency impacts of cofiring at Seward Generating Station were modest, and manageable. Dominant factors impacting efficiency include excess oxygen in the flue gas, moisture in the flue gas from the fuel moisture and from the fuel hydrogen, flue gas exit temperature, and unburned carbon in the flyash and bottom ash. The practice of cofiring did not impact excess oxygen in the flue gas or flue gas exit temperature. Although there was some burning in the dry bottom ash pit, the impact of cofiring on unburned carbon in the bottom ash was negligible.

The impact of cofiring on unburned carbon in the flyash is shown in Figure 3-7. Although there was a general slight upward trend, it was not statistically significant. 


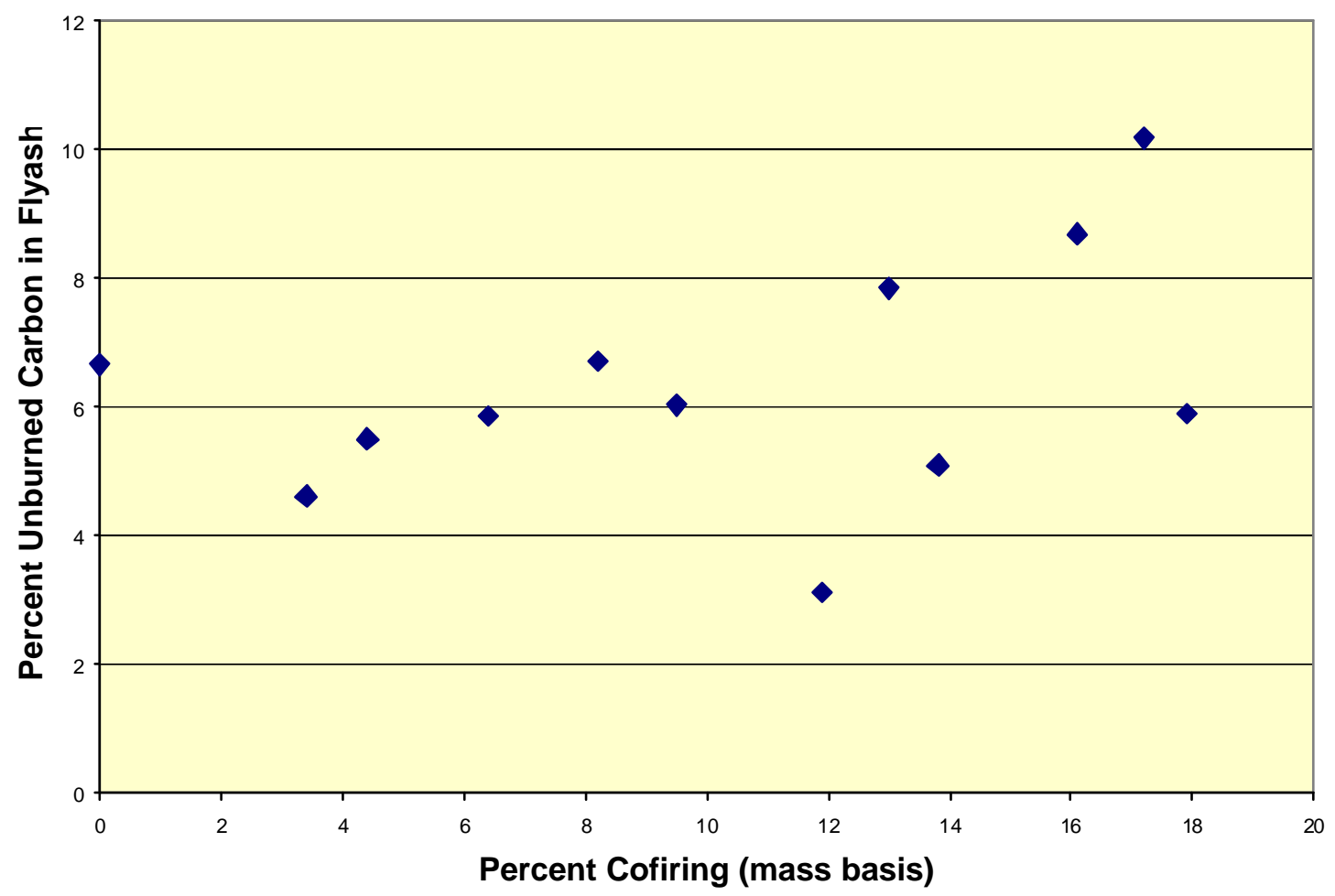

Figure 3-7. Unburned Carbon in Flyash During the Seward Parametric Tests

No practical linear regression or polynomial equation could be constructed with a coefficient of determination $\left(\mathrm{r}^{2}\right)$ greater than 0.38 . Note that, until cofiring exceeds 12 percent (mass basis), there is an apparent decrease in unburned carbon (UBC) or loss on ignition (LOI), followed by an increase when cofiring reaches the $14-20$ percent region.

Moisture in the flue gas was the dominant actor in causing an efficiency reduction. That efficiency reduction, over all tests conducted in December 1996 and July 1997, is shown in Figure 3-8. Note that the efficiency losses are modest until cofiring exceeds about 15 percent (mass basis). This experience is consistent with that shown previously for the Allen Fossil Plant. 


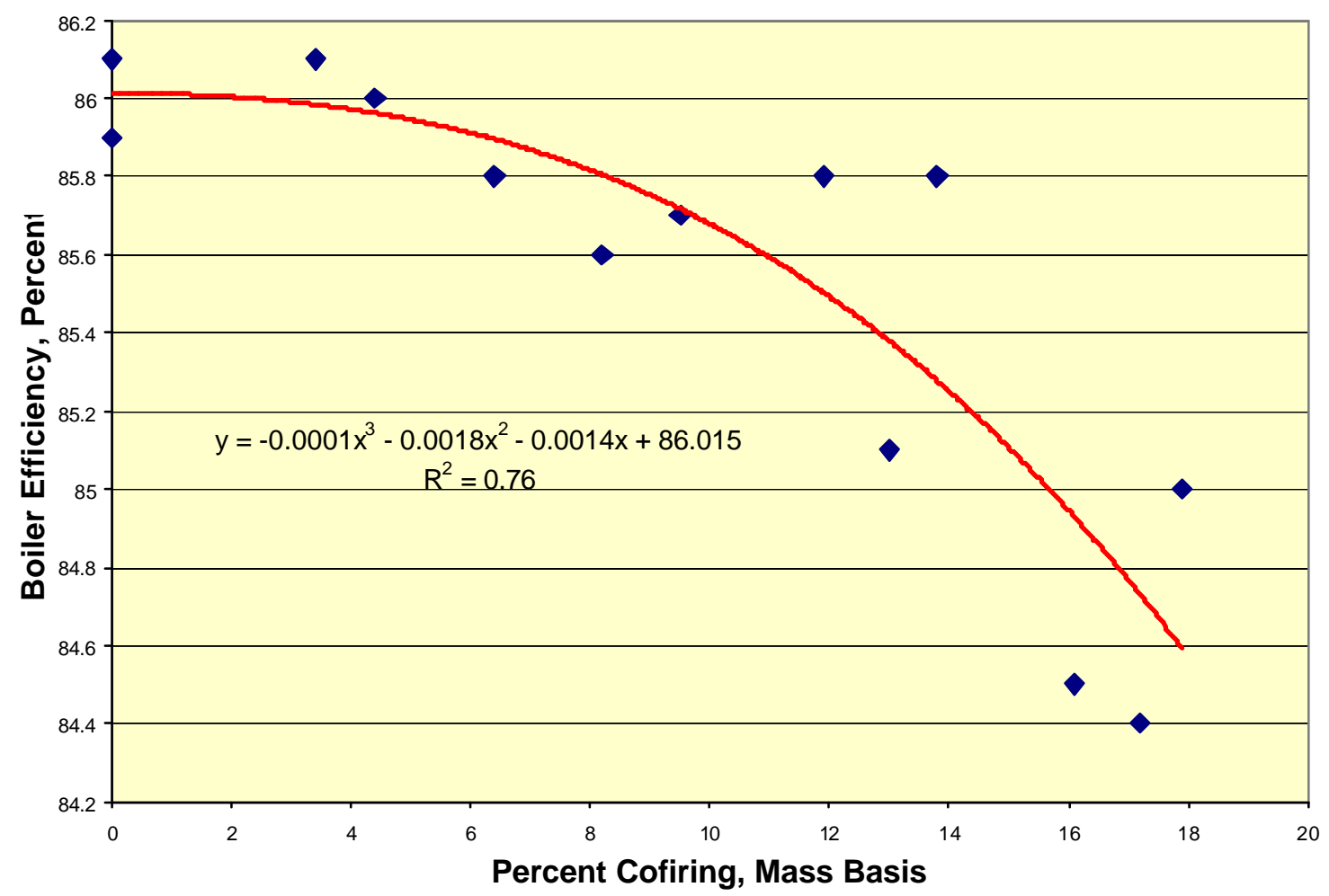

Figure 3-8. Boiler Efficiency Measured During the Seward Parametric Tests

The efficiency results, with a coefficient of determination, $\mathrm{r}^{2}=0.76$, document the fact that numerous other variables besides cofiring level were impacting boiler performance. These variables included (not exhaustive) biomass moisture content, coal moisture content, boiler load and the operating conditions required to satisfy load, and other similar considerations. Unburned carbon in the flyash was a consideration in the lost efficiencies when cofiring at or above 16 percent (mass basis).

A parallel efficiency graph can be shown measuring cofiring on a heat input or Btu basis, as is shown in Figure 3-9. Note that the coefficient of determination declines to 0.70 , based upon variability in the Btu content of the biomass and the moisture content of the biomass or sawdust. 


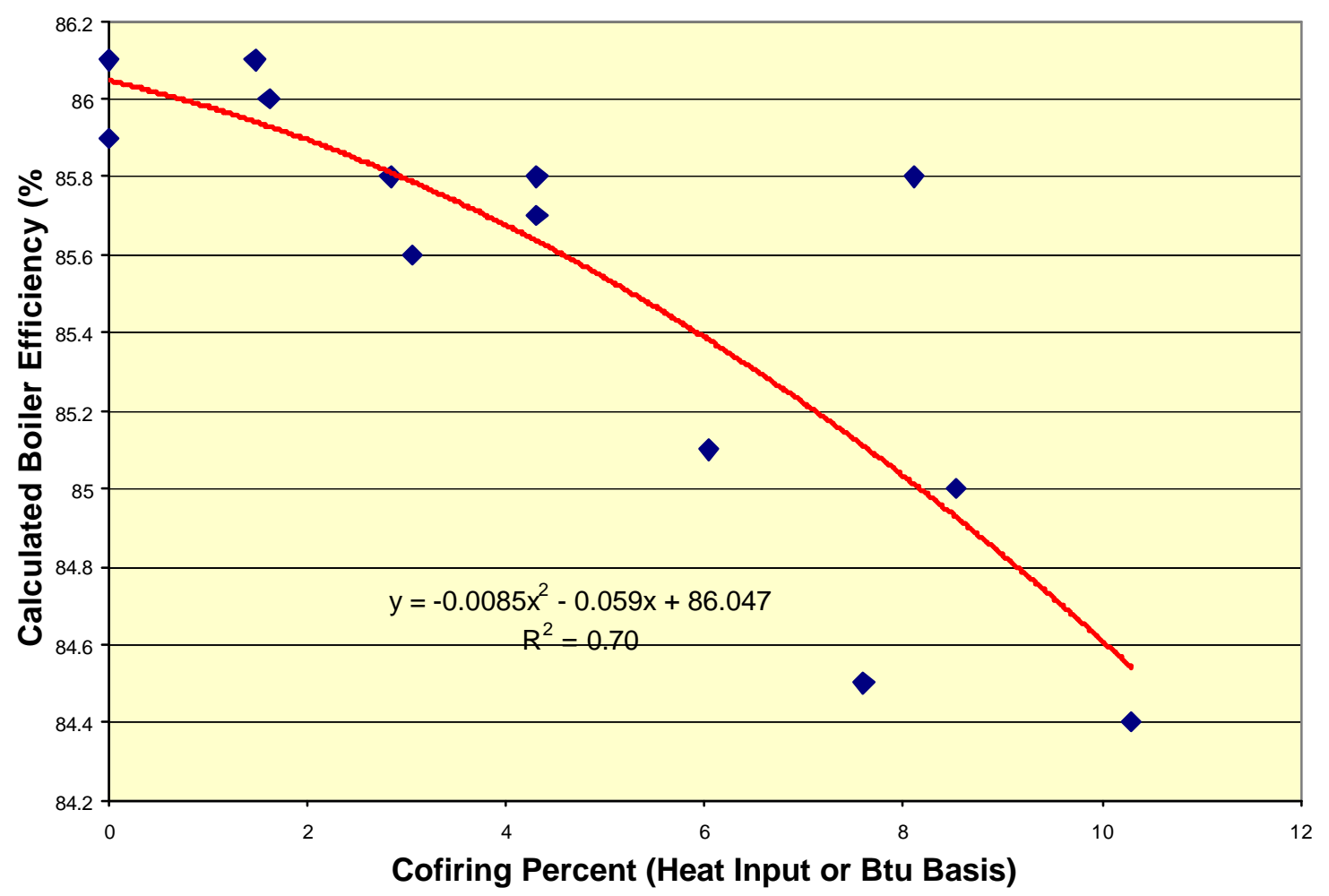

Figure 3-9. Boiler Efficiency at the Seward Tests as Influenced by Cofiring Level (Btu Basis)

The issue of efficiency is accompanied by the consideration of cofiring impacts on flame temperature. Using Gibbs Free Energy calculations, flame temperatures were calculated during the December 1996 tests as shown in Table 3-6. The Gordon-McBride code, CET-89 (Gordon and McBride, 1976), was used to perform these calculations. There is very little flame temperature impact from cofiring.

Table 3-6. Calculated Flame Temperatures During December 1996 Seward Tests

\begin{tabular}{|c|c|c|c|c|c|c|c|}
\hline Test No. & \multicolumn{2}{|c|}{ Percent Coal } & \multicolumn{2}{|c|}{ Percent Wood $^{*}$} & Excess $\mathrm{O}_{2} \%$ & Adiabatic & Est. Actual \\
\hline & mass & heat & mass & heat & (plant data) & $\begin{array}{c}\text { Flame Temp } \\
\left({ }^{\circ} \mathrm{F}\right)\end{array}$ & $\begin{array}{c}\text { Flame Temp } \\
\left({ }^{\circ} \mathrm{F}\right)\end{array}$ \\
\hline 1 & 100 & 96.9 & 0 & 0 & 4.49 & 3440.9 & 2660.8 \\
\hline 2 & 90.3 & 93.3 & 9.7 & 3.7 & 4.32 & 3329.3 & 2571.5 \\
\hline 3 & 82.3 & 90.1 & 17.7 & 7.2 & 3.90 & 3466.1 & 2681.0 \\
\hline 4 & 90.9 & 94.2 & 9.1 & 2.9 & 4.46 & 3424.7 & 2678.9 \\
\hline 5 & 83.3 & 91.7 & 16.7 & 5.7 & 4.02 & 3552.5 & 2750.1 \\
\hline 6 & 79.3 & 88.7 & 20.7 & 8.7 & 4.49 & 3431.9 & 2653.6 \\
\hline 7 & 85.2 & 91.1 & 14.8 & 5.9 & 5.16 & 3356.3 & 2593.1 \\
\hline 8 & 79.5 & 89.9 & 20.5 & 7.2 & 4.64 & 3323.9 & 2567.2 \\
\hline $9 \mathrm{a}$ & 100 & 96.5 & 0 & 0 & 6.95 & 3248.0 & 2506.7 \\
\hline $9 \mathrm{~b}$ & 81.1 & 90.4 & 18.9 & 6.5 & 4.95 & 3206.9 & 2473.6 \\
\hline 10 & 100 & 96.6 & 0 & 0 & 5.93 & 3323.9 & 2567.2 \\
\hline
\end{tabular}


- The difference between the total heat input, and the heat input from the coal and the wood, is the heat input from the combustion air exiting the FD fan.

Resulting from all of the efficiency calculations is the following equation $\left(r^{2}=.89\right)$ :

$$
\eta=87.6-0.14(\mathrm{EO} 2)-0.16(\mathrm{UBC})-0.11(\mathrm{~W})
$$

Where EO2 is percent excess $\mathrm{O}_{2}$ measured on a wet basis, $\mathrm{UBC}$ is percent unburned carbon in the flyash, and $\mathrm{W}$ is percent wood in the fuel mix on a heat input or Btu basis. The probabilities of the equation, or any component, being random are as follows: total equation, 0.000125; intercept, 4.24x10 $0^{-24}$; EO2, 0.77; UBC, 0.0027; and W, 0.00072. The excess O2 did not show as statistically significant simply because of the narrow range of observed values in the tests. Given these probabilities, the equation is considered to be robust, and the impact of cofiring is to reduce boiler efficiency by about 1 percent for every 10 percent on a heat input basis - or 1 percent for every 20 percent on a mass input basis. However the interrelationships between variables, particularly at high levels of cofiring (e.g., higher UBC or LOI values when cofiring >16 percent on a mass basis) creates the curves shown in Figures 3-8 and 3-9.

The emissions impacts of cofiring during the parametric tests at the Seward Generating Station included impacts on opacity, $\mathrm{SO}_{2}$ emissions, $\mathrm{CO}$ emissions, and $\mathrm{NO}_{\mathrm{x}}$ emissions. These are in addition to the benefits of reducing fossil $\mathrm{CO}_{2}$ emissions by substituting sawdust for coal and reducing sawdust disposal.

Opacity was largely not impacted by cofiring at Seward Generating Station. $\mathrm{SO}_{2}$ emissions were reduced in proportion to the heat input of biomass into the boiler, adjusted for efficiency impacts. These results were consistent with previous parametric testing.

Carbon monoxide emissions were measured during the December 1996 tests, as shown in Table 3-7.

Table 3-7. Carbon Monoxide Emissions from Cofiring Tests at Seward Generating Station

\begin{tabular}{|c|c|c|c|c|c|c|}
\hline $\begin{array}{l}\text { Test } \\
\text { No. }\end{array}$ & \multicolumn{2}{|c|}{ Percent Coal* } & \multicolumn{2}{c|}{$\begin{array}{c}\text { Percent } \\
\text { Wood* }\end{array}$} & $\begin{array}{c}\text { Excess } \mathrm{O}_{2} \\
\%\end{array}$ & CO \\
\hline & Mass & Heat & Mass & Heat & (Plant) & ppmv \\
\hline 1 & 100 & 96.9 & 0 & 0 & 4.49 & 11.5 \\
\hline 2 & 90.3 & 93.3 & 9.7 & 3.7 & 4.32 & 10.5 \\
\hline 3 & 82.3 & 90.1 & 17.7 & 7.2 & 3.90 & 13.0 \\
\hline 4 & 90.9 & 94.2 & 9.1 & 2.9 & 4.46 & 12.5 \\
\hline 5 & 83.3 & 91.7 & 16.7 & 5.7 & 4.02 & 16.0 \\
\hline 6 & 79.3 & 88.7 & 20.7 & 8.7 & 4.49 & 12.0 \\
\hline 7 & 85.2 & 91.1 & 14.8 & 5.9 & 5.16 & 13.0 \\
\hline 8 & 79.5 & 89.9 & 20.5 & 7.2 & 4.64 & 17.5 \\
\hline $9 \mathrm{a}$ & 100 & 96.5 & 0 & 0 & 6.95 & 12.0 \\
\hline $9 \mathrm{~b}$ & 81.1 & 90.4 & 18.9 & 6.5 & 4.95 & 18.0 \\
\hline
\end{tabular}




\begin{tabular}{|c|c|c|c|c|c|c|}
\hline 10 & 100 & 96.6 & 0 & 0 & 5.93 & 8.5 \\
\hline$\bullet$
\end{tabular}

Note that there was no impact of cofiring on CO emissions. This is consistent with the LOI results shown previously. There were slightly elevated $\mathrm{CO}$ emissions only when cofiring was practiced at levels $>16$ percent (mass basis). Even then, $\mathrm{CO}$ emissions were $<20 \mathrm{ppmv}$. Cofiring did not impact fuel burnout in any significant way.

$\mathrm{NO}_{\mathrm{x}}$ emissions decreased as a function of cofiring, as is shown in Figures 3-10 and 3-11. Note that the boiler was not equipped with low- $\mathrm{NO}_{\mathrm{x}}$ burners, and the consequent baseline emissions were quite high. The decreases experienced were on the order of the $\mathrm{NO}_{\mathrm{x}}$ reductions measured previously at the Allen Fossil Plant.

It is useful to evaluate the mechanisms associated with NOx emissions in wall-fired PC boilers to determine their similarities and differences from the mechanisms operating in T-fired PC boilers and cyclone boilers. Again the tools used for analysis were statistical calculations. Comparisons were made to reduced fuel nitrogen content as well.

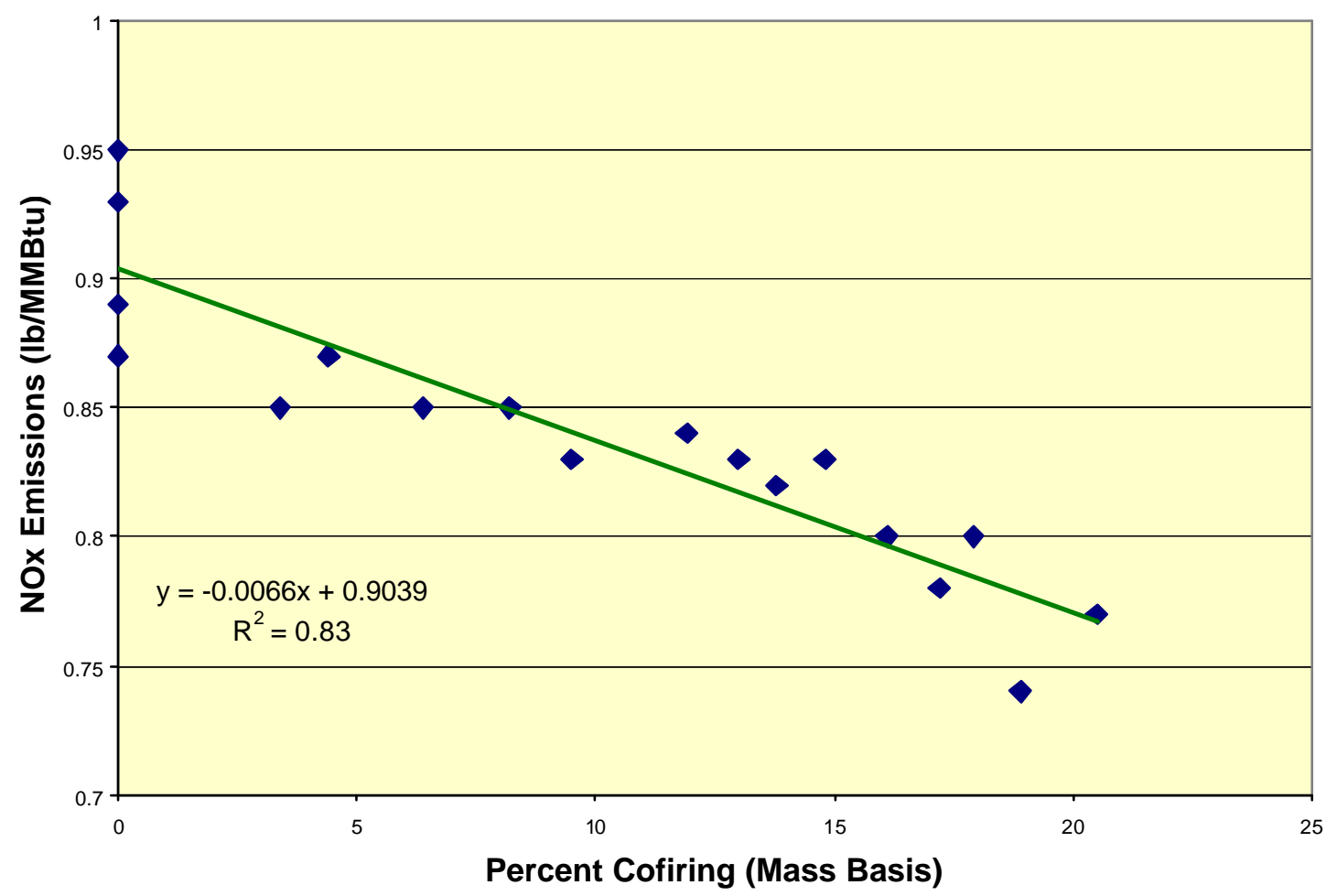


Figure 3-10. $\mathrm{NO}_{\mathrm{x}}$ Emissions Measured at the Seward Parametric Tests as a Function of Cofiring (mass basis)

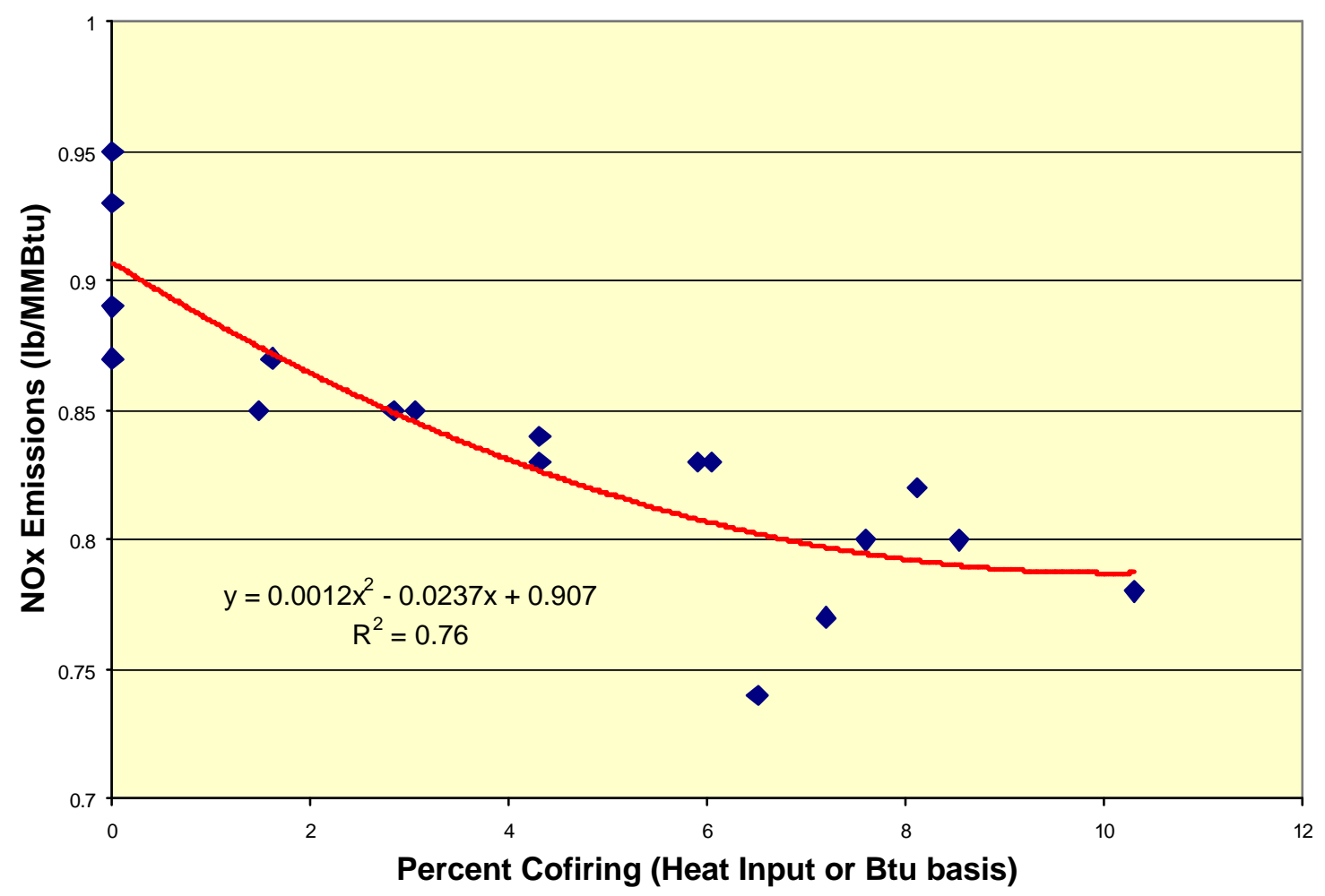

Figure 3-11. $\mathrm{NO}_{\mathrm{x}}$ Emissions Measured at the Seward Parametric Tests as a Function of Cofiring (heat input or Btu basis)

The initial mechanism examined was reduction in fuel nitrogen of the total fuel. This resulted in the following regression equation:

$$
\mathrm{NO}_{\mathrm{x}}=0.5834 \mathrm{FN}+0.2556
$$

Where $\mathrm{NO}_{\mathrm{x}}$ is measured in $\mathrm{lb} / 10^{6} \mathrm{Btu}$, and $\mathrm{FN}$ is fuel nitrogen in $\mathrm{lb} / 10^{6} \mathrm{Btu}$. However the $\mathrm{r}^{2}$ for this equation is only 0.235 . The probability of the outcome being random is only 0.041 , indicating that fuel nitrogen impacts the emissions, however it is not the dominant actor. When fuel nitrogen is combined with traditional parameters-firing rate, excess $\mathrm{O}_{2}$, and fuel volatility, the resulting regression equation is as follows:

$$
\mathrm{NO}_{\mathrm{x}}=1.36+0.000265(\mathrm{FR})+0.0161(\mathrm{EO} 2)-0.38(\mathrm{FN})-0.741(\mathrm{~V} / \mathrm{FC})
$$

Where NOx is measured in $\mathrm{lb} / 10^{6} \mathrm{Btu}$, FR is firing rate $\left(10^{6} \mathrm{Btu} / \mathrm{hr}\right), \mathrm{EO} 2$ is percent excess $\mathrm{O}_{2}$ on a wet basis, $\mathrm{FN}$ is fuel nitrogen measured in $1 \mathrm{~b} / 10^{6} \mathrm{Btu}$, and V/FC is the volatile/fixed carbon ratio from the proximate analysis. The $\mathrm{r}^{2}$ for this equation is 0.75 . The probability that the equation is a random 
occurrence is 0.000721 . The probabilities of the individual components are interesting, however, as shown below:

- Probability that the intercept occurs as a random event: 0.0008

- Probability that FR occurs as a random event: 0.65

- Probability that EO2 occurs as a random event: 0.35

- Probability that FN occurs as a random event: 0.30

- Probability that V/FC occurs as a random event: 0.0009

The equation, taken as a whole, is robust. Of the variables, however, only the volatility of the fuel is highly significant. The influence of the volatility of the fuel is a function of mass percentage, rather than heat input percentage. It is shown in Figure 3-12.

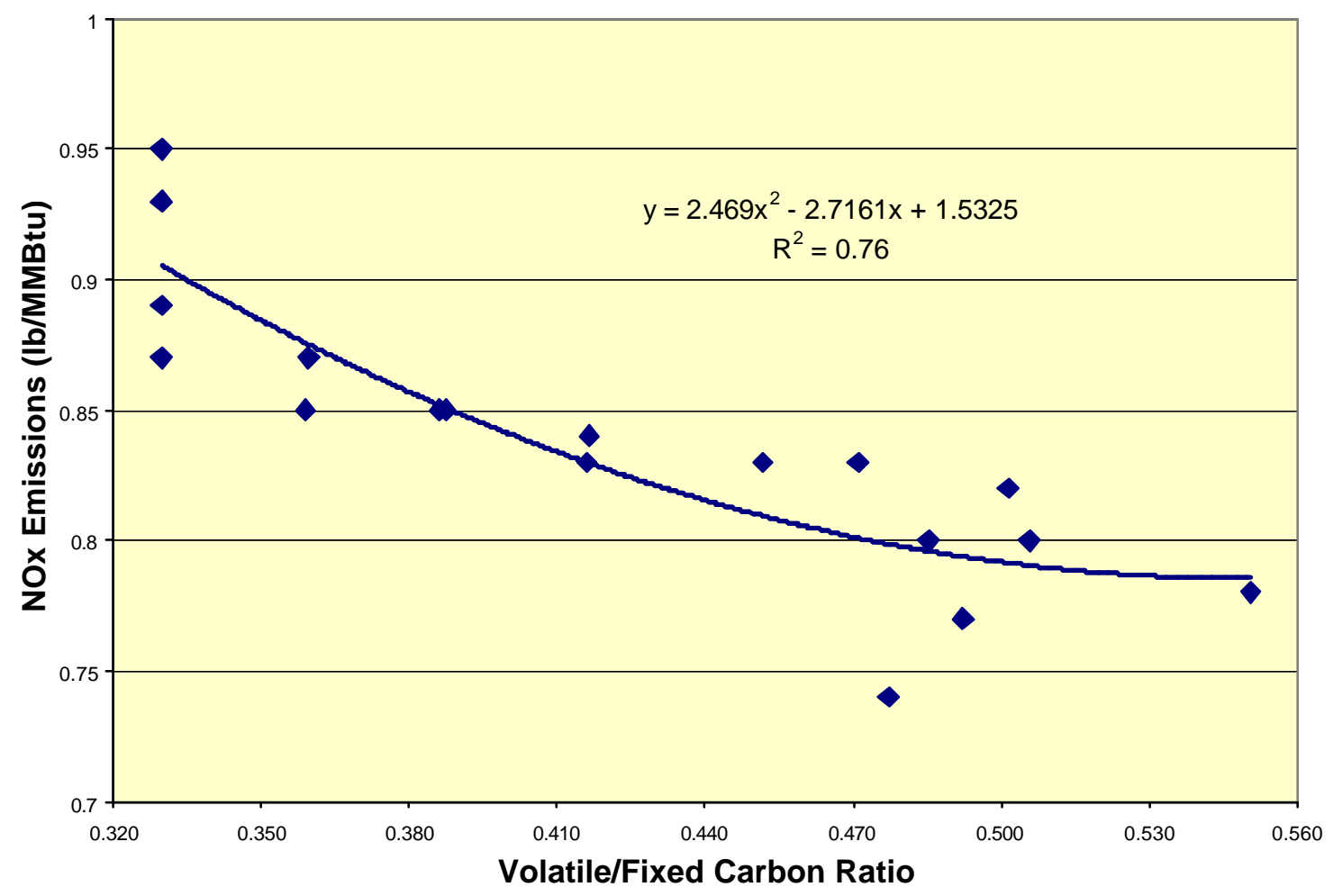

Figure 3-12. $\mathrm{NO}_{\mathrm{x}}$ Emissions as a Function of Volatile/Fixed Carbon Ratio During the Parametric Tests at Seward Generating Station

Based upon the analyses made during the parametric testing at Seward Generating Station, significant $\mathrm{NO}_{\mathrm{x}}$ reductions occurred as a consequence of cofiring, as is summarized in Figure 3-13. These reductions resulted largely from flooding the coal flames with volatiles, creating a strong reducing environment at the base of the flame. Previously it was shown that sawdust releases its volatiles rapidly_and its nitrogen volatiles even more rapidly_causing them to be released in a fuel-rich environment (see Figure 2-7). This contrasts with the pattern of nitrogen volatile release from eastern 
bituminous coal (see Baxter et. al., 1996c). Further, it is important to note the kinetics of sawdust devolatilization and char oxidation relative to eastern bituminous coal devolatilization and char oxidation. Arrhenius equation parameters for devolatilization and char oxidation are shown in Table 3-8.

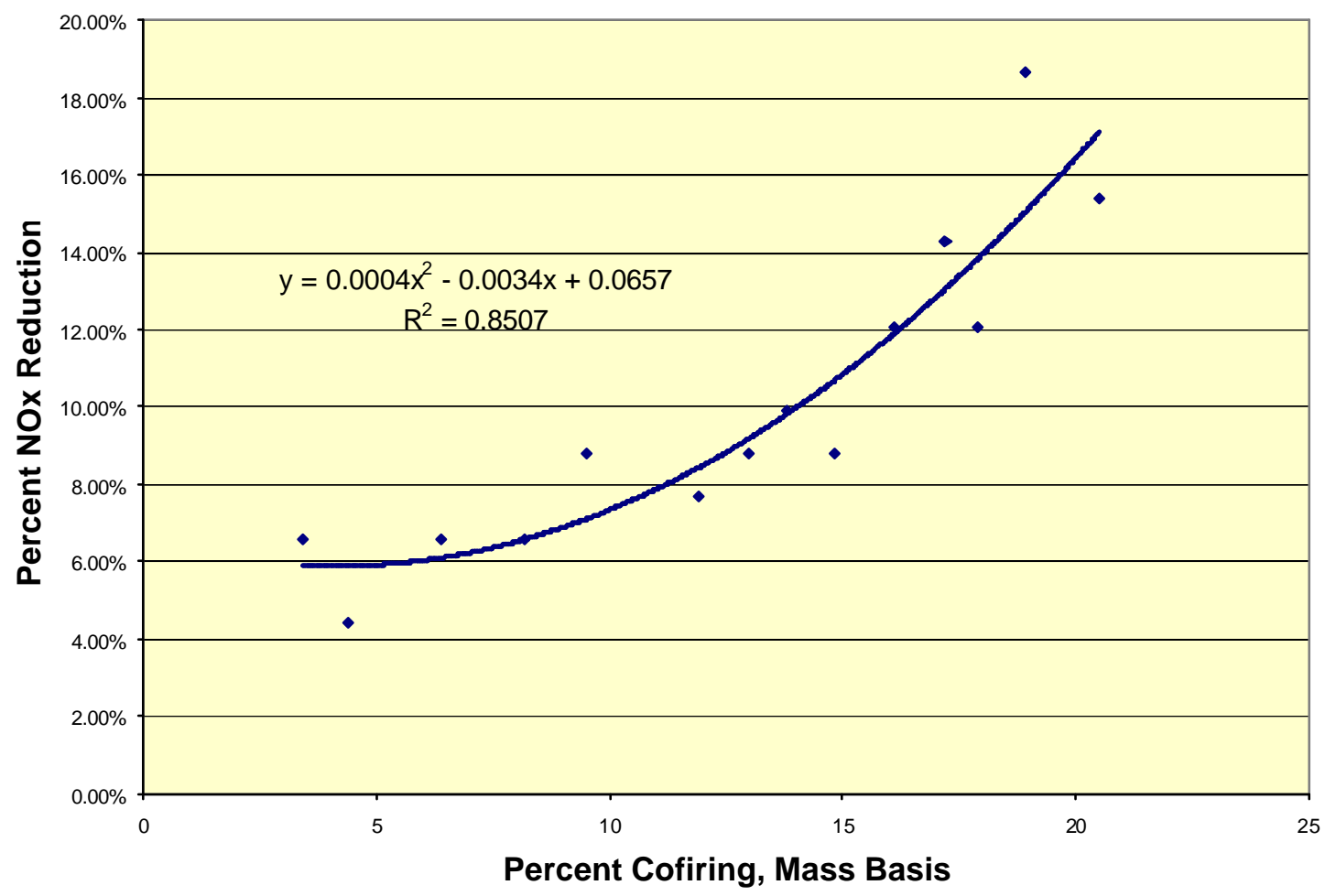

Figure 3-13. Percentage $\mathrm{NO}_{\mathrm{x}}$ Reductions Measured During Parametric Testing at Seward Generating Station.

Table 3-8. Kinetic Parameters for Sawdust and Pittsburgh Seam Bituminous Coal

\begin{tabular}{|c|c|c|c|}
\hline Fuel & Reaction & $\begin{array}{c}\text { Pre-exponential } \\
\text { Constant A (1/sec) }\end{array}$ & $\begin{array}{c}\text { Activation Energy E } \\
(\mathrm{kcal} / \mathrm{mol})\end{array}$ \\
\hline Sawdust & $\begin{array}{c}\text { Low Temperature } \\
\text { Devolatilization }(400- \\
\left.600^{\circ} \mathrm{C}\right)\end{array}$ & 1.17 & 0.681 \\
\hline Sawdust & $\begin{array}{c}\text { Higher Temperature } \\
\text { Devolatilization }(600- \\
\left.1000^{\circ} \mathrm{C}\right)\end{array}$ & 5.74 & 3.42 \\
\hline Pittsburgh Seam Coal & $\begin{array}{c}\text { Devolatilization }(1000- \\
\left.1700^{\circ} \mathrm{C}\right)\end{array}$ & 66.2 & 10.3 \\
\hline Sawdust & Char Oxidation & $1.63 \mathrm{E}+5$ & 25.7 \\
\hline \multicolumn{2}{|r|}{} & $3.27 \mathrm{E}+9$ & 40.4 \\
\hline Pittsburgh Seam Coal & Char Oxidation & & \\
\hline
\end{tabular}

Source: Johnson et. al., 2001. 
The ability of sawdust to devolatilizes rapidly, and at low temperatures, has the potential to create ignition of the entire fuel mass in a fuel rich environment. This process can result in staging of combustion within the flame, thereby reducing $\mathrm{NO}_{\mathrm{x}}$ emissions. Because the fuel nitrogen is also released early, and in the fuel rich environment, it converts to $\mathrm{N}_{2}$ as there is insufficient oxygen available to oxidize this nitrogen to NO.

The parametric tests at Seward Generating Station of GPU Genco were considered highly successful. They documented the potential for increasing the cofiring percentage by separate injection into wall fired PC boilers. They documented potential beneficial impacts when cofiring with wet coal, and additional emissions benefits. They also documented the fact that efficiency impacts would be modest, and could be managed. The success of this test program led to the decision on the part of GPU and the EPRIUSDOE Cooperative Agreement to pursue a demonstration at that site.

\subsubsection{The Seward Generating Station Demonstration}

Based upon the success of the parametric testing, Seward Generating Station proceeded with the development of a cofiring demonstration facility utilizing separate injection of the sawdust into the \#12 boiler. The design of the facility was based upon maximum use of the parametric test equipment. Further, the design was based upon the following principles:

- Providing a separate pressurized line, with positive air and fuel flow control, to each injection point in the boiler

- Preparing the fuel by screening, rather than grinding, with only oversized material being ground to <1/4" x 0 " particle sizes

- Complete integration of the controls into the power plant Bailly control system

The test program was designed to conform with, and amplify, the parametric tests. Again the emphasis was on capacity, efficiency, and emissions.

\subsubsection{Design of the Seward Generating Station Demonstration System}

The design of the Seward facility called for equipment to receive sawdust in walking floor vans, and to unload that sawdust in a manner that would minimize exposure to weather. The sawdust, therefore, would be unloaded into a walking floor unloader (see Figure 3-14). Once unloaded the sawdust would be immediately transported by means of a incline screw conveyor to a trommel screen (see Figure 315) for processing. The sawdust, screened to $<1 / 4$ " particle size, would then be pneumatically transported into a Harvistore Silo shown in Figure 3-14. 


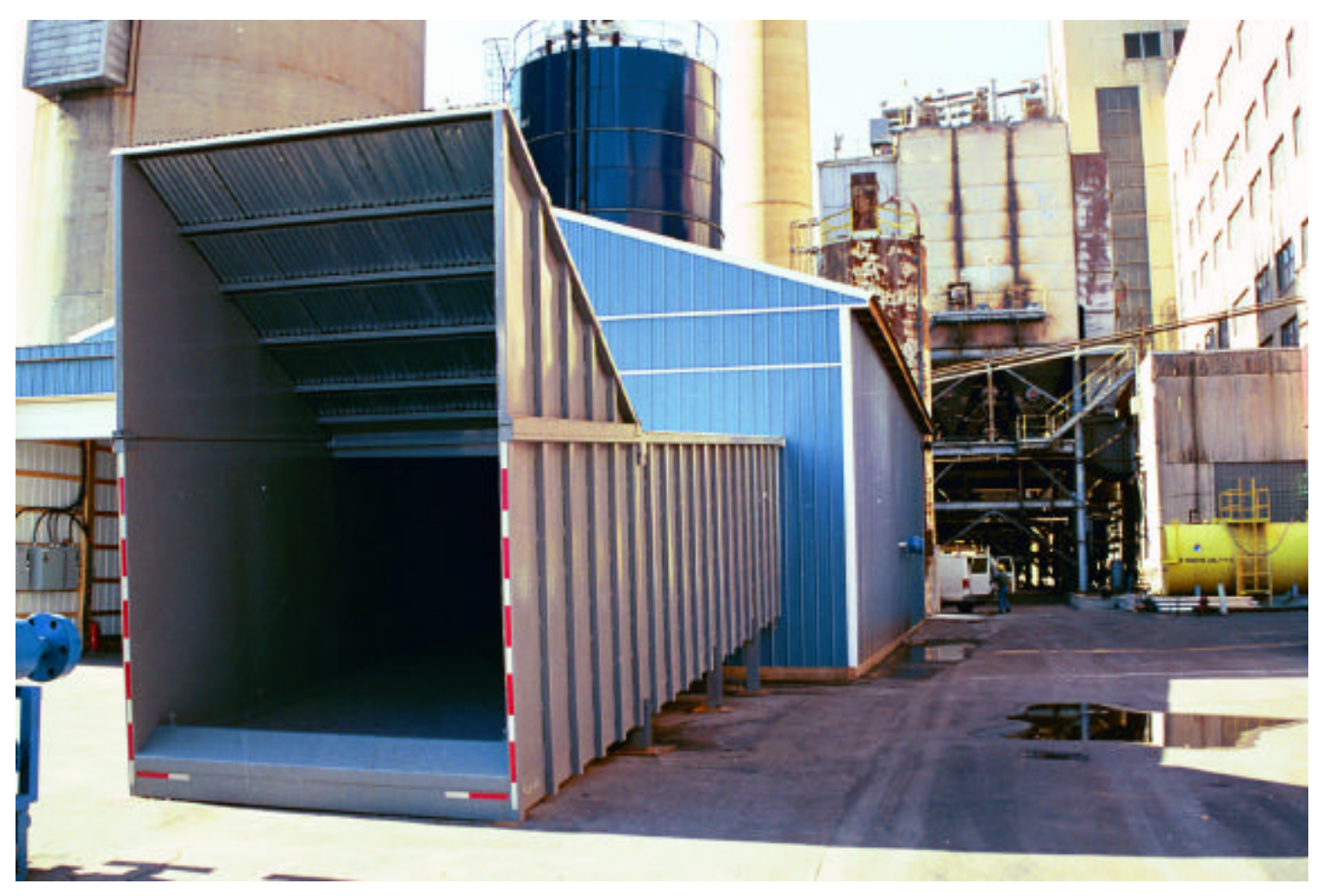

Figure 3-14. The Seward Demonstration Facility Walking Floor Sawdust Unloader

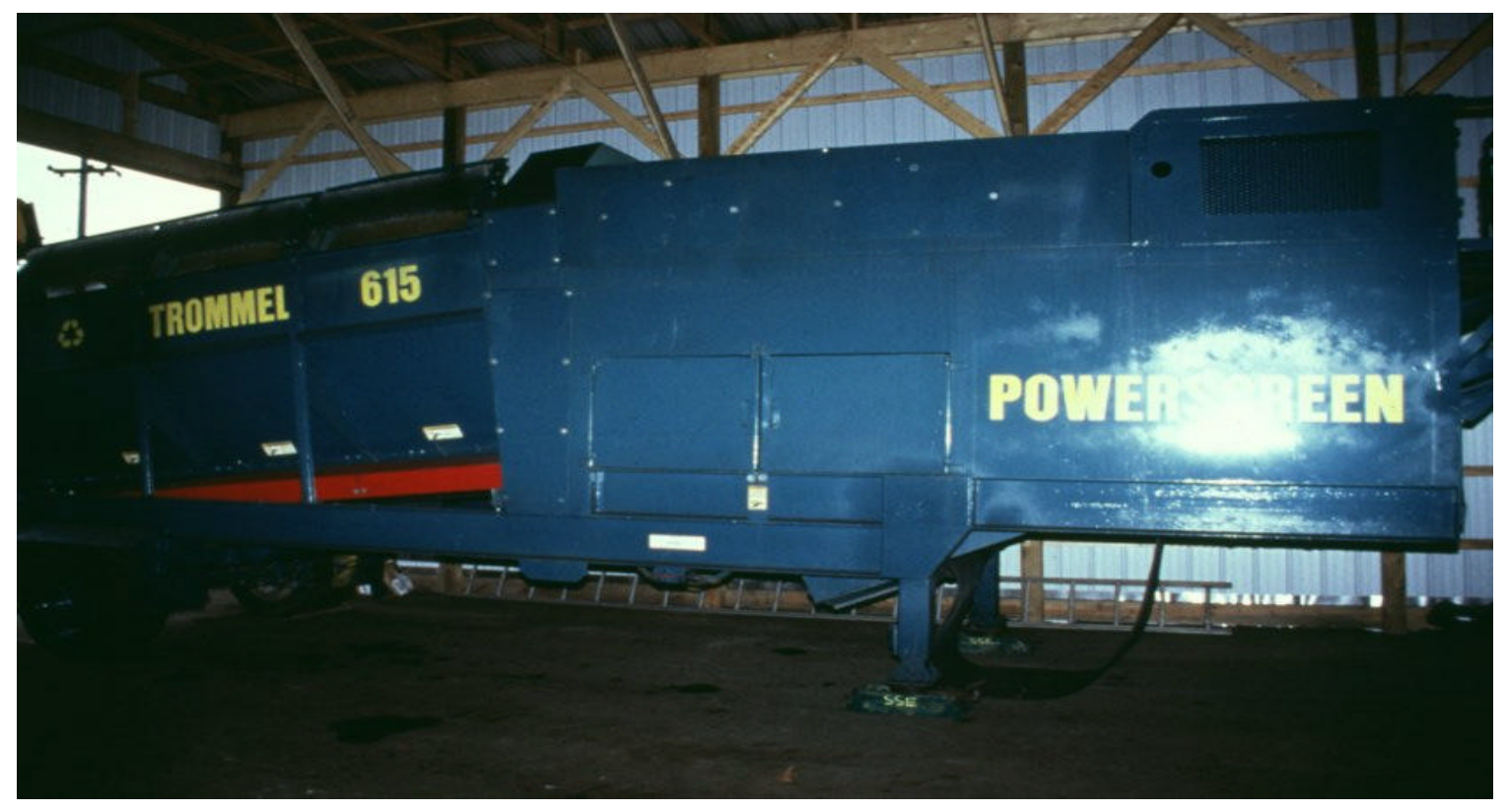

Figure 3-15. Installation of the Trommel Screen for Sawdust Preparation at Seward Generating Station 
Sawdust was to be reclaimed from the silo using a Laidig unloader, and would be transported to a surge hopper with a paddle conveyor, then from the surge hopper across a weigh belt feeder, and then deposited into a live bottom bin where metering screws would transport the sawdust to rotary air locks. The rotary air locks would discharge the sawdust into pneumatic transport lines. Each transport line would be supplied by an individual blower. Each burner of the boiler would be fed by a separate pneumatic transport line in order to control the flow of sawdust to each combustion system.

The sawdust, once transported, would be injected down the centerpipe of the selected burners. While the parametric test program involved firing the sawdust into each burner in the top row of burners, difficulties with the flame scanners resulted in a change during the demonstration. The sawdust was blown down the centerpipe of the two center burners - feeding sawdust to one burner in each row (see Figure 3-16). Once the sawdust entered the centerpipe, it was transported to the burner front. There the sawdust was diffused into the coal flame using the same diffusers and techniques employed during the parametric tests (see Figures 3-5 and 3-6 as previously shown). The transport velocity of the sawdust to the burner is $5,000 \mathrm{ft} / \mathrm{min}$ in order to overcome the flame speed of wood waste. The angle on the diffuser is set at $130^{\circ}$ compared to a burner basket angle of $120^{\circ}$. This creates a "flame within a flame" for sound combustion of the sawdust as previously discussed.

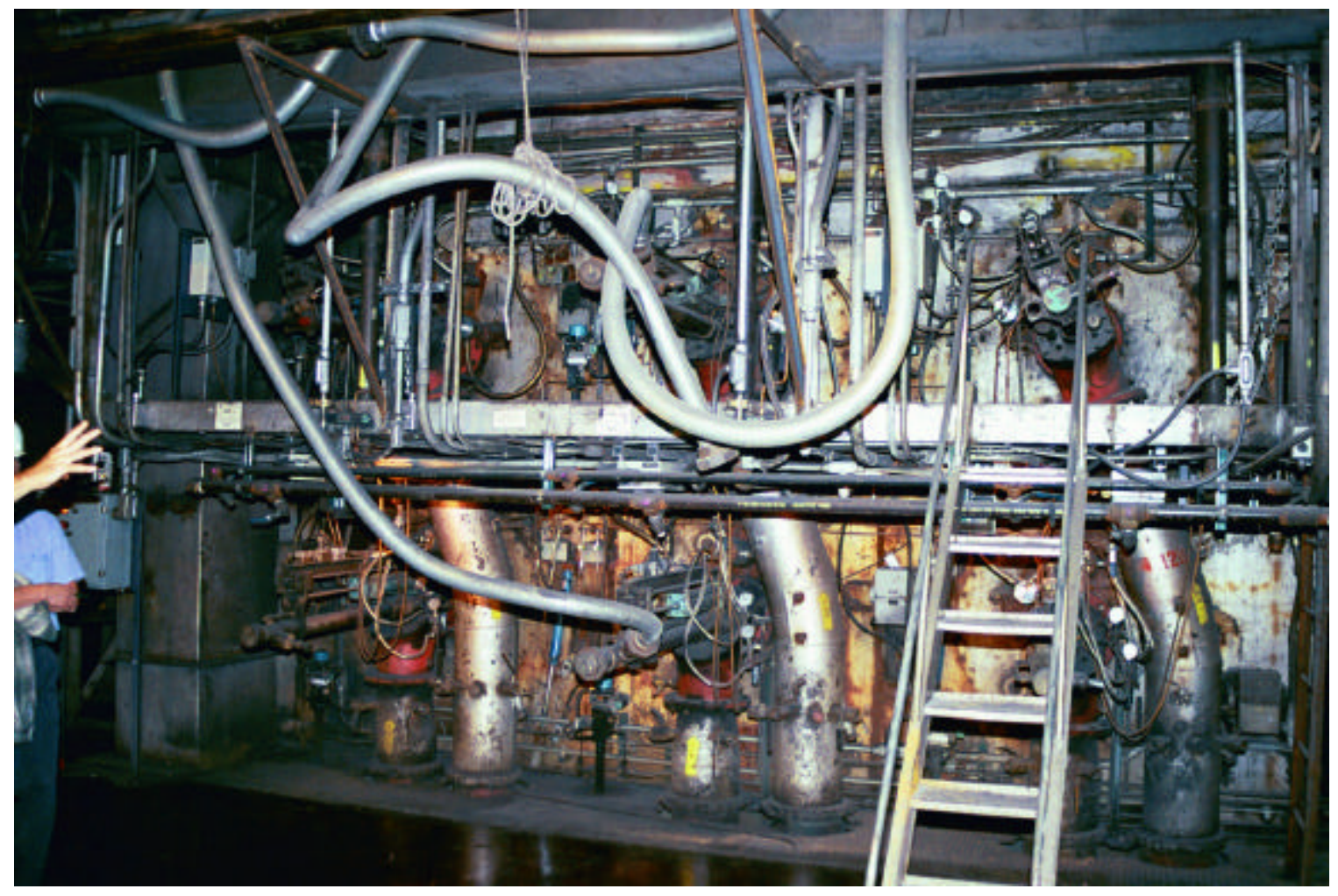

Figure 3-16. Flexible Pipe Connections for the Sawdust at the Seward Burner Front

The facility was constructed during the last quarter of 1998 and the first quarter of 1999. At that time GPU Genco expressed significant interest in expanding the project to Boiler \#15, a $147 \mathrm{MW}_{\mathrm{e}}$ tangentially-fired unit. Foster Wheeler designed special inserts for pneumatic injection of sawdust 
through unused oil gun ports between the A and B rows of coal burners. These inserts permit the sawdust injectors to follow burner tilts as controlled by the operators. Additional piping was installed. A fourth transport line was installed to provide for reaching all corners of the T-fired boiler. The rotary air locks and blowers were replaced with larger, more robust systems to facilitate pneumatic transport to all corners of Boiler \#15.

The entire facility was originally constructed for $\$ 988,000$. The expansion cost $\$ 687,000$. The expansion included an expanded capacity truck dump, increased capacity rotary airlocks, an additional rotary airlock, additions to the capacity of the surge bin, an additional metering screw, increased capacity blowers and an additional blower, additional piping and additional controls. Table 3-9 presents the capital costs of the initial Seward cofiring system, the expansion, and the total.

The original system was capable of firing $2.5 \mathrm{ton} / \mathrm{hr}$ of sawdust to boiler \#12. At $10 \times 10^{6} \mathrm{Btu} / \mathrm{ton}$, the sawdust is capable of delivering $25 \times 10^{6} \mathrm{Btu} / \mathrm{hr}$ to the boiler. Seward Generating Station boiler \#12 is a 32 MW unit that was installed in 1946, and has a net station heat rate (NSHR) of $\sim 14,000 \mathrm{Btu} / \mathrm{kWh}$. On this basis, the system supports the generation capacity of $1,785 \mathrm{~kW}$ of electricity. For this installation, the capital cost is $\$ 553 / \mathrm{kW}$ of biomass-supported capacity. A modern generating station would have a NSHR of about $10,000 \mathrm{Bu} / \mathrm{kWh}$. On that basis, the installation would have a capital cost of $\$ 395 / \mathrm{kW}$ supported by biofuel. Note, however, that the boiler is very small, and consequently the capital cost is very high. Several items were purchased at a minimum size, regardless of the boiler capacity. Consequently, as noted previously, engineering for modification of this system to cofire in Boiler \#15 was initiated.

The Seward \#15 project was sized for $10 \mathrm{ton} / \mathrm{hr}$, or the support of $10 \mathrm{MW}_{\mathrm{e}}$ of capacity. Operationally the unit probably would have fired $6-8 \mathrm{ton} / \mathrm{hr}$ of biofuel. The modified system increased the capital cost to $\$ 1,646,000$. Because Seward Unit \#15 was much larger than Seward \#12, the total capital cost was equivalent to $\$ 165 / \mathrm{kW}$ supported by biofuel. Note the dramatic difference in capital cost on a $\$ / \mathrm{kW}$ basis; this is the consequence of economies of scale between $32 \mathrm{MWe}$ and $147 \mathrm{MWe}$.

\subsubsection{Seward Demonstration Test Results}

Once the Seward system, as originally configured, was constructed it was ready for testing. Difficulties arose because of a warm winter; there was little need for the capacity of Boiler \#12. Because this is an old unit, constructed in the late 1940's, it is low on the dispatch ladder. When the unit was ready for firing, additional problems were encountered with the flame scanners, necessitating the change from injecting biofuel in the three top burners to injecting biofuel in the two center burners. Delays were encountered with the original truck unloading design, causing the modification previously noted. Trucks required $>1$ hour to unload.

Table 3-9. Capital Cost Breakdown for the Seward Demonstration System

\begin{tabular}{|l|l|}
\hline \multicolumn{1}{|c|}{ COST CATEGORY } & Cost $(*)$ \\
\hline INITIAL INSTALLATION & \\
\hline
\end{tabular}




\begin{tabular}{|c|c|}
\hline Powerscreen Trommel (20 ton/hr) & $\$ 120,000$ \\
\hline Weigh Belt Feeder Supply & $\$ 33,000$ \\
\hline Fuel Barn Supply & $\$ 90,000$ \\
\hline Fuel Silo Supply & $\$ 175,000$ \\
\hline Electrical Design, Supply, and Erection & $\$ 75,000$ \\
\hline Control Room Supply Subcontract & $\$ 15,000$ \\
\hline Incline Conveyor Supply & $\$ 80,000$ \\
\hline Surge Bin Supply & $\$ 15,000$ \\
\hline Motor Control Center & $\$ 10,000$ \\
\hline Other Vendor Costs (Mechanical Erection, Misc.) & $\$ 133,000$ \\
\hline Total of Vendor Costs & $\$ 843,000$ \\
\hline All Other Costs & $\$ 145,000$ \\
\hline TOTAL SYSTEM COSTS FOR THE INITIAL INSTALLATION & $\$ 988,000$ \\
\hline TOTAL SYSTEM COSTS FOR THE EXPANSION & $\$ 687,000$ \\
\hline TOTAL SEWARD DEMONSTRATION CAPITAL COSTS & $\$ 1,675,000(* *)$ \\
\hline \multicolumn{2}{|c|}{$\begin{array}{l}(*) \text { Totals may not add due to rounding } \\
(* *) \text { Totals do not include costs incurred for the injectors and equipment associated with th } \\
\text { parametric tests; however there was sufficient rework of those items to make this a reasonabl } \\
\text { representative number. }\end{array}$} \\
\hline
\end{tabular}

When those issues were addressed, the system was ready for intensive testing. Capacity implications could not be tested because of the warm weather. However, efficiency and emissions could be addressed. Such testing occurred in April 1999. Table 3-10 documents the composition of sawdust and coal obtained for the cofiring demonstration tests in April 1999.

The testing was conducted cofiring up to 15 percent by mass ( 7 percent by heat) in Boiler \#12. Load was varied between about 65 percent and 100 percent. Excess $\mathrm{O}_{2}$ varied between 3 percent and 4.5 percent. The testing followed the conventional form of obtaining fuel samples for analysis, obtaining flyash and bottom ash samples for analysis, and taking data in the control room. Data taking was accomplished both manually and with plant computers. For analytical purposes, the computergenerated data set was used. Test conditions used during the Seward Demonstration Boiler \#12 tests are shown in Table 3-11. Basic results are shown in Table 3-12.

Table 3-10. Composition and Characteristics of Fuels Used in Seward Cofiring Demonstration Parameter Fuel 


\begin{tabular}{|c|c|c|}
\hline & Sawdust & Coal \\
\hline \multicolumn{3}{|l|}{ Proximate Analysis (weight percent } \\
\hline Fixed Carbon & 11.46 & 57.63 \\
\hline Volatile Matter & 49.27 & 21.66 \\
\hline Ash & 0.31 & 14.81 \\
\hline Moisture & 38.96 & 5.91 \\
\hline \multicolumn{3}{|l|}{ Ultimate Analysis (weight percent) } \\
\hline Carbon & 30.27 & 71.27 \\
\hline Hydrogen & 3.61 & 4.05 \\
\hline Oxygen & 26.62 & 0.68 \\
\hline Nitrogen & 0.11 & 1.30 \\
\hline Sulfur & 0.01 & 1.99 \\
\hline Ash & 0.31 & 14.81 \\
\hline Moisture & 38.96 & 5.91 \\
\hline Higher Heating Value (Btu/lb) & 5,165 & 12,179 \\
\hline \multicolumn{3}{|l|}{ Performance Parameters } \\
\hline Volatile/Fixed Carbon Ratio & 4.30 & 0.375 \\
\hline Lbs Fuel/ $/ 10^{6}$ Btu & 193.61 & 82.11 \\
\hline Lbs Moisture $/ 10^{6} \mathrm{Btu}$ & 75.92 & 4.84 \\
\hline Lbs Ash $/ 10^{6} \mathrm{Btu}$ & 0.60 & 12.16 \\
\hline Lbs Fuel Nitrogen $/ 10^{6} \mathrm{Btu}$ & 0.21 & 1.07 \\
\hline Lbs Fuel Sulfur/ $10^{6} \mathrm{Btu}$ & 0.04 & 3.26 \\
\hline
\end{tabular}

Table 3-11. Test Conditions at the Seward Generating Station Demonstration

\begin{tabular}{|c|c|c|c|c|c|}
\hline $\begin{array}{c}\text { Test } \\
\text { No. }\end{array}$ & $\begin{array}{l}\text { Main Steam } \\
\text { Flow (kpph) }\end{array}$ & $\begin{array}{l}\text { Excess } \mathrm{O}_{2} \% \\
\text { (total basis) }\end{array}$ & $\begin{array}{l}\text { Cofiring Rate } \\
\text { (tons/hr) }\end{array}$ & \multicolumn{2}{|l|}{ Cofiring Percentage } \\
\hline & & & & Mass Basis & Btu Basis \\
\hline 1 & 309.76 & 3.50 & 0.00 & 0.00 & 0.00 \\
\hline 2 & 300.14 & 4.42 & 0.75 & 4.89 & 2.16 \\
\hline 3 & 297.30 & 4.18 & 1.50 & 9.63 & 4.37 \\
\hline 4 & 286.49 & 4.43 & 2.10 & 13.60 & 6.32 \\
\hline 5 & 299.36 & 3.90 & 2.25 & 13.86 & 6.45 \\
\hline 6 & 319.20 & 3.77 & 2.40 & 13.89 & 6.47 \\
\hline 7 & 319.70 & 3.76 & 2.56 & 14.66 & 6.86 \\
\hline 8 & 255.29 & 4.29 & 0.00 & 0.00 & 0.00 \\
\hline 9 & 235.52 & 5.53 & 1.50 & 11.74 & 5.39 \\
\hline 10 & 277.25 & 4.21 & 1.65 & 11.10 & 5.08 \\
\hline 11 & 272.88 & 4.04 & 1.80 & 12.19 & 5.62 \\
\hline 12 & 283.16 & 3.83 & 1.95 & 12.62 & 5.83 \\
\hline 13 & 286.37 & 3.73 & 2.10 & 13.43 & 6.24 \\
\hline 14 & 283.08 & 4.05 & 2.25 & 14.42 & 6.74 \\
\hline
\end{tabular}


Table 3-12. Basic Results at the Seward Generating Station Demonstration

\begin{tabular}{|c|c|c|c|c|c|c|c|}
\hline \multirow{2}{*}{$\begin{array}{l}\text { Test } \\
\text { No. }\end{array}$} & \multirow{2}{*}{$\begin{array}{l}\text { Main Steam } \\
\text { Flow (kpph) }\end{array}$} & \multicolumn{2}{|c|}{ Cofiring Percentage } & \multirow{2}{*}{$\begin{array}{lr}\text { Total } & \text { Heat } \\
\text { Input } & \text { to } \\
\text { Boiler } & \left(10^{6}\right. \\
\text { Btu/hr }) & (*) \\
\end{array}$} & \multirow{2}{*}{$\begin{array}{l}\text { Useful Heat } \\
\text { Generated by } \\
\text { Boiler } \quad\left(10^{6}\right. \\
\text { Btu/hr }) \\
\end{array}$} & \multirow{2}{*}{$\begin{array}{l}\text { Boiler } \\
\text { Efficiency } \\
\text { (percent) }\end{array}$} & \multirow{2}{*}{$\begin{array}{l}\mathrm{NO}_{\mathrm{x}} \\
\text { Emissions } \\
\left(\mathrm{lb} / 10^{6} \mathrm{Btu}\right)\end{array}$} \\
\hline & & Mass Basis & Btu Basis & & & & \\
\hline 1 & 309.76 & 0.00 & 0.00 & 361.57 & 311.06 & 86.0 & 0.796 \\
\hline 2 & 300.14 & 4.89 & 2.16 & 350.97 & 301.38 & 85.9 & 0.832 \\
\hline 3 & 297.30 & 9.63 & 4.37 & 346.75 & 297.23 & 85.7 & 0.782 \\
\hline 4 & 286.49 & 13.60 & 6.32 & 335.62 & 287.16 & 85.6 & 0.763 \\
\hline 5 & 299.36 & 13.86 & 6.45 & 352.22 & 300.83 & 85.4 & 0.751 \\
\hline 6 & 319.20 & 13.89 & 6.47 & 374.75 & 319.51 & 85.3 & 0.742 \\
\hline 7 & 319.70 & 14.66 & 6.86 & 376.90 & 320.74 & 85.1 & 0.735 \\
\hline 8 & 255.29 & 0.00 & 0.00 & 304.30 & 261.79 & 86.0 & 0.779 \\
\hline 9 & 235.52 & 11.74 & 5.39 & 280.85 & 241.17 & 85.9 & 0.811 \\
\hline 10 & 277.25 & 11.10 & 5.08 & 328.00 & 281.16 & 85.7 & 0.739 \\
\hline 11 & 272.88 & 12.19 & 5.62 & 323.64 & 276.91 & 85.6 & 0.699 \\
\hline 12 & 283.16 & 12.62 & 5.83 & 337.87 & 288.58 & 85.4 & 0.703 \\
\hline 13 & 286.37 & 13.43 & 6.24 & 340.09 & 289.96 & 85.3 & 0.735 \\
\hline 14 & 283.08 & 14.42 & 6.74 & 337.33 & 287.07 & 85.1 & 0.744 \\
\hline
\end{tabular}

The efficiency implications of cofiring at the Seward Demonstration are shown in Figures 3-17 and 318. Note that the efficiency degradation is $<1$ percent when cofiring at about $14-15$ percent (mass basis), and is $<0.4$ percent when cofiring at about 10 percent (mass basis). The efficiency penalties are modest and economically manageable. 


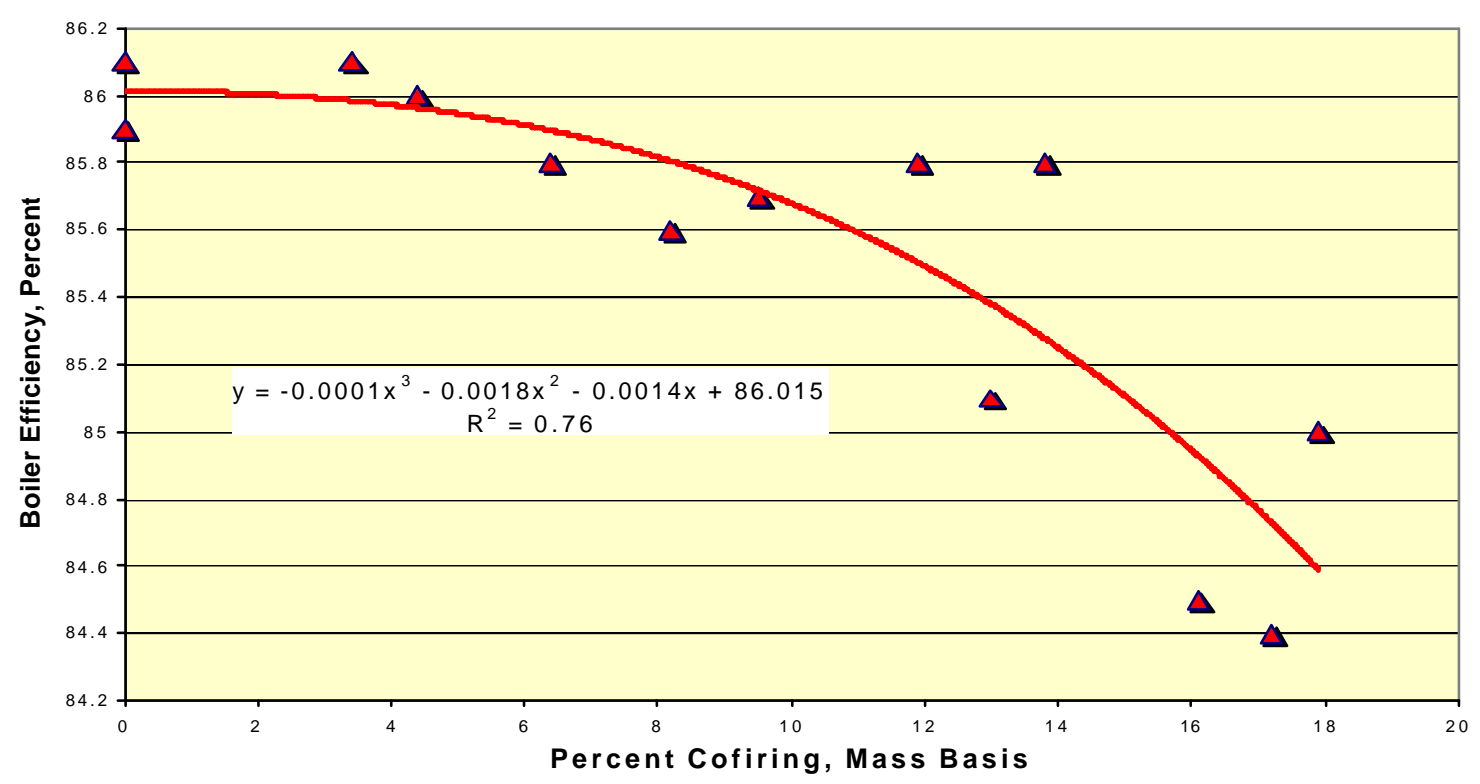

Figure 3-17. Boiler Efficiency Loss as a Function of Cofiring Percentage (Mass Basis) at the Seward Generating Station Cofiring Demonstration

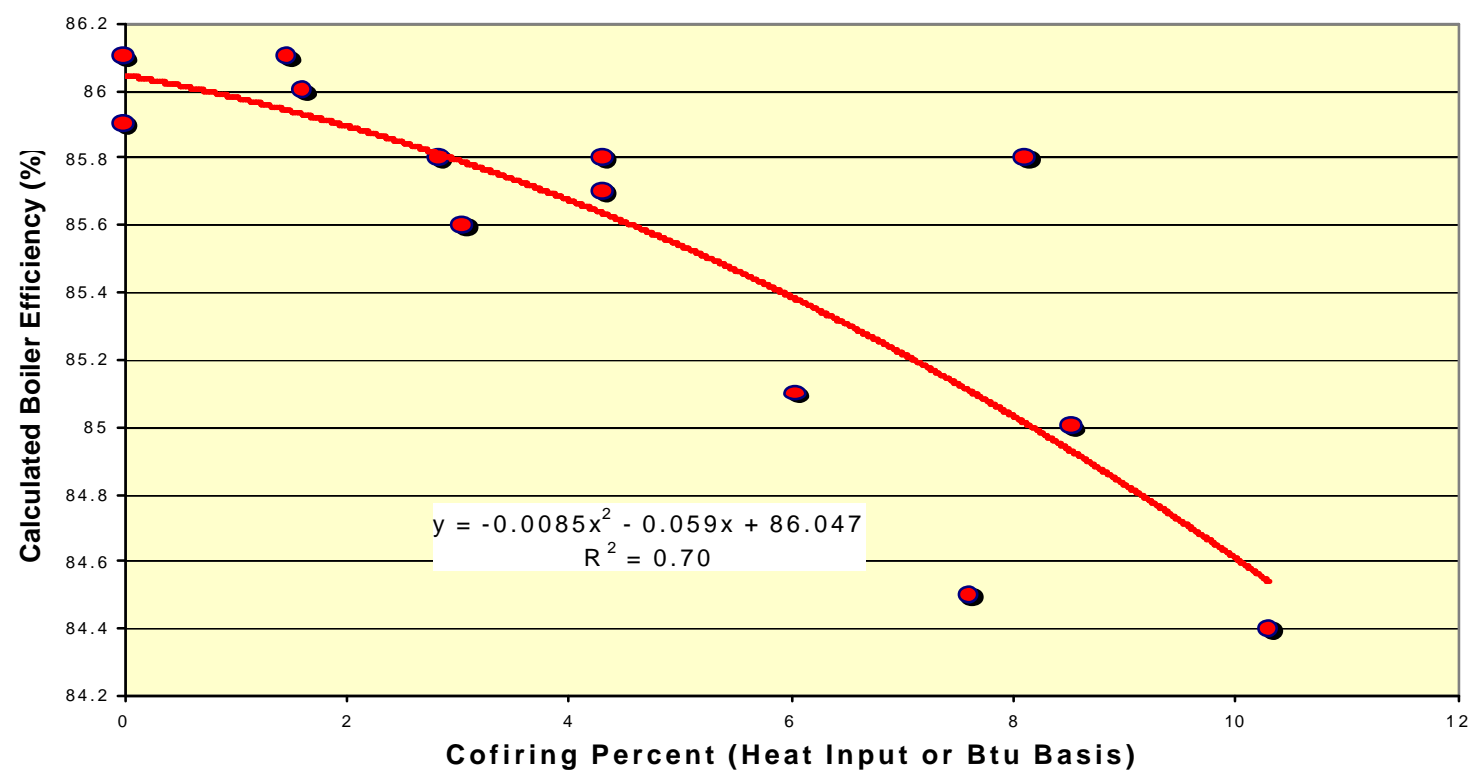

Figure 3-18. Boiler Efficiency Loss as a Function of Cofiring Percentage (Heat Input Basis) at the Seward Generating Station Cofiring Demonstration 
The determinants of efficiency were largely moisture in the fuel and hydrogen content in the fuel. The influence of cofiring on excess $\mathrm{O}_{2}$ requirements is shown in Figure 3-19; the influence of cofiring on unburned carbon in the flyash is shown in Figure 3-20. Note that there is a downward trend in the excess $\mathrm{O}_{2}$ used as a function of increased cofiring levels. Note, also, that the apparent slight upward trend in unburned carbon or loss on ignition in the flyash is modest indeed - and not statistically significant.

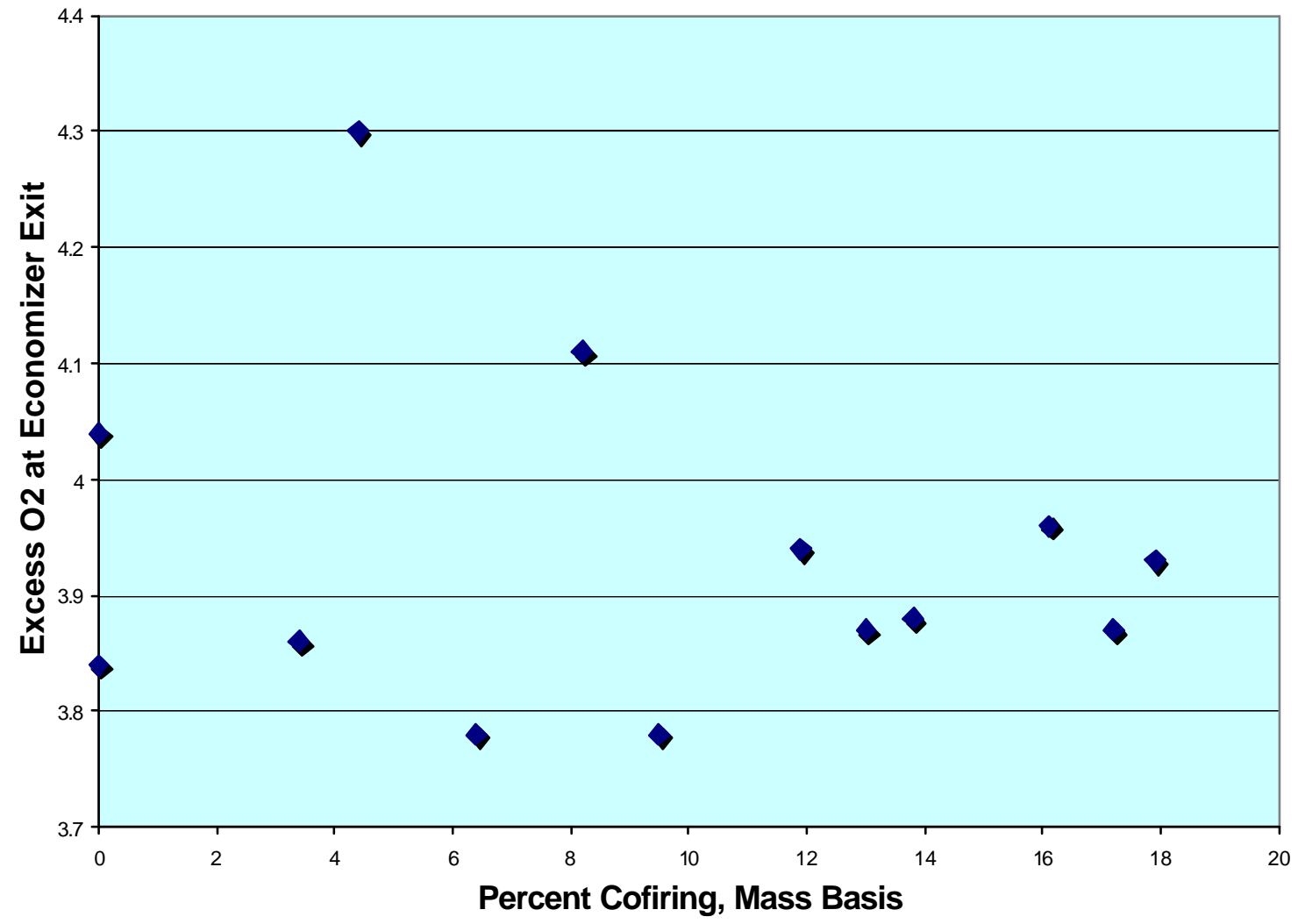

Figure 3-19. Influence of Cofiring on Excess Oxygen Used in Combustion 


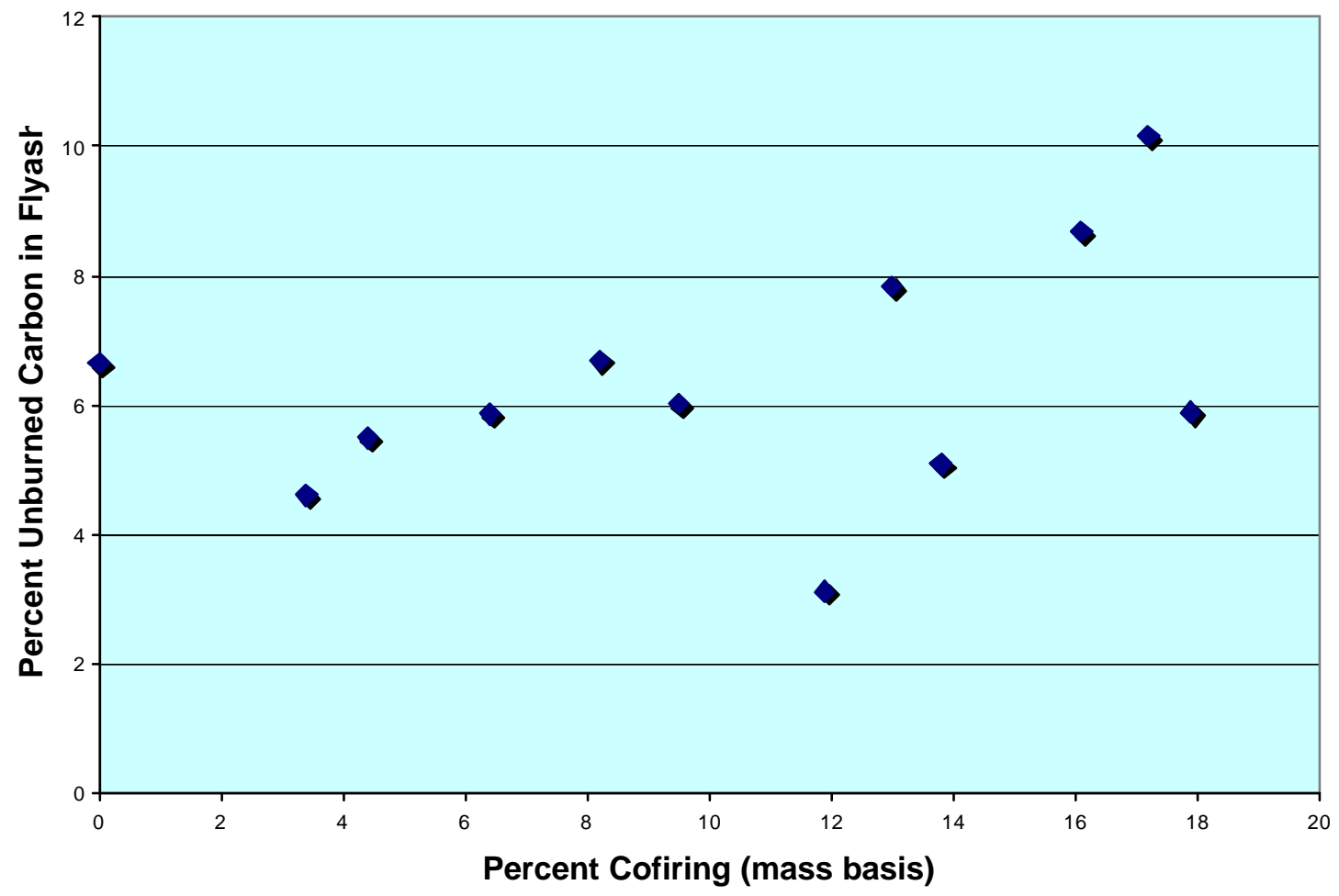

Figure 3-20. Influence of Cofiring on Unburned Carbon in the Flyash

Cofiring had a favorable impact on airborne emissions at the Seward Generating Station Demonstration. Opacity was not impacted. $\mathrm{SO}_{2}$ was reduced proportional to the cofiring percentage on a heat input basis. NOx emissions were dramatically reduced as is shown in previously in Table 3-12. . Figures 321 through 3-23 also graphically depict the trends in $\mathrm{NO}_{\mathrm{x}}$ emissions as a function of cofiring. Figures 321 and 3-22 depict $\mathrm{NO}_{\mathrm{x}}$ emissions as a function of cofiring level. Figure 3-23 relates $\mathrm{NO}_{\mathrm{x}}$ emissions to volatile/fixed carbon ratio, documenting the influence of volatility on $\mathrm{NO}_{\mathrm{x}}$ formation. V/FC ratios increase with increased cofiring. 


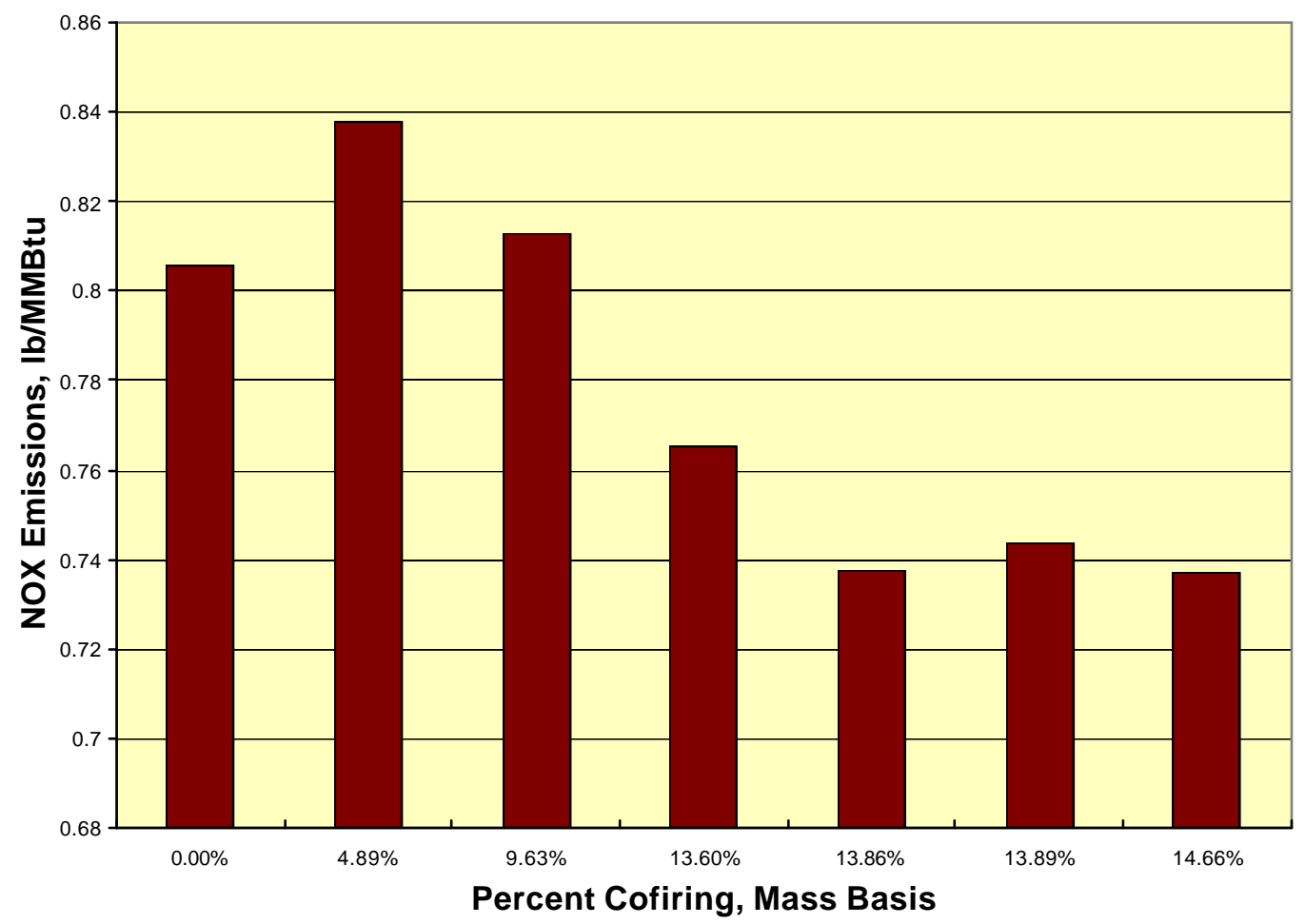

Figure 3-21. $\mathrm{NO}_{\mathrm{x}}$ Emissions During the Seward Demonstration as a Function of Cofiring Percentage (Mass Basis)

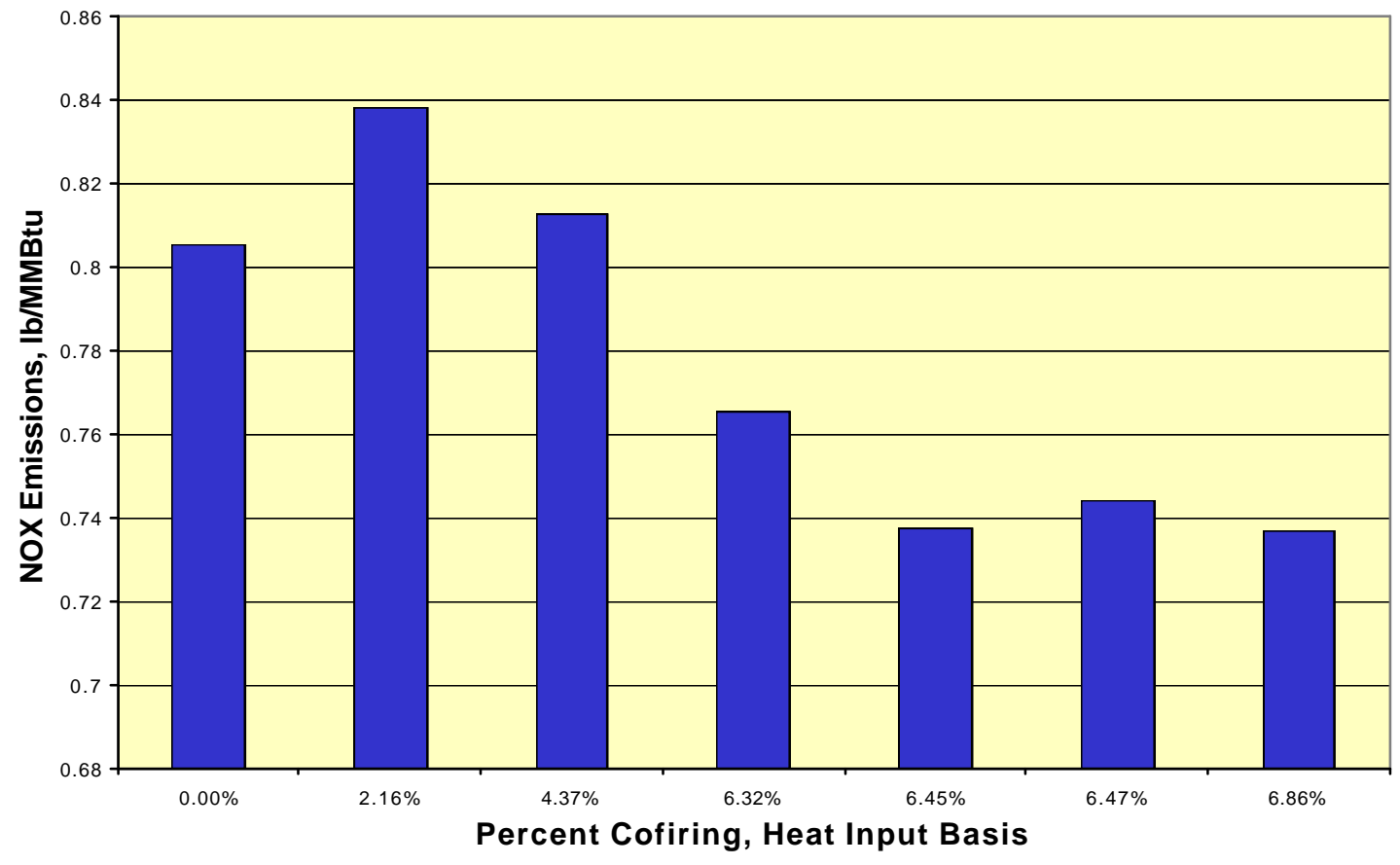


Figure 3-22. $\mathrm{NO}_{\mathrm{x}}$ Emissions During the Seward Demonstration as a Function of Cofiring Percentage (Heat Input Basis)

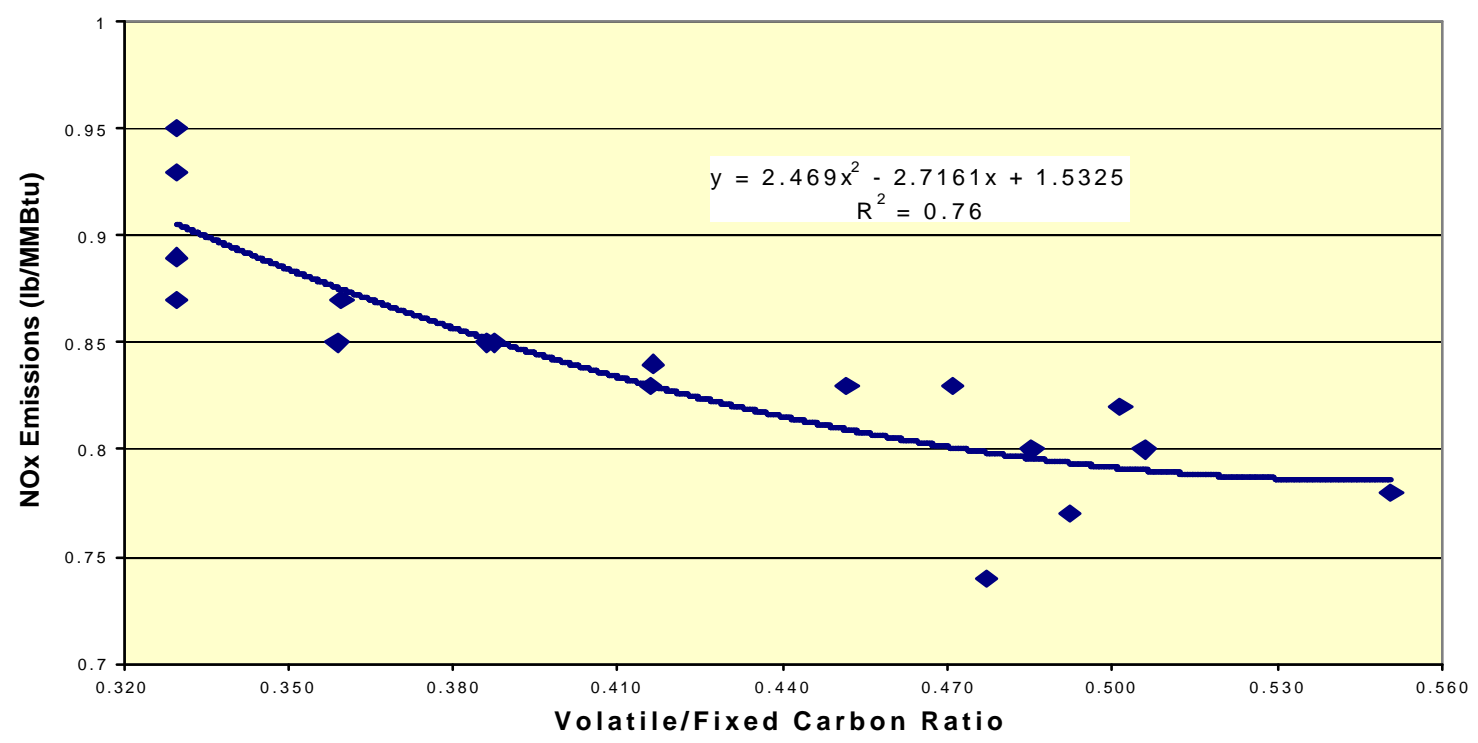

Figure 3-23. $\mathrm{NO}_{\mathrm{x}}$ Emissions at the Seward Generating Station Cofiring Demonstration as a Function of Volatile/Fixed Carbon Ratio

These $\mathrm{NO}_{\mathrm{x}}$ data lead to two $\mathrm{NO}_{\mathrm{x}}$ reduction equations:

$$
\mathrm{NO}_{\mathrm{x}}=0.030+0.0017(\mathrm{~L})+0.082(\mathrm{EO} 2)-1.917\left(\mathrm{~W}_{\mathrm{h}}\right)
$$

Where $\mathrm{NO}_{\mathrm{x}}=$ oxides of nitrogen, $\mathrm{lb} / 10^{6} \mathrm{Btu}, \mathrm{L}=$ load measured as main steam flow in $\mathrm{kpph}, \mathrm{EO} 2=$ excess $\mathrm{O}_{2}$ reported in the control room (total basis), and $\mathrm{W}_{\mathrm{h}}=$ wood cofiring percentage, heat input basis. The coefficient of determination for equation [14] is very high; $r^{2}=0.93$. Further, the probability that any term is a random occurrence is extremely small. These probabilities are as follows: $\mathrm{L}=$ $2.09 \times 10^{-5} ; \mathrm{EO} 2=2.53 \times 10^{-5} ; \mathrm{W}_{\mathrm{h}}=8.39 \times 10^{-7}$; and the equation as a whole $=4.36 \times 10^{-6}$.

$$
\mathrm{NO}_{\mathrm{x}}=0.026+0.0017(\mathrm{~L})+0.083(\mathrm{EO} 2)-0.899\left(\mathrm{~W}_{\mathrm{m}}\right)
$$

Where $\mathrm{W}_{\mathrm{m}}=$ wood cofiring percentage, mass basis. Again the $\mathrm{r}^{2}=0.93$. The probabilities are essentially identical in equation [15] to those of equation [14].

The data presented above demonstrate that biomass cofiring in wall-fired pulverized coal boilers, when properly managed, can have a significant benefit in $\mathrm{NO}_{\mathrm{x}}$ reduction. These $\mathrm{NO}_{\mathrm{x}}$ reductions are not 
sufficient to preclude using other $\mathrm{NO}_{\mathrm{x}}$ control strategies. However they can be used in association with other technologies to control these emissions.

The Seward Generating Station cofiring demonstration was successful. Unfortunately it was truncated as a consequence of the fact that the boiler was old, small, and inefficient. It was idled, and used quite sparingly. Its capacity factor fell to $<10$ percent. Seward Generating Station Unit \#15 houses a hybrid Selective Catalytic Reduction/Selective Non-Catalytic Reduction system for $\mathrm{NO}_{\mathrm{x}}$ control, and therefore could not be used for cofiring demonstration due to the catalyst deactivation issue.

\subsection{THE BLOUNT ST. STATION SWITCHGRASS COFIRING TEST}

The test program at Blount St Station of Madison Gas \& Electric, described by Aerts and Ragland (1997) and Ragland, Aerts, and Weiss (1996), was the first cofiring test using switchgrass as the biomass fuel. Testing was sponsored by the Great Lakes Regional Biomass Program with support from EPRI through the Cooperative Agreement, Wisconsin Power \& Light (now Alliant Energy), and the Nebraska Public Power District. The test program was conducted by the University of Wisconsin Department of Mechanical Engineering under Professor Kenneth Ragland. Again the basis of this test program was separate injection of the biomass without impacting the coal delivery system.

The objectives of the program were to demonstrate that switchgrass could be cofired successfully at up to 15 percent (mass basis) without impacting boiler capacity. The objectives included evaluating the slagging and fouling consequences of cofiring switchgrass, along with determining the impact of cofiring on airborne emissions including opacity, $\mathrm{SO}_{2}$, and $\mathrm{NO}_{x}$.

\subsubsection{The Blount St. Station Facility}

The Blount St. Station boiler used for this test program is unit \#8 a $50 \mathrm{MW}_{\mathrm{e}}$ front wall fired unit generating some $400,000 \mathrm{lb} / \mathrm{hr}$ of $1250 \mathrm{psig} / 950^{\circ} \mathrm{F}$ steam. It is not a reheat unit. The boiler is equipped with 3 rows of burners, with each row containing 3 burners. Essentially this boiler is one size larger than the Seward \#12 boiler. Figure 3-24 depicts Blount St. Station Unit \#8 boiler. Unit \#8, like its sister unit \#9 has been modified to fire paper-derived fuel (PDF). It has a PDF processing facility which ultimately injects the opportunity fuel between the first and second row of burners.

The PDF facility was used to handle the switchgrass. While the switchgrass was initially shredded in the PDF facility, this proved impractical. Consequently the switchgrass was shredded in a tub grinder off site, and then trucked to the alternate fuel handling system at Blount St. where it was bunkered and then fed into the boiler. Figure 3-25 depicts the PDF handling system used to manage the switchgrass. Note that the figure shows a shredder/hammermill in the process. This was used only in some preliminary runs. 


\subsubsection{Characteristics of the Switchgrass}

The University of Wisconsin considered switchgrass from Chariton Valley, IA and switchgrass grown in Wisconsin. The Wisconsin grass, obtained on a research basis from CRP lands, was ultimately used for the bulk of the testing. The ultimate analysis of the switchgrass is shown in Table 3-13. Note that it is significantly drier than sawdust, and also contains substantially more nitrogen and ash or inorganic material than the typical woody biomass used in cofiring.

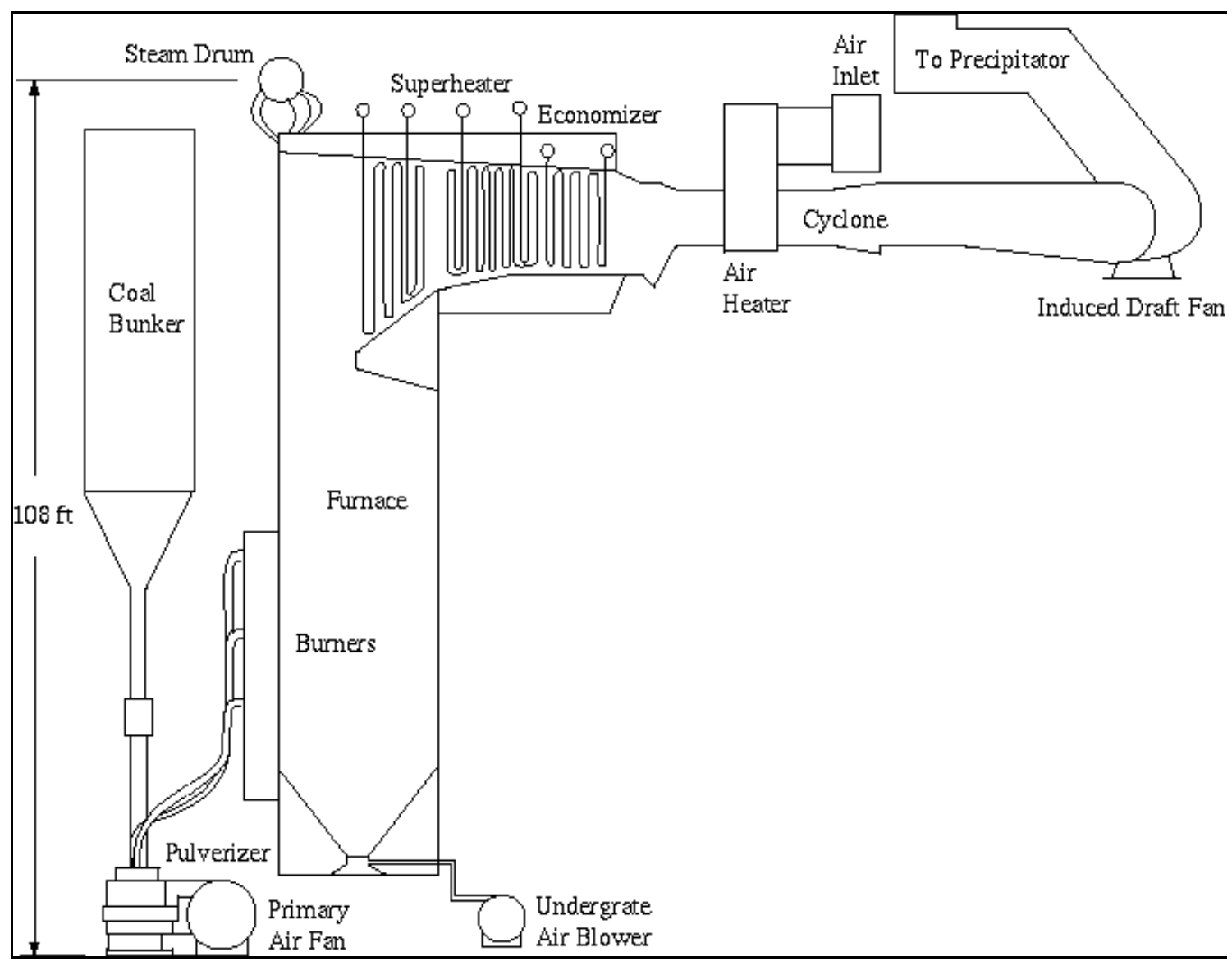

Figure 3-24. Boiler \#8 at Blount St. Station, Used for Switchgrass Cofiring (Source: Aerts and Ragland, 1997) 


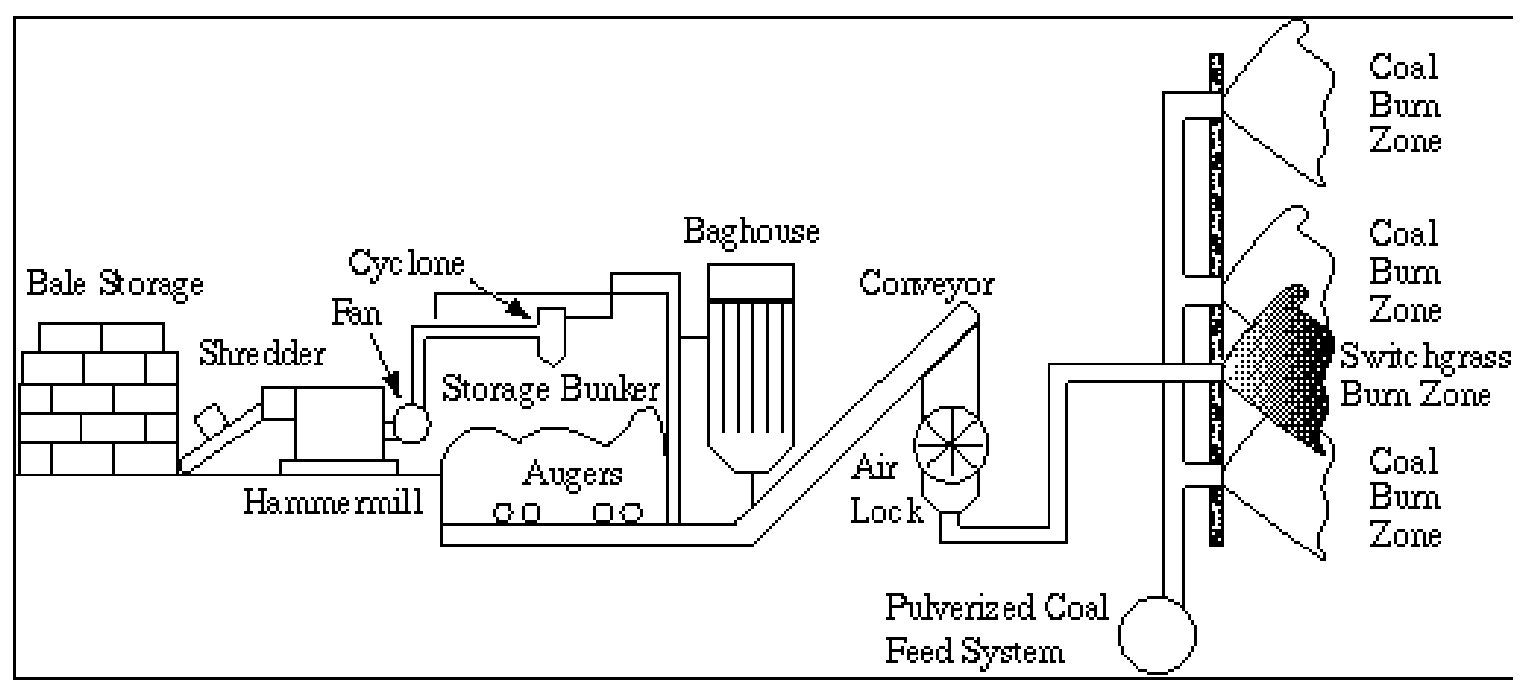

Figure 3-25. The Opportunity Fuel Handling System at Blount St. Station Used for Switchgrass Cofiring

(Source: Aerts and Ragland, 1997)

Table 3-13. Typical Proximate and Ultimate Analysis for Switchgrass

\begin{tabular}{|r|c|c|}
\hline \multicolumn{2}{|c|}{ Parameter } & \multicolumn{2}{|c|}{ Switchgrass } \\
\hline Proximate Analysis (wt \%) & As-Received Basis & Dry Basis \\
\hline Fixed Carbon & 9.5 & 10.68 \\
\hline Volatile Matter & 74.69 & 83.97 \\
\hline Ash (Inorganic Matter) & 4.76 & 5.35 \\
\hline Moisture & 11.05 & 0.00 \\
\hline Carbon & & 47.57 \\
\hline Hydrogen & 42.31 & 5.76 \\
\hline Oxygen & 5.12 & 40.44 \\
\hline Nitrogen & 35.97 & 0.80 \\
\hline Sulfur & 0.71 & 0.18 \\
\hline Chlorine & 0.16 & 0.03 \\
\hline Moisture & 0.03 & 5.22 \\
\hline Analysis (wt \%) (Inorganic Matter) & 4.65 & 0.00 \\
\hline Higher Heating Value (Btu/lb) & 11.05 & 7945 \\
\hline
\end{tabular}

Source: Aerts and Ragland, 1997.

The ash analysis is particularly interesting, as shown in Tables 3-14 and 3-15. Note that the base/acid ratio determined from the data in Table 3-14 is 0.45 . This is significantly higher than the B/A ratio for typical bituminous coals. The relatively high concentration of potassium in the switchgrass ash is the dominant contributor to the increased B/A ratio; it further suggests the potential for slagging and fouling 
problems (see Baxter et. al., 1996b). Note, also, that the ash fusion temperatures reported in Table 315 are substantially lower than those typically associated with bituminous coals.

Table 3-14. Ash Elemental Analysis of Switchgrass Inorganic Matter

\begin{tabular}{|c|c|}
\hline Element, in Oxide Form & Wt Percent (dry basis) in Ash \\
\hline $\mathrm{SiO}_{2}$ & 61.31 \\
\hline $\mathrm{Al}_{2} \mathrm{O}_{3}$ & 0.72 \\
\hline $\mathrm{TiO}_{2}$ & 0.05 \\
\hline $\mathrm{Fe}_{2} \mathrm{O}_{3}$ & 0.48 \\
\hline $\mathrm{CaO}$ & 9.62 \\
\hline $\mathrm{MgO}$ & 5.53 \\
\hline $\mathrm{Na}_{2} \mathrm{O}$ & 0.38 \\
\hline $\mathrm{K}_{2} \mathrm{O}$ & 11.91 \\
\hline $\mathrm{SO}_{3}$ & 2.34 \\
\hline $\mathrm{P}_{2} \mathrm{O}_{5}$ & 7.07 \\
\hline $\mathrm{Mn}_{3} \mathrm{O}_{4}$ and Other & 0.59 \\
\hline Base/Acid Ratio & $\mathbf{0 . 4 5}$ \\
\hline
\end{tabular}

Source: Aerts and Ragland, 1997.

Table 3-15. Ash fusion temperatures for Switchgrass $\left({ }^{\circ} \mathrm{F}\right)$

\begin{tabular}{|l|c|c|}
\hline & \multicolumn{2}{|c|}{ Switchgrass Ash } \\
\hline & Reducing & Oxidizing \\
\hline Initial Deformation & 1905 & 1995 \\
\hline Softening & 2175 & 2230 \\
\hline Hemispheric & 2235 & 2275 \\
\hline Fluid & 2365 & 2380 \\
\hline
\end{tabular}

Source: Aerts and Ragland, 1997

\subsubsection{Test Program and Results}

The test program was conducted over several time periods. Baseline tests were conducted from June 21 - 26, 1996 and July 9 - 16, 1996. Cofiring tests were conducted April 30 - May 15, 1996, May 30 - June 27, 1996, October 1 - 5, 1996, March 7, 1997, and April 24 - 30, 1997. The maximum cofiring percentages achieved were 15.3 percent on a mass basis or 10.2 percent on a heat input basis. These test conditions are shown in Table 3-16. 
Table 3-16. Test summary - co-fire conditions.

\begin{tabular}{|l|c|c|c|c|c|}
\hline & Load & Duration & \multicolumn{2}{|c|}{ Cofiring Percentage } & Excess \\
\hline Date & $(\mathrm{MW})$ & $(\mathrm{hr})$ & Mass $(\%)$ & Btu $(\%)$ & $\mathrm{O}_{2}(\%)$ \\
\hline $5-30-96$ & 34.5 & 2.5 & 14.1 & 9.8 & na \\
\hline $6-27-96$ & 48.5 & 3.0 & 7.1 & 4.8 & na \\
\hline $10-1-96$ & 39.9 & 3.5 & 15.3 & 10.2 & 6.4 \\
\hline $10-2-96$ & 46.4 & 4.0 & 11.6 & 7.9 & 2.8 \\
\hline $10-3-96$ & 43.8 & 5.5 & 9.2 & 6.0 & 3.1 \\
\hline $10-4-96$ & 47.3 & 4.5 & 7.8 & 5.1 & 3.0 \\
\hline $10-7-96$ & 40.1 & 4.0 & 10.3 & 6.6 & 2.6 \\
\hline $3-7-97$ & 48.0 & 2.0 & na & na & na \\
\hline $4-24-97$ & 48.3 & 9.0 & 10.4 & 6.4 & 2.8 \\
\hline $4-25-97$ & 49.6 & 8.0 & 10.6 & 6.6 & 2.6 \\
\hline $4-28-97$ & 49.1 & 8.0 & 10.5 & 6.2 & 2.5 \\
\hline $4-29-97$ & 49.2 & 8.0 & 10.4 & 6.5 & 2.6 \\
\hline $4-30-97$ & 49.0 & 8.5 & 10.4 & 6.5 & 2.1 \\
\hline
\end{tabular}

na - data not available

Source: Aerts and Ragland, 1997

Data were obtained from these tests measuring the impact of cofiring on boiler capacity, efficiency, emissions, and slagging and fouling.

Capacity Impacts. Cofiring did not impact the capacity of the boiler. Because cofiring added a fuel stream without impacting the coal delivery system, the only area where capacity could be impacted was ID fan capacity. This was not compromised.

Efficiency Impacts. The cofiring tests increased auxiliary loads by $236 \mathrm{~kW}$, or about 9 percent of the total house load for the boiler. This decreased net efficiency by about 0.5 percent. The boiler thermal efficiency decreased by an average of 1.1 percent during the cofiring tests. This decrease in efficiency resulted from increased air heater exit temperatures (the opportunity fuel is delivered by ambient air) and consequently increased dry gas losses. Because ambient air delivered the biomass to the boiler, less combustion air was passed through the air heater. This resulted in less heat being transferred from the flue gas to the incoming combustion air-decreasing the thermal efficiency of the boiler. The decrease in efficiency was also caused by increased hydrogen in the fuel. While there was some increase in LOI in the flyash in some-but not all—tests, there were also tests where LOI decreased as a consequence of cofiring.

Slagging and Fouling Impacts. The tests conducted were short term in nature. At the same time, however, observations were made visually. These were supported by measuring the rate of temperature increase at various points (e.g., economizer gas outlet). NETL engineers inserted a water cooled deposition probe in the superheater section during the testing as well. There was no evidence that slagging and fouling would be an operational problem as a consequence of these tests. 
Airborne Emissions Impacts. The impacts on airborne emissions were generally quite favorable as shown in Table 3-17. For all tests-baseline and cofiring tests- $\mathrm{CO}$ emissions were $<50 \mathrm{ppmv}$. Opacity decreased by a factor of 2, from an average of 21.6 percent during the baseline tests at 40 $\mathrm{MW}_{\mathrm{e}}$ to an average of 10.5 percent during cofiring tests at $40 \mathrm{MW}_{\mathrm{e}}$. At $49 \mathrm{MW}_{\mathrm{e}}$ of capacity the opacity was 28.6 percent when firing coal during baseline tests, and 11.1 percent when cofiring switchgrass and coal. The opacity results may be a result of precipitator power requirements, however (see Table 3-17). Precipitator power consumption was significantly higher during cofiring than during baseline testing. Interestingly, although a 6 percent reduction in $\mathrm{SO}_{2}$ emissions was expected, no definitive trend of $\mathrm{SO}_{2}$ reductions was achieved. $\mathrm{NO}_{\mathrm{x}}$ emissions, however, were reduced by an average of 31 percent!

The $\mathrm{NO}_{\mathrm{x}}$ reductions are dramatic indeed. Aerts and Ragland attribute these results largely to the volatility of the switchgrass as is shown in Figure 3-26.

The Blount St. Station test also demonstrated that, while total $\mathrm{CO}_{2}$ emissions increase during cofiring when compared to baseline operations, fossil fuel-based $\mathrm{CO}_{2}$ emissions do decrease as a consequence of cofiring.

The net result of the switchgrass test by the University of Wisconsin is the extension of previous cofiring results from woody biomass to switchgrass. These results further demonstrate the ability to use separate injection cofiring in wall-fired PC boilers to achieve significant environmental gains without compromising boiler capacity and with only minor impacts on boiler efficiency.

Table 3-17. Average measured flue gas emissions at 3\% excess oxygen.

\begin{tabular}{|l|l|c|c|c|c|c|c|}
\hline Test & Load & Co-fire & Measured & Measured & Measured & Precip. & Precipitator \\
\hline Condition & $(\mathrm{MW})$ & Mass $(\%)$ & $\mathrm{SO}_{2} \mathrm{lb} / 10^{6} \mathrm{Btu}$ & $\mathrm{NO}_{\mathrm{x}} \mathrm{lb} / 10^{6} \mathrm{Btu}$ & Opacity $(\%)$ & $\left(\mathrm{kV}^{2}\right)$ & Power $(\mathrm{kW})$ \\
\hline Coal-only & 40.2 & 0.0 & 2.417 & 0.511 & 17.9 & 1849 & 10.34 \\
\hline Coal-only & 40.7 & 0.0 & 2.188 & 0.509 & 25.3 & 1980 & 4.87 \\
\hline Coal-only & 48.8 & 0.0 & 2.487 & 0.574 & 26.8 & 1936 & 5.22 \\
\hline Coal-only & 49.2 & 0.0 & 2.233 & 0.544 & 30.5 & 1980 & 4.92 \\
\hline Co-fire & 39.9 & 15.3 & 3.040 & 0.471 & 8.7 & 1806 & 14.41 \\
\hline Co-fire & 40.1 & 10.3 & 2.291 & 0.371 & 12.2 & 1980 & 9.21 \\
\hline Co-fire & 43.8 & 9.2 & 2.340 & 0.411 & 15.3 & 1980 & 7.03 \\
\hline Co-fire & 46.4 & 11.6 & 2.300 & 0.422 & 14.1 & 1892 & 9.97 \\
\hline Co-fire & 47.3 & 7.8 & 2.431 & 0.462 & 15.5 & 1936 & 6.55 \\
\hline Co-fire & 48.3 & 10.4 & 2.375 & 0.496 & 11.7 & 1849 & 10.75 \\
\hline Co-fire & 49.0 & 10.4 & 1.843 & 0.364 & 11.0 & 1681 & 17.22 \\
\hline Co-fire & 49.1 & 10.5 & 2.286 & 0.432 & 15.1 & 1849 & 8.19 \\
\hline Co-fire & 49.2 & 10.4 & 1.995 & 0.364 & 9.9 & 1681 & 17.98 \\
\hline Co-fire & 49.6 & 9.9 & 2.303 & 0.411 & 8.0 & 1936 & 14.88 \\
\hline
\end{tabular}

Source: Aerts and Ragland, 1997. 


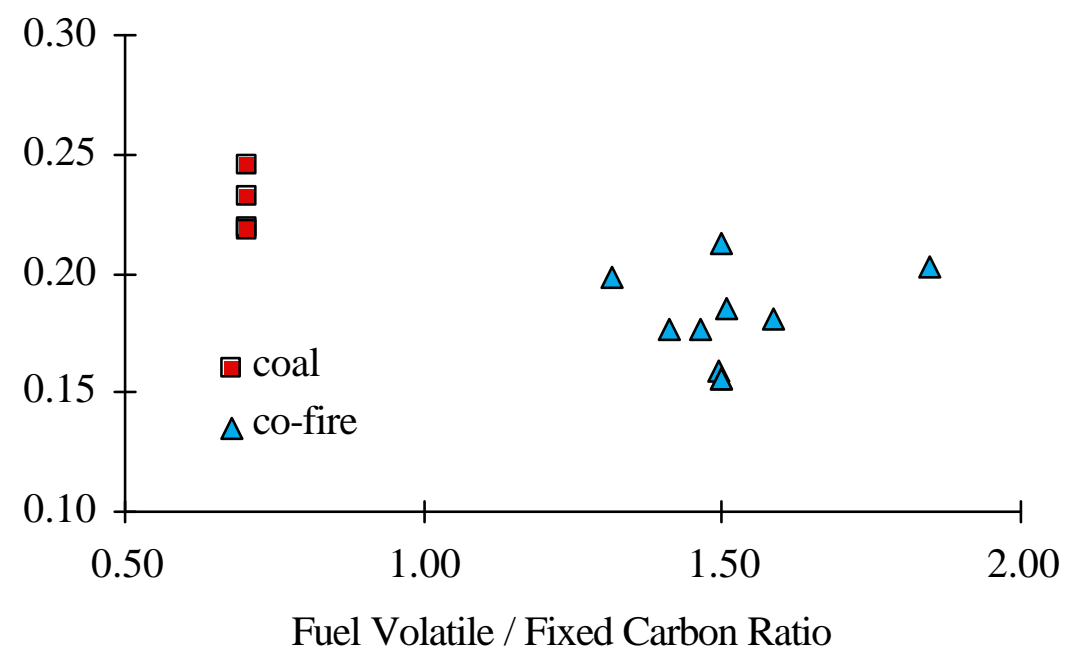

Figure 3-26. $\mathrm{NO}_{\mathrm{x}}$ Emissions in $\mathrm{g} / \mathrm{MJ}$ at Blount St. Station as a Function of Volatile/Fixed Carbon Ratio of the Combined Fuel Feed

Source: Aerts and Ragland, 1997.

\subsection{CONCLUSIONS REGARDING COFIRING IN WALL FIRED PULVERIZED COAL BOILERS}

The EPRI-USDOE Cooperative Agreement proved highly useful in promoting commercialization of biomass cofiring in wall-fired PC boilers. It was used to commercialize low percentage cofiring at the Colbert Fossil Plant of TVA, and to demonstrate its usefulness in cofiring at higher percentages using direct injection technologies. Cofiring did cause modest declines in boiler efficiency in the Seward and Blount St. Station tests. However it was instrumental in reducing airborne emissions including $\mathrm{NO}_{\mathrm{x}}$. The testing demonstrated that the volatile yield of biomass can be instrumental in modifying the combustion process in wall fired PC boilers to the advantage of operations. 


\subsection{COOPERATIVE AGREEMENT SUPPORT FOR COFIRING IN TANGENTIALLY-FIRED PULVERIZED COAL BOILERS}

\subsection{INTRODUCTION}

The process of combustion in T-fired PC boilers is fundamentally different from the process of combustion in wall-fired PC boilers. While wall-fired boilers employ discrete burners with distinct flames and combustion zones, T-fired boilers employ a single fireball in the center of the furnace. Tfired boilers have been conceptually viewed as operations where the furnace is the burner, and the burner has multiple fuel and air injection points. Typically Tfired boilers have lower furnace heat release rates $\left(\mathrm{Btu} / \mathrm{ft}^{3}-\mathrm{hr}\right.$ of furnace volume) than wall-fired boilers. Typically, also, T-fired boilers have lower $\mathrm{NO}_{\mathrm{x}}$ emissions than wall-fired boilers.

The fact that T-fired boilers have a single fireball, as opposed to discrete flames from individual burners, has made them an appealing technology for cofiring. They have been considered to be highly flexible in the application of cofiring. Consequently EPRI supported the initial tests at the Kingston Fossil Plant of TVA. Through the Cooperative Agreement, EPRI and USDOE supported cofiring demonstrations at Greenidge Station of New York State Electric and Gas (NYSEG - now AES), the Albright Generating Station of Allegheny Energy Supply Company, LLC (Allegheny), and Plant Gadsden, a Southern Company. In the Greenidge and Gadsden tests and demonstrations, EPRI and the Cooperative Agreement had a minor supporting role. In the Albright Generating Station demonstration of Allegheny, EPRI funded the test program.

\subsection{DEMONSTRATING BIOMASS COFIRING AT GREENIDGE STATION}

The Greenidge Station project is described by Benjamin (1995) and Benjamin (1996). Beginning in 1994, NYSEG began investigations into cofiring biomass at their Greenidge Station in Dresden, NY. This program ultimately resulted in the development of a commercial demonstration of biomass cofiring. The project originally obtained funding from New York State Research and Development Authority (Benjamin, 1995). Subsequently it obtained significant corporate funding. EPRI provided supporting funds as a secondary participant. This project is summarized by Battista and Hughes (2000).

Greenidge Station, located on the shores of Lake Seneca, houses three boilers: Units \#6, \#7, and \#8. Unit \#6, chosen for cofiring, is a 750,000 lb/hr Tfired boiler connected to a $108 \mathrm{MW}_{\mathrm{e}}$ turbinegenerator (Battista and Hughes, 2000). The plant is located in reasonably close proximity to forests and wood products industries in New York, and to numerous farms capable of growing willow or hybrid poplar as energy crops. It has good truck access and rail access.

This unit was equipped with a separate injection cofiring system capable of supporting 30 percent cofiring on a mass input basis. Much of the equipment came from Rochester, NY-from the former refuse-derived fuel (RDF) plant installed at that location. Initially NYSEG evaluated installing either a 
separate pneumatic injection of $1 / 4 " \mathrm{x} 0$ " material to be burned in suspension, or a system for pneumatically injecting 2" x 0 " wood chips, with the latter system requiring a dump grate as well as a fuel transport system. NYSEG chose to install the first option capable of delivering $7.5 \mathrm{ton} / \mathrm{hr}$ of finely divided woody biomass to the boiler.

The unit receives dry wood waste and fires this material 16 hours/day. The wood waste is received and ground to a 1/4" x 0" particle size in two hammermills. Every pound of biomass goes through the hammermills, rather than screens. Following grinding, the wood particles are blown through two separate transport lines to the boiler. Typically the unit cofires at 15 percent (heat input basis), and fired over 30,000 ton of dry wood waste in 1999. This wood waste typically has $10-40$ percent moisture and 4,500 - 8,000 Btu/lb. The target material contains little moisture and 7,800 Btu/lb.

Cofiring at Greenidge Station is an economic proposition. Typically the unit experiences an efficiency decrease of 0.8 percent. Particulate emissions and carbon monoxide emissions from the unit have not increased as a consequence of cofiring. $\mathrm{SO}_{2}$ emissions decreased by about 15 percent, consistent with the firing of a low sulfur fuel.

Initial indications were that there would be a modest $\mathrm{NO}_{\mathrm{x}}$ reduction (Benjamin, 1996), although the early tests were not conclusive. Operating data continues to show some $\mathrm{NO}_{\mathrm{x}}$ reduction, although that reduction is not considered significant (Battista and Hughes, 2000).

The Greenidge program, then, shows that cofiring can be performed in a cost-effective manner, depending upon the relative costs of wood and coal, and depending upon the performance of the unit when cofiring.

\subsection{COFIRING AT THE ALBRIGHT GENERATING STATION OF ALLEGHENY ENERGY SUPPLY CO., LLC.}

Allegheny Energy Supply Company, LLC initiated a cofiring demonstration at its $140 \mathrm{MW}_{\mathrm{e}}$ (net) tangentially-fired Albright Generating Station boiler \#3 in 2000. Funding for construction of the facility was supplied by USDOE-EERE and USDOE-NETL. Funding for the testing portion of the demonstration was supplied by EPRI through the Cooperative Agreement. This program has been described in several recent papers and presentations (see Payette and Tillman, 2001; Tillman and Payette, 2001; Tillman, Payette, and Battista, 2000).

The objective of the biomass cofiring system at the Albright Generating Station was emissions reduction - particularly $\mathrm{NO}_{\mathrm{x}}$ emissions reduction. It provided a means for evaluating cofiring as an approach to the "3P Strategy" - addressing simultaneously the emissions of $\mathrm{NO}_{\mathrm{x}}, \mathrm{SO}_{2}$, and mercury. Because Albright Unit \#3 is equipped with a 3-level separated overfire air (SOFA) system, particular attention has been given to the ability to integrate sawdust cofiring into the staged combustion strategy for $\mathrm{NO}_{\mathrm{x}}$ control. The initial investigations of this demonstration were quite favorable; sawdust could be obtained in a cost-competitive manner for this demonstration. 


\subsubsection{Design of the Albright Generating Station Cofiring System}

The cofiring system was designed around the following principles:

- Screening of all sawdust to a particle size of $1 / 4$ " x 0 "

- Separate pneumatic lines, and separate blowers, for each injection point

- Maximum attention to safety issues, including check valves on injection lines and high velocity transport of the sawdust to the boiler

The equipment originally installed at the Seward Generating Station was relocated to Albright and upgraded (see Figure 41). Sawdust is received in the walking floor unloader (see Figure 4-2). It is then transported to the screen. The trommel screen installed at Seward was replaced with a disc screen to minimize dust generation (see Figure 43). Screened material is then transported to the silo for storage. It is reclaimed from the silo, metered using the weigh belt feeder (Figure 4-4), and injected into the pneumatic transport lines through rotary airlocks. The sawdust, blown to the boiler, is injected into the boiler through two specially designed biomass injectors (see Figure 4-5) that are installed in opposite corners of the furnace. There are four rows of coal injectors in Albright Unit \#3; the sawdust injectors are installed between the $\mathrm{B}$ and $\mathrm{C}$ levels. The entire system is controlled in the control room (see Figure 4-6). The operator can set the desired cofiring level consistent with operating conditions at the time. 


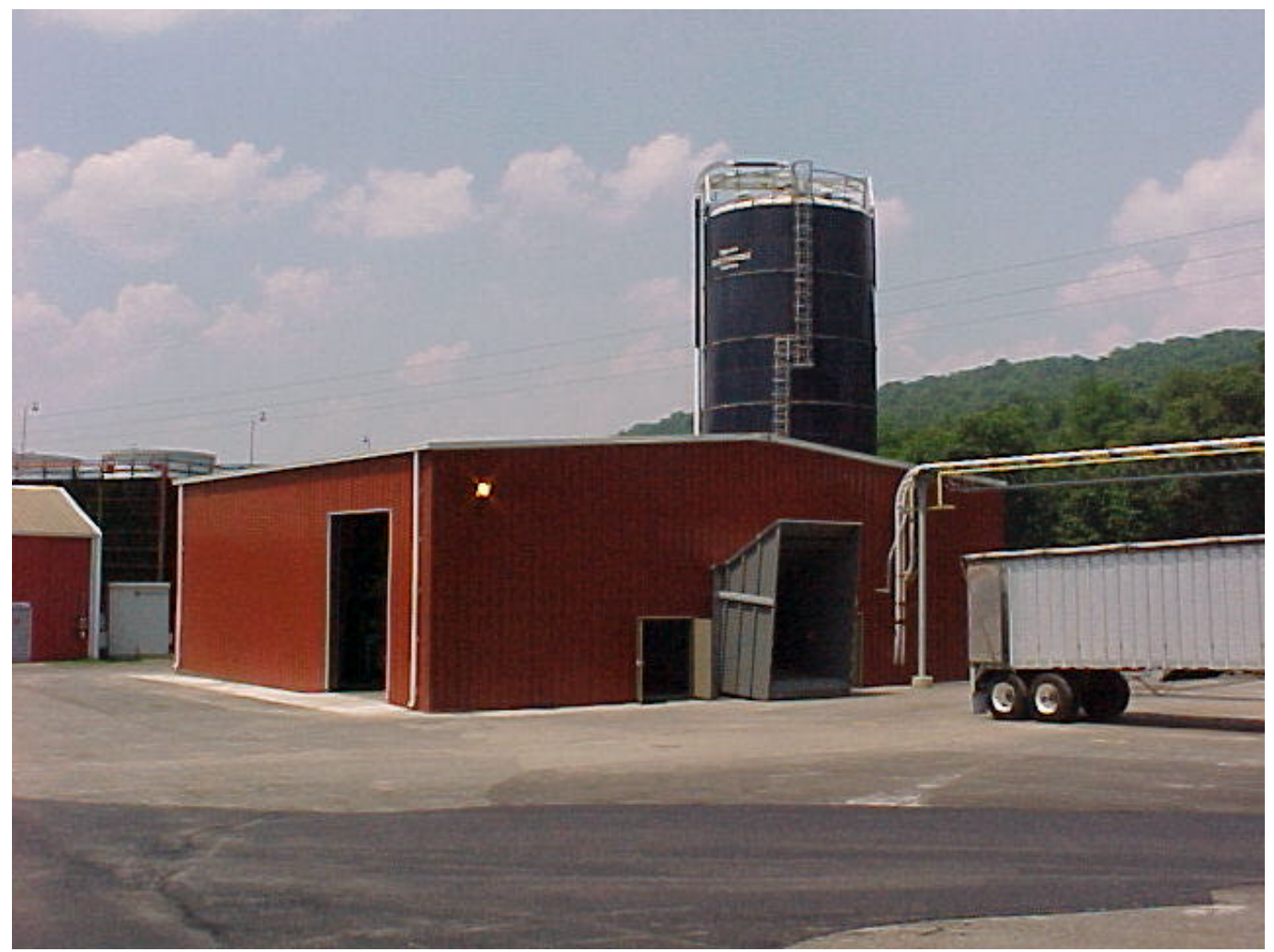

Figure 4-1. Overview of the Cofiring Installation at Albright Generating Station 


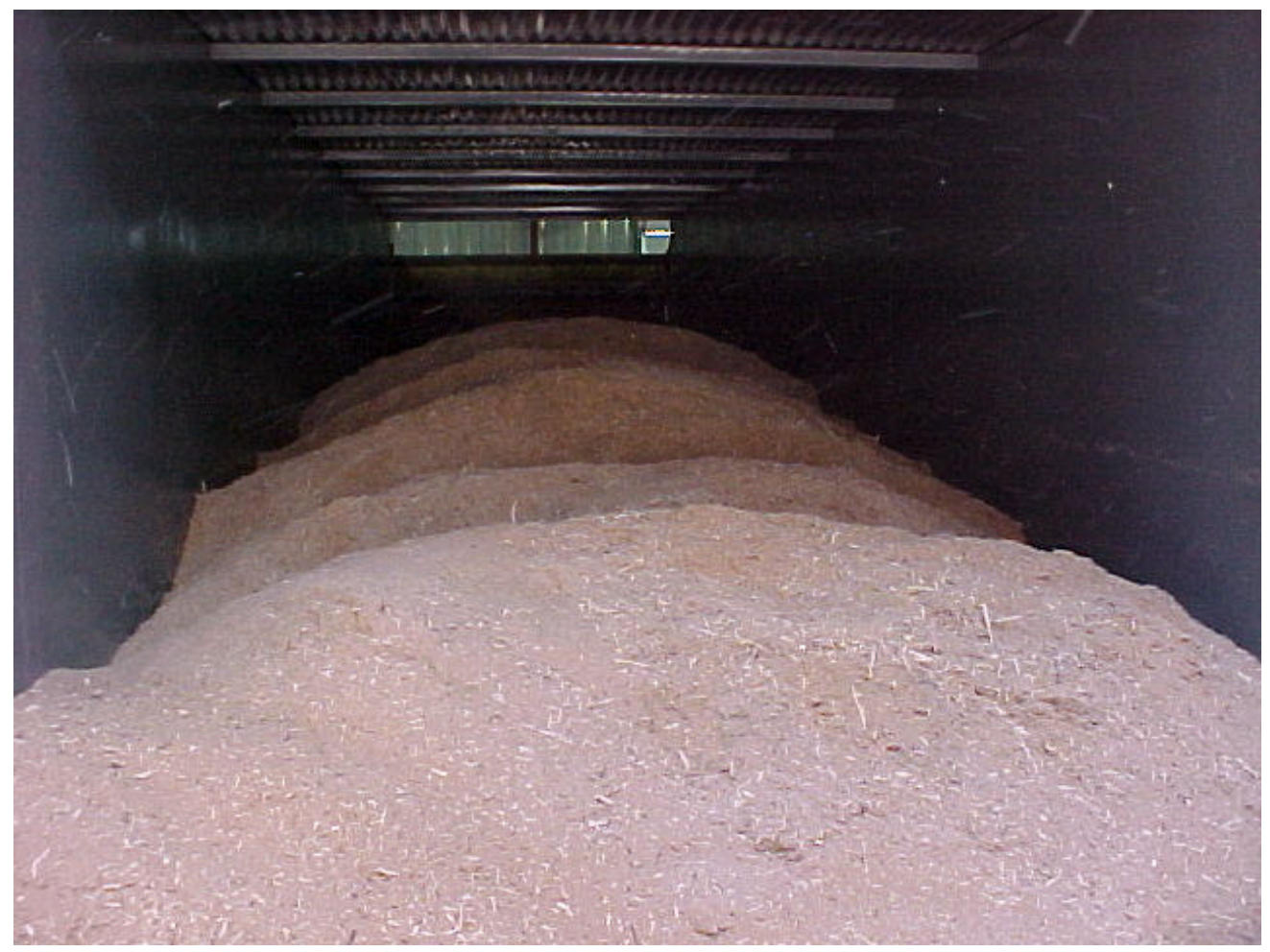

Figure 4-2. Sawdust Being Transported Up the Walking Floor Unloader
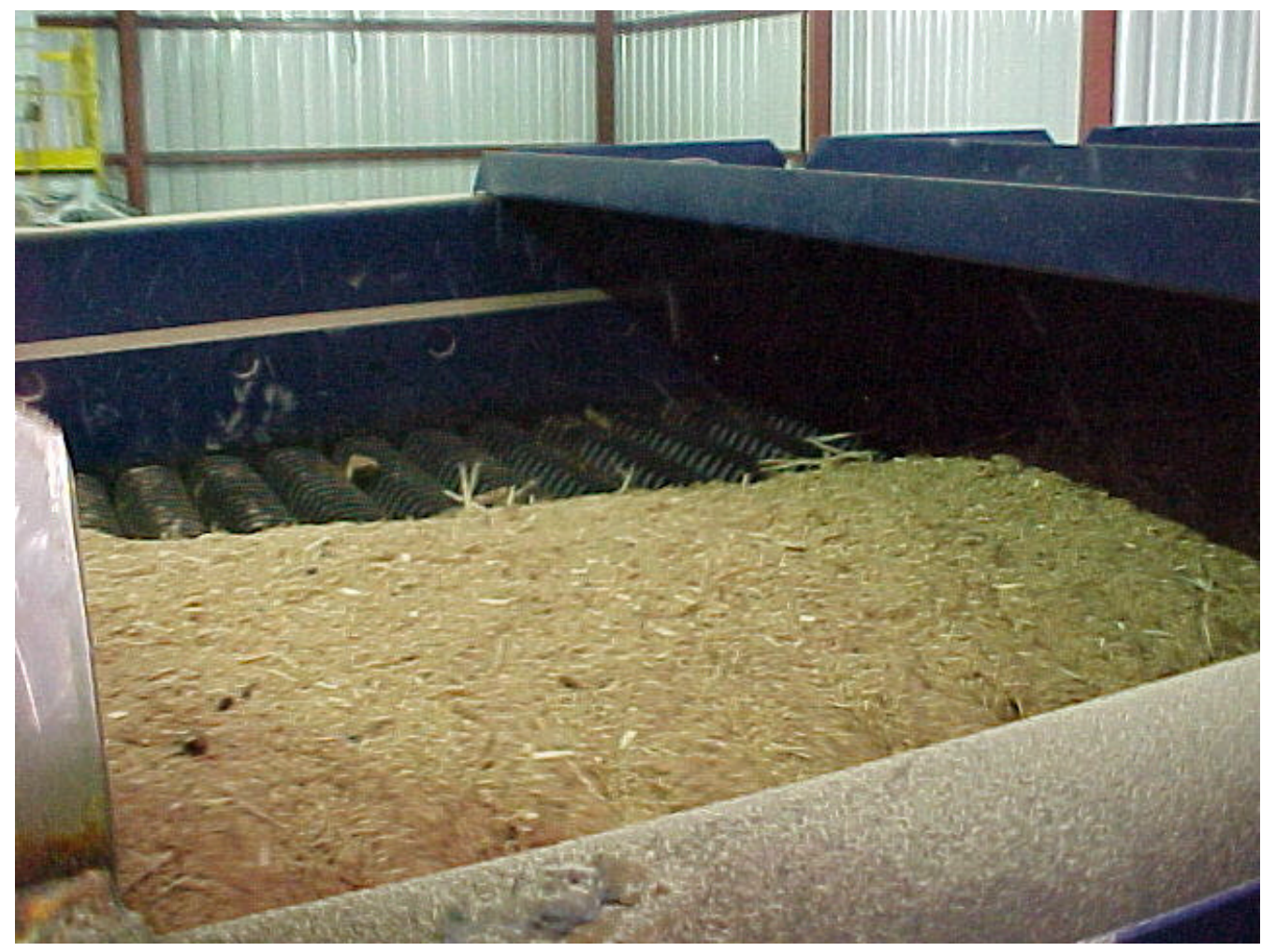

Figure 4-3. Sawdust Being Screened on the Disc Screen 


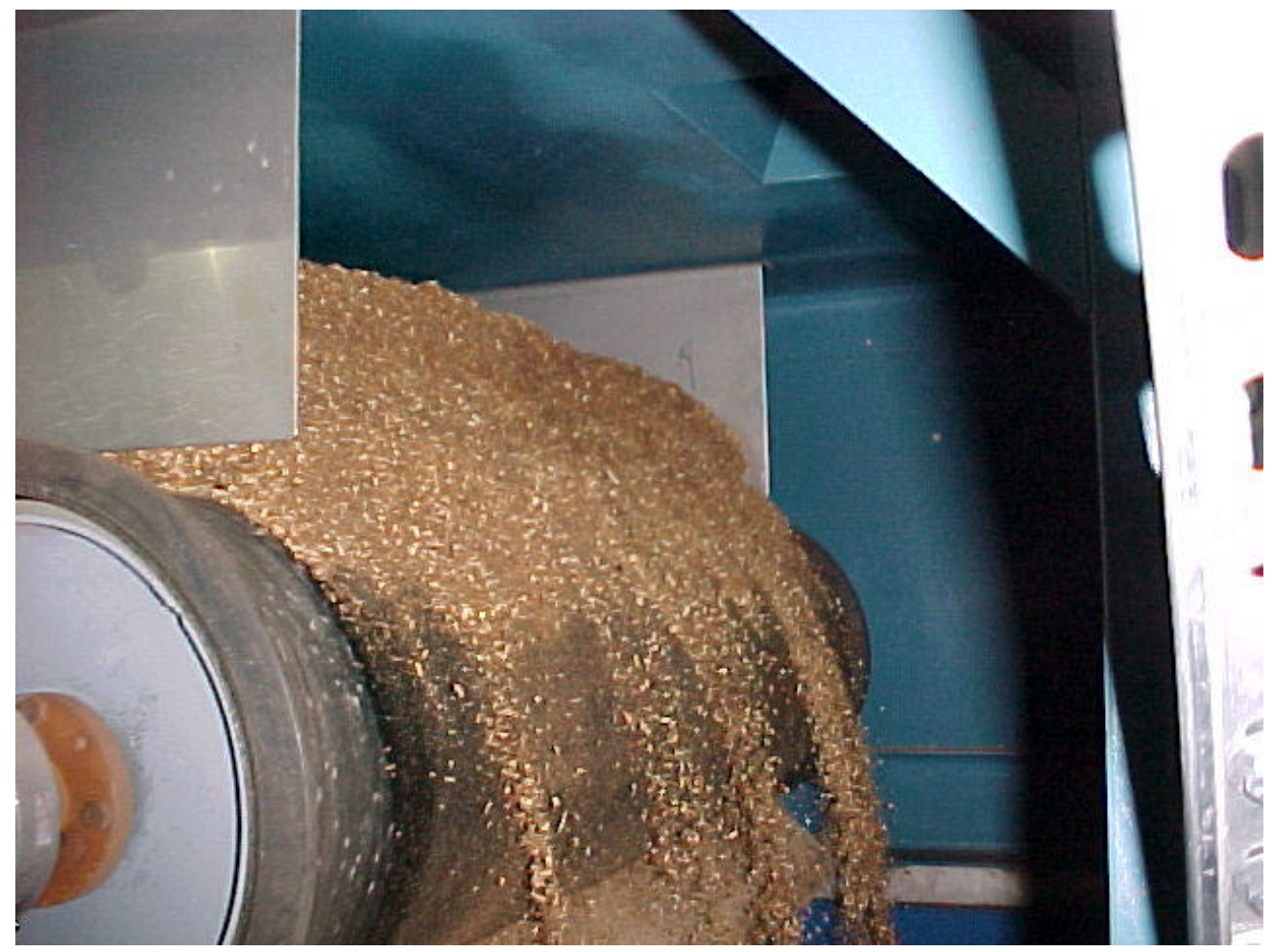

Figure 4-4. Sawdust Being Metered on the Weigh Belt Feeder

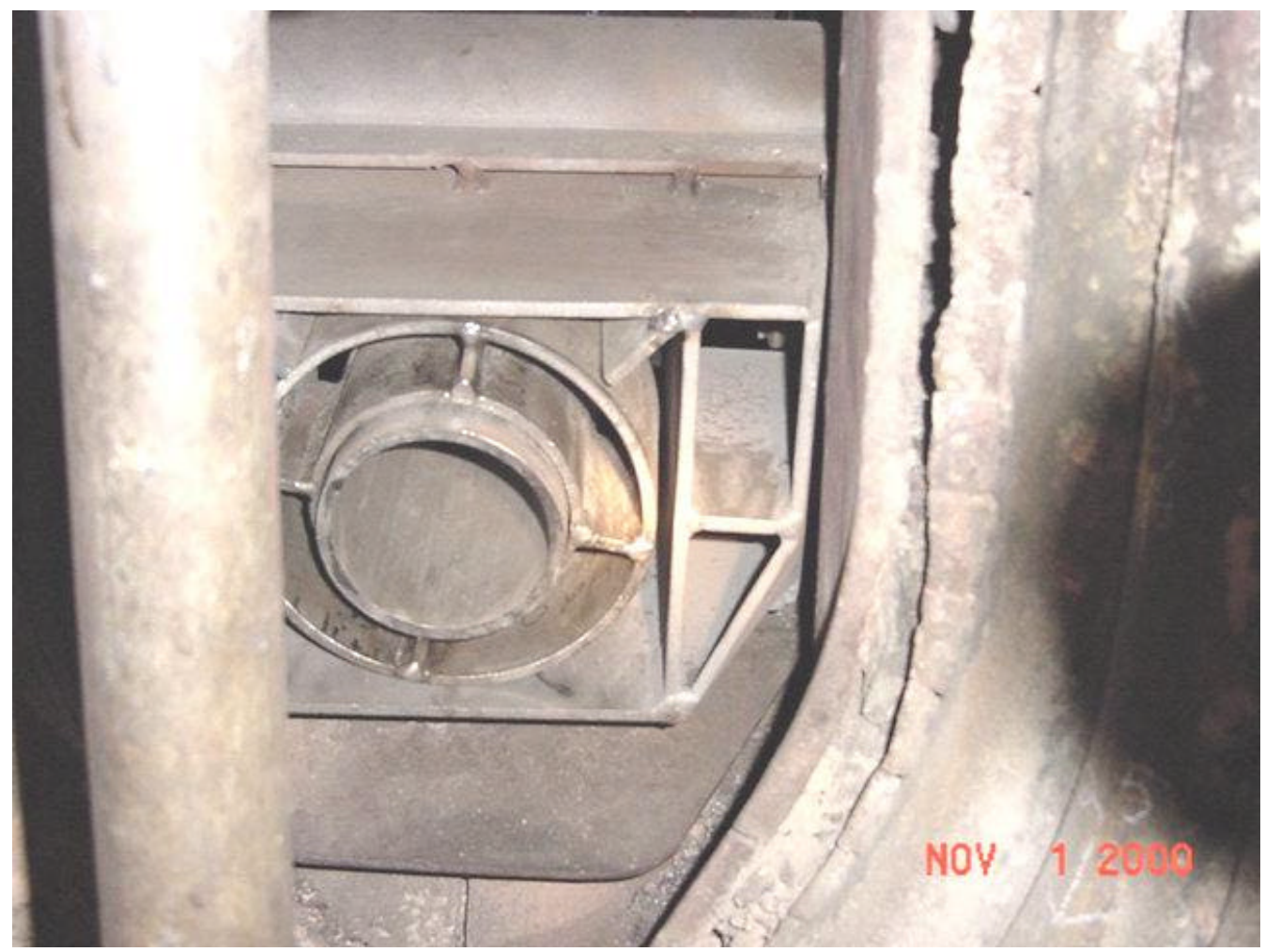

Figure 4-5. The Sawdust Injector in the Albright Boiler \#3 


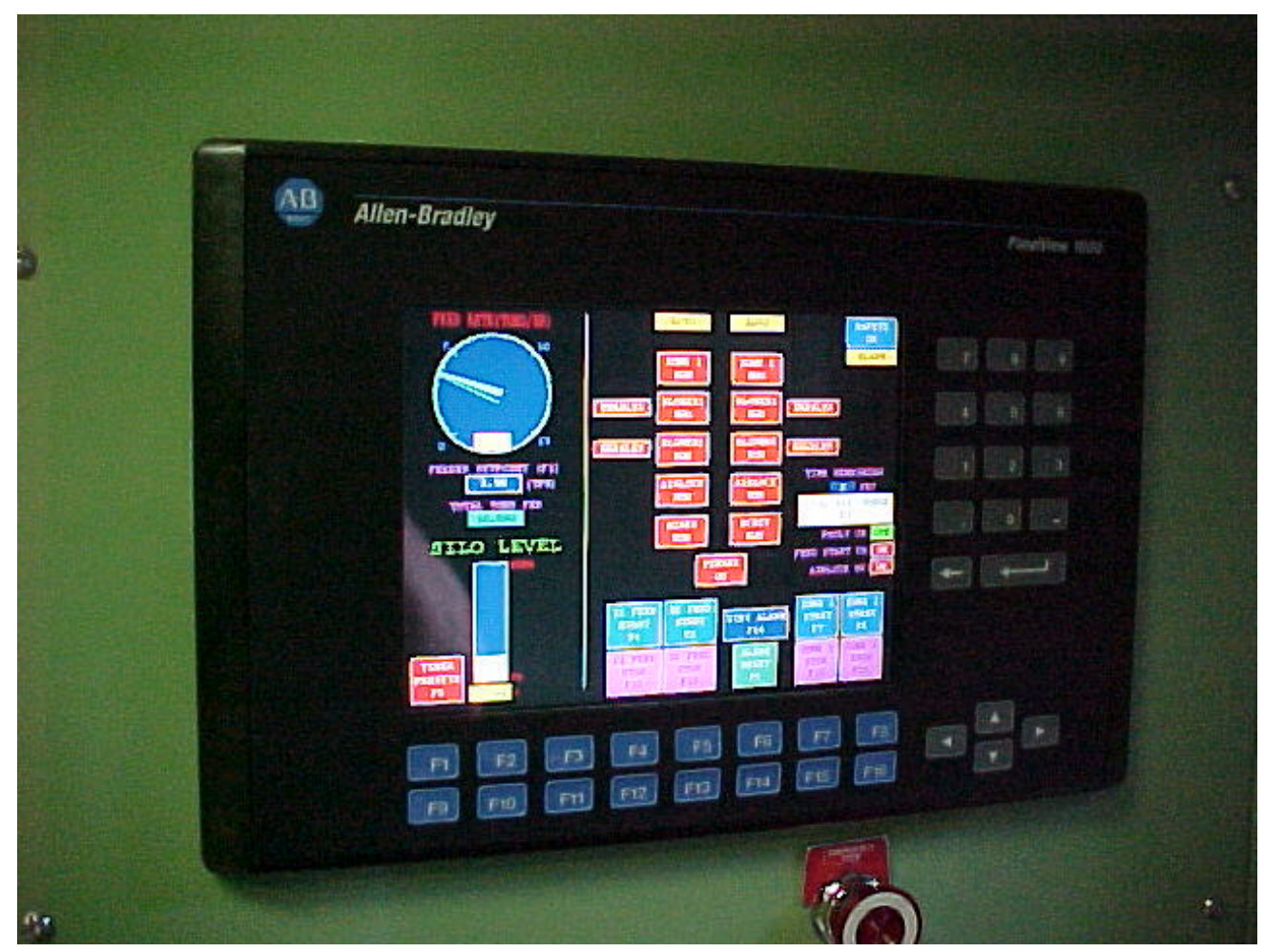

Figure 4-6. Controls for the Cofiring System at Albright Generating Station

This design reflects the basic approach of screening rather than grinding every particle. It is designed to incorporate grinding of oversized particles, should that become economically desirable.

The project was constructed in late 2000 and early 2001. It was commissioned for cofiring operations on June 19, 2001 and dedicated on June 29, 2001.

\subsubsection{Demonstration Results}

Extensive testing of this cofiring system has been conducted during the period May, 2000 - July, 2001. Some 68 test hours have been completed with extensive data acquisition. Fuels have been characterized, along with operating parameters and airborne emissions. Test variables have included load, excess $\mathrm{O}_{2}$, cofiring percentage, and extent to which SOFA has been employed. The results have been favorable, with an indication that cofiring can address the $3 \mathrm{P}$ 's $-\mathrm{SO}_{2}, \mathrm{NO}_{\mathrm{x}}$, and mercury-in a cost-effective manner.

Table 4-1 summarizes the ultimate analysis of the coal and sawdust burned at the Albright Generating Station. Note the low nitrogen, sulfur, and ash concentrations in the sawdust. Table 41 presents averages. There is inherent variability in both the coal and the sawdust burned at the Albright Generating Station, and this variability influences the measurement of emissions and emissions reduction. 
Table 4-1. Typical Analyses of the Coal and Sawdust at Albright Generating Station

\begin{tabular}{|c|c|c|}
\hline Element/Compound (wt \%) & Coal & Sawdust \\
\hline Carbon & $70.10 \%$ & $29.87 \%$ \\
\hline Hydrogen & $4.30 \%$ & $3.51 \%$ \\
\hline Oxygen & $4.38 \%$ & $26.66 \%$ \\
\hline Nitrogen & $1.30 \%$ & $0.12 \%$ \\
\hline Sulfur & $1.50 \%$ & $0.01 \%$ \\
\hline Chlorine & $0.00 \%$ & $0.00 \%$ \\
\hline Moisture & $7.40 \%$ & $39.53 \%$ \\
\hline Ash & $11.02 \%$ & $0.30 \%$ \\
\hline Total & $100.00 \%$ & $100.00 \%$ \\
\hline Higher Heating Value (Btu/lb) & 12302 & 5087 \\
\hline
\end{tabular}

Cofiring at Albright Unit \#3 was performed at levels up to 10 percent (mass basis, or 4.7 percent on a heat input basis). This is equivalent to firing 6 ton/hr of sawdust at full bad operations. Excess $\mathrm{O}_{2}$ varied from 2.5 percent to 4.9 percent during the test program. There are three SOFA levels at Albright Unit \#3, with each level having dampers with $0-100$ percent open capability. During the testing, SOFA damper positions ranged from 15 percent open (dampers were opened only on one level) to 240 percent open (from a total of 300 percent).

Cofiring did not significantly impact either opacity or CO emissions, as is shown in Figures 4-7 and 4-8. These emissions also are an indication of carbon conversion efficiency. Note that there is a slight apparent upward trend in opacity largely as a result of one 4-hour period of time. For the vast majority of operations, opacity remained between 3 and 4 percent. It is useful to note that cofiring did not increase unburned carbon in flyash or bottom ash appreciably, also supporting the data in Figures 47 and 4-8.

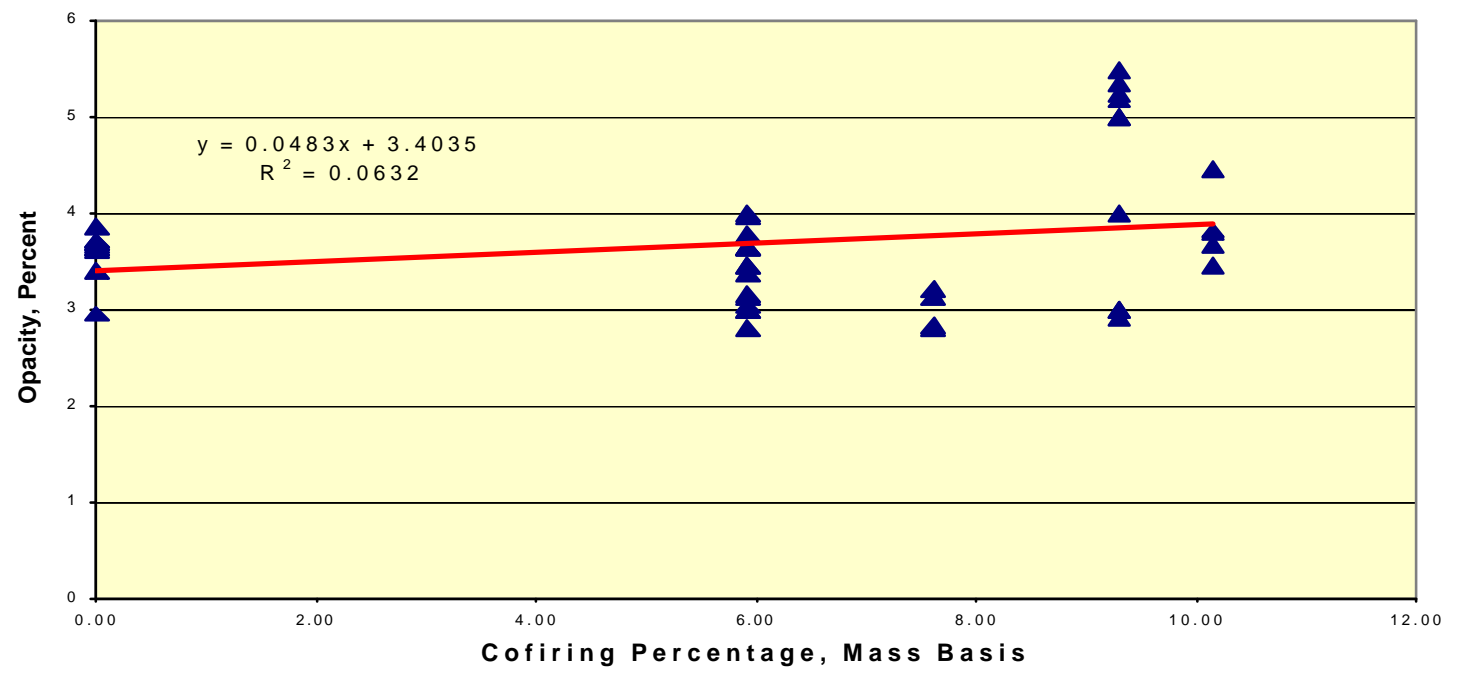


Figure 4-7. Opacity Emissions (Percent) as a Function of Cofiring at Albright Generating Station.

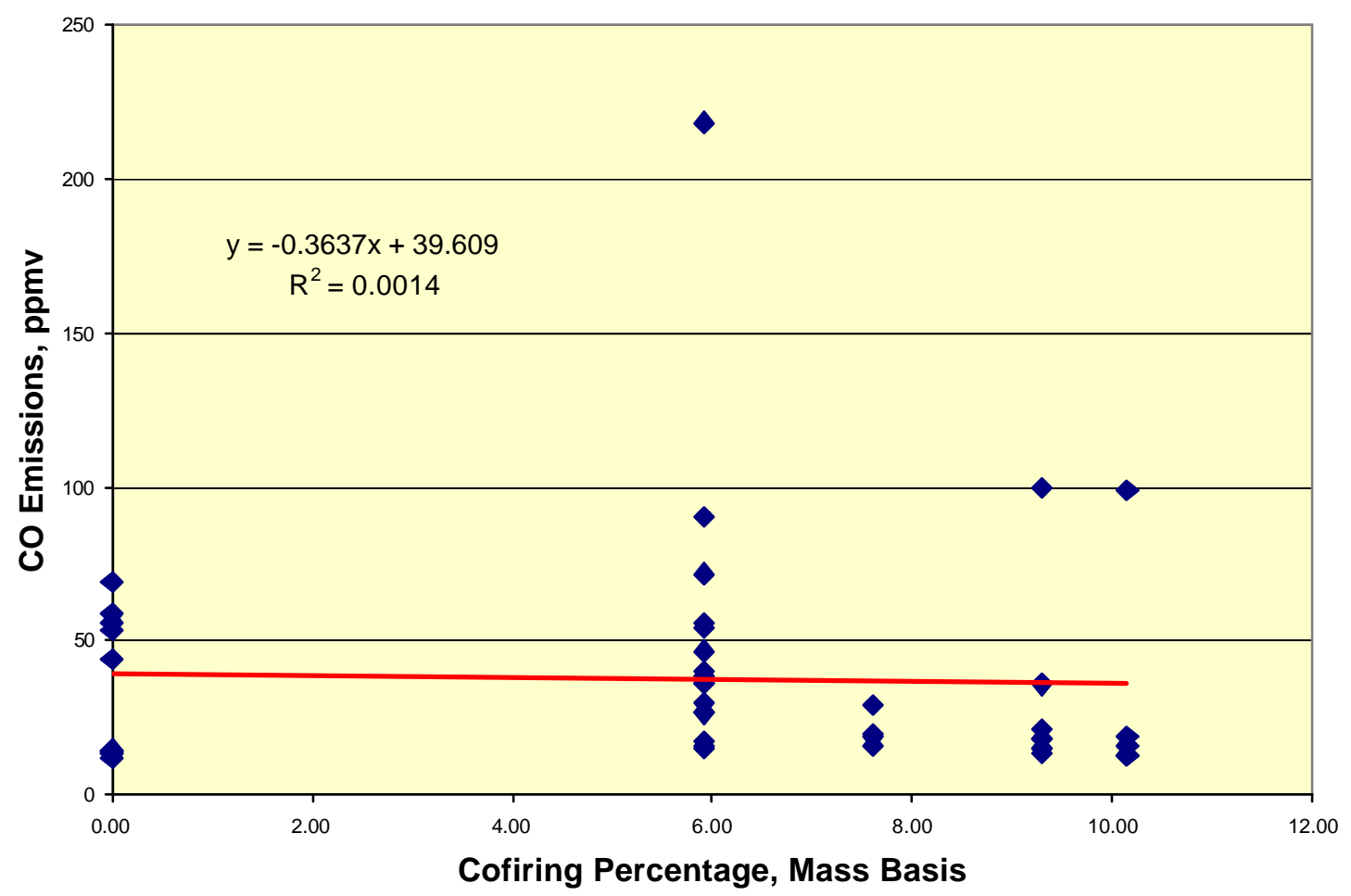

Figure 4-8. Influence of Cofiring on Carbon Monoxide Emissions at Albright Generating Station

The data presented in Figures 4-7 and 4-8 relates to normal full load (130 $\mathrm{MW}_{\mathrm{e}}$ net) operation. There was no evidence of increased opacity or CO emissions at part load operation.

$\mathrm{SO}_{2}$ emissions generally decreased as a function of fuel substitution. The inherent variability in the fuel quality results in some scatter in the data generated. These $\mathrm{SO}_{2}$ results are presented in Figures 4-9 and 4-10 on a ppmv basis. 


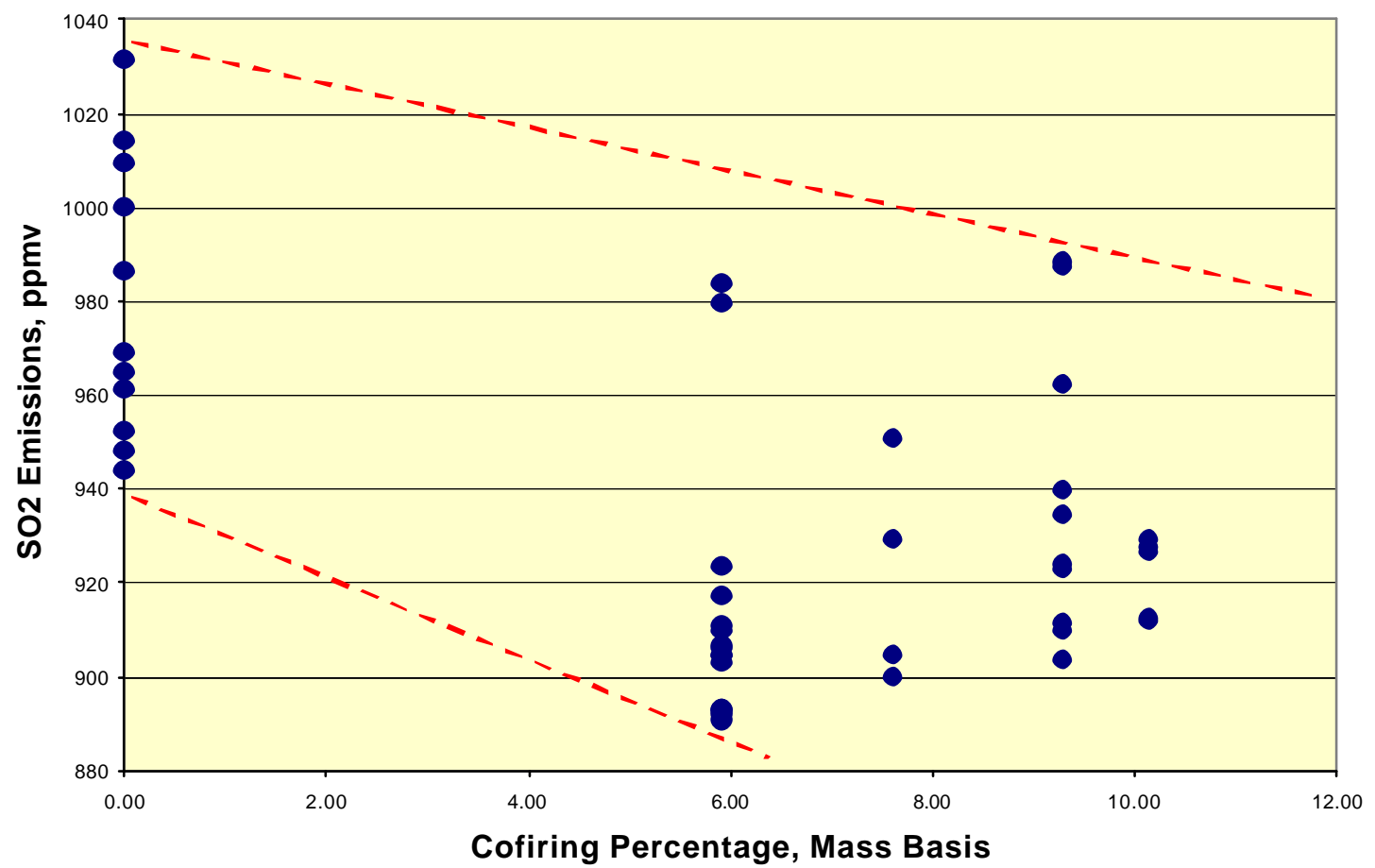

Figure 4-9. $\mathrm{SO}_{2}$ Emissions as a Function of Cofiring at Albright Generating Station (mass basis)

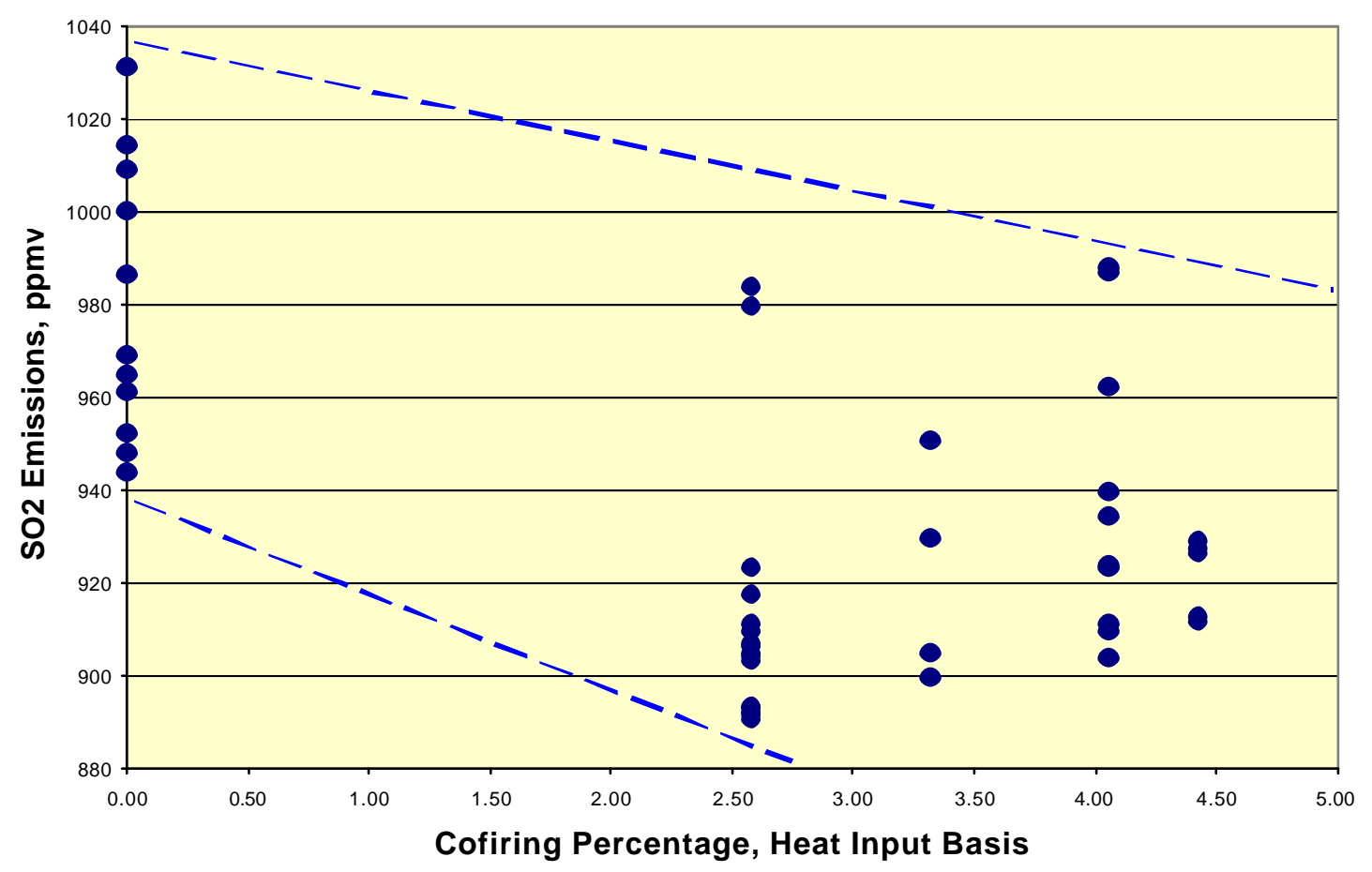

Figure 4-10. $\mathrm{SO}_{2}$ Emissions as a Function of Cofiring at Albright Generating Station (heat input basis) 
The cofiring demonstration at Albright Generating Station has reduced $\mathrm{NO}_{\mathrm{x}}$ emissions as a function of cofiring level and the management of other known $\mathrm{NO}_{\mathrm{x}}$ - causing variables: excess $\mathrm{O} 2$ and SOFA usage. Figure 4-11 depicts the $\mathrm{NO}_{\mathrm{x}}$ reductions achieved. Note that the variability implied by the data results from the numerous variables employed to achieve $\mathrm{NO}_{\mathrm{x}}$ reduction.

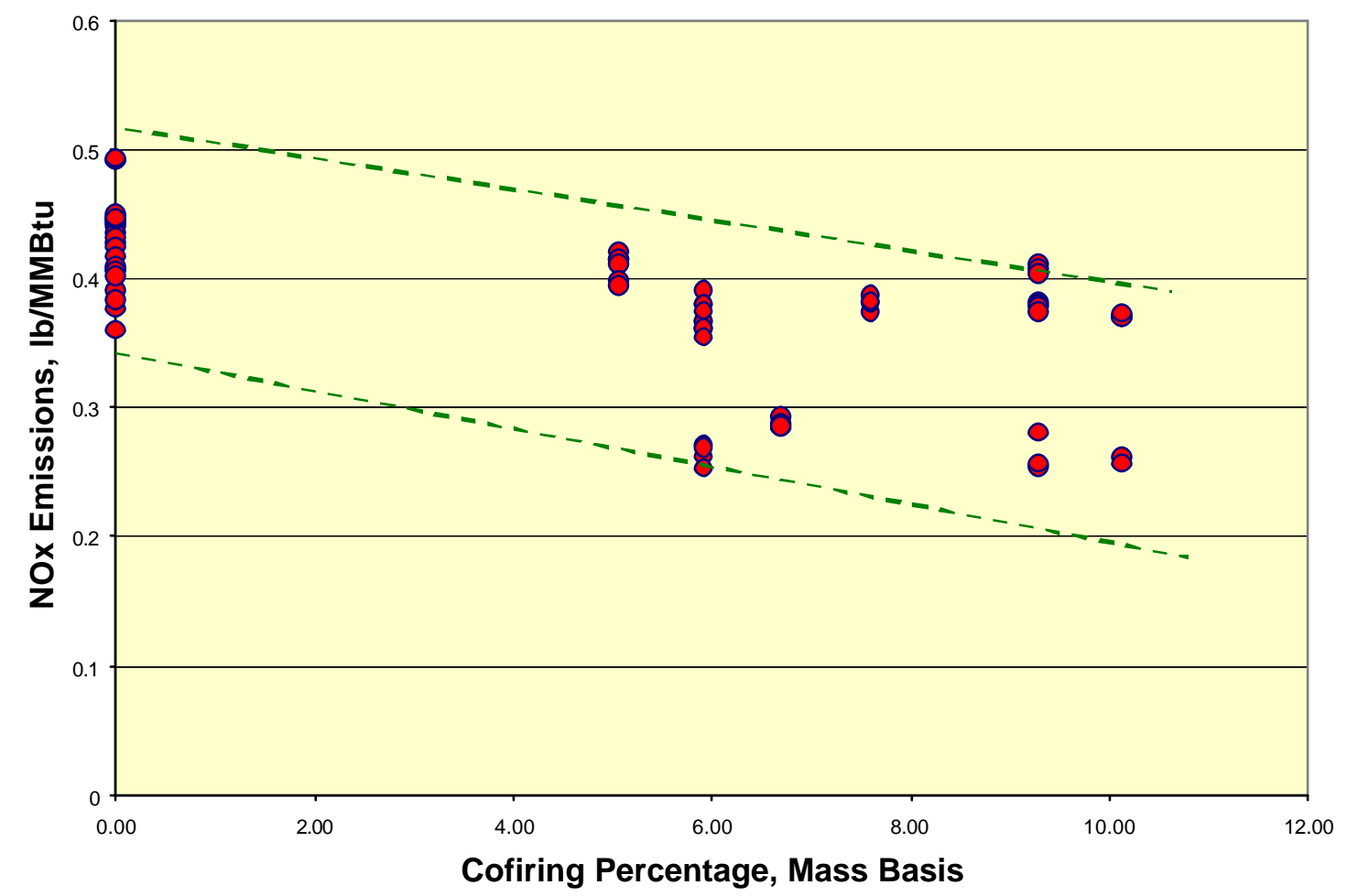

Figure 4-11. $\mathrm{NO}_{\mathrm{x}}$ Reduction from Cofiring at the Albright Generating Station

The data generated during the testing were converted into a single, robust, regression equation as shown below. The $r^{2}$ for this equation is 0.873 with 68 data points, or 67 degrees of freedom.

$$
\mathrm{NO}_{\mathrm{x}}\left(\mathrm{lb} / 10^{6} \mathrm{Btu}\right)=0.361-0.0043(\mathrm{~W} \%)+0.0217\left(\mathrm{O}_{2} \%\right)-0.00055(\mathrm{SOFA})[16]
$$

Where, $\mathrm{W} \%$ is sawdust percentage in the fuel on a mass basis, $\mathrm{O}_{2} \%$ is the percentage excess oxygen measured at the furnace exit, and SOFA is the total percentage of the three SOFA dampers expressed as percent open. Note that the range of $\mathrm{W}$ terms is $0-10$, the range of $\mathrm{O}_{2} \%$ terms is $2.5-4.9$, and the range of SOFA terms is $15-240$. This may explain the difference in the coefficients.

Table 42 demonstrates the robustness of equation 16. It presents the probabilities that any given calculated value occurs randomly. Any probability $<0.05$ can be considered significant; any probability $<0.01$ can be considered highly significant. 
Table 4-2. Probability That The Equation, or any Term, Occurred Randomly

\begin{tabular}{|c|l|l|}
\hline Number & Parameter Evaluated & $\begin{array}{l}\text { Probability of } \\
\text { Randomness }\end{array}$ \\
\hline 1 & Total Equation & $4.17 \times 10^{-28}$ \\
\hline 2 & Intercept & $5.23 \times 10^{-25}$ \\
\hline 3 & Sawdust Percentage & $3.13 \times 10^{-6}$ \\
\hline 4 & Excess O2 Percent & $8.20 \times 10^{-4}$ \\
\hline 5 & SOFA Dampers Percent & $2.58 \times 10^{-22}$ \\
\hline
\end{tabular}

Figure 412 compares the observed $\mathrm{NO}_{\mathrm{x}}$ emissions to those predicted by this equation. Note that there is some deviation from the trend predicted; the equation clearly lacks all explanatory terms. Note, also, that the equation explains the vast majority of the $\mathrm{NO}_{\mathrm{x}}$ reduction observed during the test program.

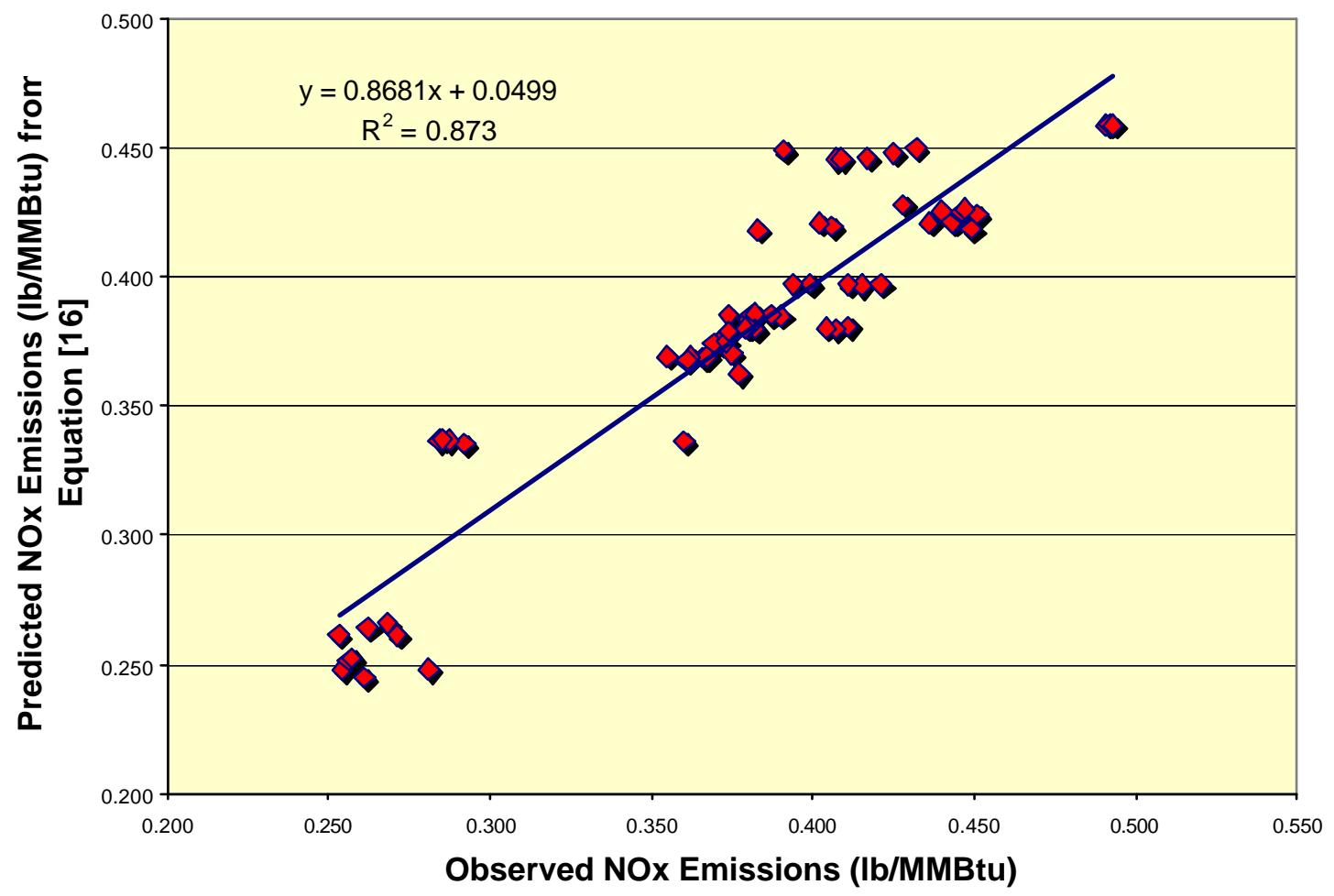

Figure 4-12. Comparison of Observed and Predicted $\mathrm{NO}_{\mathrm{x}}$ Emissions Based Upon Equation [16]

The $\mathrm{NO}_{\mathrm{x}}$ reduction observed was, therefore, consistent and substantial. To further understand the mechanisms of $\mathrm{NO}_{\mathrm{x}}$ reduction involved in cofiring at Albright Generating Station, fuel characterization experiments were conducted at Pennsylvania State University evaluating the pattern of nitrogen evolution from the sawdust and coal at Albright Generating Station (Johnson et. al., 2001a; Johnson et. al., 2001b). These experiments were patterned after work by Baxter et. al. (1996c) concerning the evolution of volatile nitrogen from coals. Both the sawdust and Albright coals were analyzed. The fuels were reacted in a drop tube reactor (DTR) at temperatures ranging from $400^{\circ} \mathrm{C}$ to $1700^{\circ} \mathrm{C}$. The total 
volatile matter evolution was measured, along with the total nitrogen evolved as volatile matter and the total carbon evolved as volatile matter. Figures 413 and 4-14 present the results for the sawdust; Figure 415 presents the results for the coal burned at Albright. Note that Figures 413 and 415 present the data in terms of DTR temperature. Figure 14 normalizes the volatile evolution from the sawdust to the total volatile evolution from the coal as another means of analysis.

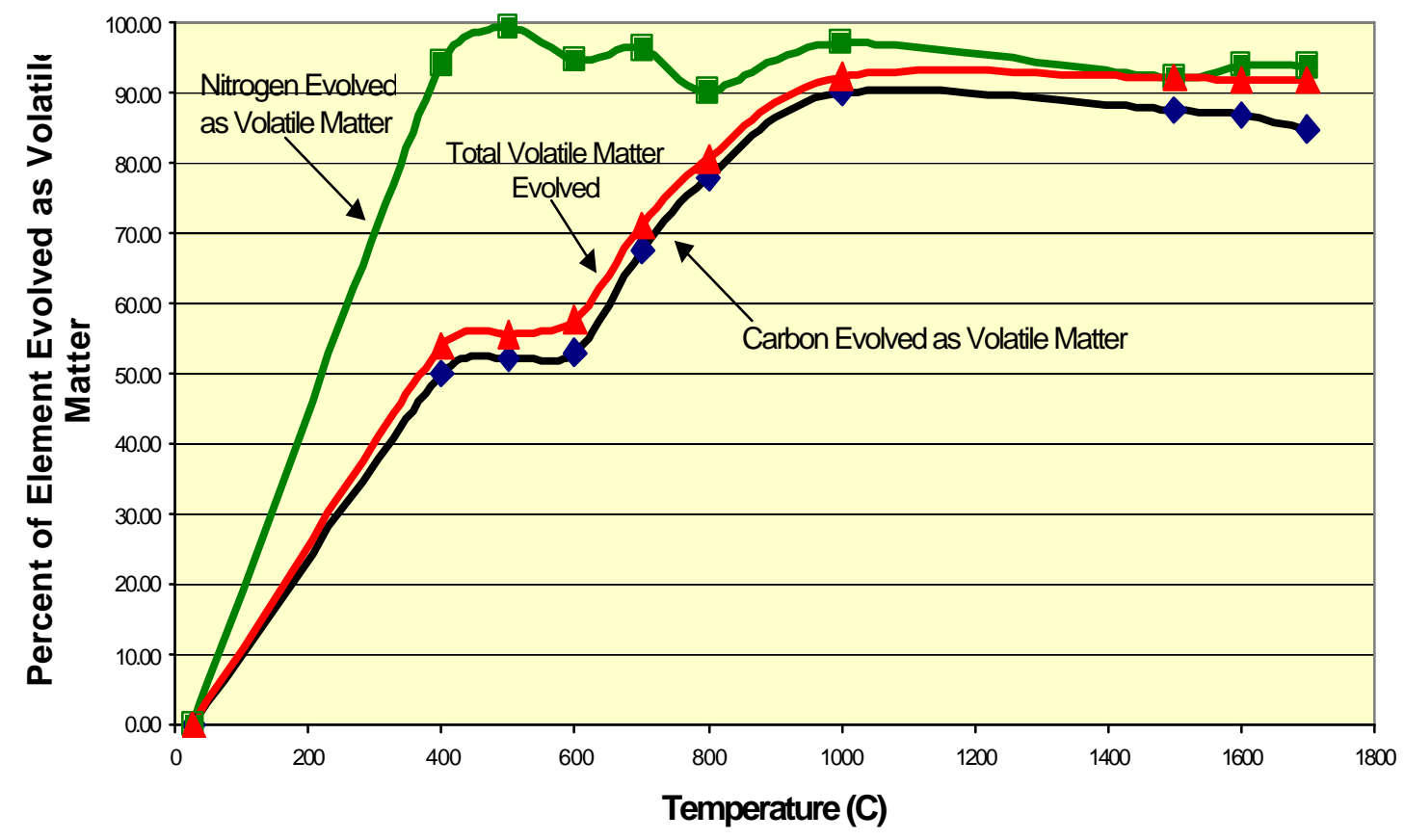

Figure 4-13. Nitrogen Volatile Evolution from Sawdust as a Function of Temperature

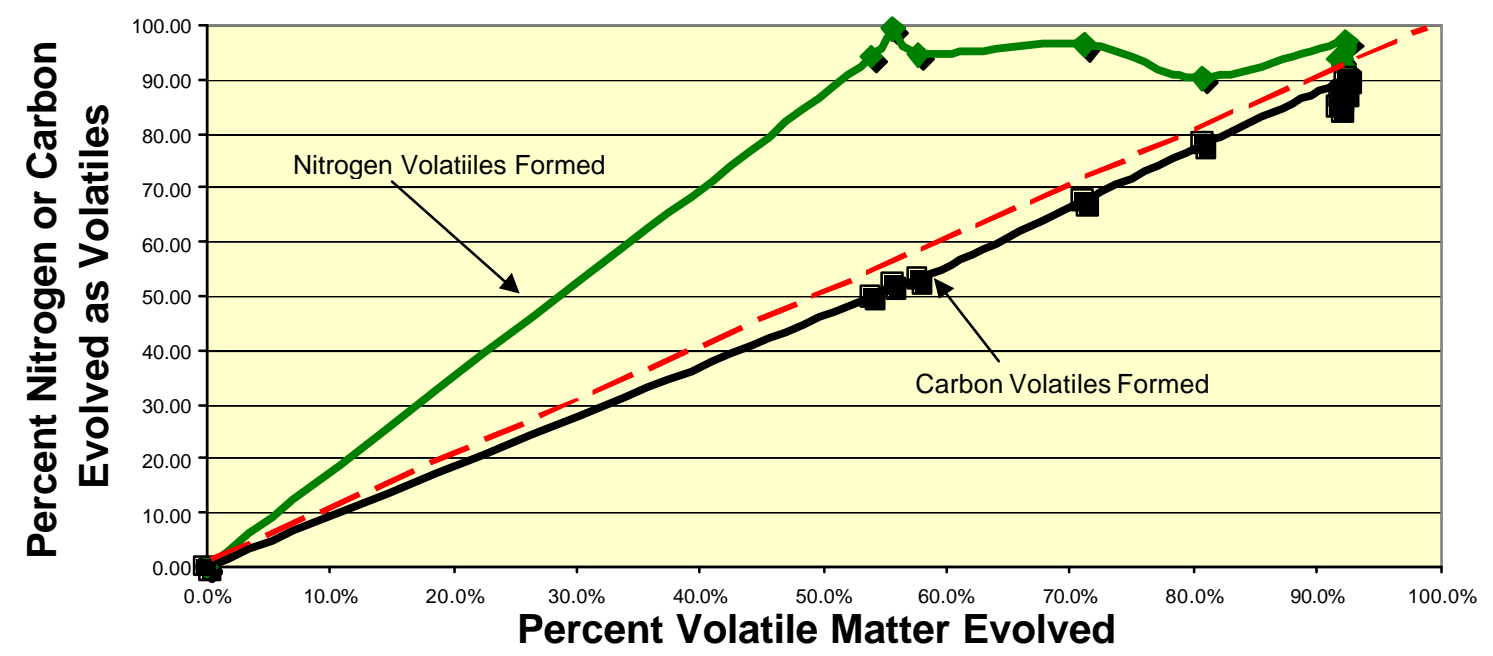

Figure 4-14. Nitrogen Volatile Evolution from Sawdust Normalized to Total Volatiles 


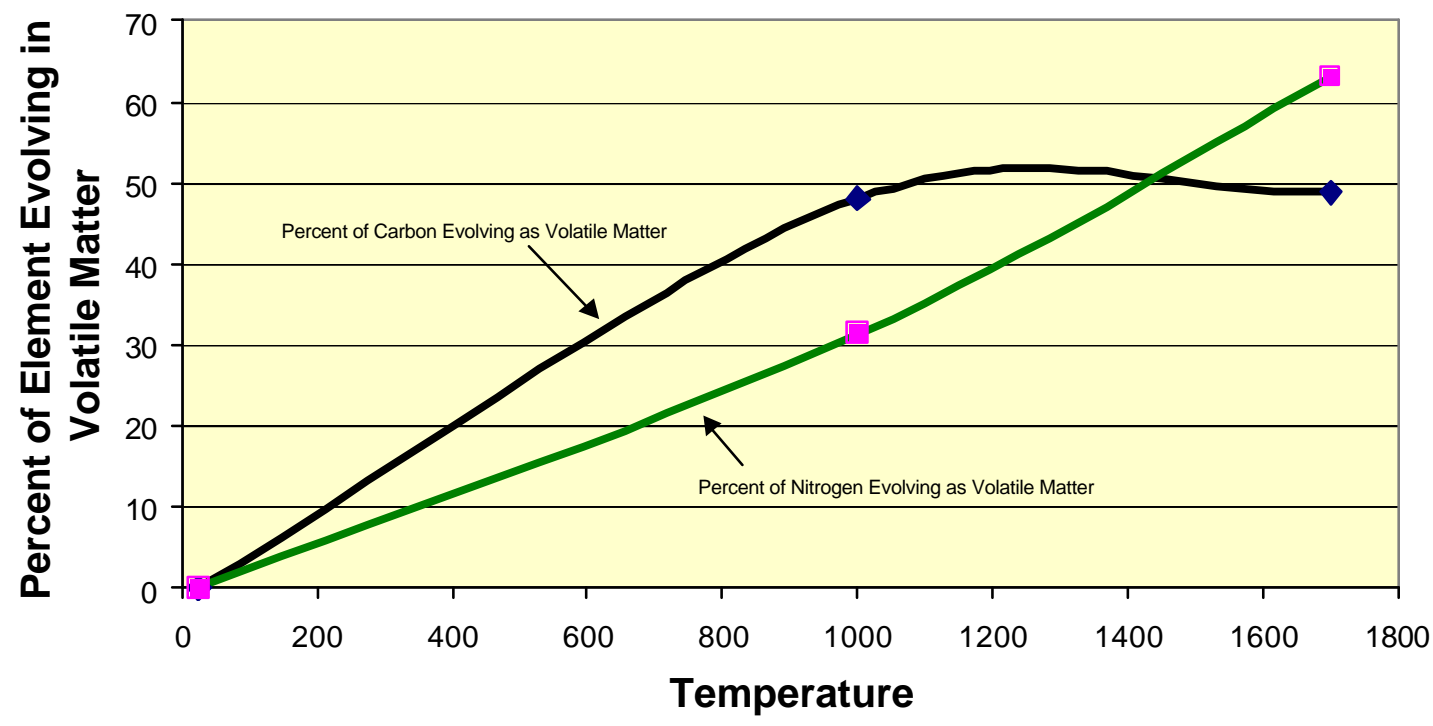

Figure 4-15. Nitrogen Volatile Evolution from Coal Burned at Albright Generating Station

Several factors become significant. the volatile evolution from sawdust is complete by $1000^{\circ} \mathrm{C}$ or $1800^{\circ} \mathrm{F}$. Further, over 90 percent of the dry wood evolves as volatile matter. The volatile evolution from coal burned at Albright Generating Station does not reach completion until $1700^{\circ} \mathrm{C}$ or $3092^{\circ} \mathrm{F}$. Further, only 52 percent of the dry coal matter evolves as volatile matter. The nitrogen volatiles evolve from the sawdust more rapidly than the carbon volatiles - or the total volatile matter. For the Albright coal, like virtually all bituminous coals, the nitrogen volatilization lags behind the carbon volatilizationand total volatile matter evolution — until the final stages of the pyrolysis process. Further, some 95 percent of the sawdust nitrogen evolves as volatile matter while only 62 percent of the coal nitrogen evolves as volatile matter.

The sawdust is injected into the center of the fireball in a transport air stream where the stoichiometric ratio is substantially below 1.0. The volatiles from the sawdust evolve rapidly, contributing to fuel staging in the fireball. The nitrogen volatiles also evolve rapidly and are readily converted to $\mathrm{N}_{2}$. This use of volatile flooding has been shown with the testing at the Allen Fossil Plant and the Seward Generating Station. It works synergistically with the management of excess $\mathrm{O}_{2}$ and the use of a SOFA system to maximize NOx reductions without compromising combustion/carbon conversion efficiency.

The influence of cofiring on mercury emissions can be inferred from available data in the literature. DeVito, Rosendale, and Conrad (1994) show mercury concentrations at $0.11 \mathrm{mg} / \mathrm{kg}$ in the total coal from 10 Pittsburgh Seam mines. This is equivalent to $3.67 \mathrm{mg} / 10^{6} \mathrm{Btu}$. This is consistent with research reported by Clarke, Sloss, and Grant (1992). Toxic Release Inventory data developed by Allegheny Energy from 1999 and 2000 show some variability in the mercury concentrations in coal burned at Albright; however it shows a consistent average of $0.18 \mathrm{mg} / \mathrm{kg}$ or $0.18 \mathrm{ppmw}$ in dry coal. Measurements made by Foster Wheeler concerning cofiring at the Albright Generating Station place the concentration of mercury in wood waste at $0.003-0.009 \mathrm{mg} / \mathrm{kg}$ or ppmw in dry fuel. These data were 
developed from clean sawdust samples of fuel burned at the Albright station. They indicate a significant contribution of cofiring to the reduction of mercury emissions at this generating station. These trends are consistent with a comparison of mercury concentrations in bituminous coal and sawdust (see, for example, Finkelman, 1994; Envirosphere, 1984; Tillman, 1994).

The cofiring at Albright Generating Station, then, makes significant contributions to a 3P strategy, and on all fronts. It achieves reductions in $\mathrm{SO}_{2}, \mathrm{NO}_{\mathrm{x}}$, and mercury emissions without increasing $\mathrm{CO}$ or opacity emissions.

\subsection{SWITCHGRASS COFIRING TESTING AT PLANT GADSDEN}

Plant Gadsden is the third T-fired cofiring test supported through the EPRI-USDOE Cooperative Agreement. This project was largely supported by USDOE-EERE directly, however EPRI provided some supplementary funding through the Cooperative Agreement. This project is described in several publications (Boylan et. al., 2001; Boylan, Bush, and Bransby, 2000; Boylan, Zemo, and Eastis, 2001). This was the only switchgrass cofiring project in a T-fired boiler that was participated in by the Cooperative Agreement. The switchgrass was delivered to Plant Gadsden in round bales and they were stacked 3-high and stored in the weather for about 6 months. This switchgrass was grown locally in Alabama.

The cofiring system at Plant Gadsden consisted of a tub grinder for particle size reduction of the switchgrass. The switchgrass was ground and blown into a surge bin. From there it entered a single transport pipe through an exhauster. It was blown to Plant Gadsden Unit \#2, a $70 \mathrm{MW}_{\mathrm{e}} \mathrm{T}$-fired boiler with three elevations of coal burners. Figures 4-16 through 4-21 depict the switchgrass cofiring system installed at Plant Gadsden and its operation.

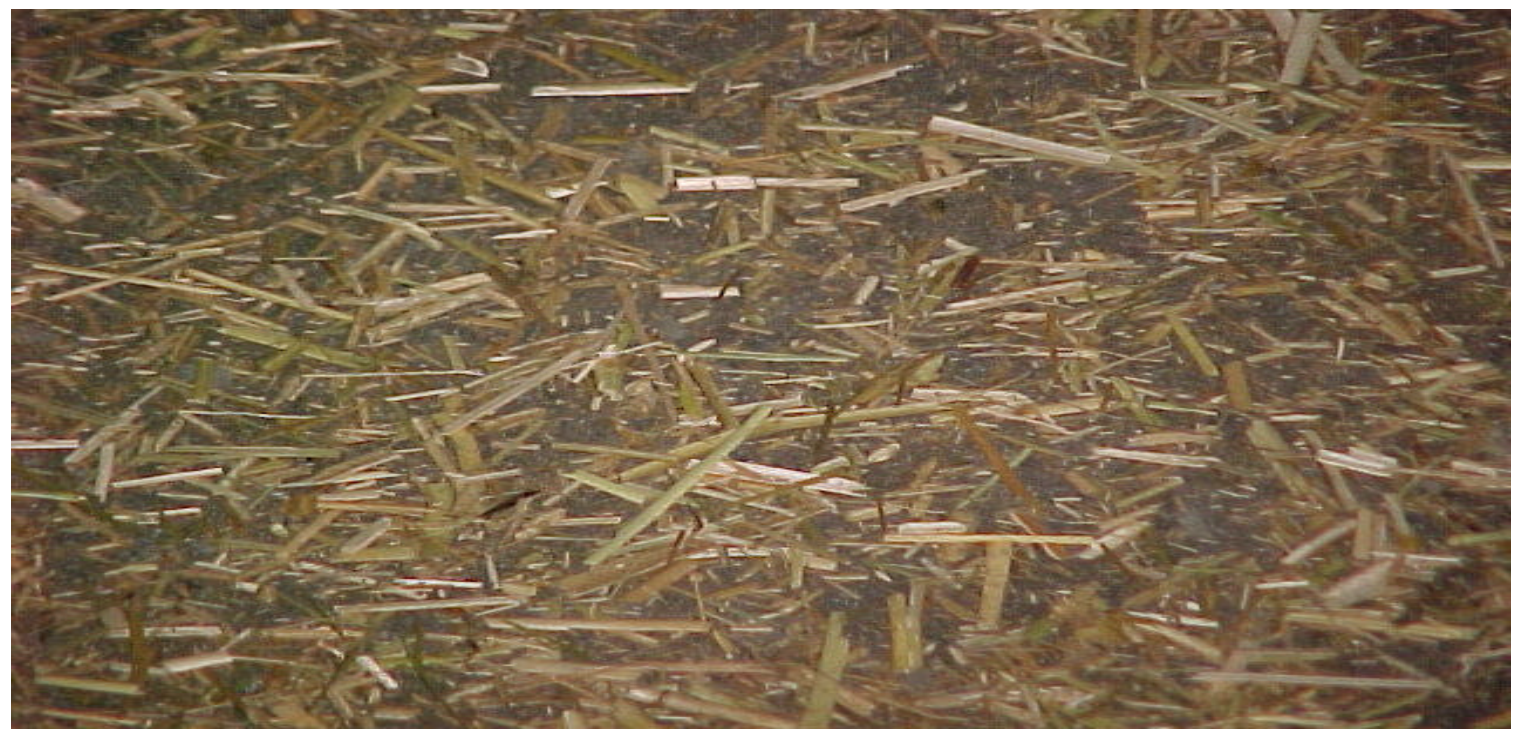

Figure 4-16. Switchgrass Burned at Plant Gadsden 


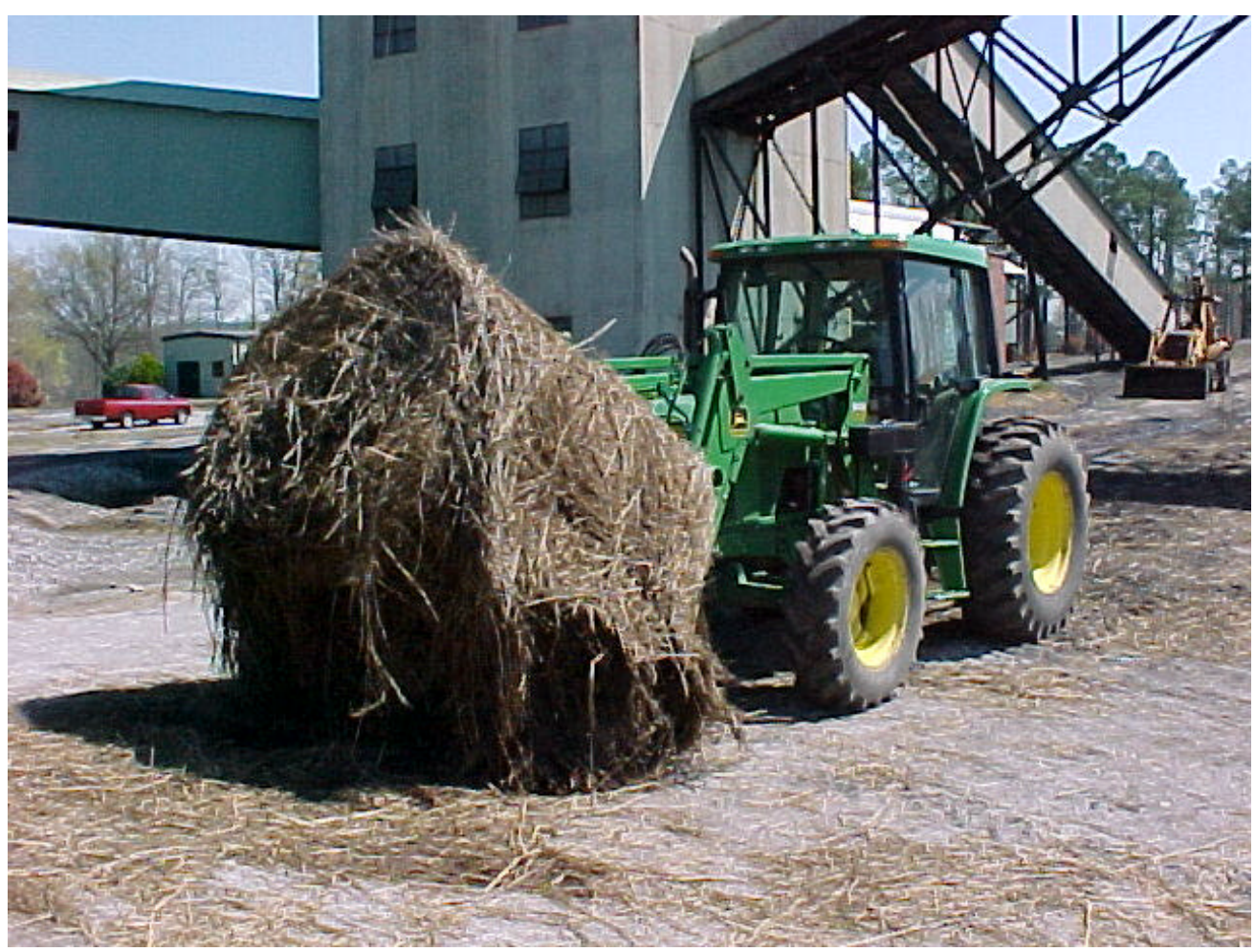

Figure 4-17. Transporting Switchgrass to the Tub Grinder at Plant Gadsden

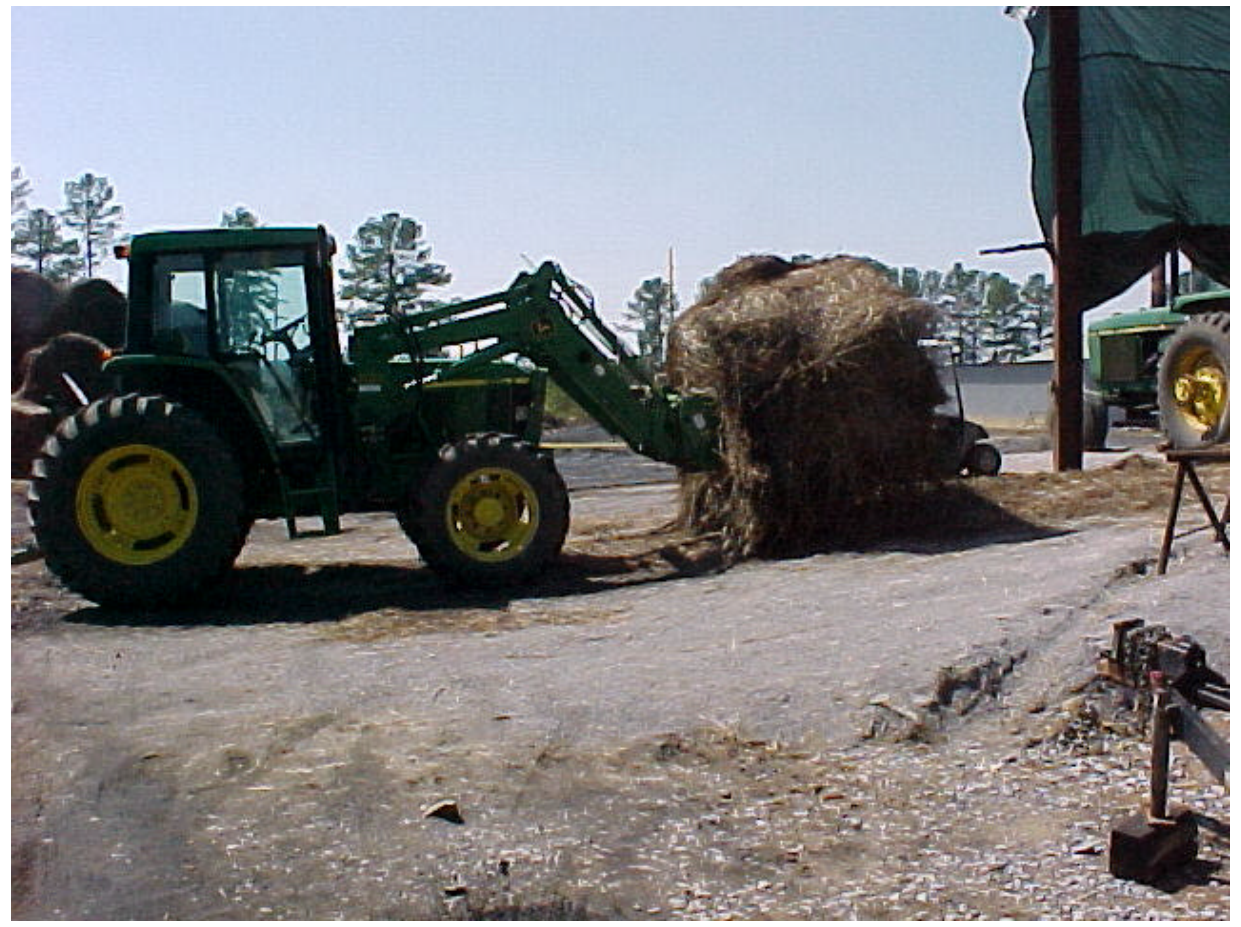

Figure 4-18. Loading the Tub Grinder with Baled Switchgrass 


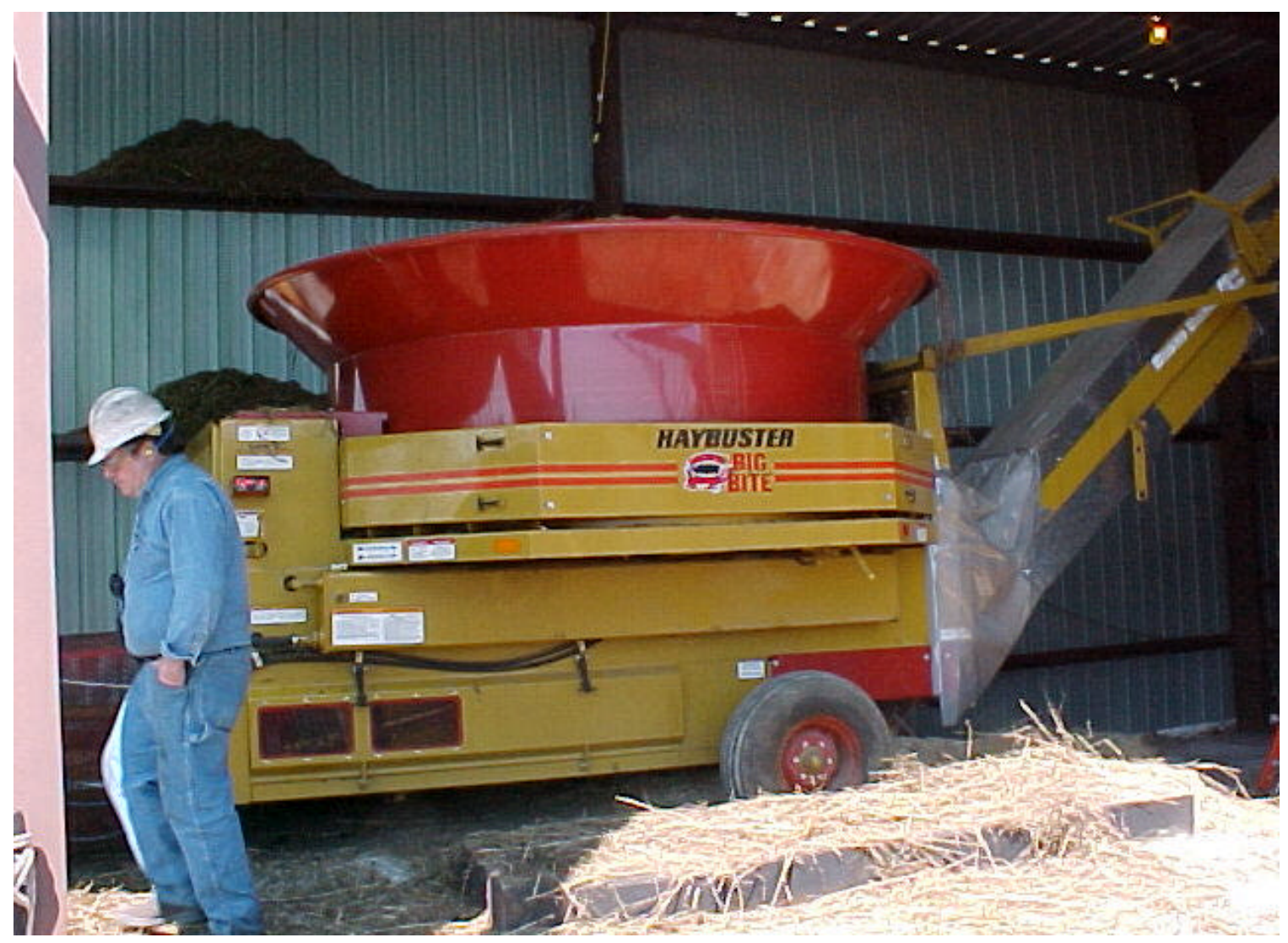

Figure 4-19. The Switchgrass Tub Grinder at Plant Gadsden

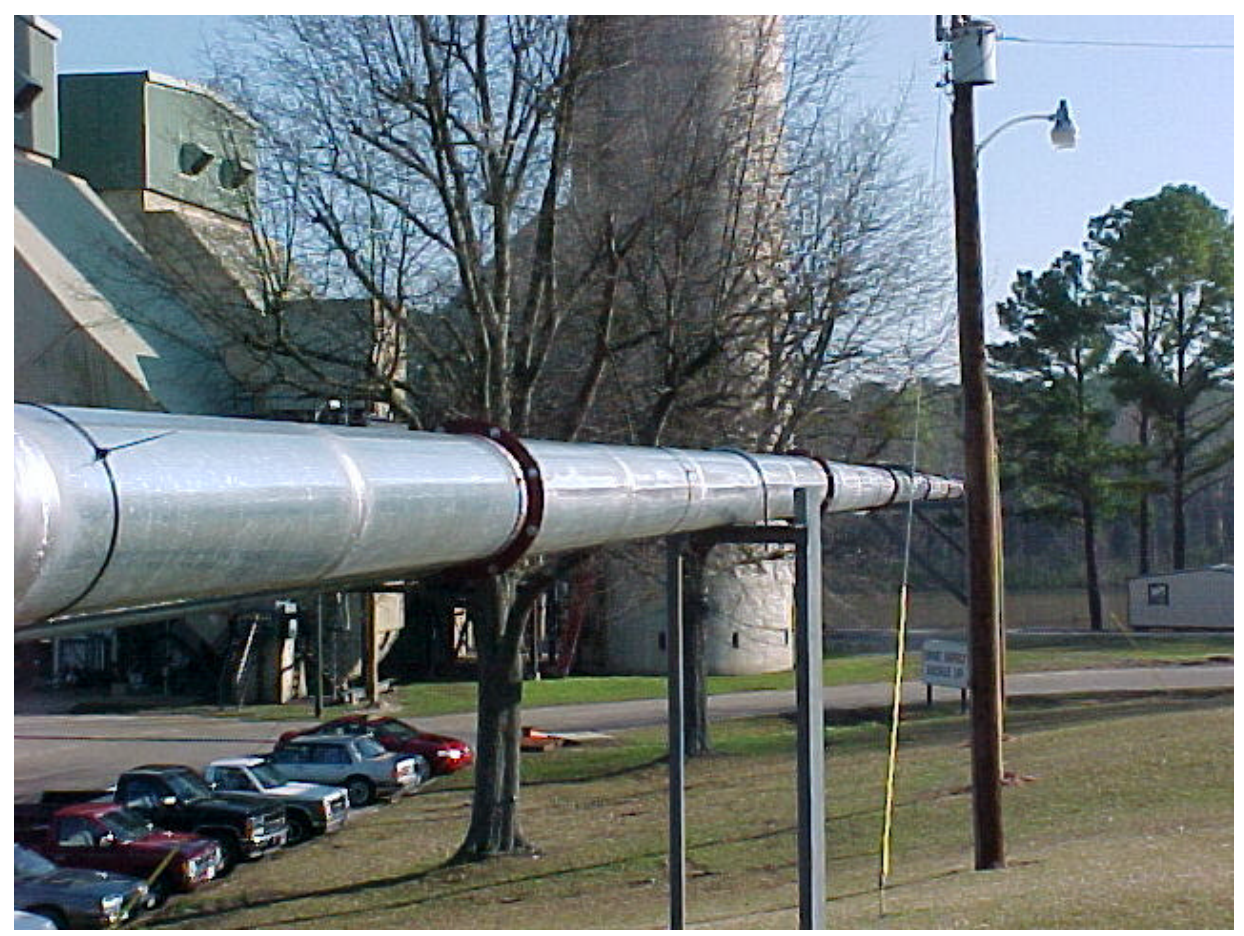

Figure 4-20. The Pneumatic Transport Pipe for Switchgrass at Plant Gadsden 


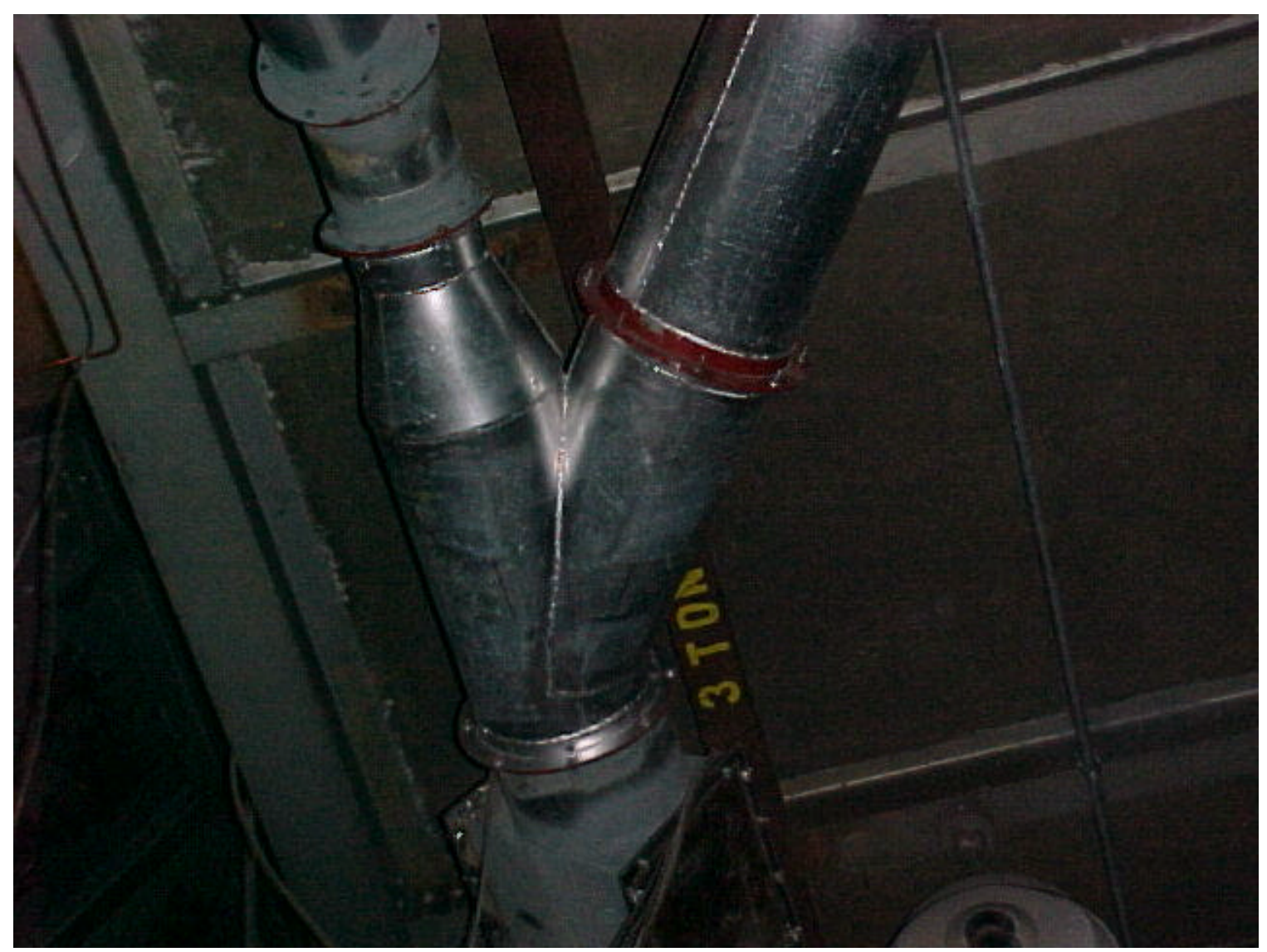

Figure 4-21. The Splitter for Transporting Switchgrass to Opposite Corners of \#2 Boiler

Switchgrass was cofired against synthetic fuel, with properties essentially identical to bituminous coal. Cofiring rates as high as 10 percent were achieved during this cofiring test. The switchgrass was extensively characterized and shown to have $8,000-8,135 \mathrm{Btu} / \mathrm{lb}$ and ash fusion temperatures of $1844^{\circ} \mathrm{F}-2264^{\circ} \mathrm{F}$. Most ash fusion temperatures reported were $<2,100^{\circ} \mathrm{F}$.

The objectives of the test were to demonstrate direct injection cofiring of switchgrass in a T-fired boiler, determine the maximum cofiring percentage that could be cofired, and examine the impact of cofiring on airborne emissions, and boiler efficiency. The test was successful in demonstrating cofiring at 10 percent, and determining the impacts of cofiring on emissions and efficiency. Some 40 tests were completed over a 5-week period. Variables tested included percent cofiring, excess $\mathrm{O}_{2}$, unit load, and injection level (between the first and second row of burners, and between the second and third row of burners).

The testing showed that cofiring switchgrass - a dry biofuel-does cause a modest decrease in boiler efficiency. At the same time it causes no increase in opacity, and causes a modest decrease in $\mathrm{SO}_{2}$ emissions. Substituting a sulfur-free biomass for coal caused the latter emissions reduction.

Interestingly, the test showed no reduction in $\mathrm{NO}_{\mathrm{x}}$ emissions. This is unusual, particularly when compared to the sawdust testing at other generating station. It also conflicts with the results obtained by 
Aerts and Ragland (1997) at Blount St. Station. However there are several potential explanations for the results at Plant Gadsden. Because the bulk density of the fuel is typically $\sim 5 \mathrm{lb} / \mathrm{ft}^{3}$, it may be more difficult to achieve stoichiometric ratios $<1.0$ between the grass and the transport air. The T-fired boiler, with its single fireball, could possibly make this more problematical. The switchgrass fired at Plant Gadsden also functions fundamentally differently from the sawdust fired at Albright Generating Station.

A sample of the switchgrass was obtained from Southern Company and tested at Pennsylvania State University (see Johnson et. al., 2001a). The switchgrass was prepared in the same manner as the sawdust-air-dried and ground to $70 \times 140$ mesh. The particle size distributions were essentially identical. The switchgrass was then subjected to drop tube reactor (DTR) testing. While its maximum volatile yield was comparable to that of sawdust—91 percent — it did not reach maximum volatile yield until $1500^{\circ} \mathrm{C}$. It volatilized more slowly than sawdust. Further, its nitrogen volatile release was comparable to a young coal, rather than a sawdust as is shown in Figures 4-22 and 4-23. Consequently the switchgrass may have behaved just like coal in the Plant Gadsden boiler.

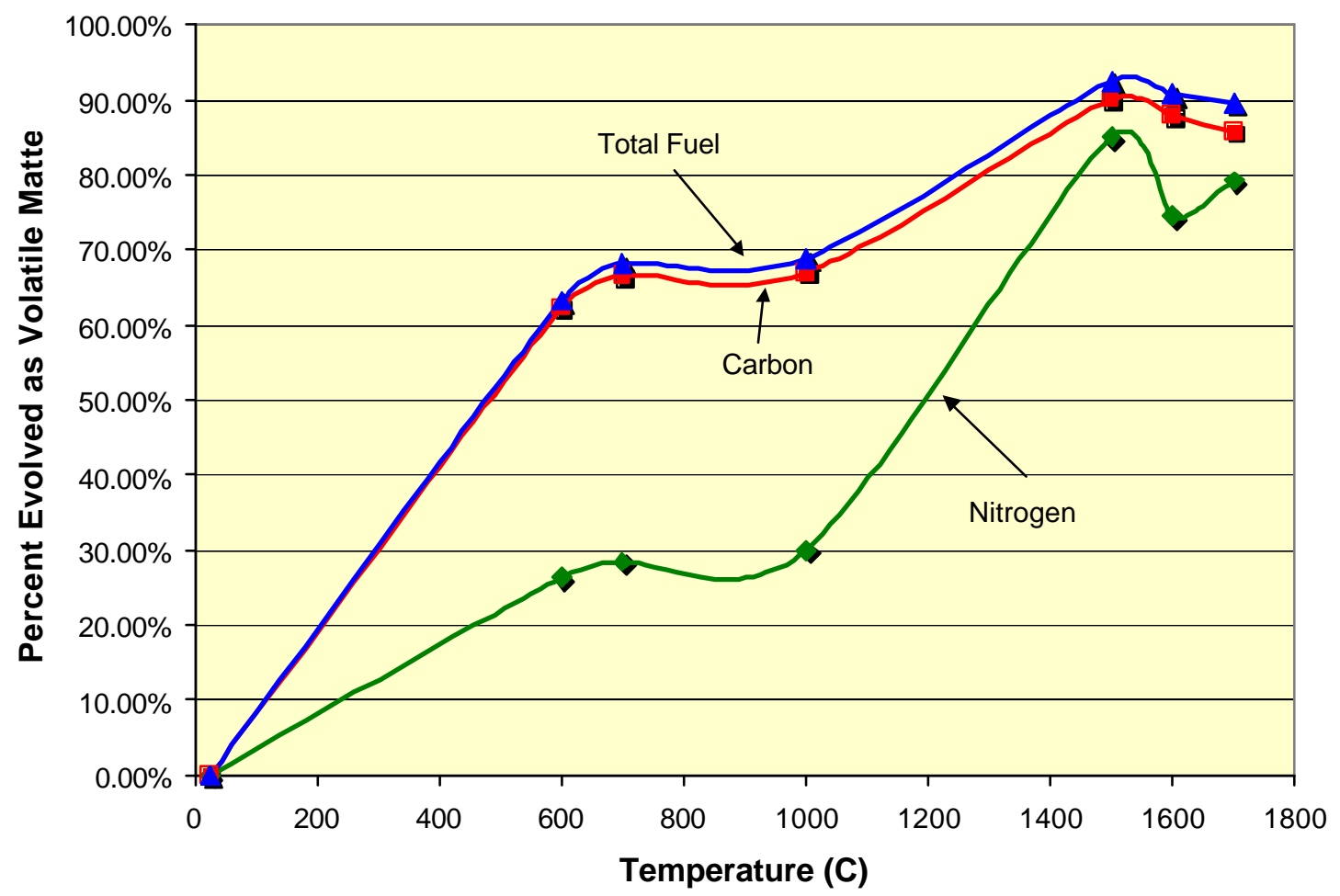

Figure 4-22. Evolution of Nitrogen from Switchgrass Obtained From the Plant Gadsden Tests 


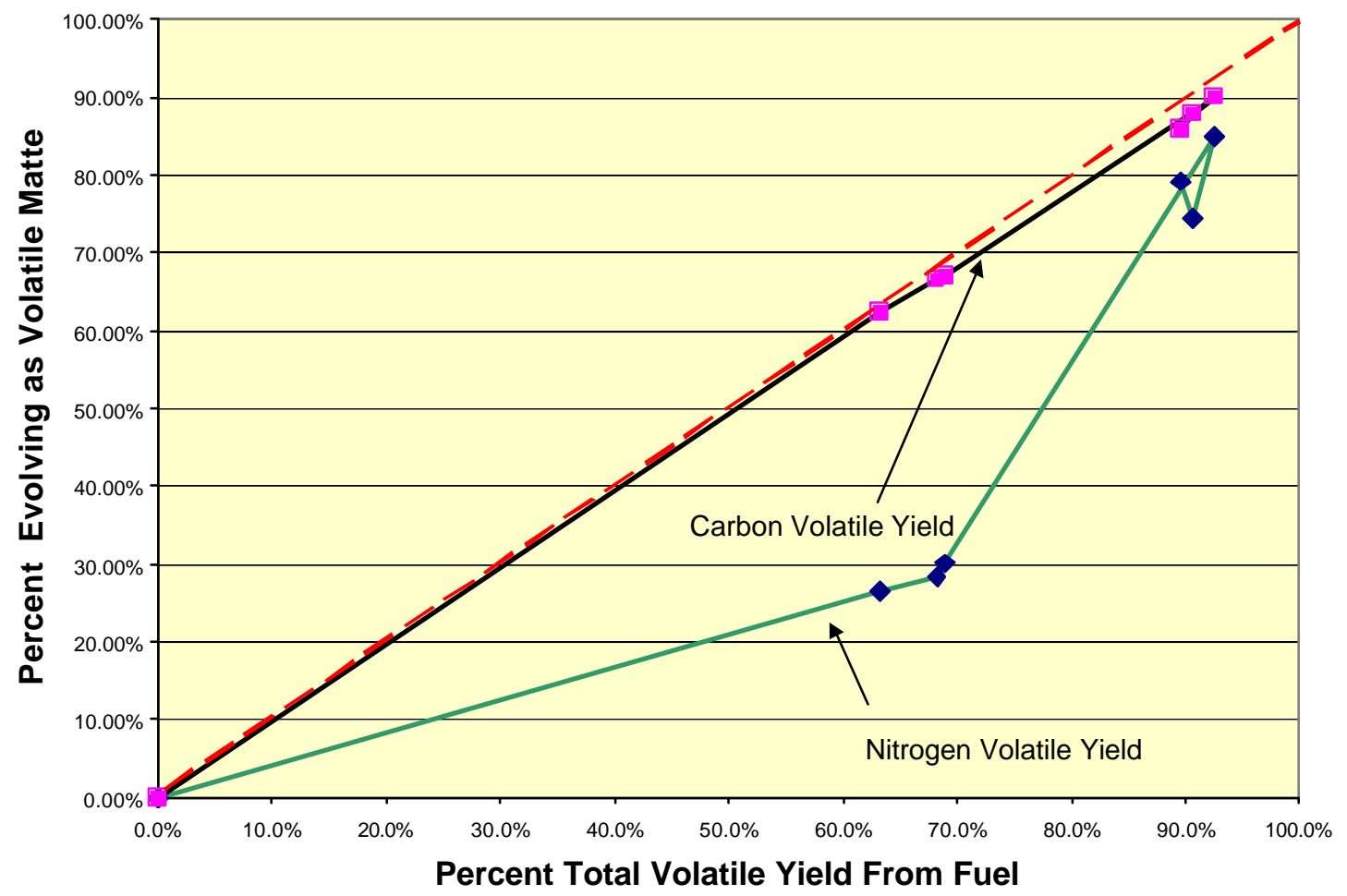

Figure 4-23. Evolution of Nitrogen Normalized to Total Volatile Yield from Switchgrass Obtained from the Plant Gadsden Test

The tests at Plant Gadsden, then, were successful in documenting the ability to cofire switchgrass in a Tfired boiler. They highlighted potentials and issues in the areas of efficiency and emissions.

\subsection{CONCLUSIONS REGARDING COFIRING IN TANGENTIALLY-FIRED PULVERIZED COAL BOILERS}

The EPRI-USDOE Cooperative Agreement was highly successful in promoting cofiring of biomass in T-fired boilers. It contributed to the successful commercialization of the technology in an initial installation at Greenidge Station. It demonstrated that cofiring could be a significant contributor to a 3P strategy at Albright Generating Station—and that cofiring could be used synergistically with staged fuel and staged air combustion technologies such as separated overfire air. It contributed to the successful testing of switchgrass cofiring at Plant Gadsden in Alabama. In these actions, the EPRI-USDOE Cooperative Agreement moved biomass cofiring significantly towards full commercial implementation. 


\subsection{COOPERATIVE AGREEMENT SUPPORT FOR COFIRING IN CYCLONE BOILERS}

\subsection{INTRODUCTION}

Cofiring in cyclone boilers is unlike cofiring in PC boilers. Cyclones accept crushed coal, typically sized to $1 / 4$ " $\mathrm{x}$ 0". The coal is fed directly to the cyclone barrel where it is swept into a cyclonic action by primary air fed to the burner section of the cyclone. Secondary air fed to the cyclone barrel maintains the cyclonic action. The fuel is flung to the walls of the cyclone where it is trapped in the slag layer and burns. Air distributions in cyclones are fundamentally different from PC boilers; typically $\sim 85$ percent of the air fed to the cyclone is as secondary air. Primary and tertiary air make up $\sim 15$ percent of the combustion air. Heat release rates are on the order of $500,000-850,000 \mathrm{Btu} / \mathrm{ft}^{3}-\mathrm{hr}$ in the cyclone barrel. Unlike PC boilers, where 80 percent of the solid products of combustion exit as flyash, 70 percent of the solid products of combustion from cyclone boilers exits as bottom ash—slag which flows from the cyclones to the bottom of the furnace where it exits through slag taps into quench tanks. The quenched slag is ground and ultimately typically sold. Cyclones typically generate relatively high $\mathrm{NO}_{\mathrm{x}}$ emissions - a factor contributing to the decline of this technology. The electricity generating industry has not installed a new cyclone boiler since 1975. At the same time cyclones comprise about 9 percent of US electricity-generating capacity, with a high concentration being located in the upper Midwest. They are an optimum target for cofiring because of the absence of pulverizers. At the same time, however, attention has to be paid to issues of maintaining slag viscosity and lower furnace temperatures to promote slag tapping. Further, manipulating the combustion process in a cyclone barrel is significantly different from manipulating the combustion process in a PC boiler.

Cofiring in cyclone boilers has been tested by other utilities including King Generating Station of Northern States Power, La Cygne Generating Station of Kansas City Power \& Light, and Thomas Hill Energy Center outside of Columbia, MO, owned by Associated Electric Cooperative. The King Station cofired dry sawdust from Andersen Windows, pneumatically transporting it into three of 12 cyclones at that 600 MWe unit. Both the La Cygne and Thomas Hill cofiring tests successfully cofired spent railroad ties in cyclone boilers (Battista and Hughes, 2000). Both of these were very short tests of cyclone cofiring. Cyclone boilers had also been used to cofire tire-derived fuel (TDF) at Baldwin Station of Illinois Power; Rock River, Edgewater, and Nelson Dewey Generating Stations of Wisconsin Power \& Light; and elsewhere. Cyclones appeared to be ideal candidates for biomass cofiring.

Despite the flexibility of cyclone boilers, certain issues remained: Would the $\mathrm{NO}_{\mathrm{x}}$ reductions achieved when cofiring with Midwestern and western bituminous coals be reproduced when cofiring with Powder River Basin (PRB) coals? Could multiple opportunity fuel blends be developed to obtain the advantages of biomass cofiring without suffering the efficiency penalties? Northern Indiana Public Service Company (NIPSCO)—now part of NiSource_-addressed these questions with test programs at the Michigan City Generating Station and the Bailly Generating Station. 


\subsection{COFIRING TESTING AT MICHIGAN CITY GENERATING STATION}

Cofiring was tested at NIPSCO Boiler \#12, at the Michigan City Generating Station. This project is described in numerous papers and publications (Tillman et. al., 1998a; Tillman et. al., 1998b; Tillman et. al., 1997). The test implemented at Michigan City involved receiving 1,000 tons of clean (untreated wood basis) urban wood waste and kiln dried wood waste. The wood came largely from the manufactured housing industry, the RV manufacturing industry, and the pallet industry. Kiln dried sawdust was also obtained from southern Indiana. This material was screened to fuel particles $1 / 2$ " x 0 " and immediately blended with Shoshone coal on a 1:1 volumetric basis. Screening was performed using a large deck screen rented by NIPSCO (see Figure 5-1). Blending was performed by bucket blending in the coal yard.

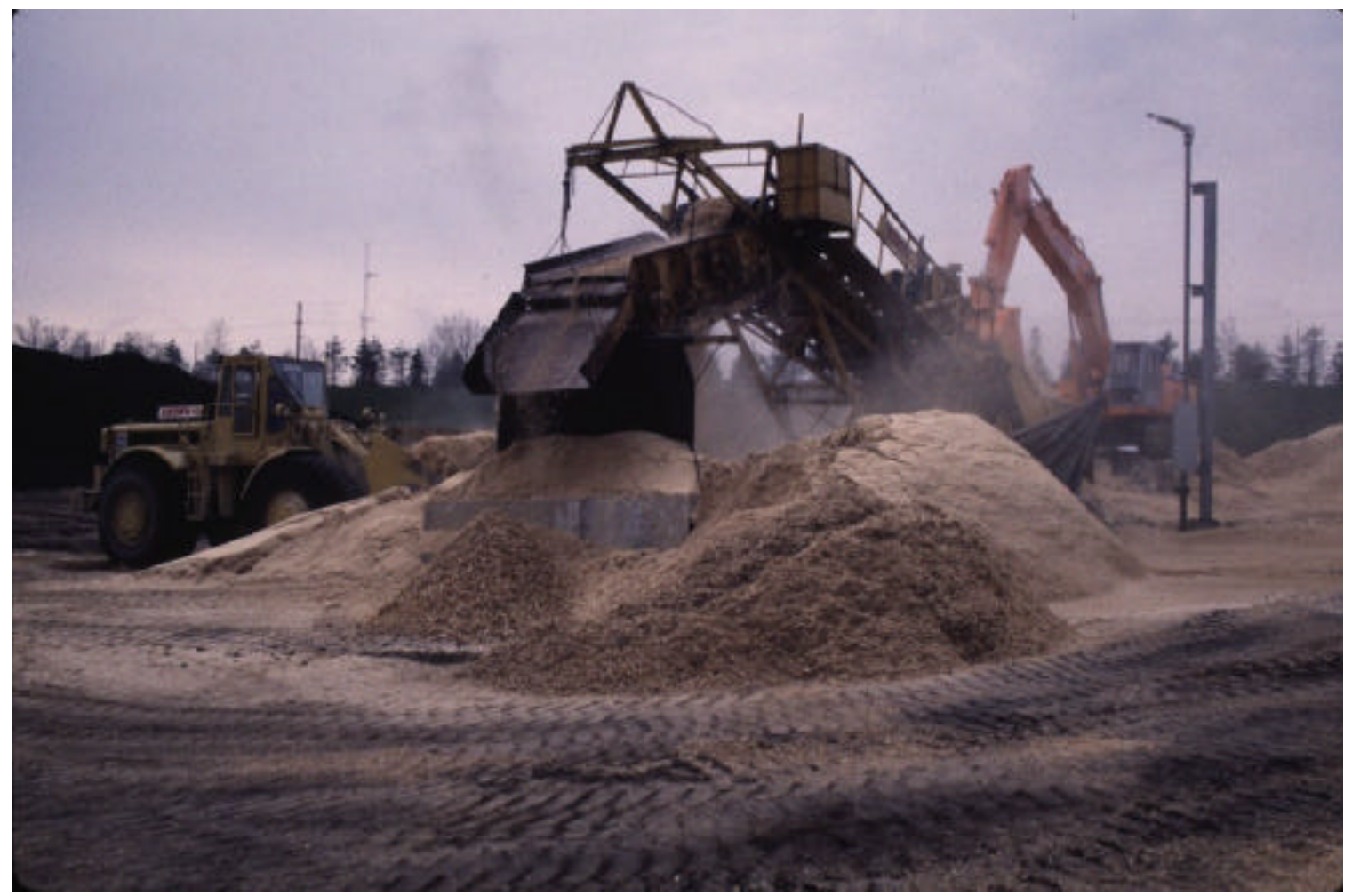

Figure 5-1. Screening Urban Wood Waste at Michigan City Generating Station

This blend was stocked out and stored during the summer of 1997 as shown in Figure 5-2. Storage of the blend during the hot, humid days of summer was monitored closely to ensure no incidents of spontaneous combustion. Storage occurred safely. 


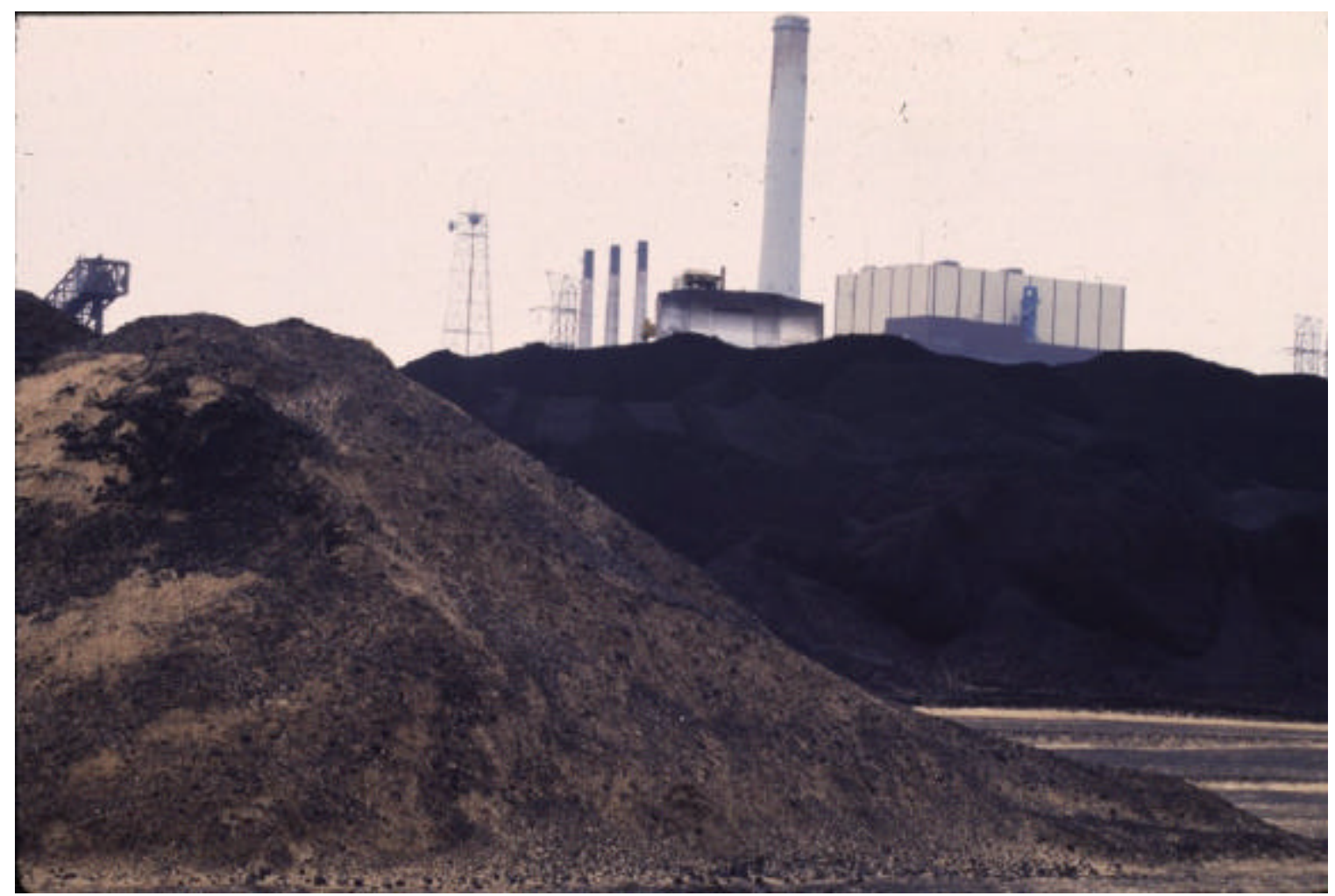

Figure 5-2. The Blend of Urban Wood Waste/Shoshone Coal Stocked Out in the Michigan City Generating Station Coal Yard

During the cofiring combustion tests the blend shown in Figure 5-2 was blended with PRB coal to achieve a total fuel mixture of 50 percent PRB, 40 percent Shoshone, and 10 percent wood waste on a mass basis. This was equivalent to cofiring wood waste at about 6.5 percent on a heat input basis. The PRB coal used was either Caballo Rojo (used during the baseline tests) or Black Thunder (used during the cofiring tests).

\subsubsection{Characteristics of the Fuels}

Table 5-1 summarizes the proximate and ultimate analysis for the four different fuels used. The urban wood waste and dry wood waste from Southern Indiana are combined into a single fuel, since the separate analyses show the only material difference being the moisture content. After the fact, representative samples of the various coals were analyzed by Pennsylvania State University to provide insights into the structural and behavioral characteristics of these fuels. Carbon 13 Nuclear Magnetic Resonance $\left({ }^{13} \mathrm{C} \mathrm{NMR}\right)$ testing was employed to evaluate the structural characteristics of the fuels (Clifford, 2001). DTR testing as previously discussed was employed to evaluate devolatilization and char oxidation kinetics, and to evaluate the nitrogen evolution patterns of the various fuels. Table 5-2 presents the results of these analyses. The data were developed to fit the standard Arrhenius equation. 
Table 5-1. Proximate and Ultimate Analysis of Fuels Burned at Michigan City Cofiring Tests

\begin{tabular}{|r|c|c|c|c|}
\hline & \multicolumn{5}{|c|}{ Fuel } \\
\hline & Wood Waste & Black Thunder & Caballo Rojo & Shoshone \\
\hline Proximate (Wt \%) & & & & 16.41 \\
\hline Moisture & 27.64 & 27.89 & 31.05 & 5.48 \\
\hline Ash & 0.74 & 5.38 & 4.63 & 36.93 \\
\hline Volatile Matter & 61.61 & 33.06 & 33.04 & 41.20 \\
\hline Fixed Carbon & 10.01 & 33.66 & 31.28 & \\
\hline Ultimate (Wt \%) & & & & 62.05 \\
\hline Carbon & 37.40 & 53.80 & 48.41 & 3.98 \\
\hline Hydrogen & 4.13 & 2.89 & 3.45 & 10.04 \\
\hline Oxygen & 29.90 & 10.95 & 11.26 & 0.41 \\
\hline Nitrogen & 0.18 & 0.78 & 0.38 & 16.41 \\
\hline Sulfur & 0.02 & 0.40 & 31.05 & 5.48 \\
\hline Moisture & 27.64 & 27.89 & 4.63 & 10474 \\
\hline Ash & 0.74 & 5.38 & 8424 & \\
\hline $\begin{array}{l}\text { Higher Heating } \\
\text { Value (Btu/lb) }\end{array}$ & 5944 & 8888 & & \\
\hline
\end{tabular}

With respect to the values shown in Table 5-2, it should be noted that sawdust and Caballo Rojo coal exhibit low temperature devolatilization which is more reactive than that shown. For wood waste devolatilizing in the $400-600^{\circ} \mathrm{C}$ region, the pre-exponential constant (A) is 1.17 and the activation energy is 0.681. For Caballo Rojo coal devolatilizing in the temperature region of $600-1000^{\circ} \mathrm{C}$, the pre-exponential constant (A) is 5.33 and the activation energy is 3.68. Note that all of these fuels are far more reactive than the typical eastern bituminous coal with an aromaticity of $\sim 0.7,13-15$ aromatic carbons/cluster, and with higher activation energies for both devolatilization and char oxidation. 
Table 5-2. Structural and Kinetic Data Representative of Fuels Burned at Michigan City Cofiring Tests

\begin{tabular}{|c|c|c|c|c|}
\hline & \multicolumn{4}{|c|}{ Fuel } \\
\hline & $\begin{array}{l}\text { Wood Waste } \\
(* * *)\end{array}$ & $\begin{array}{l}\text { Black } \\
\text { Thunder }\end{array}$ & Caballo Rojo & Shoshone \\
\hline $\begin{array}{l}\text { Aromaticity (Number of Aromatic Carbon } \\
\text { Atoms/Total Number of Carbon Atoms) }\end{array}$ & 0.08 & 0.57 & 0.64 & 0.61 \\
\hline $\begin{array}{l}\text { Average Number of Aromatic } \\
\text { Carbons/Cluster }\end{array}$ & 6 & 10 & 10 & 11 \\
\hline \multicolumn{5}{|l|}{ Devolatilization Kinetics $(*)$} \\
\hline Temperature Range $\left({ }^{\circ} \mathrm{C}\right)$ & $600-1000$ & $800-1700$ & $1000-1700$ & $800-1700$ \\
\hline Pre-exponential Constant (A) (1/sec) & 5.74 & 59.1 & 89.3 & 36.2 \\
\hline Activation Energy (E) (kcal/mol) & $3.42(* * * *)$ & 9.53 & 10.8 & 8.06 \\
\hline \multicolumn{5}{|l|}{ Char Oxidation Kinetics $(* *)$} \\
\hline Pre-exponential Constant (A) (1/sec) & $1.63 \times 10^{5}$ & $7.61 \times 10^{4}$ & $1.83 \times 10^{4}$ & $3.24 \times 10^{5}$ \\
\hline Activation Energy (E) (kcal/mol) & 25.7 & 27.4 & 26.2 & 29.0 \\
\hline \multicolumn{5}{|c|}{$\begin{array}{l}\text { (*) Determined by Drop Tube Reactor Measurements } \\
(* *) \text { Determined by Thermogravimetric Analysis of Chars Generated at } 1700^{\circ} \mathrm{C} \text { or } 3092^{\circ} \mathrm{F} \\
(* * *) \text { Values are for Sawdust and Considered Representative of the Wood Waste Burned at Michigan } \\
\text { City } \\
(* * * *) \text { Determined for the temperature range } 600-1000^{\circ} \mathrm{C} \text {; Activation energy is } 0.681 \text { for the } \\
\text { temperature range } 400-600^{\circ} \mathrm{C}\end{array}$} \\
\hline
\end{tabular}

Source: Johnson et. al., $2001 \mathrm{~b}$.

The data developed also indicated different nitrogen volatile evolution patterns as illustrated in Figures 5-3 through 5-5. 


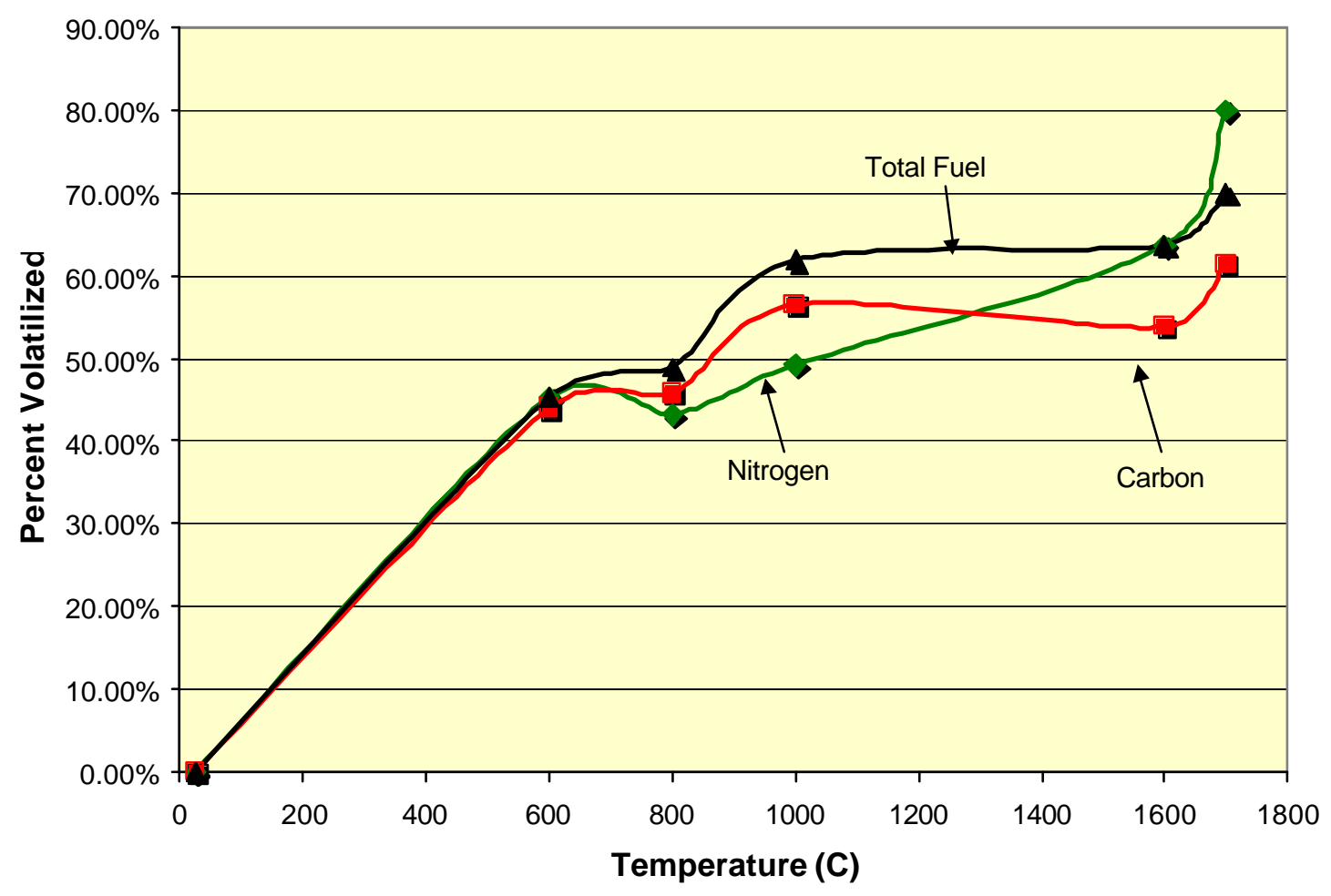

Figure 5-3. Nitrogen and Total Fuel Volatile Evolution Patterns for Black Thunder Coal 


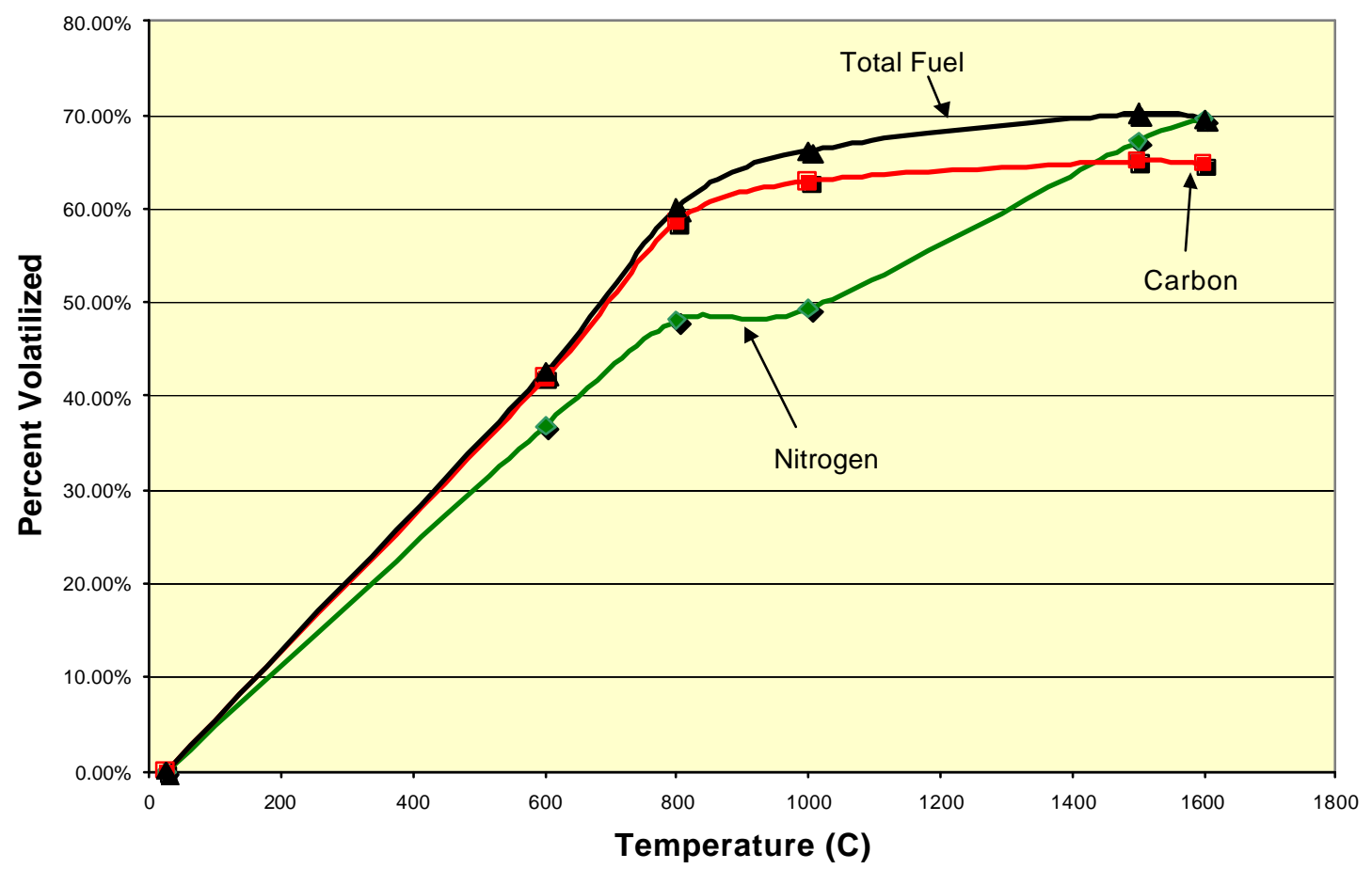

Figure 5-4. Volatile Evolution Patterns for Caballo Rojo Coal

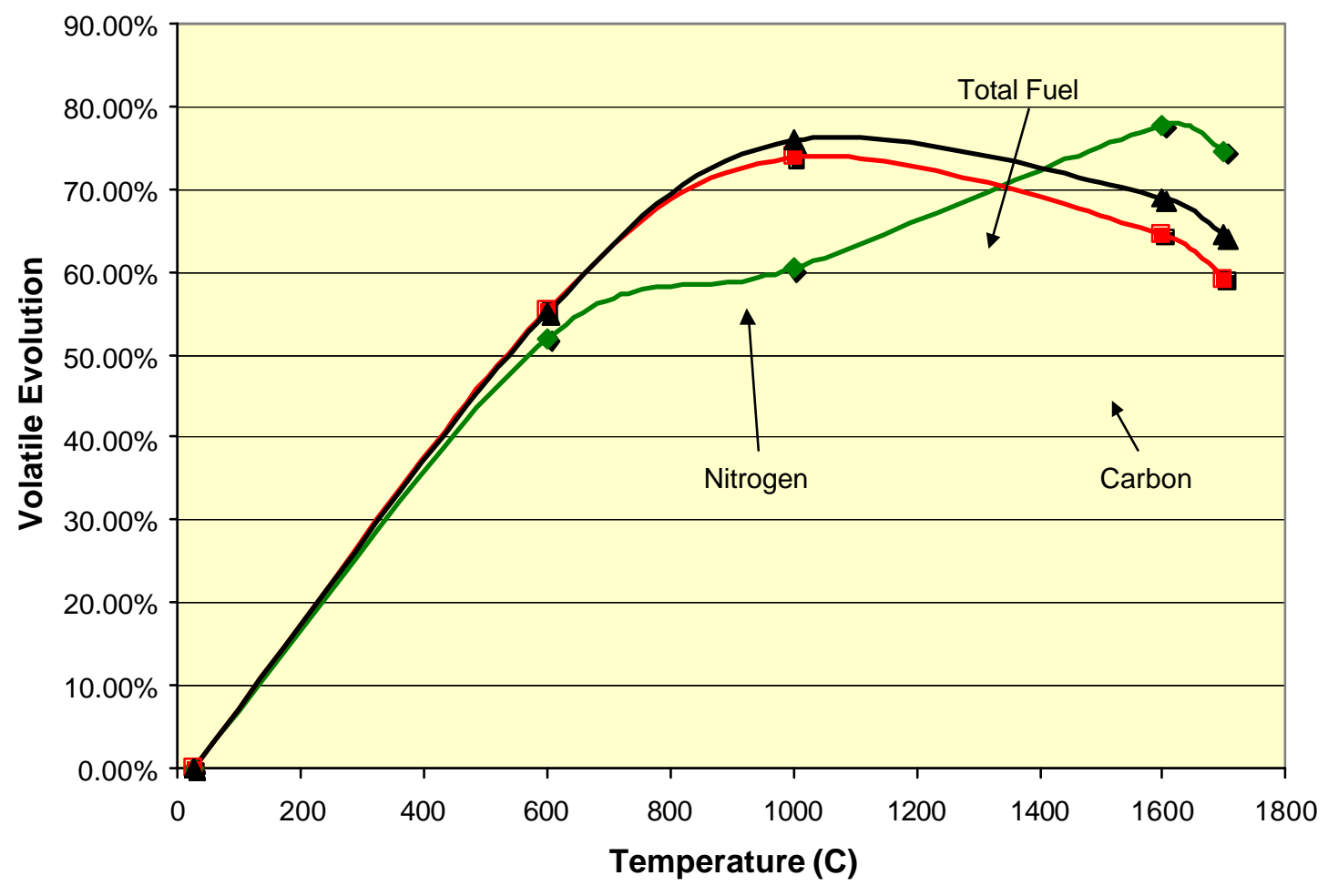

Figure 5-5. Volatile Evolution Patterns for Shoshone Coal 
Note that the nitrogen volatile evolution lags behind the carbon volatile evolution, and the total volatile evolution, for all three coals - but that the lag shown is not as pronounced as that measured for eastern bituminous coal (see Figure 415). The lag is most pronounced for the Shoshone coal, and least pronounced for the Black Thunder coal. Cofiring at Michigan City, with western and PRB coals as the base fuel, is quite different from cofiring with eastern bituminous coals as the base fuel.

\subsubsection{The Cofiring Tests}

Because the Michigan City \#12 boiler had been fired for some time on the conventional blend of 60 percent Black Thunder/40 percent Shoshone, it had been derated to $430 \mathrm{MW}_{\mathrm{e}}$ based upon economizer exit temperatures. Consequently, tests were run at full load-nominally $425 \mathrm{MW}_{\mathrm{e}}$-and at minimum load of $300 \mathrm{MW}_{\mathrm{e}}$. Tests were performed over 3 to 4 hour periods. Variables, other than load, included cofiring vs. baseline testing, excess $\mathrm{O}_{2}$ percentages, and related operating parameters. Extensive data sets were taken in the control room, and at the inlet and outlet of the air heater, in order to evaluate the impact of 10 percent cofiring on boiler capacity, efficiency, operability, and emissions. Samples of all fuels were taken for proximate and ultimate analysis; samples of flyash were taken from the flue gas stream and from the precipitator hoppers to determine the influence of cofiring on unburned carbon. Deposition was evaluated by considering the impact of cofiring on temperatures at the exit of the air heater between sootblowing cycles. These efforts provided a complete data set for test analysis. The test conditions were generally consistent throughout the entire time of cofiring. However one critical parameter impacted the testing, and the interpretation of results. The test was conducted during a period of time when utilities serviced by the Union Pacific Railroad were having difficulties with coal shipments. The plant had only 8 days of coal on the ground when testing commenced. Consequently the baseline was performed using Caballo Rojo as the PRB coal. The cofiring testing, however, was conducted using Black Thunder as the PRB coal. Interpreting the results, and documenting the differences between the baseline and the cofiring tests, required calculation techniques documenting the influence of PRB coal type. The tests were conducted in September, 1997. They focused upon issues of capacity, efficiency, temperature impacts, and environmental impacts.

\subsubsection{Capacity Impacts}

Table 5-3 presents the overall conditions existing during the 3 baseline tests and the 6 cofiring tests. Note that there was no loss of load associated with cofiring; and steam flows with biofuel in the total fuel blend were within 30,000 lb/hr (1.5 percent) of steam flows during baseline testing.

The data in Table 5-3 suggest no impact on capacity. However, feeder speeds were also measured, as shown in Figure 5-6. Feeder speeds to the cyclones averaged about 8 percent higher when cofiring than when operating the unit only on coal. The difference in feeder speeds can be attributed both to the lower heat content of the wood waste relative to the coal, and the lower bulk density of the wood waste relative to the coal. The feeder speed data indicate that cofiring would result in a maximum plant capacity of $\sim 430 \mathrm{MW}_{\mathrm{e}}$ when cofiring regardless of the cleanliness of the boiler. This capacity limitation 
results from the fact that the boiler was originally designed for Illinois Basin coal and was converted to lower sulfur, lower Btu, lower efficiency PRB-western coal blends.

Table 5-3. Test Conditions at the Michigan City Cofiring Test Program

\begin{tabular}{|r|c|c|c|c|c|c|c|c|c|}
\hline Parameter & \multicolumn{9}{|c|}{ Cofiring Test } \\
\hline & 1 & 2 & 3 & 4 & 5 & 6 & 7 & 8 & 9 \\
\hline Date & $9 / 23$ & $9 / 24$ & $9 / 24$ & $9 / 24$ & $9 / 25$ & $9 / 25$ & $9 / 25$ & $9 / 26$ & $9 / 26$ \\
\hline $\begin{array}{r}\text { Start Time } \\
\text { End Time }\end{array}$ & 1400 & 0400 & 0915 & 1700 & 0400 & 0900 & 1400 & 0715 & 1030 \\
\hline Load & 425.73 & 306.08 & 426.6 & 425.85 & 306.42 & 425.92 & 424.75 & 424.38 & 424.64 \\
MW $_{\mathrm{e}}$ & & & & & & & & & \\
\hline Percent Cofire & 0 & 0 & 0 & 10 & 10 & 10 & 10 & 10 & 10 \\
\hline $\begin{array}{r}\text { Main Steam } \\
\text { Flow kpph }\end{array}$ & 2914 & 2015 & 2918 & 2878 & 2020 & 2880 & 2881 & 2865 & 2872 \\
\hline $\mathrm{O}_{2}$ Percent & 2.42 & 2.79 & 2.40 & 2.48 & 2.88 & 2.82 & 2.38 & 2.42 & 2.29 \\
\hline
\end{tabular}

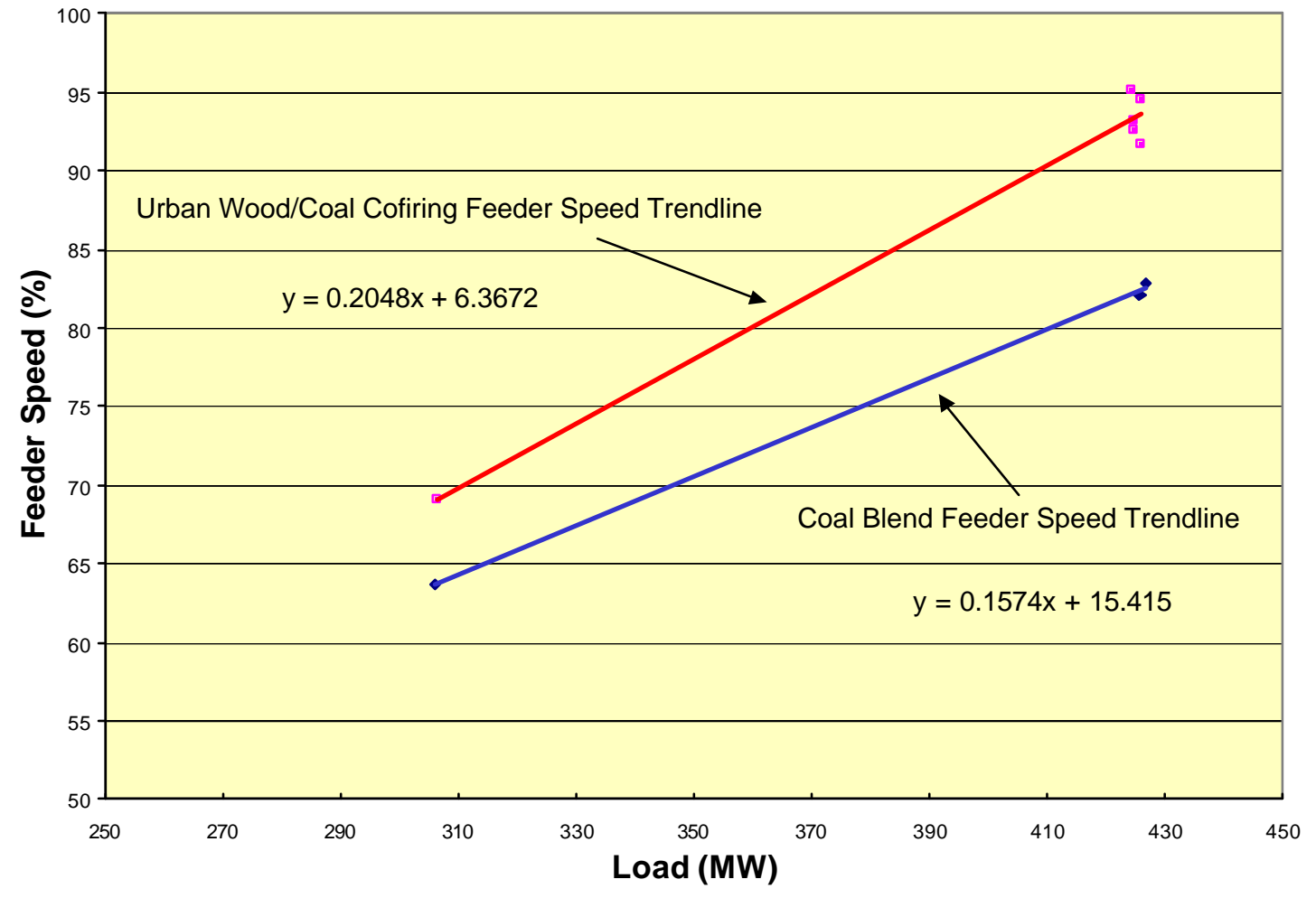

Figure 5-6. Impact of Cofiring on Cyclone Feeder Speeds at Michigan City Cofiring Tests 


\subsubsection{Efficiency Impacts}

Efficiency impacts of cofiring are shown in Table 5-4. There is no apparent impact associated with cofiring, however, Caballo Rojo coal at $8424 \mathrm{Btu} / \mathrm{lb}$ was used in the baseline testing and Black Thunder coal was used during the cofiring tests. Additional calculations show that, if the PRB coal type is held constant, there may be an efficiency loss of $\sim 0.3$ - 0.5 percent when cofiring at 10 percent wood waste by mass (6.5 percent biomass on a heat input basis). It is significant, however, that cofiring did not cause an increase in unburned carbon in the flyash, cause an increase in excess $\mathrm{O}_{2}$ required, or cause an increase in air heater exit temperature.

The apparent increase in boiler efficiency associated with Test 2 and Test 5 is an artifact of low load testing. Under low load testing the air heater exit temperature declined dramatically, creating this phenomenon. The efficiency number is an economic number, limiting the economic value of biofuel. As PRB coal has demonstrated, low cost fuels having a modest negative impact on heat rate can still be economically desirable in coal-fired boilers.

Table 5-4. Efficiency Measurements During Cofiring Tests at Michigan City Generating Station

\begin{tabular}{|r|c|c|c|c|c|c|c|c|c|}
\hline \multicolumn{1}{|c|}{ Parameter } & \multicolumn{9}{|c|}{ Test } \\
\hline Date & 1 & 2 & 3 & 4 & 5 & 6 & 7 & 8 & 9 \\
\hline $\begin{array}{r}\text { Start Time } \\
\text { End Time }\end{array}$ & 1400 & 0400 & 0915 & 1700 & 0400 & 0900 & 1400 & 0715 & 1030 \\
& 1800 & 0700 & 1015 & 2000 & 0645 & 1200 & 1645 & 1015 & 1300 \\
\hline $\begin{array}{l}\text { Load (MW }) \\
425.7\end{array}$ & 306.0 & 426.6 & 425.8 & 306.4 & 425.9 & 424.7 & 424.3 & 424.6 \\
8 & 5 & & 5 & 2 & 2 & 5 & 8 & 4 \\
\hline Percent Cofire & 0 & 0 & 0 & 10 & 10 & 10 & 10 & 10 & 10 \\
\hline $\begin{array}{l}\text { Main Steam Flow } \\
(\mathrm{kpph})\end{array}$ & 2914 & 2015 & 2918 & 2878 & 2020 & 2880 & 2881 & 2865 & 2872 \\
\hline $\mathrm{O}_{2}$ Percent & 2.42 & 2.79 & 2.24 & 2.48 & 2.88 & 2.82 & 2.38 & 2.42 & 2.29 \\
\hline AHTR Exit ${ }^{\circ} \mathrm{F}$ & 366 & 318 & 372 & 368 & 316 & 372 & 372 & 372 & 368 \\
\hline $\begin{array}{l}\text { AHTR Inleakage } \\
(\%)\end{array}$ & 5.25 & 8.90 & 7.40 & 7.20 & 5.30 & 7.40 & 6.50 & 8.80 & 9.50 \\
\hline $\begin{array}{l}\text { Unburned } \\
\text { Carbon (\%) }\end{array}$ & 0.75 & 0.57 & 1.18 & 0.65 & 0.62 & 0.76 & 0.69 & 0.93 & NA \\
\hline $\begin{array}{l}\text { Boiler Efficiency } \\
(\%)\end{array}$ & 84.6 & 85.3 & 84.4 & 84.6 & 85.7 & 84.4 & 84.7 & 84.5 & 84.6 \\
\hline
\end{tabular}




\subsubsection{Temperature Impacts of Cofiring.}

The economizer exit temperature and the air heater exit temperature were not impacted by cofiring. Similarly, the recirculated flue gas temperature was not impacted by cofiring. Figure 5-7 illustrates the impact of cofiring on calculated combustion/flame temperatures while Figure 5-8 illustrates the impact of cofiring on measured furnace exit gas temperature (FEGT). Note that there is an apparent slight rise in flame temperature potentially caused by the volatility of the biofuel and the switch in PRB coals. Note, also, that there is a decrease in measured FEGT when cofiring.

The phenomenon creating the drop in FEGT is typically that the highly volatile wood waste ignites rapidly in the exit of the scroll section of the cyclone barrel, helping to ignite the coal and thereby increasing the relative percentage of combustion occurring in the cyclone barrel. This decreases the combustion in the primary furnace, thereby reducing FEGT.

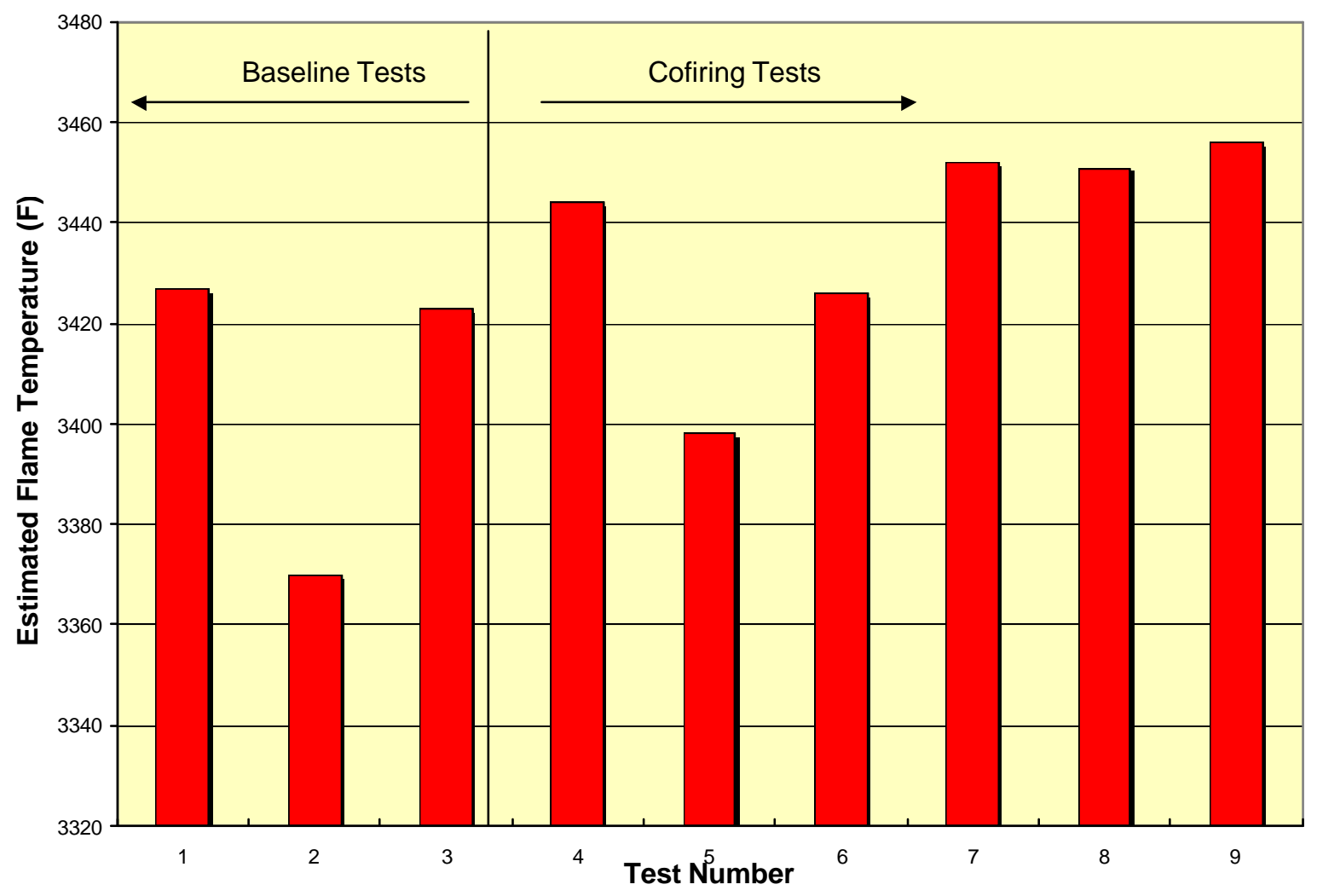

Figure 5-7. Estimated Flame Temperatures During Cofiring at Michigan City Generating Station 


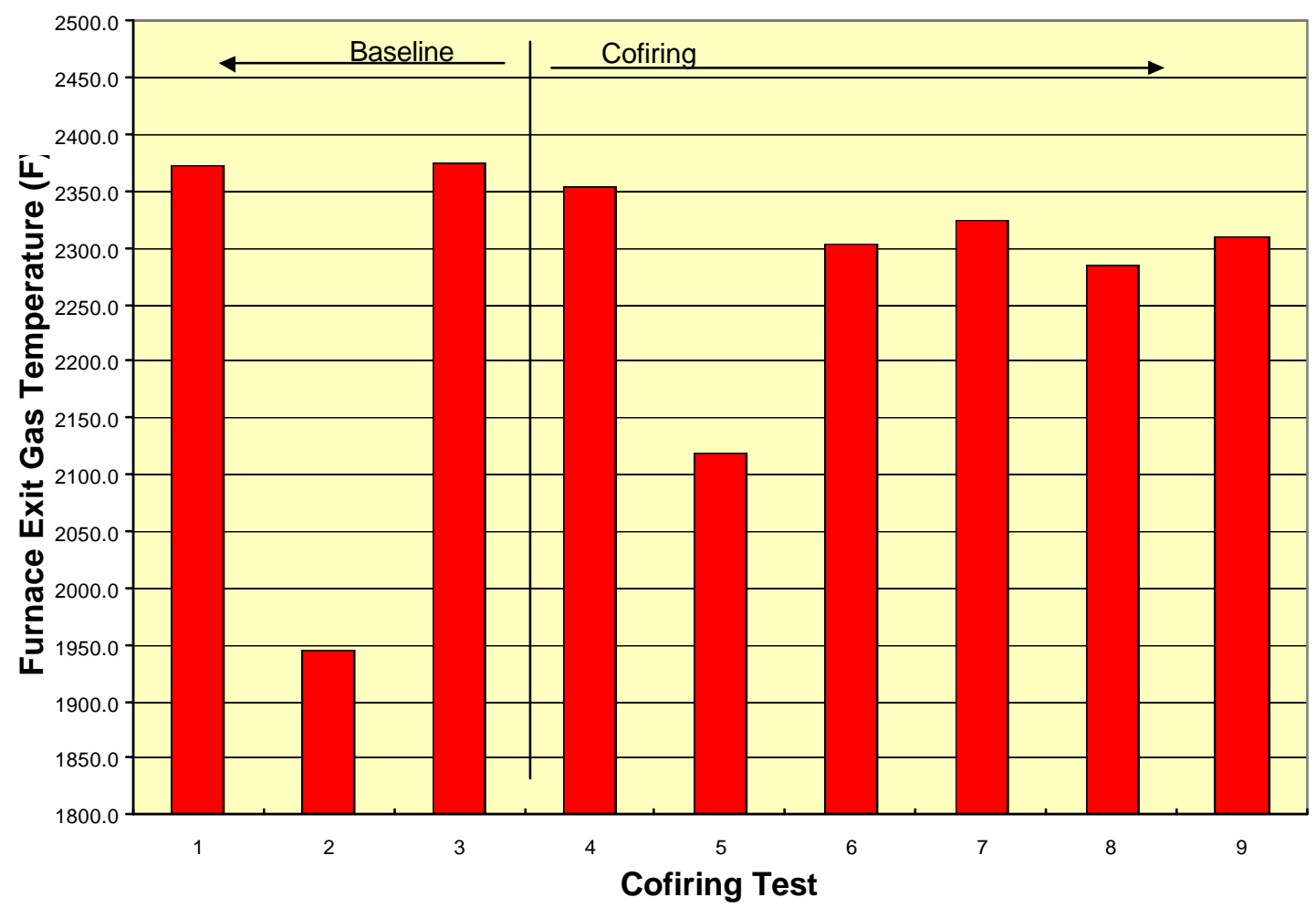

Figure 5-8. Furnace Exit Gas Temperatures Measured During Cofiring Tests at Michigan City Generating Station.

\subsubsection{Environmental Impacts of Cofiring at Michigan City Generating Station}

Cofiring at Michigan City Generating Station reduced $\mathrm{SO}_{2}, \mathrm{NO}_{\mathrm{x}}$, and opacity emissions as shown in Table 5-5. The primary environmental impacts of consequence are impacts on $\mathrm{NO}_{\mathrm{x}}$ formation and on fossil $\mathrm{CO}_{2}$ mitigation. Figures 5-9 and 5-10 illustrate the impact of cofiring on $\mathrm{NO}_{\mathrm{x}}$ emissions, with Figure 5-10 focusing on FEGT influences.

Table 5-5. Airborne Emissions From Cofiring at Michigan City Generating Station

\begin{tabular}{|r|c|c|c|c|c|c|c|c|c|}
\hline Parameter & \multicolumn{9}{|c|}{ Test } \\
\hline & 1 & 2 & 3 & 4 & 5 & 6 & 7 & 8 & 9 \\
\hline Date & $9 / 23$ & $9 / 24$ & $9 / 24$ & $9 / 24$ & $9 / 25$ & $9 / 25$ & $9 / 25$ & $9 / 26$ & $9 / 26$ \\
\hline Start Time & 1400 & 0400 & 0915 & 1700 & 0400 & 0900 & 1400 & 0715 & 1030 \\
\hline End Time & 1800 & 0700 & 1015 & 2000 & 0645 & 1200 & 1645 & 1015 & 1300 \\
\hline $\mathrm{NO}_{\mathrm{x}}\left(\mathrm{lb} / 10^{6} \mathrm{Btu}\right)$ & 1.28 & 1.05 & 1.19 & 1.16 & 1.03 & 1.16 & 1.13 & 1.14 & 1.16 \\
\hline $\mathrm{SO}_{2}\left(\mathrm{lb} / 10^{6} \mathrm{Btu}\right)$ & 0.87 & 0.86 & 0.87 & 0.84 & 0.86 & 0.85 & 0.86 & 0.81 & 0.81 \\
\hline Opacity (\%) & 25.05 & 12.86 & 24.98 & 25.73 & 12.41 & 27.55 & 22.20 & 18.64 & 19.66 \\
\hline
\end{tabular}




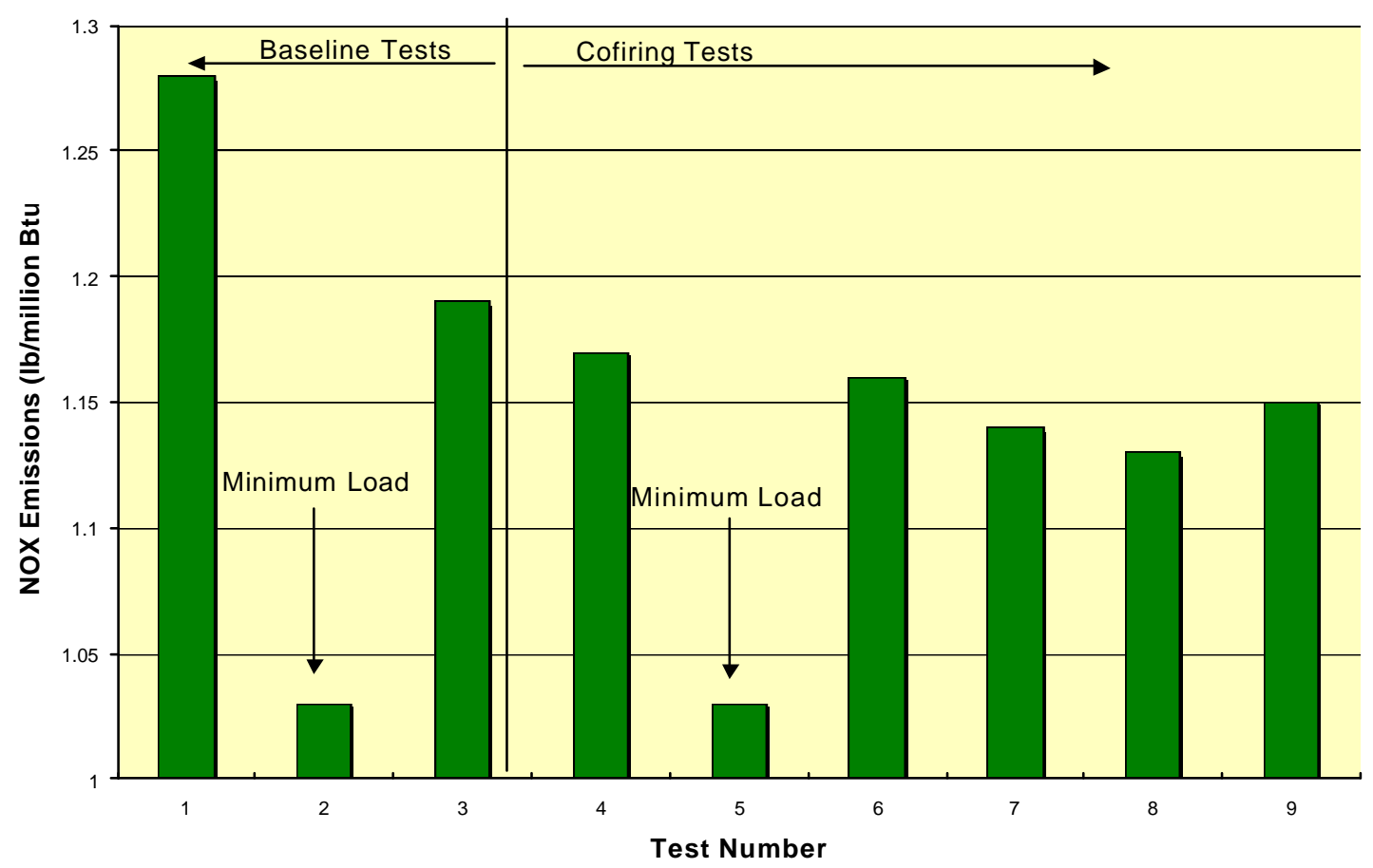

Figure 5-9. Impact of Cofiring on $\mathrm{NO}_{\mathrm{x}}$ Emissions at Michigan City Generating Station

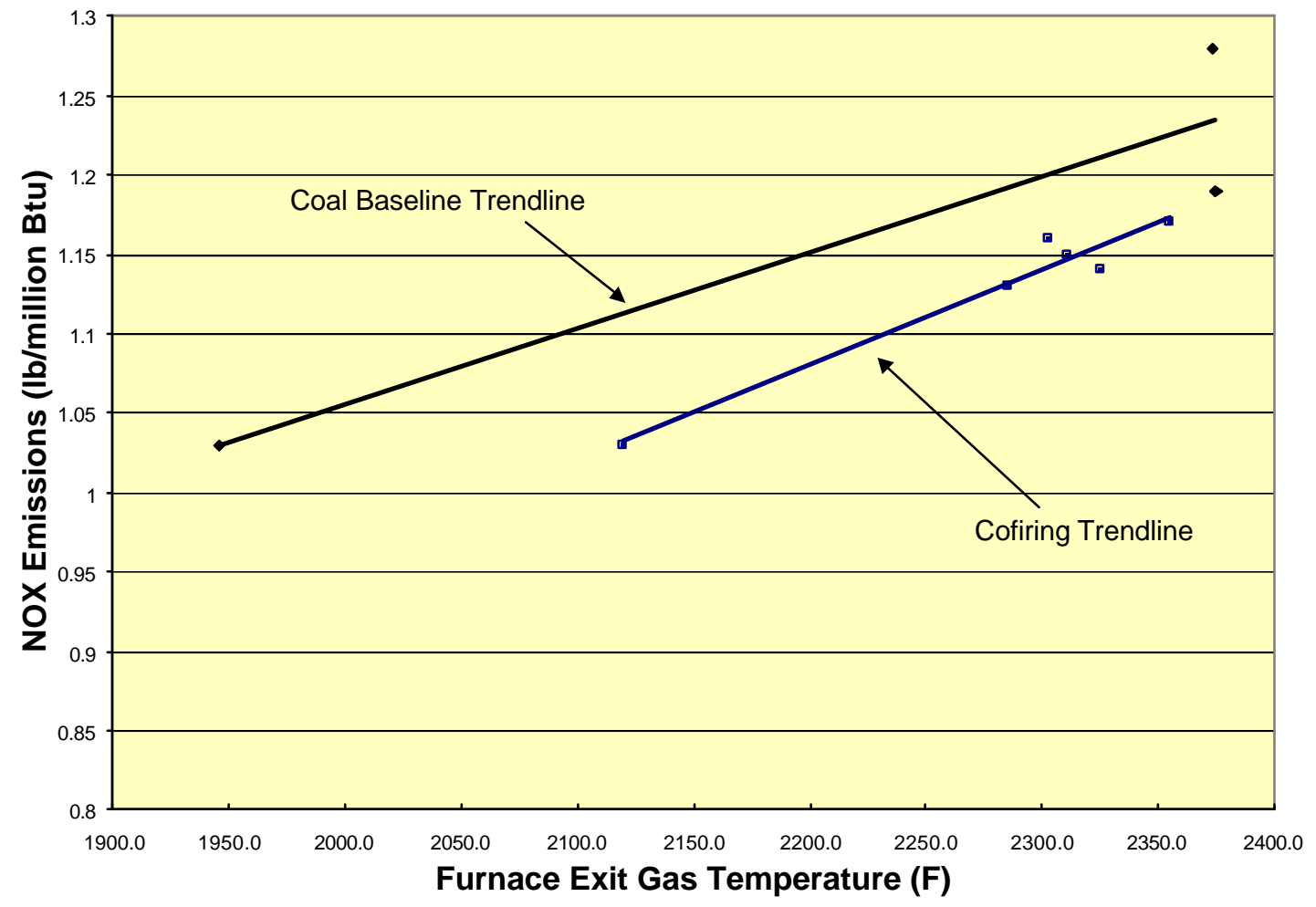

Figure 5-10. Impact of Cofiring on FEGT, and the Consequence for $\mathrm{NO}_{\mathrm{x}}$ Emissions 
There was an apparent 9.5 percent decrease in $\mathrm{NO}_{\mathrm{x}}$ emissions caused by a 6.5 percent cofiring (heat input basis). This decrease was consistent with numerous other test experiences as presented previously. The impact of cofiring on $\mathrm{NO}_{\mathrm{x}}$ emissions can be directly attributed to fuel volatility, and its impact on the combustion process as shown in equation [17].

$$
\mathrm{NO}_{\mathrm{x}}=1.764(\mathrm{FN})+0.041\left(\mathrm{O}_{2}\right)+0.0006(\mathrm{FEGT})-2.21
$$

Where $\mathrm{NO}_{\mathrm{x}}$ is measured in $\mathrm{lb} \mathrm{NO}_{\mathrm{x}}$ (as $\left.\mathrm{NO}_{2}\right) / 10^{6} \mathrm{Btu}, \mathrm{FN}$ is fuel nitrogen in $\mathrm{lb} / 10^{6} \mathrm{Btu}, \mathrm{O}_{2}$ is the percentage of oxygen in the gaseous combustion products measured at the economizer exit, and FEGT is furnace exit gas temperature, measured in ${ }^{\circ} \mathrm{F}$. The $\mathrm{r}^{2}$ for this equation is 0.979 . The probability of random occurrence for each variable is as follows: intercept, .0023; FN, .0007; $\mathrm{O}_{2}, .2832$; and FEGT, .0001 . Only the $\mathrm{O}_{2}$ term is weak. The wood waste reduced the fuel nitrogen content and, because of its volatility, reduced the FEGT. It is significant to note, however, that the reduction in FEGT did not cause any reduction in main steam or reheat steam temperature.

The tests at Michigan City demonstrated the potential of cofiring as an environmental tool, while also documenting some of the operational benefits and concerns. The potential shown from these tests led to a triburn demonstration at the Bailly Generating Station of NIPSCO.

\subsection{THE TRIBURN DEMONSTRATION AT BAILLY GENERATING STATION}

The Bailly Generating Station triburn project has been reported extensively in the literature (Hus and Tillman, 2000; Tillman and Hus, 2000; Tillman, 1999a; Tillman, 1999b; Tillman, 1999c). In this demonstration, NIPSCO sought to obtain the benefits of biomass cofiring while overcoming the efficiency penalty that has been common to most biomass cofiring programs.

To pursue this opportunity, NIPSCO worked within the framework of the EPRI-USDOE Cooperative Agreement and developed a long term demonstration firing biomass and petroleum coke with coal at its Bailly Generating Station boiler \#7, a $160 \mathrm{MW}_{\mathrm{e}}$ (net) cyclone boiler. The NIPSCO demonstration program — the triburn program — involved designing and constructing a fuel preparation and blending facility. It then involved extensive testing of firing clean urban wood waste—biomass — with coal, firing petroleum coke with coal, and firing various blends of urban wood waste and petroleum coke with coal. Results of the extensive testing program have shown that the triburn blends of biomass and petroleum coke with coal have accomplished the following: 1) increased boiler efficiency, 2) reduced fuel costs; and 3) reduced emissions of oxides of nitrogen $\left(\mathrm{NO}_{\mathrm{x}}\right)$, mercury, and fossil carbon dioxide $\left(\mathrm{CO}_{2}\right)$. At the same time, the triburn program has not increased other emissions.

\subsubsection{Overview of the Program}

Bailly Generating Station Boiler \#7 is a $160 \mathrm{MW}_{\mathrm{e}}$ (net) cyclone boiler generating about $1.2 \times 10^{6} \mathrm{lb} / \mathrm{hr}$ of $2400 \mathrm{psig} / 1000^{\circ} \mathrm{F} / 1000^{\circ} \mathrm{F}$ steam. It is typically fired with a blend of 70 percent Illinois Basin coal $/ 30$ percent Shoshone coal. It is equipped with a Pure Air scrubber for $\mathrm{SO}_{2}$ management. This boiler was 
chosen for the long-term demonstration because of the availability of the $\mathrm{SO}_{2}$ scrubber coupled with the size and flexibility of the unit.

The triburn program was designed around multiple objectives including generating green powerenvironmentally friendly renewable energy - from clean (untreated) urban wood waste without decreasing unit capacity or increasing the cost of electricity generation. The objectives also included generating green power without increasing airborne emissions or other environmental impacts. If these were achieved, the total program sought improvements in unit performance. Specific targets were improved boiler efficiency, reduced fuel cost, reduced $\mathrm{NO}_{\mathrm{x}}$ emissions, and reduced metals emissions.

To achieve the overall programmatic goals, the design objective was to be able to fire at least 10 percent wood waste along with at least 20 percent petroleum coke (mass basis) in the fuel blend. From a mechanical engineering perspective, the program objectives were to develop a simple system that could be readily integrated into the total fuel handling scheme of the Bailly Generating Station. Simplicity, ease of control, and ease of maintenance were critical design objectives of the program. It was clear from previous Michigan City test program that the biofuel, in addition to providing the green power - the environmentally friendly renewable energy — identified in the objectives, would provide an impetus for $\mathrm{NO}_{\mathrm{x}}$ and selected metals emissions reductions. The addition of petroleum coke provided a means to compensate for the concerns associated with biofuels: lower calorific value and potentially higher moisture content.

\subsubsection{System Design and Construction}

The system, designed for and constructed at Bailly Generating Station, included a pole barn housing a trommel screen, an above-ground reclaim system for metering opportunity fuel into the plant, and a conveyor linking the above ground reclaim system to the main coal supply. These facilities are shown in Figures 5-11, 5-12, and 5-13.

Fuel was received at the pole barn housing the Powerscreen trommel screen. The pole barn provided protection for the trommel from weather; at the same time it provided for dust control on the site. Biomass - clean urban wood waste from the manufacture of mobile homes and recreational vehicleswas received at the pole barn after having been processed to remove non-combustible materials and after having been screened and misted with water for dust control. Petroleum coke was also received at the pole barn area. The biomass was then screened on the Bailly site to a size of $3 / 4$ " $x$ 0". This clean wood was then blended with the petroleum coke on a specified volumetric ratio using bucket blending. The blended opportunity fuel was then transported to the reclaim area.

The reclaim system was the heart of the project. It consisted of an above-ground reclaimer and an airslide conveyor linking the reclaim to the main coal belts supplying the crushers and the subsequent bunkers. The above-ground reclaim system had the capacity to supply $800 \mathrm{ton} / \mathrm{hr}$ of fuel. The typical operating rate of this unit is on the order of $240 \mathrm{ton} / \mathrm{hr}$, or 30 percent of the total feed rate of the main coal belt. 

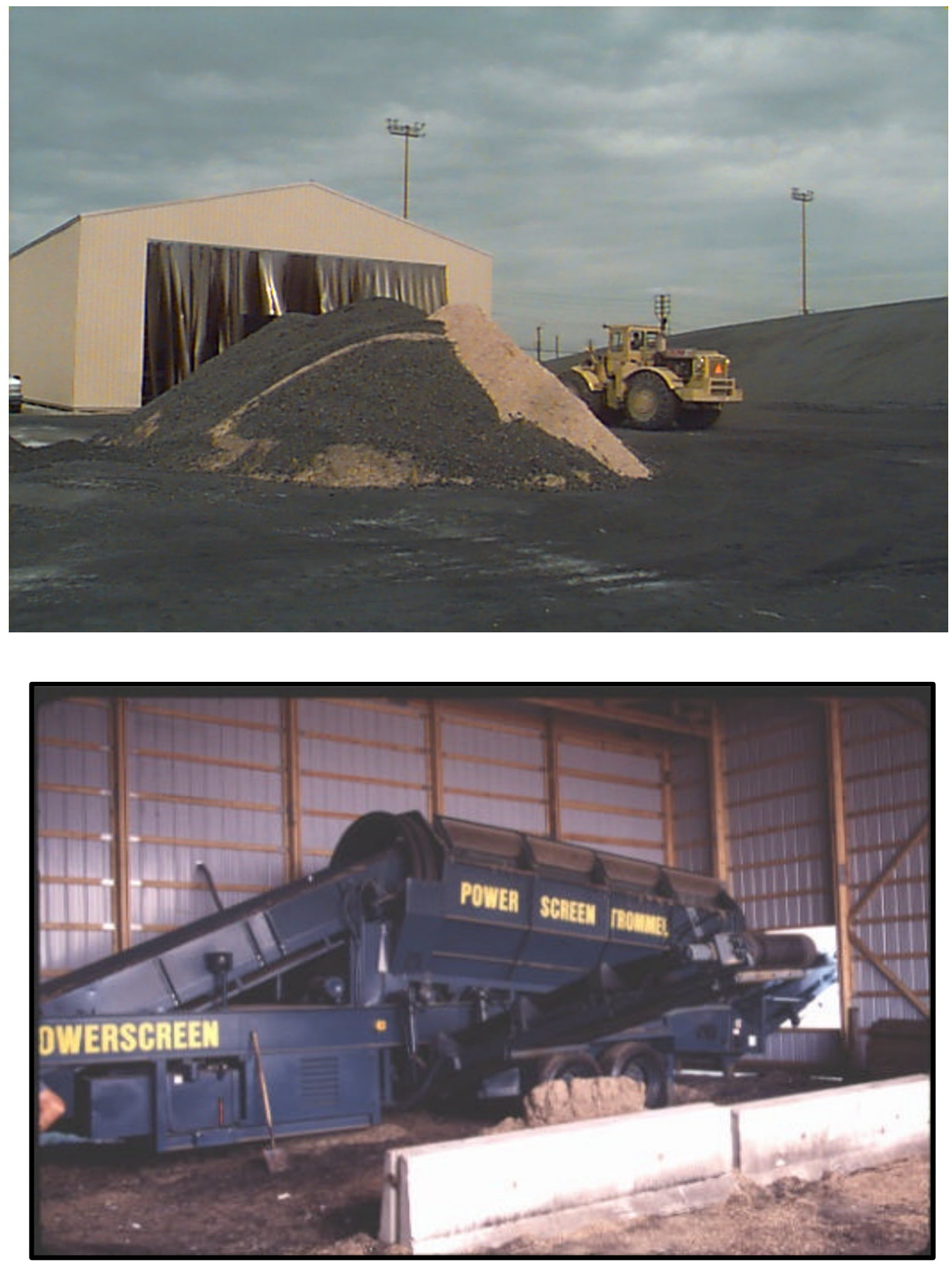

Figure 5-11. The Pole Barn at Bailly Generating Station With a Pile of Blended Fuel

Figure 5-12. The Trommel Screen Installed at the Bailly Generating Station Cofiring Project 


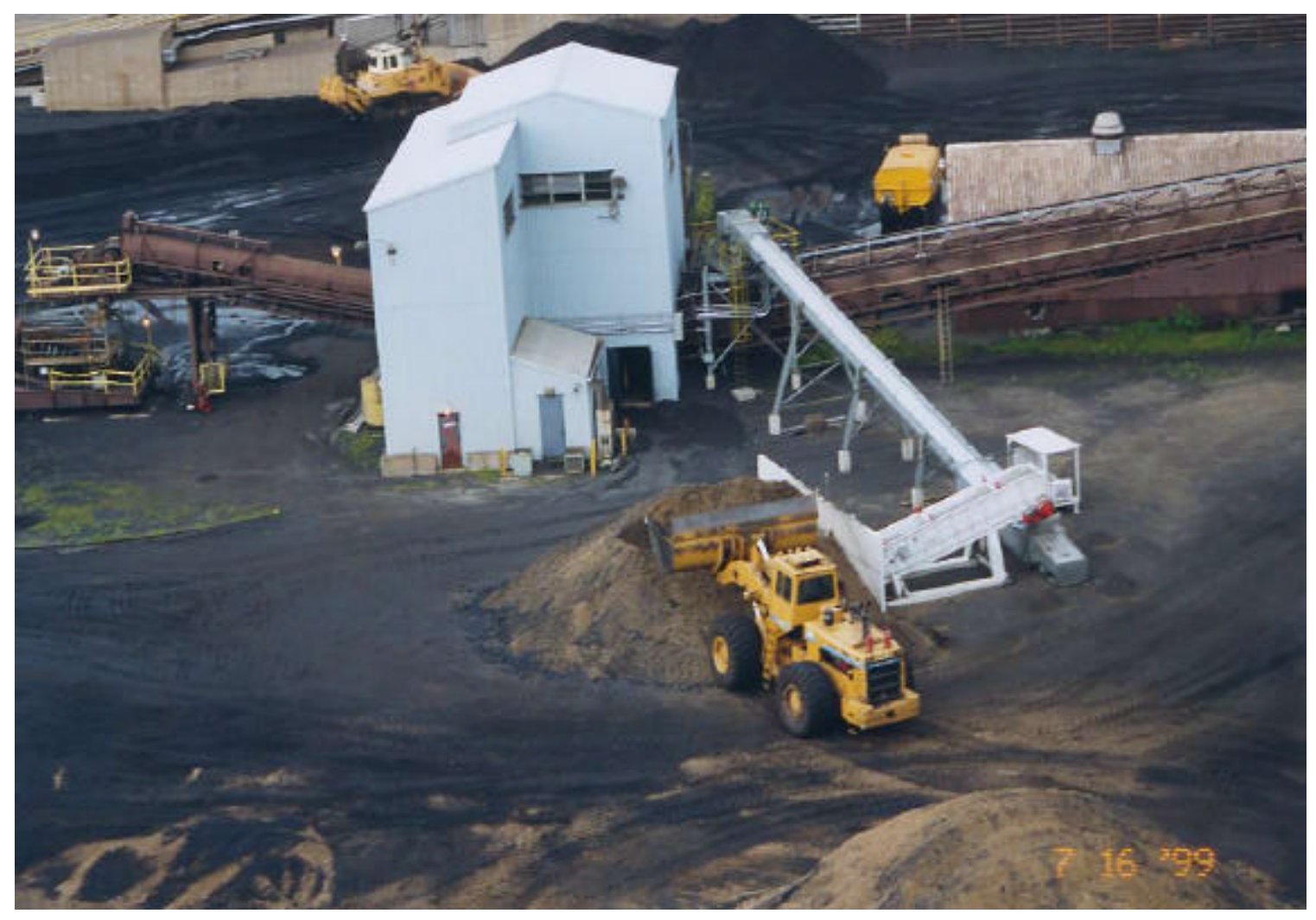

Figure 5-13. The Above Ground Reclaim and Conveyor System Used for Cofiring at Bailly Generating Station

Note from the figures that there was a significant amount of labor involved in this demonstration. The system was not designed for full commercial operation on an automated basis. Note, however, that the coal yard control room operator could set the belt speeds (in ton/hr) for both the main coal belt on the right of Figure 5-13, and the opportunity air-slide conveyor shown with the above ground reclaim system.

The capital cost for the Bailly Generating Station opportunity fuel cofiring system is $\$ 1,186,000$. Table 5-6 provides a cost breakdown for this system. It is important to note that this system currently supplies $\sim 30$ percent of the energy required in Boiler \#7, and therefore has an installed capital cost of some $\$ 25 / \mathrm{kW}$. The system is capable of supplying fuel to both Boiler \#7 and the $320 \mathrm{MWe}$ (net) Boiler \#8. Consequently it has an installed capital cost of $\$ 8 / \mathrm{kW}$ when its full capacity is utilized.

While the system was not fully automated, it should be noted that automation in terms of truck receiving, wood waste screening, and metering to the reclaimer would have capital costs along the lines of those experienced at the Seward Generating Station demonstration. This would approximately double the capital costs in $\$ / \mathrm{kW}$ to approximately $\$ 50 / \mathrm{kW}$. Note, also, that capital costs are highly site-specific. The Bailly Generating Station coal yard had ample real estate conveniently located, reducing the cost of construction. Further, the system designed did not require substantial foundation work in the form of piling or related provisions. 
Table 5-6. Capital Cost of the Bailly Station Cofiring System

\begin{tabular}{|c|c|}
\hline Cost Category & Cost \\
\hline \multicolumn{2}{|l|}{ Vendor Supplied Equipment } \\
\hline Trommel Screen & $\$ 117,000$ \\
\hline Above Ground Reclaim & $\$ 257,000$ \\
\hline Air Slide Conveyor & $\$ 218,000$ \\
\hline \multicolumn{2}{|l|}{ Design and Installation } \\
\hline Electrical Design and Installation & $\$ 124,000$ \\
\hline Civil/Mechanical Design and Installation & $\$ 203,000$ \\
\hline Other Costs & $\$ 267,000$ \\
\hline TOTAL & $\$ 1,186,000$ \\
\hline
\end{tabular}

\subsubsection{Triburn Testing and Associated Results}

Once the triburn system was constructed and commissioned, it underwent extensive testing to determine the operational impacts of the blend of biomass and petroleum coke. Impacts evaluated included boiler capacity, efficiency, formation of airborne emissions, and fates of trace metals.

\subsubsection{Test Program and Fuel Characteristics}

The testing program involved 57 discrete boiler tests. Independent variables evaluated included fuel blend, load (measured as main steam flow), and excess $\mathrm{O}_{2}$. Fuel blends employed are shown in Table 5-7. Each fuel type was tested separately in a cofiring mode prior to the trifiring blending. Load was varied between 720,000 and 1,210,000 lb/hr of main steam flow, and excess $\mathrm{O}_{2}$ was varied between 2 percent and 3.6 percent measured on a total flue gas basis rather than a dry flue gas basis. The fundamental technique involved constructing heat and mass balances about the boiler during $2.5-4$ hour test periods. Control room data were taken, along with fuel samples, flyash samples, and slag samples. Flue gas samples were taken for the heat balances, and for the emissions measurements made and analyzed within the context of the heat balances.

Table 5-7. Fuel Blends Tested at Bailly Generating Station

\begin{tabular}{|c|c|c|c|}
\hline Fuel Test Blend & \multicolumn{3}{|c|}{ Mass Percentage of Each Fuel } \\
\hline & Coal & Pet Coke & Wood Waste \\
\hline Blend 1 (Baseline) & 100 & 0 & 0 \\
\hline Blend 2 & 90 & 10 & 0 \\
\hline Blend 3 & 85 & 15 & 0 \\
\hline Blend 4 & 80 & 20 & 0 \\
\hline Blend 5 & 75 & 25 & 0 \\
\hline Blend 6 & 95 & 0 & 5 \\
\hline Blend 7 & 92.5 & 0 & 7.5 \\
\hline Blend 8 & 90 & 0 & 10 \\
\hline Blend 9 & 80 & 15 & 5 \\
\hline
\end{tabular}




\begin{tabular}{|c|c|c|c|}
\hline Blend 10 & 70 & 20 & 10 \\
\hline Blend 11 & 70 & 22.5 & 7.5 \\
\hline
\end{tabular}

The fuels as tested characterized in Tables 5-8, 5-9, and 5-10. Note that the clean urban wood waste is comparable to sawdust except that it is low in moisture and high in fuel nitrogen. Further it is higher in ash than typical sawdust or wood processing waste. At the same time, however, it is low in sulfur content and lower in trace metal content than the coals. Equally interesting is the fact that the petroleum coke contains the lowest concentration of fuel nitrogen among all of the fuels burned, when concentration is expressed in $1 \mathrm{~b} / 10^{6} \mathrm{Btu}$. Like the wood waste, it contains lower concentrations of trace metals than the coals used as a base fuel, with the exceptions being nickel and vanadium. The low concentration of volatile metals (e.g., mercury, arsenic) results from the refining process and the extensive thermal treatment of crude oil—driving the volatile metals off with the lighter fractions from the feedstock.

Table 5-8. Proximate and Ultimate Analyses of Fuels Burned During Bailly Demonstration

\begin{tabular}{|l|c|c|c|c|}
\hline $\begin{array}{l}\text { Proximate Analysis } \\
\text { (weight percent) }\end{array}$ & $\begin{array}{l}\text { Urban Wood } \\
\text { Waste }(*)\end{array}$ & High Sulfur Coal & Low Sulfur Coal & Petroleum Coke \\
\hline Fixed Carbon & 12.5 & 41.95 & 42.15 & 78.27 \\
\hline Volatile Matter & 52.56 & 34.43 & 37.56 & 13.90 \\
\hline Ash & 4.08 & 9.66 & 5.63 & 1.34 \\
\hline Moisture & 30.78 & 13.97 & 14.66 & 6.48 \\
\hline $\begin{array}{l}\text { Ultimate Analysis } \\
\text { (weight percent) }\end{array}$ & & & & \\
\hline Carbon & 33.22 & 62.30 & 63.17 & 81.11 \\
\hline Hydrogen & 3.84 & 4.34 & 4.68 & 3.39 \\
\hline Oxygen & 27.04 & 5.07 & 9.67 & 1.32 \\
\hline Nitrogen & 1.00 & 1.22 & 1.44 & 1.23 \\
\hline Sulfur & 0.07 & 3.45 & 0.74 & 5.11 \\
\hline Ash & 3.99 & 9.66 & 5.63 & 1.34 \\
\hline Moisture & 30.84 & 13.97 & 14.66 & 6.48 \\
\hline $\begin{array}{l}\text { Higher Heating Value, } \\
\text { Btu/lb }\end{array}$ & 5788 & 11113 & 10900 & 14308 \\
\hline $\begin{array}{l}(*) \text { Clean urban wood waste from the manufacture of mobile homes and recreation vehicles, rather than } \\
\text { virgin sawdust from sawmills. This causes the higher ash and nitrogen contents, and lower moisture } \\
\text { content. }\end{array}$ \\
\hline
\end{tabular}

Table 5-9. Some Characteristics of Fuels Burned During the Bailly Demonstration

\begin{tabular}{|l|c|c|c|c|}
\hline Performance Parameter & Wood Waste & High Sulfur Coal & $\begin{array}{c}\text { Low Sulfur } \\
\text { Coal }\end{array}$ & Pet Coke \\
\hline Volatile/Fixed Carbon Ratio & 4.17 & 0.82 & 0.89 & 0.18 \\
\hline Lbs Fuel $/ 10^{6} \mathrm{Btu}$ & 173 & 90 & 92 & 70 \\
\hline $\mathrm{Lbs}_{2} \mathrm{O} / 10^{6} \mathrm{Btu}$ & 53.29 & 12.57 & 13.45 & 4.53 \\
\hline
\end{tabular}




\begin{tabular}{|l|c|c|c|c|}
\hline Lbs Ash $/ 10^{6} \mathrm{Btu}$ & 6.90 & 8.69 & 5.16 & 0.94 \\
\hline Lbs N/10 $\mathrm{Btu}$ & 1.73 & 1.10 & 1.32 & 0.86 \\
\hline Lbs $\mathrm{S} / 10^{6} \mathrm{Btu}$ as $\mathrm{SO}_{2}$ & 0.23 & 6.20 & 1.36 & 7.14 \\
\hline
\end{tabular}

Table 5-10. Selected Trace Metal Concentrations in Fuels Burned During the Bailly Demonstration $(\mathrm{mg} / \mathrm{kg})$

\begin{tabular}{|l|c|c|c|c|}
\hline $\begin{array}{l}\text { Trace Metal in As- } \\
\text { Received Fuel }\end{array}$ & Wood Waste & High Sulfur Coal & Low Sulfur Coal & Pet Coke \\
\hline Arsenic & 2.145 & 2.194 & 1.402 & 0.337 \\
\hline Chromium & 6.570 & 20.361 & 8.250 & 4.676 \\
\hline Lead & 2.922 & 3.154 & 4.267 & 2.182 \\
\hline Mercury & 0.0126 & 0.0330 & 0.0200 & 0.0160 \\
\hline Nickel & 2.645 & 12.33 & 7.396 & 134.04 \\
\hline Vanadium & 3.06 & 17.21 & 11.95 & 326.37 \\
\hline
\end{tabular}

Samples of representative fuels were also sent, after the fact, to Pennsylvania State University for subsequent testing. The testing described above for the Michigan City Generating Station fuels was applied to the Bailly Generating Station fuels. Results for the high sulfur coal and petroleum coke are shown in Table 5-11. The low sulfur coal-Shoshone coal-was previously presented in Table 5-2 along with the wood waste.

Table 5-11. Structural and Kinetic Data Representative of High Sulfur Coal and Petroleum Coke Burned at the Bailly Generating Station Triburn Demonstration

\begin{tabular}{|c|c|c|}
\hline Parameter & & \\
\hline & Illinois \#6 & Petroleum Coke \\
\hline $\begin{array}{l}\text { Aromaticity (Number of Aromatic Carbon } \\
\text { Atoms/Total Number of Carbon Atoms }\end{array}$ & .74 & .81 \\
\hline Average Number of Aromatic Carbons/Cluster & 13 & 21 \\
\hline Devolatilization Kinetics $(*)$ & & \\
\hline Temperature Range $\left({ }^{\circ} \mathrm{C}\right)$ & $1000-1700$ & $1000-1700$ \\
\hline Pre-exponential Constant (A) (1/sec) & 338 & 104 \\
\hline Activation Energy (E) (kcal/mol) & 14.6 & 11.5 \\
\hline Char Oxidation Kinetics $(* *)$ & & \\
\hline Pre-exponential Constant (A) (1/sec) & $1.72 \times 10^{7}$ & $9.26 \times 10^{8}$ \\
\hline Activation Energy (E) (kcal/mol) & 35.7 & 42.2 \\
\hline $\begin{array}{l}(*) \text { Note: Devolatilization kinetics for the Illinois } \\
\text { of } 600-1000^{\circ} \mathrm{C} \text {. The pre-exponential constant } \\
\text { energy is } 4.08 \\
(* *) \text { Chemical reaction kinetics from TGA exper }\end{array}$ & $\begin{array}{l}\text { al include } \\
\text { is range is }\end{array}$ & $\begin{array}{l}\text { nperature range } \\
\text { the activation }\end{array}$ \\
\hline
\end{tabular}

Source: Johnson et. al., 2001b. 
Note that the Illinois \#6 coal is quite reactive at lower temperatures and, as its volatiles are stripped from it, becomes considerably less reactive. Note, also, that both of these fuels are considerably less reactive than the Shoshone coal or wood as presented in Table 5-2.

This testing also demonstrated that the maximum volatile yield for the petroleum coke is only 50.2 percent and it is 62.2 percent for the Illinois coal. This compares to 68.9 percent for the Shoshone coal and 70 percent for the Black Thunder and Caballo Rojo coal. The maximum nitrogen volatile yields for petroleum coke, Illinois \#6 coal, and Shoshone coal are 63.8 percent, 75.6 percent, and 77.8 percent respectively. These are considerably lower than the values for the biomass fuels or for the PRB coals.

\subsubsection{Test Results: Operating Impacts of the Triburn Program}

The analysis of results from 57 tests over 11 fuel blend conditions and a variety of load and excess $\mathrm{O}_{2}$ conditions were heavily dependent upon calculated heat and material balances about Boiler \#7. The accuracy of those balances was determined by calculating closure. The heat balance equations were established to solve for solid fuel flow, given the blends measured in the coal yard control room. The boiler control room also reported fuel flow to each cyclone, and to the plant as a whole. Closure, then, was defined as follows:

Closure $(\%)=(\mathrm{CFF} / \mathrm{MFF}) \times 100$

Where CFF is calculated fuel flow (tons/hr) and MFF is measured fuel flow in the main control room (tons/hr). Closure about the various heat and material balances was more than acceptable as is shown in Table 5-12. Closure is also shown in Figure 5-14 for every test conducted during the Bailly program.

Table 5-12. Summary of Heat and Material Balance Closures

\begin{tabular}{|l|c|}
\hline Parameter & Value \\
\hline Mean Closure Percentage & 99.63 \\
\hline Standard Deviation (Percent) & 3.11 \\
\hline 95 Percent Confidence Interval (Percent) & 0.87 \\
\hline Minimum Closure Percentage & 93.38 \\
\hline Maximum Closure Percentage & 109.60 \\
\hline
\end{tabular}

Capacity and Stability Impacts. The triburn program had no impact on boiler capacity. Main steam flows in excess of $1.2 \times 10^{6} \mathrm{lb} / \mathrm{hr}$ were achieved with all fuel blends. Testing occurred through three capacity alerts without incident. Similarly there was no impact of the triburn program on boiler stability. Stability was evaluated by taking readings in the control room every 10 minutes over $2.5-4$ hour periods. Parameters evaluated included air heater exit temperature; excess $\mathrm{O}_{2}$; feedwater, main steam, cold reheat, and hot reheat pressures, temperatures, and flows; furnace pressures; fuel feed rates to each cyclone; and related values. The data taken were then statistically evaluated. Mean values were calculated along with standard deviations and confidence intervals. In no case was the standard deviation value greater than 2 percent of the mean for any given parameter. The 95 percent confidence intervals calculated also supported the stability of the operations. 
Beyond the statistical analysis, operations were observed during all tests, including tests during very hot weather. In no case were the cyclone feeders compromised; feeder speeds never exceeded the $90-$ 92 percent range. There was ample capacity in the ID fan as well, indicating that the parameters that cofiring could impact were not negatively impacted.

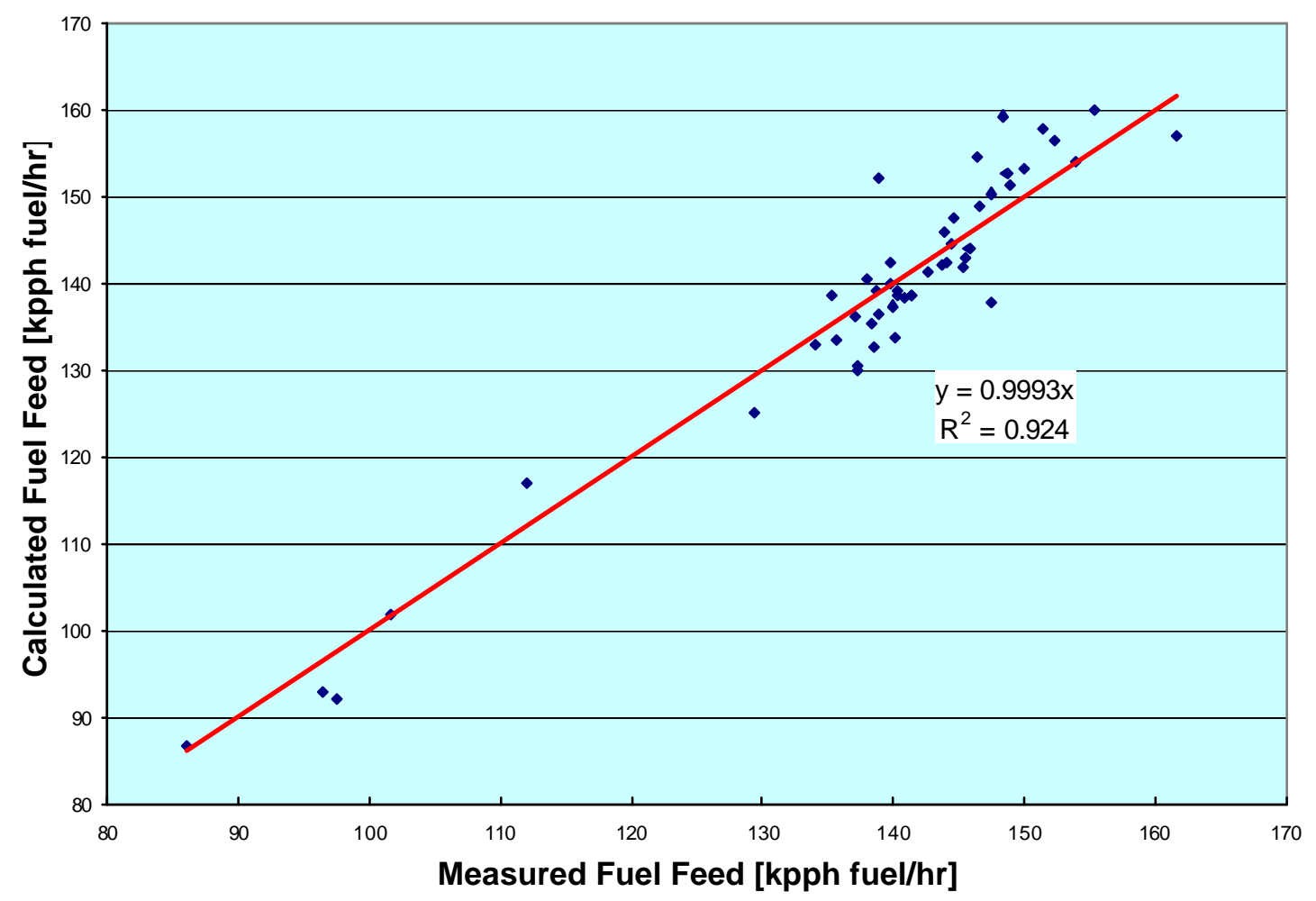

Figure 5-14. Statistical Analysis of Closure for all Tests at the Bailly Generating Station Demonstration

Efficiency Impacts. The impact of the triburn program on boiler efficiency was a function of the fuel blend, the load, and the excess $\mathrm{O}_{2}$ and air heater exit temperature parameters. The data from the 57 heat and material balances lead to an overall regression equation describing the triburn impact on boiler efficiency:

$$
\eta=86.75-0.049(\% \mathrm{~W})+0.059(\% \mathrm{PC})
$$

where $\eta$ is boiler thermal efficiency during triburn testing (including cofiring testing), $\% \mathrm{~W}$ is percent wood in the blend on a mass basis, and \% PC is percent petroleum coke in the fuel blend on a mass basis. The coefficient of determination $-r^{2}-$ for this equation is 0.86 . The probabilities of random occurrence of the results shown in equation [19] are as follows: overall equation, $2.28 \times 10^{-20}$; Intercept, $1.9 \times 10^{-103} ; \% \mathrm{~W}, 2.73 \times 10^{-9}$; and \%PC, $5.42 \times 10^{-17}$. Clearly this is a robust equation. 
The influence of cofiring on unburned carbon in the flyash—or loss on ignition (LOI) in the flyash—is illustrative. Table 5-13 summarizes the results obtained during the testing.

Table 5-13. Average Unburned Carbon Percentages in Flyash at Bailly Generating Station

\begin{tabular}{|c|c|c|c|}
\hline Percent Coal & \multicolumn{2}{|l|}{ Percent Opportunity Fuel } & Percent Unburned Carbon in Flyash \\
\hline & Wood Waste & Petroleum Coke & \\
\hline 100 & 0 & 0 & 9.1 \\
\hline 90 & 0 & 10 & 13.5 \\
\hline 80 & 0 & 20 & 22.6 \\
\hline 90 & 10 & 0 & 2.3 \\
\hline 80 & 5 & 15 & 8.9 \\
\hline 70 & 7.5 & 22.5 & 11.3 \\
\hline
\end{tabular}

Clearly the firing of wood waste decreased the unburned carbon or LOI. There were exceptional events where LOI was quite high regardless of opportunity fuel, however the biomass did tend to decrease LOI in the flyash. Unburned carbon was virtually non-existent in the bottom ash or slag regardless of fuel. Testing of the slag demonstrates a consistent 0.13 percent to 0.16 percent unburned carbon content regardless of fuel blend.

The drivers on boiler efficiency were fuel moisture content which increased with increasing wood waste and decreased with increasing petroleum coke; fuel heat content which follows the moisture trends, and unburned carbon. It is clear from the evidence at hand that petroleum coke increased the unburned carbon content in the flyash while wood waste decreased the concentration of unburned carbon in the flyash. However, only 30 percent of the solid products of combustion report as flyash while 70 percent report as slag. Consequently, while petroleum coke increased unburned carbon in the flyash, it still had an overall beneficial impact on boiler efficiency.

There was virtually no influence of opportunity fuel firing on flame temperature, as calculated by Gibbs Free Energy technique (Gordon and McBride, 1976 as updated in 1993). The average calculated flame temperature was $3,470^{\circ} \mathrm{F}$. The minimum calculated flame temperature was $3,440^{\circ} \mathrm{F}$ and the maximum calculated flame temperature was $3,520^{\circ} \mathrm{F}$. There was no apparent correlation $\left(\mathrm{r}^{2}=0.16\right)$ between calculated flame temperature and fuel blend-even with adjustments for excess $\mathrm{O}^{2}$ and adjustments for combustion air temperature.

\subsubsection{Environmental Impacts from the Triburn Program}

During the extensive testing at Bailly Generating Station, considerable attention was paid to environmental impacts. The focus was on formation and control of airborne emissions including opacity, $\mathrm{NO}_{\mathrm{x}}, \mathrm{CO}$, total hydrocarbons (THC), and the fate of trace metals. $\mathrm{SO}_{2}$ emissions were not of concern to the test program because of the presence of the Pure Air scrubber. 
NO $\mathbf{x}_{\mathbf{x}}$ Emissions Impacts. The triburn project had an immediate and dramatic impact on $\mathrm{NO}_{\mathrm{x}}$ emissions from the Bailly Generating Station Boiler \#7. Because the $\mathrm{NO}_{\mathrm{x}}$ impacts were central to the testing, and because $\mathrm{NO}_{\mathrm{x}}$ reductions had been observed in other cofiring test programs, three analytical methods were used to evaluate this outcome. The $\mathrm{lb} / \mathrm{hr}$ of $\mathrm{NO}_{\mathrm{x}}$, were determined first by calculating $10^{6}$ $\mathrm{Btu} / \mathrm{hr}$ of heat input from the heat balances, and then calculating $\mathrm{lb} / 10^{6}$ Btu from the two factors as derived (heat balance $\mathrm{NO}_{\mathrm{x}}$ emissions). They were then determined by using the USEPA F-Factor calculation, deriving an F-Factor for each fuel blend using the USEPA formula (F-Factor $\mathrm{NO}_{\mathrm{x}}$ emissions). Finally they were determined by using a statistical relationship between ppmvd $\mathrm{NO}_{\mathrm{x}}$ at 3 percent $\mathrm{O}_{2}$ in the gaseous combustion products (ppmvd-based $\mathrm{NO}_{\mathrm{x}}$ emissions). The closure between techniques can be observed from Figure 5-15, a comparison of the NOx emissions determined by methods 1 and 2 .

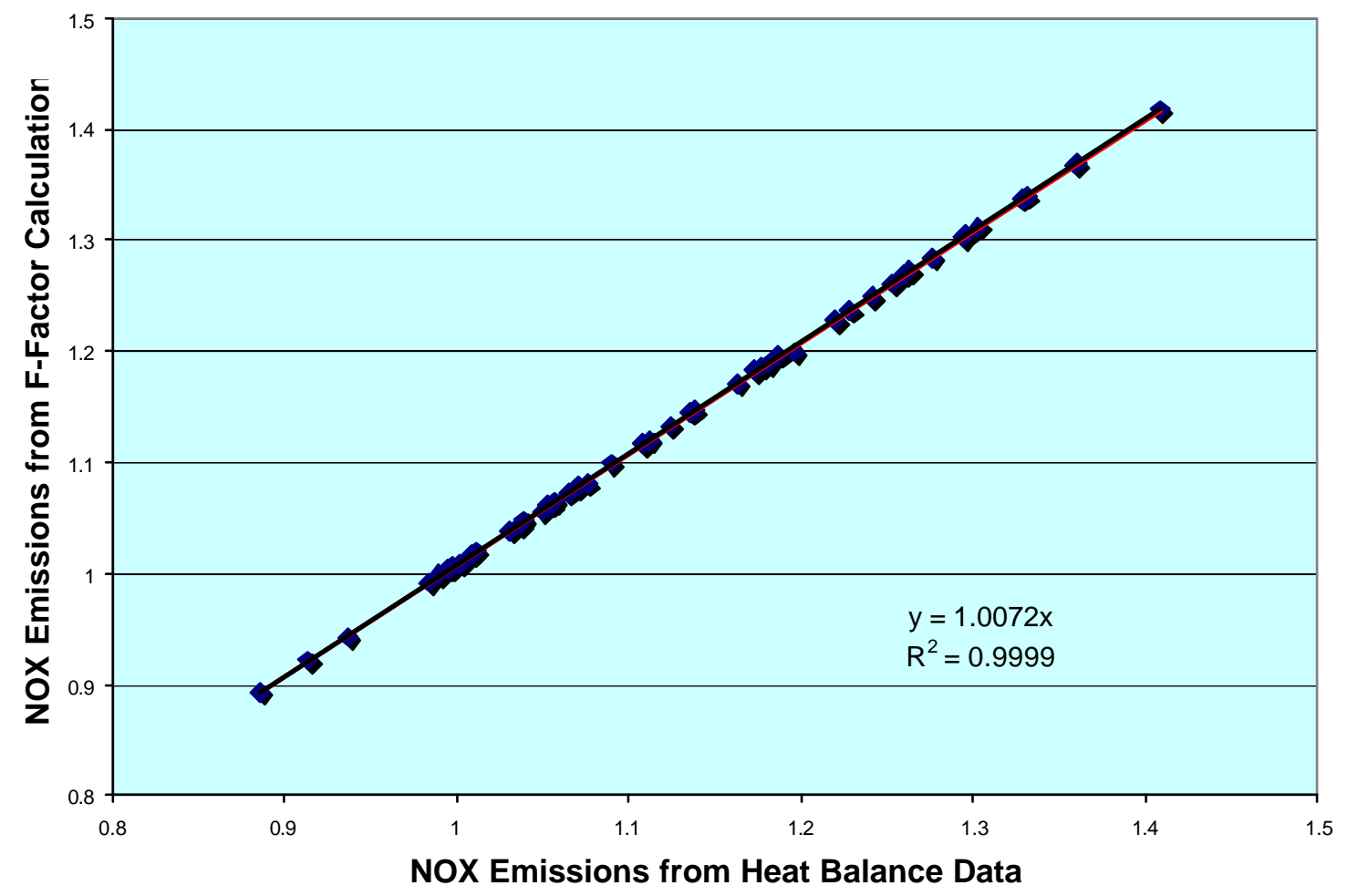

Figure 5-15. $\mathrm{NO}_{\mathrm{x}}$ Emissions in $\mathrm{lb} / 10^{6}$ Btu Calculated from Heat Balances and F-Factor Computations

$\mathrm{NO}_{\mathrm{x}}$ regression analyses were then performed, leading to the following equations:

$$
\mathrm{NO}_{\mathrm{x}}=390-6.2(\% \mathrm{~W})-6.8(\% \mathrm{PC})+0.38(\mathrm{~L})+45.97(\mathrm{EO} 2)
$$

and

$$
\mathrm{NO}_{\mathrm{x}}=0.845-0.011(\% \mathrm{~W})-0.010(\% \mathrm{PC})+0.0005(\mathrm{~L})+0.0255\left(\mathrm{EO}_{2}\right)
$$


In equation [20], $\mathrm{NO}_{\mathrm{x}}$ is expressed in ppmvd @ 3\% $\mathrm{O}_{2}$ in the dry flue gas. In equation [21], $\mathrm{NO}_{\mathrm{x}}$ is expressed in $\mathrm{lb} / 10^{6} \mathrm{Btu}$. In both equations $\mathrm{L}$ is load, expressed in $10^{3} \mathrm{lb} / \mathrm{hr}$ of main steam flow and $\mathrm{EO}_{2}$ is excess oxygen measured on a total basis and reported in the control room. With 56 degrees of freedom, equation [20] has an $r^{2}=0.73$; and equation [21] has an $r^{2}$ of 0.700 . The probability that these equations, and their terms, occurred randomly is shown in Table 5-14. Note that all terms in equation [20] are highly significant except excess $\mathrm{O}_{2}$, which is marginally significant. In equation [21] the intercept is marginally significant and excess $\mathrm{O}_{2}$ is inconsequential. However in both cases the $\% \mathrm{~W}$, $\% \mathrm{PC}$, and L terms are highly significant—as are the total equations.

Table 5-14. Significance of Total Equations and Individual Terms for Equations [20] and [21] Expressed as Probability that the Term Occurred as a Random Event

\begin{tabular}{|c|c|c|}
\hline Equation or Term & Equation [20](*) & Equation [21](*) \\
\hline Total Equation & $9.87 \times 10^{-14}$ & $6.57 \times 10^{-13}$ \\
\hline Intercept & 0.0026 & 0.077 \\
\hline Percent Wood Waste (mass) & 0.0063 & 0.0008 \\
\hline Percent Petroleum Coke (mass) & $1.36 \times 10^{-11}$ & $6.66 \times 10^{-11}$ \\
\hline Load $\left(10^{3} \mathrm{lb} / \mathrm{hr}\right.$ main steam $)$ & $2.04 \times 10^{-7}$ & $1.32 \times 10^{-6}$ \\
\hline Excess $\mathrm{O}_{2}$ (total basis) & 0.083 & 0.895 \\
\hline \multicolumn{3}{|c|}{$\begin{array}{l}\text { (*) The values reported are the probabilities that the equation, or the individual term, could have occurred } \\
\text { as a random event. Values }<0.1 \text { are somewhat significant, }<0.05 \text { are significant, and }<0.01 \text { are highly } \\
\text { significant. }\end{array}$} \\
\hline
\end{tabular}

The $r^{2}$ terms can be considered as the degree to which the equations explain the outcome. For equation [20], the equation explains 73 percent of the outcome and for equation [21], the equation explains 70 percent of the result. While 70 - 73 percent of the $\mathrm{NO}_{\mathrm{x}}$ emissions can be explained by these equations, nearly 30 percent remain unexplained. Included in the 30 percent is the synergistic effects between the wood waste and the petroleum coke. These synergies are shown in equation [22].

$$
\mathrm{NO}_{\mathrm{x}}=1.352+0.0002\left(\mathrm{OF}^{2}\right)-0.0162(\mathrm{OF})
$$

Where $\mathrm{NO}_{\mathrm{x}}$ is measured in $\mathrm{lb} / 10^{6} \mathrm{Btu}$ and $\mathrm{OF}$ is percent opportunity fuel. For this equation to work, both wood waste and petroleum coke must be in the opportunity fuel blend, the wood waste must be at least 5 percent of the total fuel mix (mass basis), and the petroleum coke must be present in at least twice the concentration of wood waste (but not more than three times the concentration of wood waste). According to equation [22], the triburn benefits continue until 40 percent opportunity fuel/60 percent coal is the blend fired. Further, note that the triburn regression equation [22] has an $r^{2}=0.87$, indicating a robust relationship given the number of tests employed.

The $\mathrm{NO}_{\mathrm{x}}$ results at the Bailly demonstration were sufficiently significant that both the fuel analyses previously reported and statistical investigations were made into possible mechanisms. Clearly the wood volatility causing the mass of fuel to burn sooner-and the nitrogen volatiles to be released in a fuel-rich environment-contributes to the reduction in $\mathrm{NO}_{\mathrm{x}}$. The fuel nitrogen concentration of the 
petroleum coke, and the fact that the coke burns in the slag layer rather than in the primary furnace, also contributes to the reduction in $\mathrm{NO}_{\mathrm{x}}$. Both of these phenomena contribute to more complete combustion in the cyclone barrel-reducing the combustion in the primary furnace and the thermal $\mathrm{NO}_{\mathrm{x}}$ formed in that furnace environment. Flame temperatures were not a factor as shown previously. Statistical analysis of the data shows that moisture in the fuel was also not a factor in $\mathrm{NO}_{\mathrm{x}}$ reduction.

CO, Hydrocarbon, and $\mathrm{SO}_{3}$ Emissions. As noted in the objectives, it was important to achieve the benefits of renewable energy without increasing other emissions. The results of testing for these three emissions are shown in Figures 5-16 and 5-17. They generally show little if any change between fuel types. $\mathrm{CO}$ emissions were within a range of 2 to 6 ppmvd, hydrocarbon emissions were within the range of 1.5 to $4.5 \mathrm{ppmvd}$, and $\mathrm{SO}_{3}$ emissions were within the range of 6 to 13 ppmvd. If the variations are other than random, then the $\mathrm{CO}$ emissions are slightly reduced with biomass and increased with petroleum coke. The reverse is true with hydrocarbons. The mechanisms operating with $\mathrm{SO}_{3}$ emissions, if the variations are other than random, are more complex and relate to sulfur availability, residence time, and $\mathrm{SO}_{3}$ capture or absorption. The very low measured values - typically $<10$ ppmvd-however, indicate that the variation is probably random and can not be definitively explained as the result of combustion mechanisms.

The $\mathrm{SO}_{3}$ results are interesting, although the emissions range of 6 to 13 ppmvd at 3 percent $\mathrm{O}_{2}$ demonstrates that cofiring or trifiring did not produce unacceptable $\mathrm{SO}_{3}$ emissions. $\mathrm{SO}_{3}$ is commonly injected into precipitators at 20 ppmvd to improve their performance on western low sulfur coals. At this time there is no satisfactory explanation regarding why SO3 emissions increased during the triburn testing. 


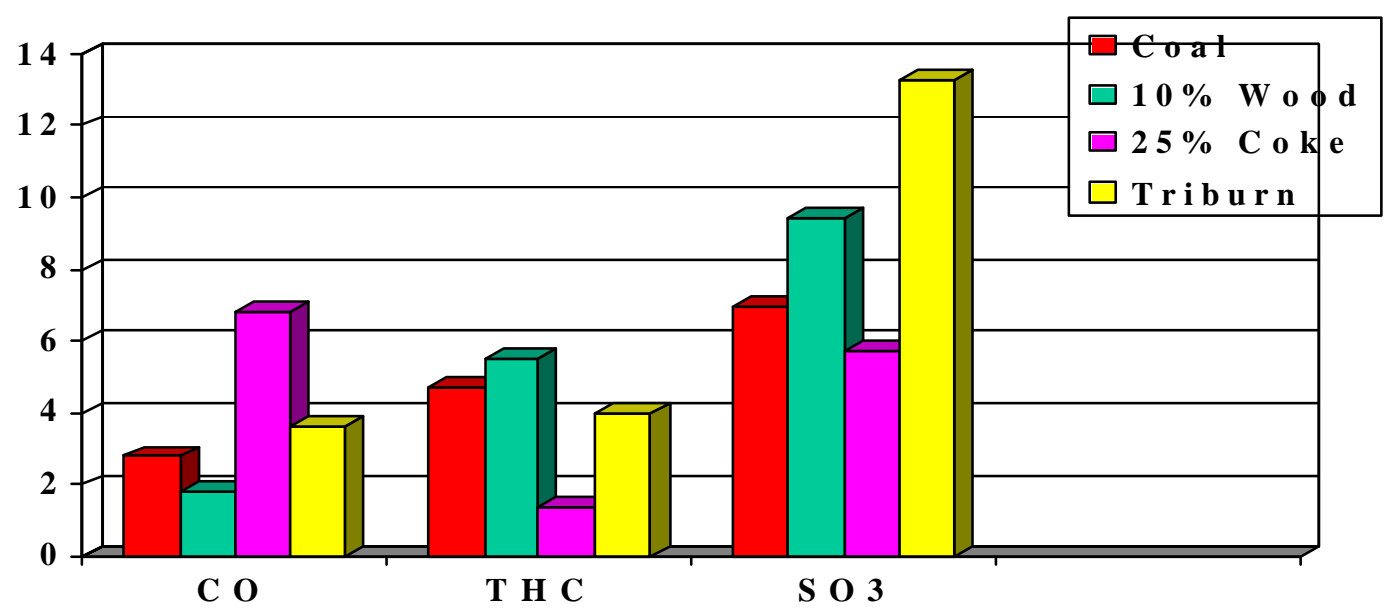

Figure 5-16. Concentrations of $\mathrm{CO}, \mathrm{THC}$, and $\mathrm{SO}_{3}$ as a function of fuel blend, with values expressed

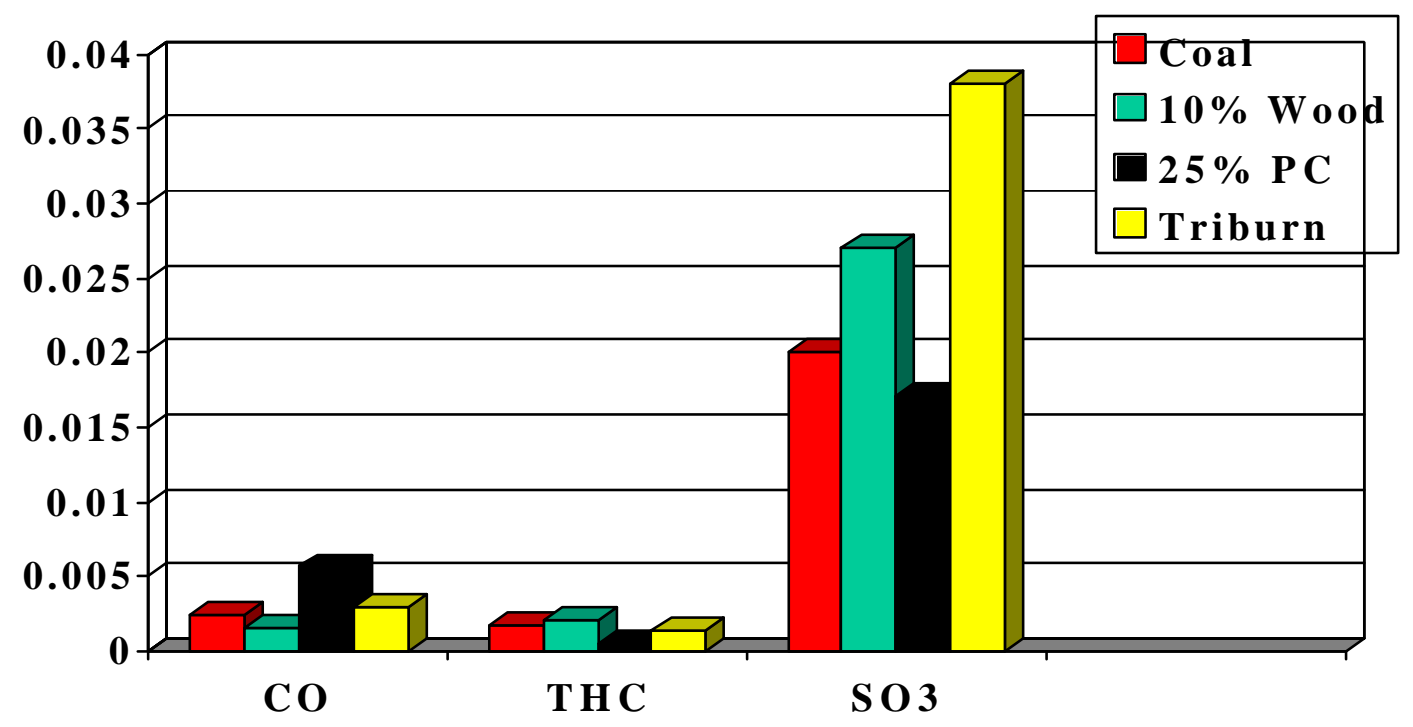

in ppmvd at 3 percent $\mathrm{O}_{2}$

Figure 5-17, Concentrations of $\mathrm{CO}, \mathrm{THC}$, and $\mathrm{SO}_{3}$ as a function of fuel blend, with values expressed in $\mathrm{lb} / 10^{6} \mathrm{Btu}$

Trace Metal Emissions Management. The impact of triburn practices on trace metal emissions can be seen in terms of the concentrations of metals in the fuel feed. Table 5-15 documented the concentrations of trace metals in the baseline coal, and in the triburn blend. Clearly the triburn process reduces the trace metal concentrations available to form emissions, with the exception of nickel and vanadium. 
Table 5-15. Trace Metal Concentrations in the Baseline Coal Blend and in the Triburn Fuel (7.5 Percent Wood Waste/22.5 Percent Petroleum Coke/70 Percent Coal) Expressed in lb/10 ${ }^{6}$ Btu

\begin{tabular}{|c|c|c|}
\hline Metal & $\begin{array}{c}\text { Concentration in } \\
\text { Baseline Coal Blend in } \\
\mathrm{lb} / \mathbf{1 0}^{6} \mathrm{Btu}\end{array}$ & $\begin{array}{l}\text { Concentration in Triburn } \\
\text { Blend in } \mathrm{lb} / 10^{6} \mathrm{Btu}\end{array}$ \\
\hline Arsenic & $1.77 \times 10^{-4}$ & $1.41 \times 10^{-4}$ \\
\hline Chromium & $1.51 \times 10^{-3}$ & $1.17 \times 10^{-3}$ \\
\hline Lead & $3.16 \times 10^{-4}$ & $2.77 \times 10^{-4}$ \\
\hline Mercury & $2.63 \times 10^{-6}$ & $2.19 \times 10^{-6}$ \\
\hline Nickel & $2.03 \times 10^{-4}$ & $2.81 \times 10^{-3}$ \\
\hline Vanadium & $1.41 \times 10^{-3}$ & $7.44 \times 10^{-3}$ \\
\hline
\end{tabular}

Particular attention was paid to mercury emissions as shown in equations [23] and [24]. Both of these document concentrations of mercury in the fuel blend as a function of the particular opportunity fuel.

$$
\mathrm{Hg}_{(\mathrm{mg} / \mathrm{kg})}=0.292-0.00016(\% \mathrm{~W})-0.00013(\% \mathrm{PC})
$$

And

$$
\mathrm{Hg}_{(\mathrm{lb} / \mathrm{MMBtu})}=2.64 \times 10^{-6}-2.9 \times 10^{-9}(\% \mathrm{~W})-1.9 \times 10^{-8}(\% \mathrm{PC})
$$

$\% \mathrm{~W}$ is percent wood on a mass basis and \%PC is percent petroleum coke on a mass basis. While the petroleum coke plays more of a role in reducing mercury concentrations in the fuel fed to the boiler, the biomass - the wood waste - also contributes to a reduction in mercury in the feedstock. Subsequent testing has demonstrated that the triburn process indeed results in reduced mercury emissions. These mercury emissions results showing reductions caused by biomass are consistent with the results from Albright Generating Station.

Vanadium and nickel are the final metals of consideration. As expected, the petroleum coke increased the concentrations of these metals while the wood waste decreased the concentrations of these metals as shown in Table 5-16.

Table 5-16. Concentrations of Vanadium and Nickel in the Fuels Burned at Bailly Generating Station (values in $\mathrm{mg} / \mathrm{kg}$ or ppmw)

\begin{tabular}{|l|l|l|l|l|}
\hline \multicolumn{1}{|c|}{ Metal } & \multicolumn{4}{c|}{ Fuel } \\
\hline & Wood Waste & Petroleum Coke & High Sulfur Coal & Low Sulfur Coal \\
\hline Vanadium & 3.06 & 326.37 & 17.21 & 11.95 \\
\hline Nickel & 2.65 & 134.04 & 12.33 & 7.40 \\
\hline
\end{tabular}

Equations [25] and [26] document the influence of each opportunity fuel on the blended fuel concentration of vanadium and nickel. 


$$
\mathrm{V}_{(\mathrm{mg} / \mathrm{kg})}=15.63-0.126(\% \mathrm{~W})+3.11(\% \mathrm{PC})
$$

And

$$
\mathrm{Ni}_{(\mathrm{mg} / \mathrm{kg})}=10.85-0.081(\% \mathrm{~W})+1.23(\% \mathrm{PC})
$$

It is important to note that the partitioning of nickel and vanadium reduce the potential for emissions of these materials. Testing at Bailly indicated that some 75 percent of the nickel reports to the slag and is essentially "glassified" there, and only 25 percent reports to the flyash; the vanadium is about evenly split between the slag and the flyash. Figure 5-18 documents this partitioning.

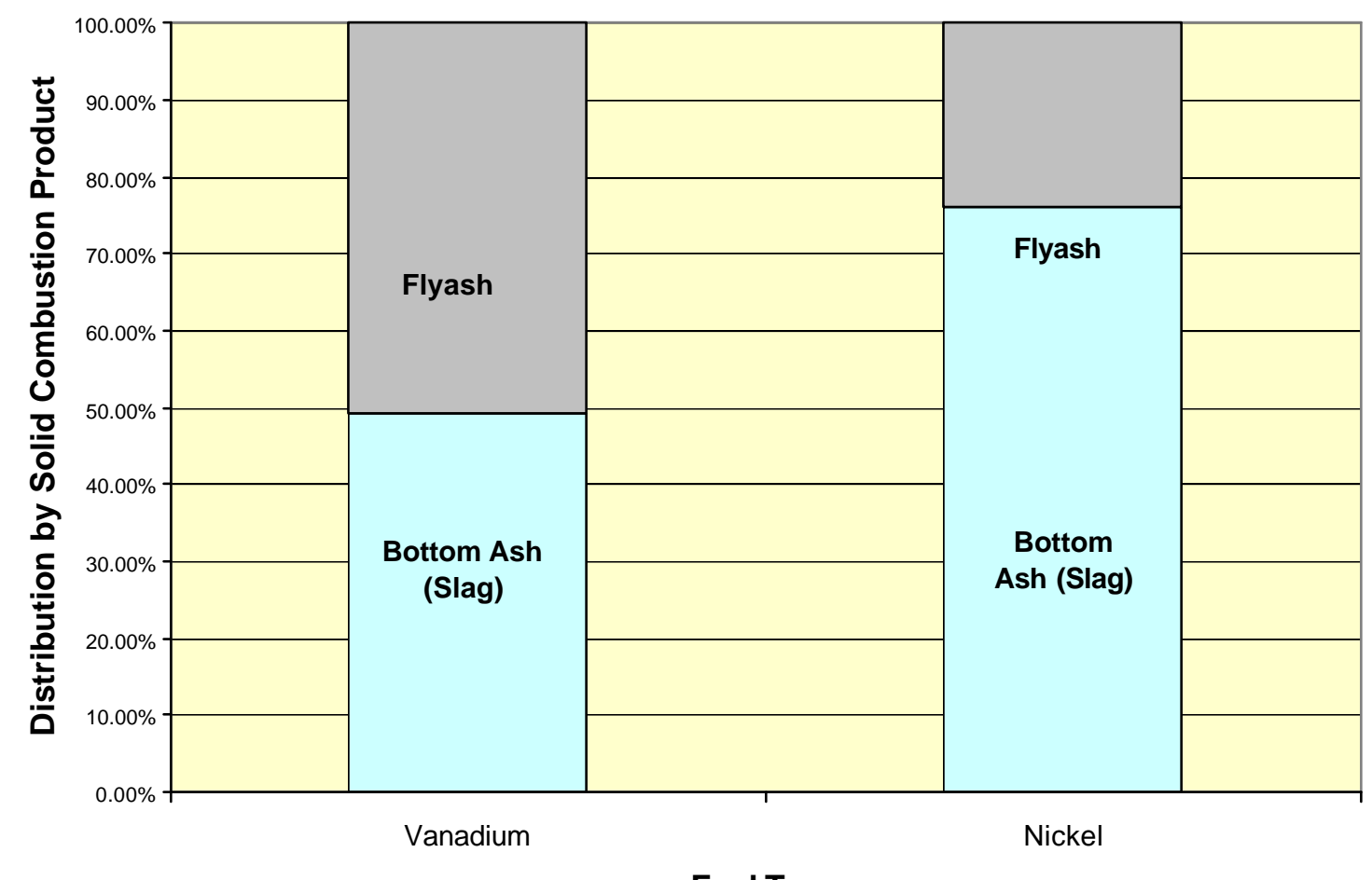

Fuel Type

Figure 5-18. Partitioning of Vanadium and Nickel During Triburn Testing at Bailly Generating Station

Because of the potential issues associated with vanadium in the flyash occurring as vanadium pentoxide $\left(\mathrm{V}_{2} \mathrm{O}_{5}\right)$, X-Ray diffraction of samples with the highest concentrations of vanadium was performed over a period of 16 hours to maximize the pattern. The results of the analysis indicated that the most prominent forms of vanadium were $\mathrm{V}_{2} \mathrm{O}_{3}$ and $\mathrm{V}_{2} \mathrm{O}_{4}$; there were substantial concentrations of vanadium in association with carbon, and these concentrations of vanadium typically do not oxidize completely to $\mathrm{V}_{2} \mathrm{O}_{5}$. However there were significant concentrations of $\mathrm{V}_{2} \mathrm{O}_{5}$ in the sample as well. Figures 5-19 and 5-20 are the X-Ray diffraction results from two runs on the flyash. 


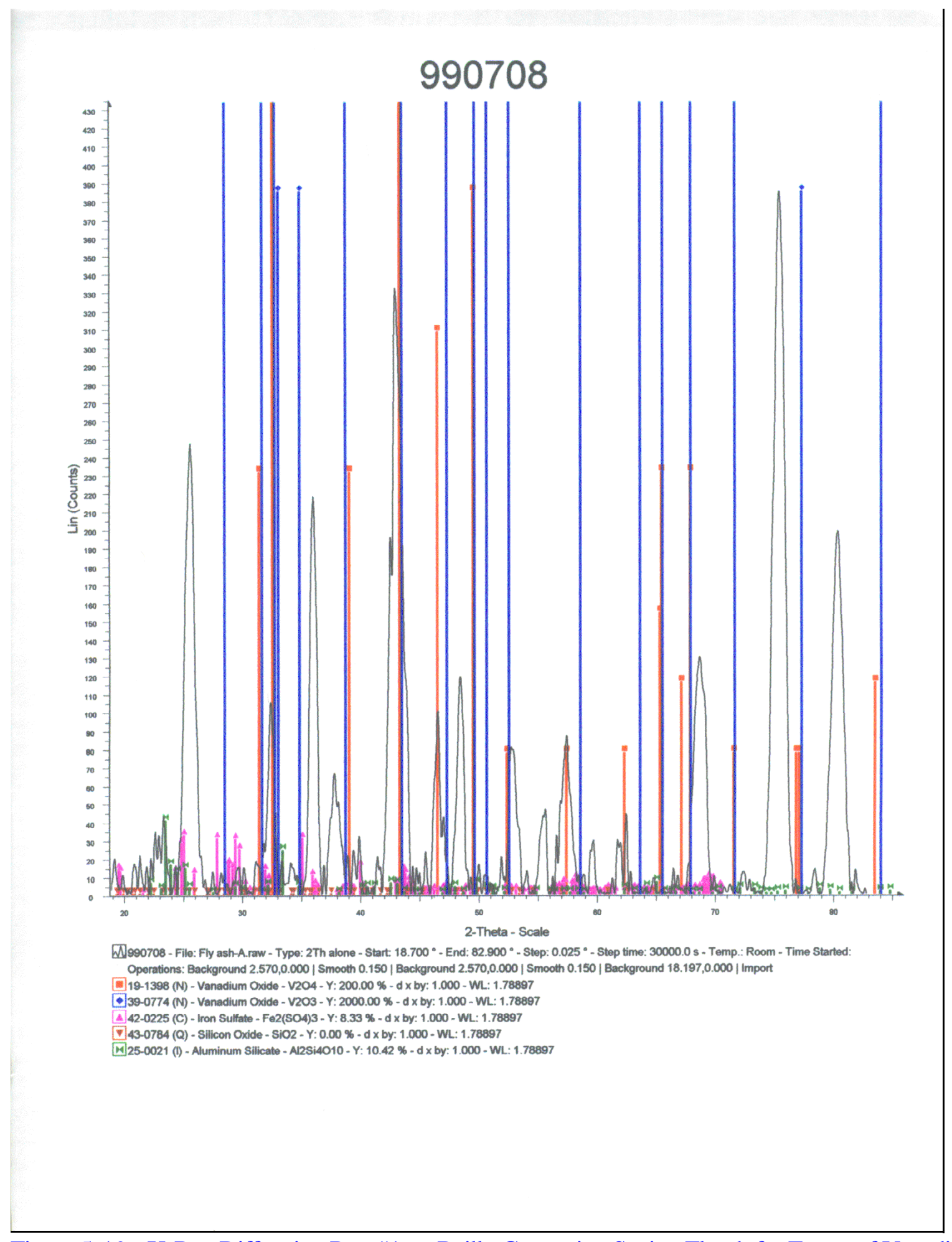

Figure 5-19. X-Ray Diffraction Run \#1 on Bailly Generating Station Flyash for Forms of Vanadium 


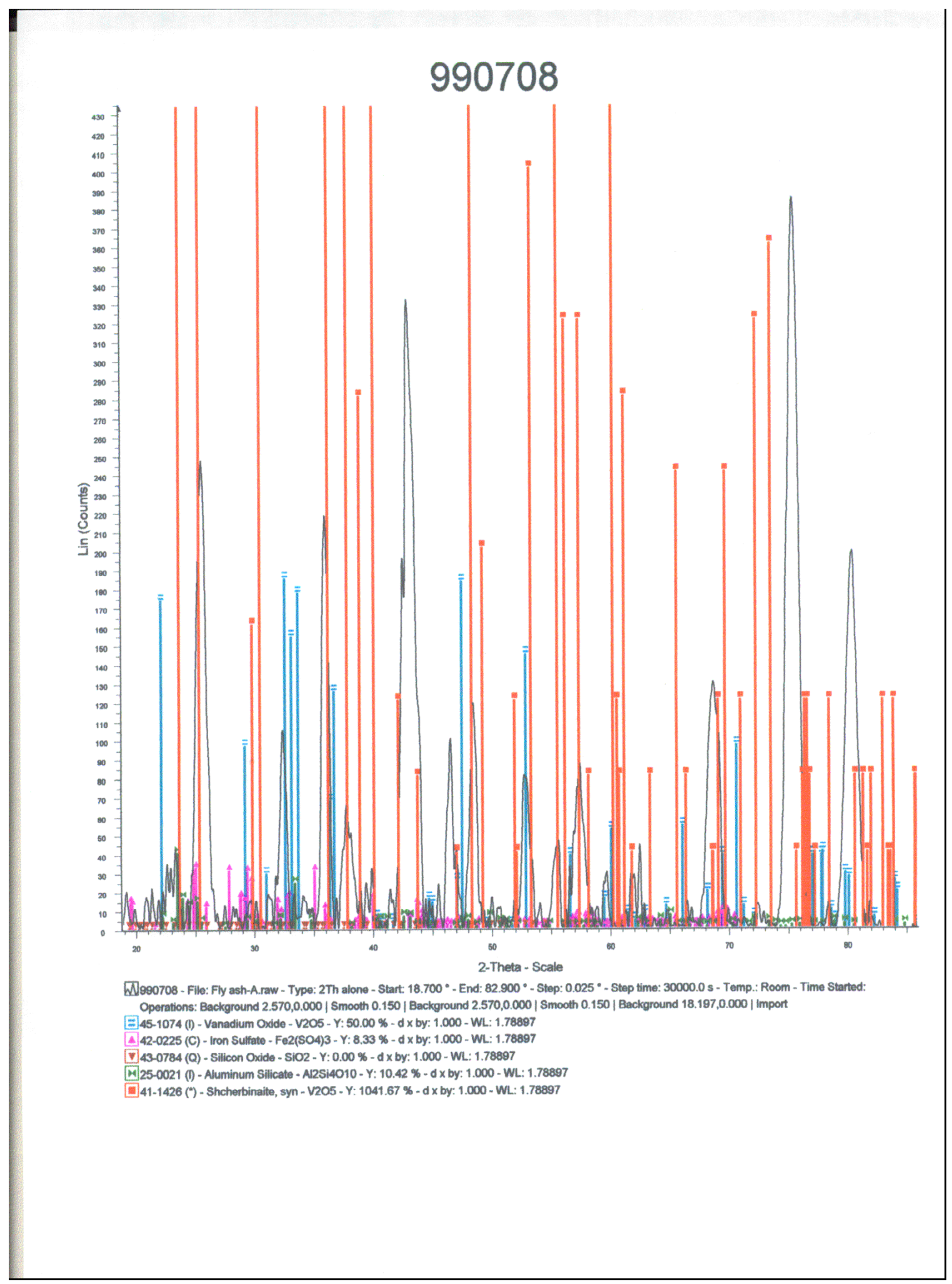

Figure 5-20. X-Ray Diffraction Run \#2 on Bailly Generating Station Flyash for Forms of Vanadium 
Fossil $\mathrm{CO}_{2}$ Mitigation. One of the primary benefits sought by the program involved greenhouse gas mitigation-generation of environmentally friendly renewable energy. Greenhouse gas mitigation is measured in terms of fossil $\mathrm{CO}_{2}$ emissions reduction, and three sources of reduction occurred through this project: 1) displacement of coal burned for generation of electricity, 2) improved boiler efficiency from the use of petroleum coke, and 3) reduced landfilling of urban wood waste, with the urban wood waste being available to decompose and form methane.

The direct fossil $\mathrm{CO}_{2}$ reductions result from a savings of 1.05 ton of fossil $\mathrm{CO}_{2}$ for every ton of wood waste burned at this plant. This includes the efficiency impacts of firing wood waste. Under these conditions, when wood waste was 5 percent of the total mass of fuel, the direct annual fossil $\mathrm{CO}_{2}$ savings at this boiler, were on the order of 27,000 tons. When wood waste was 7.5 percent of the mass of fuel, then the annual fossil $\mathrm{CO}_{2}$ savings are on the order of 41,000 tons from Boiler \#7 alone. When wood waste is 10 percent of the total mass of fuel, then the annual fossil $\mathrm{CO}_{2}$ savings are on the order of 56,000 tons.

The Fossil $\mathrm{CO}_{2}$ savings from this project, however, can be leveraged considerably. The wood waste being burned would otherwise be sent to landfill. That is based upon current practices of the wood waste supplier. On that basis, the wood waste not burned will decompose and create methane gas-a far more significant contributor to greenhouse gas emissions than $\mathrm{CO}_{2}$. The commonly accepted calculation factors are that methane is 21 times as potent a greenhouse gas as $\mathrm{CO}_{2}$, and that only about $1 / 2$ of the methane generated in landfills is combusted in a flare or other device. Various calculations have been made documenting this leveraging effect. The leveraging can be a factor of 2.8 to 4.2. Further, the increased boiler efficiency caused by the combustion of petroleum coke reduces fossil $\mathrm{CO}_{2}$ emissions. The annual savings from burning petroleum coke at Bailly Generating Station Boiler \#7 are about 7,300 tons. The total leveraging effect is on the order of 3.0 to 4.4 , yielding a total fossil $\mathrm{CO}_{2}$ (equivalent) emissions reduction from this project of 81,000 to 119,000 tons/year when burning 5 percent wood waste and 15 percent petroleum coke, or 122,000 to 180,000 tons/year when burning 7.5 percent wood waste and 22.5 percent petroleum coke.

The Bailly triburn project, then, has demonstrated that biomass can be blended with petroleum coke to form a new opportunity fuel. This opportunity fuel achieved the objectives of generating environmentally favorable energy without causing negative impacts to the operating characteristics or emissions of the unit. In practice, the triburn project achieved boiler efficiency improvements while reducing $\mathrm{NO}_{\mathrm{x}}$ emissions and trace metal concentrations in the fuel while significantly reducing fossil $\mathrm{CO}_{2}$ emissions.

\subsection{CONCLUSIONS REGARDING CYCLONE COFIRING}

The testing at Michigan City, and the demonstration at Bailly, demonstrated the opportunities for cofiring in cyclone boilers. Properly managed, cofiring can be used to reduce emissions without undue economic costs. Proper management, however, requires attention to the base coals being employed as cofiring against PRB coal is fundamentally different from cofiring against bituminous coal. Designing blends of opportunity fuels provides the most significant opportunities available. 


\subsection{SUPPORTING STUDIES}

\subsection{INTRODUCTION}

While testing and demonstrations were at the heart of the EPRI-USDOE Cooperative Agreement, additional studies were performed to broaden the base of cofiring by providing information to electricity generators concerning engineering studies and opportunities. At the same time the supporting studies were used to investigate alternative approaches to cofiring.

\subsection{DEVELOPING A COFIRING DATABASE}

The Cooperative agreement was used to fund an extensive fuels-based database for cofiring (see Prinzing, 1996). This database presented the following properties for biomass fuels along with various coals and other opportunity fuels.

- Alfalfa stems

- Almond hulls

- Almond shells

- Auto shredder fluff

- Bagasse

- Bamboo

- Banana stems

- Miscanthus

- Municipal waste, refuse-derived fuel (RDF), and various RDF fractions

- Non-recyclable paper

- Olive pits

- Pistachio shells

- Pulp mill sludge

- Railroad ties

- Reed Canary Grass

- Rice Straw

- Right-of-way trimmings

- Sawdust (hardwood)

- Sawdust (softwood)

- Sewage treatment sludge

- Switchgrass

- Tire-derived fuel (TDF)

- Utility (telephone) poles

- Wheat Straw

- Willow grown as short rotation woody crop

- Wood-various softwoods and hardwoods

- Wood pyrolysis char 
- Wood pyrolysis oil

- Blends of wood waste and agricultural materials

- Eastern bituminous coal

- Illinois basin coal

- Utah bituminous coal

- Decker (PRB) coal

- Spring Creek (PRB) coal

- Orimulsion

The database presented proximate analyses, ultimate analyses, heating values, ash elemental analyses, and trace metal contents wherever available. The database was compiled from secondary sources, and from tests performed by Ebasco Environmental and Foster Wheeler Environmental as part of the EPRIUSDOE Cooperative Agreement.

Using basic calculations, the database provided additional information, depending upon the basic data availability, including:

- Fuel volatility

- Inherent stoichiometric ratio (to account for high oxygen fuels)

- Stoichiometric air required (lb air/lb fuel)

- Maximum theoretical boiler efficiency at stoichiometric ratio of 1.0 and air heater exit temperature of $300^{\circ} \mathrm{F}$

- Adiabatic flame temperature

- Ash classification (bituminous, lignitic)

- Base/acid ratio

- $\mathrm{T}_{250}$ Temperature

- Slagging and fouling indices

\subsection{DEVELOPMENT OF COFIRING GUIDELINES}

Based upon the early test programs, certain trends continued to be repeated as shown in the preceding chapters. Through the Cooperative Agreement, Foster Wheeler developed cofiring guidelines (Tillman, 1997). These guidelines summarized the testing and engineering that had occurred from $1992-1996$. They included simple modeling of combustion processes cofiring applications.

The Guidelines addressed the following issues:

- Fuel characteristics impacting cofiring including composition, particle size, chemical structure, and ash chemistries

- Fuel management, handling, and preparation including methods of fuel receiving and storage, fuel preparation (screening, grinding), fuel blending as appropriate, and fuel transport to the furnace (for separate injection methods), and methods for measuring fuel feed rates 
- Cofiring combustion including capacity, efficiency, and stability considerations

- Combustion consequences of cofiring including boiler capacity, stability, and efficiency when cofiring

- Environmental consequences of cofiring including addressing criteria pollutants $\left(\mathrm{SO}_{2}\right.$, $\mathrm{NO}_{\mathrm{x}}$, particulates), trace metals, and greenhouse gas emissions

- Economic issues including capital investment requirements, fuel costs, and operating costs

The Guidelines report was superceded by a review of all cofiring experience to date (Battista and Hughes, 2000) that summarizes the cofiring experience of 26 plants with cofiring testing. Plants include the Allen Fossil Plant, Bailly Generating Station, Big Stone Unit \#1, Branch (Harlee) Generating Station, Colbert Fossil Plant, Dunkirk Steam Plant, B.L. England Station, Escalante Generating Station, Gadsden Steam Plant, F.J. Gannon Generating Station, Greenidge Generating Station, Hammond Generating Station, Jeffries Generating Station, Allen S. King Generating Station, Kingston Fossil Plant, Plant Kraft, La Cygne Generating Station, W.S. Lee Station, Michigan City Generating Station, NIOSH, Ottumwa Generating Station, Pittsburgh Brewing Company, Seward Generating Station, Shawville Generating Station, Thomas Hill Energy Center, and Vermilion Power Station. The Battista and Hughes (2000) report provides 2-page summaries of each cofiring experience.

\subsection{ASSESSMENT OF GASIFICATION-BASED COFIRING AT ALLEN FOSSIL PLANT}

Gasification-based cofiring has been well demonstrated in Finland (see Raskin, Palonen, and Niemanen, 2000). Its potential includes the following factors:

- Separation of the biomass ash from coal ash to address the ash sales issue associated with ASTM Specification C-618 concerning Pozzolan

- Broadening the base of biomass available to a single location by using the gasifier as a fuel preparation technique

- Provide a basis for $\mathrm{NO}_{\mathrm{x}}$ reduction through reburning — should that technique be appropriate for any given boiler

Gasification was evaluated for the Allen Fossil Plant of TVA. The Allen Fossil Plant had several unique advantages: 1) considerable effort had gone into understanding the combustion processes at this installation (see Chapter 2), 2) the plant management was favorably disposed to cofiring and to alternative fuels, and 3) the plant was planning to integrate a stream of $500 \mathrm{Btu} / \mathrm{ft}^{3}$ wastewater treatment gas into the fuel supply of one boiler. The biomass gasification process could be integrated with the wastewater treatment gas. This combination—initially evaluated at the Allen Fossil Plant—has broad application to using biomass gasification in concert with landfill gas. 
The initial phase of this investigation was a biomass fuel study including not only the traditional wood wastes that were cofired at Allen Fossil Plant, but also the following:

- Cotton gin trash

- Non-recyclable paper

- Non-recyclable cardboard

- Pallet wastes

- Select, segregated, components of pre-commercial urban waste

Following successful identification of considerable biomass available in the region, the gasification design studies proceeded.

The applicability of several types of gasifiers was evaluated including:

- Fixed bed updraft (countercurrent) gasifiers

- Fixed bed downdraft (cocurrent) gasifiers

- Entrained flow gasifiers

- Fluidized bed gasifiers

Both atmospheric and pressurized gasifiers were considered. Air-blown and oxygen-blown gasification was reviewed. A survey was conducted of the various gasification systems offered by numerous vendors. Gas clean-up systems were briefly considered, however it was believed that transport of hot $\left(>1500^{\circ} \mathrm{F}\right)$ gas to the boiler would be more economical and avoid creation of a wastewater treatment problem with condensed tars.

A system was designed to evaluate gasification. While it was based upon a fixed bed updraft gasifier, the design was sufficiently flexible that any type of hardware could ultimately be used. The system design included the following elements:

- Fuel receiving and materials handling

- The gasification island

- The gas transport system

- Ancillary systems

- System controls

The study indicated that gasification-based cofiring could achieve its objectives in terms of broadening the resource base and separating the biomass flyash from the coal flyash. It could achieve other environmental benefits as well. The results of the study were sufficiently interesting that TVA pursued bids from several gasification vendors for the installation of a system. The project, however, was not pursued beyond the bid process. 


\subsection{OTHER SPECIAL STUDIES}

Other small, special studies conducted under the EPRI-USDOE Cooperative Agreement included fuel availability studies for selected utilities (e.g., Duquesne Light), fuel characterizations (e.g., willow grown as short rotation woody crop material), and international opportunities (e.g., the potential for cofiring wood waste with coal in New Zealand). The Cooperative Agreement sponsored a small study of the greenhouse gas mitigation impacts of cofiring at NIPSCO. These studies supplemented the larger efforts such as the fuels database and the gasification-based cofiring study. Further, they extended the reach of the cofiring tests and demonstrations.

\subsection{CONCLUSIONS REGARDING SPECIAL STUDIES}

The special studies buttressed the overall test and demonstration program. They provided essential data for evaluating further cofiring opportunities, and provided analyses of alternative approaches to cofiring. As such they complemented the entire effort to commercialize cofiring of biomass in coal-fired boilers. 


\subsection{REFERENCES}

Adams, B.R. and N.S. Harding. 1996. Modeling of Wood Reburning for NOx Control. Proc. 1996 International Joint Power Generation Conference: Environmental Control/Fuels and Combustion Technologies. Houston, TX. American Society of Mechanical Engineers, New York. pp. 445-454.

Aerts, D. and K. Ragland. 1997. Co-Firing Switchgrass and Coal in a 50 MW Pulverized Coal Utility Boiler. Final Report. Prepared for Great Lakes Regional Biomass Energy Program. Department of Mechanical Engineering, University of Wisconsin-Madison. Madison, WI.

Battista, J.J. and E. Hughes. 2001. Biomass Cofiring in the United States: A Survey of Past Tests. Proc. $26^{\text {th }}$ International Technical Conference on Coal Utilization \& Fuel Systems. Clearwater, FL. March 5-8. pp. 227-236.

Battista, J.J. and E.E. Hughes. 2000. A Survey of Biomass Cofiring Experience in the United States. Electric Power Research Institute, Palo Alto, CA.

Battista, J.J., E.E. Hughes, and D.A. Tillman. 2000. Biomass Cofiring at Seward Station. Biomass and Bioenergy. 19(6): 419-428.

Battista, J., D. Tillman, and E. Hughes. 2000. Biomass Cofiring at Seward Station: An Update. Proc. $25^{\text {th }}$ International Technical Conference on Coal Utilization and Fuel Systems. Clearwater, FL. ASME-FACT, USDOE, and CTA. March 6-9. pp. 95-106.

Battista, J., D. Tillman, and E. Hughes. 1999. Cofiring at the Seward Generating Station - a Long Term Demonstration. Proc. 24 ${ }^{\text {th }}$ International Technical Conference on Coal Utilization and Fuel Systems. Clearwater, FL. ASME-FACT, USDOE, and CSTA. March 8-11. pp. 325-332.

Battista, J.J., D. Tillman, and E. Hughes. 1998. Cofiring Wood Waste with Coal in a Wall-Fired Boiler: Initiating a 3-Year Demonstration Program. Proc. Bioenergy '98. Madison, WI. Oct 4-8. pp. 243-250.

Battista, Joseph, Evan Hughes, David Tillman, and David Prinzing. 1996. Co-Firing Wood Waste With Coal at the Seward Generating Station. Presented at the Engineering Foundation Conference on the Economic and Environmental Aspects of Coal Utilization-VII. Santa Barbara, CA. Feb 18-21.

Battista, J.J., D.A. Tillman, D.E. Prinzing, and E.F. Hunt. 1996. Wood Cofiring Test Results: Shawville Generating Station. FETC Contractors Conference, Pittsburgh, PA. July. 
Baxter, L.L. et. al. 1996a. The Behavior of Inorganic Material in Biomass-Fired Power Boilers: Field and Laboratory Experiences. Proc. Biomass Usage for Utility and Industrial Power. Engineering Foundation Conference. Snowbird, UT. April 28-May 3.

Baxter, L.L. et. al. 1996b. The Behavior of Inorganic Material in Biomass-Fired Power BoilersField and Laboratory Experiences: Vol II of Alkali Deposits Found in Biomass Power Plants. SAND96-8225 Volume 2 and NREL/TP-433-8142.

Baxter, L.L. et. al. 1996c. Nitrogen Release during Coal Combustion. ENERGY \& FUELS. 10(1): 188-196.

Benjamin, W.H. 1996a. Building Biomass into the Utility Fuel Mix at NYSEG: System Conversion and Testing Results for Greenidge Station. Proc. Bioenergy '96. Nashville, TN. September 15-20. pp. $135-141$.

Benjamin, W.H. 1996b. Renewable Wood Fuel: Fuel Feed System for a Pulverized Coal Boiler. New York State Energy Research and Development Authority, Albany, NY.

Boylan, D., B. Zemo, and J. Eastis. 2001. Final Report: Switchgrass Cofiring at Alabama Power's Plant Gadsden. Southern Company, Birmingham, AL. Report to USDOE.

Boylan, D. et. al. 2001. Switchgrass Cofiring at Plant Gadsden. Presented at the Biomass Cofiring Project Review Meeting, NETL, Pittsburgh, PA. June 21-22.

Boylan, D., V. Bush, and D.I. Bransby. 2000. Switchgrass cofiring: pilot scale and field evaluation. Biomass and Bioenergy. 19(6): 411-417.

Boylan, D.M. 1993. Southern Company Tests of Wood/Coal Cofiring in Pulverized Coal Units. Proc. Strategic Benefits of Biomass and Waste Fuels. EPRI Conference. Washington, DC. March 30-April 1.

Brouwer, J. et. al. 1995. Cofiring Waste Biofuels and Coal for Emissions Reduction. Proc. Second Biomass Conference of the Americas. Portland, OR. August 21 - 24. pp. 390-399.

Brouwer, J. et. al. 1994. The Use of Wood as a Reburning Fuel in Combustion Systems. Proc. Bioenergy '94. Reno, NV. Pp. 123-130.

Brobjorg, J. 1993. RDF Experience at Northern States Power's Plants. Proc. Strategic Benefits of Biomass and Waste Fuels. EPRI Conference. Washington, DC. March 30-April 1.

Bush, P.V., D.M. Boylan, and D.I. Bransby. 1999. Southern Company Evaluation of Switchgrass. Proc. Fourth Biomass Conference of the Americas, Vol 2. Elsevier, Oxford, England. pp. 13071308. 
Bryers, R.W. and N.S. Harding (eds). 1994. Coal - Blending and Switching of Low-Sulfur Western Coals. American Society of Mechanical Engineers, New York.

Bryers, R.W. 1994. Analysis of a Suite of Biomass Samples. Foster Wheeler Development Corporation, Livingston, NJ. Report FWC/FWDC/TR-94/03.

Clarke, L. L. Sloss, and J. Grant. 1992. Trace Element Emissions from Coal Combustion and Gasification. International Energy Agency. London, England.

DeVito, M.S., LW. Rosendale, and V.B. Conrad. 1994. Comparison of Trace Element Contents of Raw and Clean Commercial Coals. Fuel Processing Technology. 39(1-3): 87-106.

Downing, M. et. al. 1998. Agricultural Cooperatives and Marketing Bioenergy Crops. Case Studies of Emerging Cooperative Development for Agriculture and Energy. Proc. Bioenergy 98. Madison, Wisconsin. Oct 4-8. pp. 100-111.

Downing, M. and R.L. Graham. 1993. Evaluating a Biomass Resource: The TVA Region-Wide Biomass Resource Assessment Model. Proc. First Biomass Conference of the Americas. Aug 30 Sep 2. Burlington, VT. pp. 54-67.

Energy Information Administration. 2001. Renewable Energy Annual 2000. US Department of Energy, Washington, DC. (DOE/EIA-0603 (2000)).

Energy Information Administration. 2000. Annual Energy Review 1999. US Department of Energy, Washington DC.

Envirosphere Co. 1984. Final Biomass Ash Study. Prepared for the California Energy Commission. Contract 500-81-037.

Enzer, H., W. Dupree, and S. Miller. 1975. Energy Perspectives: A Presentation of Major Energy and Energy-Related Data. U.S. Department of the Interior, Washington, D.C.

Finkelman, R.B. 1994. Modes of Occurrence of Potentially Hazardous Elements in Coal: Levels of Confidence. Fuel Processing Technology. 39(1-3): 21-34.

Foster Wheeler Development Corporation. 1998. Assessment of Gasification-based Biomass Cofiring. Electric Power Research Institute, Palo Alto, CA.

Foster Wheeler Environmental Corporation. 1997a. Wood Cofiring in a Cyclone Boiler at TVA's Allen Fossil Plant. Electric Power Research Institute, Palo Alto, CA. Report TR-109378. 
Foster Wheeler Environmental Corporation. 1997b. Cofiring Wood Waste with Coal at the Seward Generating Station: December 1996. Prepared for GPU Genco, Federal Energy Technology Center, and Electric Power Research Institute. Foster Wheeler Environmental Corporation, Sacramento, CA.

Foster Wheeler Environmental Corporation. 1995a. Report of the Cofiring Combustion Testing at the Allen Fossil Plant Using Utah Bituminous Coal as the Base Fuel. Prepared for the Tennessee Valley Authority and the Electric Power Research Institute. Foster Wheeler Environmental Corporation, Sacramento, CA.

Foster Wheeler Environmental Corporation. 1995b. Report of the Cofiring Combustion Testing at the Kingston Fossil Plant, August 23-30, 1994. Prepared for Tennessee Valley Authority. Foster Wheeler Environmental Corporation, Sacramento, CA.

Foster Wheeler Environmental Corporation. 1994a. Self-Heating Assessment of Coal/Wood Fuel Blends. Prepared for Tennessee Valley Authority, Chattanooga, TN. Foster Wheeler Environmental Corporation, Sacramento, CA.

Foster Wheeler Environmental Corporation. 1994b. Report of the Cofiring Combustion Testing at the Allen Fossil Plant: August 19 - 25, 1994. Prepared for the Electric Power Research Institute and the Tennessee Valley Authority. Foster Wheeler Environmental, Sacramento, CA.

Freeman, M.C., P.M. Goldberg, and S.I. Plasynski. 1998. Biomass Cofiring R\&D and Utility Experiences: What's Happened, What's Next. Proc. Bioenergy '98. Madison, WI. Oct 4-8. pp. 263-274.

Gamble, M.B. 1993. RDF/Wood/Coal Cofiring: Tacoma City Light Steam Plant No 2 Utilizing Fluidized Bed Combustors. Proc. Strategic Benefits of Biomass and Waste Fuels. EPRI Conference. Washington, DC. March 30-April 1.

Gillen, J.E., and A.J. Szempruch. 1993. Ohio Edison Tires-to-Energy Project. Proc. Strategic Benefits of Biomass and Waste Fuels. EPRI Conference. Washington, DC. March 30-April 1.

Gordon, S. and B.J. McBride. 1976. Computer Program for Calculation of Complex Chemical Equilibrium Compositions, Rocket Performance, Incident and Reflected Shocks, and Chapman-Jouget Detonations. Interim Revision. NASA SP-273. NASA Lewis Research Center. March, 1976. Updated with Interim Revisions in 1989 and 1993.

Greene, W.T. 1988. Wood Ash Disposal and Recycling Sourcebook. OMNI Environmental Services, Beaverton, OR.

Harding, N.S. and B.R. Adams. 2000. Biomass as a Reburning Fuel: a Specialized Cofiring Application. Biomass and Bioenergy. 19 (6): 429-445. 
Hus, P.J. and D.A. Tillman. 2000. Cofiring Multiple Opportunity Fuels with Coal at Bailly Generating Station. Biomass and Bioenergy. 19(6): 385-394.

Hughes, E. and D. Tillman. 1996. Biomass Cofiring: Status and Prospects 1996. Proc. Engineering Foundation Conference. Snowbird, UT. April 28 - May 3.

Johnson, D.K. et. al. 2001a. Characterizing Biomass Fuels for Cofiring Applications. Proc. $5^{\text {th }}$ Biomass Conference of the Americas. Sep 17 - 21. Orlando, FL.

Johnson, D.K., et. al. 2001b. Report to Foster Wheeler on Pyrolysis and Char Oxidation Kinetics. Pennsylvania State University, University Park, PA.

McGowin, C. and B. Gold. 1992. Potential Benefits of Co-firing Wood and Coal. Presented at the $5^{\text {th }}$ Annual National Biofuels Conference. Oct 19-22. Newton, MA.

McGowin, C. and E. Hughes. 1992. Efficient and Economical Energy Recovery from Waste by Cofiring with Coal In Clean Energy from Waste and Coal. ACS Symposium Series. ACS Press, Washington, D.C.

Miles, T.R., et. al. 1993. Alkali Slagging Problems with Biomass Fuels. Proc. First Biomass Conference of the Americas. Aug 30 - Sep 2. Burlington, VT. pp. 406-421.

Murphy, P.M. and M.R. Tesla. 1993. Co-Firing Tire Derived Fuel in a Stoker Fired Boiler. Proc. Strategic Benefits of Biomass and Waste Fuels. EPRI Conference. Washington, DC. March 30-April 1.

Nast, Van. 1993. TDF C0-Firing Experience in a Cyclone Boiler. Proc. Strategic Benefits of Biomass and Waste Fuels. EPRI Conference. Washington, DC. March 30-April 1.

National Energy Policy Development Group. 2001. Reliable, Affordable, and Environmentally Sound Energy for America's Future. US Government Printing Office, Washington DC. May 2001.

Noon, C. 1993. TVA GIS-Based Biomass Resource Assessment. Proc. First Biomass Conference of the Americas. Aug $30-$ Sep 2. Burlington, VT. pp. 74-78.

Norwood, C., and W. Warnick. 1982. Consumption of Wood Fuels in the United States 1971-1980. in Progress in Biomass Conversion, Vol 3. Academic Press, New York. pp. 129-182.

Pawlowski, D. 1993. RDF Pellet Cofiring Experience at Otter Tail Power's Big Stone Plant. Proc. Strategic Benefits of Biomass and Waste Fuels. EPRI Conference. Washington, DC. March 30-April 1. 
Payette, K. and D. Tillman. 2001. Progress on the Allegheny Energy Supply Co., LLC Cofiring Projects. Presented at the Biomass Cofiring Project Review Meeting. June 21-22. National Energy Technology Laboratory, Pittsburgh, PA

Plasynski, S.I., P.M. Goldberg, and Z.Y. Chen. 2001. DOE's Biomass Cofiring Program: Summary and Results. Proc. $26^{\text {th }}$ International Technical Conference on Coal Utilization \& Fuel Systems. Clearwater, FL. March 5-8. pp. 203-214.

Plasynski, Sean I., Raymond Costello, Evan Hughes, and David Tillman. 1999. Biomass Cofiring in Full-Sized Coal-Fired Boilers. . Proc. $24^{\text {th }}$ International Technical Conference on Coal Utilization and Fuel Systems. ASME-FACT, USDOE, and Coal Technology Association. Clearwater, FL. March 8-11. pp.281-292.

Prinzing, D.E. 1996. EPRI Alternative Fuels Database. Electric Power Research Institute, Palo Alto, CA. Report TR-107602.

Prinzing, D.E. E.F. Hunt, and J.J. Battista. 1996. Co-firing Biomass With Coal at Shawville. Proc. Bioenergy '96. Nashville, TN. September 15-20. pp. $121-128$.

Prinzing, D.E. and E.F. Hunt. 1996. Impacts of Wood Cofiring on Coal Pulverization at the Shawville Generating Station. Proc. Biomass Usage for Utility and Industrial Power. Proc. Engineering Foundation Conference. Snowbird, UT. April 28 - May 3.

Prinzing, D.E., N.S. Harding, and D.A. Tillman. 1993. Fuel Characterization Requirements for Cofiring Biomass in Coal-Fired Boilers. Proc. First Biomass Conference of the Americas. Aug $30-$ Sep 2. Burlington, VT. pp. $1671-1684$

Ragland, K.W., D.J. Aerts, and C. Weiss. 1996. Co-Firing Switchgrass in a 50 MW Pulverized Coal Boiler. Proc. Bioenergy '96. Nashville, TN. September 15-20. pp. 113-120.

Raskin, N., J. Palonen, and J. Nieminen. 2000. Power Boiler Fuel Augmentation with a Biomass Fired Atmospheric Circulating Fluid-bed Gasifier. Biomass \& Bioenergy. 20:471-481.

Rollins, M.L., L.D. Reardon, and D.A. Tillman. 1998. Commercializing Cofiring at the Colbert Fossil Plant of TVA. Proc. Bioenergy '98. Madison, WI. Oct 4-8. pp. 307-314.

Schreuder, G. and D. Tillman. 1980. Wood Fuels Consumption Methodology and 1978 Results. in Progress in Biomass Conversion, Vol 2. Academic Press, New York. pp. 59 - 88.

Stopek, D.J. et. al., 1993. Tire Derived Fuel (TDF) Cofiring in a Cyclone Boiler - at Baldwin Station. Proc. Strategic Benefits of Biomass and Waste Fuels. EPRI Conference. Washington, DC. March 30-April 1. 
Sweterlitsch, J.J. and R.C. Brown. NOx Emissions Reduction: An Application of Biomass Reburning Technology. Proc. Fourth Biomass Conference of the Americas. Elsevier, Oxford, England. pp. 1329-1335.

Tillman, D.A. 2000. Biomass Cofiring: The Technology, The Experience, The Combustion Consequences. Biomass and Bioenergy. 19(6): 365-384.

Tillman, D.A. 1999a. Biomass Cofiring: Field Test Results. Electric Power Research Institute, Palo Alto, CA. Report TR-113903.

Tillman, David. 1999b. Use of Multiple Opportunity Fuels in Coal-Fired Cyclone Boilers. Proc. $24^{\text {th }}$ International Technical Conference on Coal Utilization and Fuel Systems. ASME-FACT, USDOE, and Coal Technology Association. Clearwater, FL. March 8-11. pp. 313-324.

Tillman, David A. 1999c. Cofiring Biomass for Greenhouse Gas Mitigation. Proc. PowerGen. New Orleans. Nov 29 - Dec. 2.

Tillman, D.A. and K. Payette. 2001. Developing a Designer Opportunity Fuel System for Willow Island Generating Station. Proc. $26^{\text {th }}$ International Technical Conference on Coal Utilization and Fuel Systems. ASME-FACT, USDOE, and CSTA. Clearwater, FL. March 5-8.

Tillman, D.A., K. Payette, and J. Battista. 2000. Designer Opportunity Fuels for the Willow Island Generating Station of Allegheny Energy Supply Company, LLC. Proc. $17^{\text {th }}$ Annual Pittsburgh Coal Conference. Pittsburgh, PA. Sep 11-14.

Tillman, D.A. and P.J. Hus. 2000. Blending Opportunity Fuels with Coal for Efficiency and Environmental Benefit. Proc. $25^{\text {th }}$ International Technical Conference on Coal Utilization and Fuel Systems. Clearwater, FL. March 6-9. pp. 659-670.

Tillman, David A., Evan Hughes, and Sean. Plasynski. 1999. Commercializing Biomass-Coal Cofiring: The Process, Status, and Prospect. Proc. The Pittsburgh Coal Conference. Pittsburgh, PA. Oct 1113.

Tillman, David A., Sean Plasynski, and Evan Hughes. 1999. Biomass cofiring in Coal-Fired Boilers: Test Programs and Results. Proc. $4^{\text {th }}$ Biomass Congress of the Americas. Oakland, CA. Aug $30-$ Sep 2. pp. 1287-1292.

Tillman, D.A. et. al. 1998a. Cofiring Biomass in Cyclone Boilers Using Powder River Basin Coal: Results of Testing at the Michigan City Generating Station. Proc. Bioenergy '98. Madison, WI. Oct 4-98. pp. 284-294. 
Tillman, D.A. et. al. 1998b. Cofiring Urban Wood Waste with Powder River Basin Coal at the Michigan City Generating Station. Proc. $23^{\text {rd }}$ International Technical Conference on Coal Utilization and Fuel Systems. ASME-FACT, USDOE, and CSTA. Clearwater, FL. March 9-13. pp. 35-46.

Tillman, D., J. Battista, and E. Hughes. 1998. Cofiring Wood Waste with Coal at the Seward Generating Station. Proc. $23^{\text {rd }}$ International Technical Conference on Coal Utilization and Fuel Systems. ASME-FACT, USDOE, and CSTA. Clearwater, FL. March 9-13. pp. 371-384.

Tillman, D.A. et. al. 1997. Cofiring Woody Biofuel at the Michigan City Generating Station of Northern Indiana Public Service Company: Results and Analysis. Electric Power Research Institute, Palo Alto, CA.

Tillman, D.A., R. Stahl, and K. Therkelsen. 1997. Results of Cofiring Wood Waste with Coal at the Colbert Fossil Plant, 1997. Prepared for the Electric Power Research Institute and the U.S. Department of Energy Federal Energy Technology Center. Foster Wheeler Environmental Corporation, Sacramento, CA.

Tillman, D., M. Rollins, L. Reardon, and E. Hughes. 1997. Cofiring Wood Waste for NOx Control in Cyclone Boilers: Identifying the Mechanisms. Proc. Third Biomass Conference of the Americas. Montreal, Que. Aug 24-29. Elsevier Science. pp. 777 - 786.

Tillman, David A. 1997. Biomass Cofiring Guidelines. Electric Power Research Institute Report TR108952. Palo Alto, CA.

Tillman, D.A., L.D. Reardon, and M.L. Rollins. 1996. Cofiring Alternate Fuels in Coal-Fired Cyclone Boilers. Proc. American Flame Research Committee International Symposium: Combustion in Industry - Status and Needs into the $21^{\text {st }}$ Century. Baltimore, MD. September 30 - October 2.

Tillman, D.A., et. al. 1996a. Fuel Blending and Switching for NOx Control Using Biofuels With Coal in Cyclone Boilers. Proc. Biomass Usage for Utility and Industrial Power. Engineering Foundation Conference. Snowbird, UT. April 28 - May 3.

Tillman, D.A. et. al. 1996b. Tri-Firing Wood Waste and Tire-Derived Fuel with Coal in a Cyclone Boiler. Proc. Bioenergy '96. Nashville, TN. September 15 -20. pp. 129 - 134.

Tillman, D.A. et. al. 1995. Cofiring Wood Waste and Coal in Cyclone Boilers: Test Results and Prospectus. Proc. Second Biomass Conference of the Americas. Portland, OR. August $21-24$. pp. $3821-389$.

Tillman, D.A. 1994. Trace Metals in Combustion Systems. Academic Press, San Diego, CA. 
Tillman, D.A. and D.E. Prinzing. 1994. Fundamental Biofuel Characteristics Impacting Coal-Biomass Cofiring. Proc. The Effects of Coal Quality on Power Plants: Fourth International Conference. Charleston, SC. August 17-24.

Tillman, D.A., E. Hughes, and B. Gold. 1993. Cofiring of Biofuels in Coal Fired Boilers: Results of Case Study Analysis. Proc. First Biomass Conference of the Americas. Aug 30 - Sep 2. Burlington, VT. pp. 368-381.

Tillman, D.A. et. al. 1993. Wood Fuel Cofiring at TVA Power Plants, Vol I: Retrofitting Existing Boilers to Cofire Wood Fuel. Electric Power Research Institute. Palo Alto, CA. Report TR-103830.

Tillman, D.A. 1991. The Combustion of Solid Fuels and Wastes. Academic Press, San Diego, CA.

Tillman, D.A. and C. Leone. 1990. Control of Trace Metals in Flyash at the Tacoma, Washington Multifuels Incinerator. Proc. American Flame Research Committee 1990 Fall International Symposium: NOx Control, Waste Incineration, and Oxygen Enriched Combustion. San Francisco. Oct 8-10.

Tillman, D.A. and W.R. Smith. 1982. Evolution of Volatiles from the Pyrolysis of Red Alder Bark. Presented at the Forest Products Research Society Annual Meeting, St. Paul, Minnesota, June 24, 1982.

Tillman, David A. 1978. Wood as an Energy Resource. Academic Press. New York.

Tillman, David A. 1977. Combustible Renewable Resources. CHEMTECH. 7(10): 611-615.

Utility Data Institute, 1996. Power Plant Equipment Directory, $2^{\text {nd }}$ Ed. Utility Data Institute, Washington, D.C. (UDI 2055-96)

Walsh, M.E. and D. Becker. 1996. Biocost: A Software Program to Estimate the Cost of Producing Bioenergy Crops. Proc. Bioenergy 96. Nashville, TN. Sep 15-20. pp. 480-486.

Wiltsee, G. 1998. Advanced Biomass Technology Characterizations, Status, and Lessons Learned. Electric Power Research Institute, Palo Alto CA.

Wright, L. and J.H. Cushman. 1997. A National Research and Development Strategy for Biomass Crop Feedstocks. Proc. Third Biomass Congress of the Americas. Montreal, Que, Canada. Aug 24-29. pp. 109-120.

Zamansky, V.M., P.M. Maly, V.V. Lissianski, and M.C. Freeman. 1998. Development of Biomass Reburning Technologies. Proc. Bioenergy '98. Madison, WI. Oct 4-8. pp. 327-336. 


\section{APPENDIX A. SELECTED ACRONYMS}

\begin{tabular}{|c|c|}
\hline Acronym & Definition \\
\hline A & Pre-exponential constant in Arrhenius equation \\
\hline СССТ & Combined cycle combustion turbine \\
\hline $\mathrm{CO}$ & Carbon monoxide \\
\hline $\mathrm{CO}_{2}$ & Carbon dioxide \\
\hline CTMP & Chemi-Thermomechanical Pulping \\
\hline $\mathrm{E}$ & Activation energy in Arrhenius equation \\
\hline EE-RE & Office of Energy Efficiency and Renewable Energy, USDOE \\
\hline EJ & Exajoule $\left(10^{18} \mathrm{~J}\right)$ \\
\hline $\mathrm{EO}_{2}$ & Excess $\mathrm{O}_{2}$ in gaseous combustion products \\
\hline EPRI & Electric Power Research Institute \\
\hline FEGT & Furnace exit gas temperature \\
\hline FETC & \begin{tabular}{|l} 
Federal Energy Technology Center, now NETL \\
\end{tabular} \\
\hline FN & Fuel nitrogen \\
\hline GJ & Gigajoule \\
\hline $\mathrm{Hg}$ & Mercury \\
\hline HGI & Hardgrove Grindability index \\
\hline Kpph & Thousand pounds per hour (typically of main steam) \\
\hline $\mathrm{kWh}$ & Kilowatt-hour \\
\hline LOI & $\begin{array}{l}\text { Loss on ignition (treated as approximately equal to unburned carbon) in } \\
\text { flyash }\end{array}$ \\
\hline MG\&E & Madison Gas \& Electric \\
\hline MJ & Megajoule \\
\hline $\mathrm{MW}_{\mathrm{e}}$ & Megawatt electric \\
\hline $\mathrm{MW}_{\mathrm{th}}$ & Megawatt thermal \\
\hline MWh & Megawatt-hour \\
\hline NETL & National Energy Technology Laboratory, USDOE \\
\hline NIPSCO & Northern Indiana Public Service Company (Part of NiSource) \\
\hline $\mathrm{NO}_{\mathrm{x}}$ & Oxides of Nitrogen (including $\mathrm{NO}, \mathrm{NO}_{2}, \mathrm{~N}_{2} \mathrm{O}$ ) \\
\hline NYSEG & New York State Electric and Gas \\
\hline NYSERDA & New York State Energy Research and Development Authority \\
\hline $\mathrm{PC}$ & Pulverized Coal \\
\hline PDF & Paper-derived fuel \\
\hline PRB & Powder River Basin \\
\hline RDF & Refuse-derived fuel \\
\hline ROW & Right-of-way (applies to trimmings from right-of-way maintenance) \\
\hline $\mathrm{SO}_{2}$ & Sulfur dioxide \\
\hline
\end{tabular}




\begin{tabular}{|l|l|}
\hline $\mathrm{SO}_{3}$ & Sulfur trioxide \\
\hline SOFA & Separated overfire air system \\
\hline SRWC & Short Rotation Woody Crop \\
\hline TDF & Tire-derived fuel \\
\hline THC & Total hydrocarbon emissions \\
\hline TMP & Thermomechanical Pulping \\
\hline TVA & Tennessee Valley Authority \\
\hline UBC & Unburned carbon (typically in flyash; see LOI) \\
\hline UDI & Utility Data Institute \\
\hline USDOE & U.S. Department of Energy \\
\hline V/FC & Ratio of volatile matter to fixed carbon from the proximate analysis \\
\hline
\end{tabular}

